\title{
Characterisation of the Oxidation and Creep Behaviour of Novel Mo-Si-Ti Alloys
}

Zur Erlangung des akademischen Grades einer Doktorin der Ingenieurwissenschaften (Dr.-Ing.)

von der KIT-Fakultät für Maschinenbau des Karlsruher Instituts für Technologie (KIT) angenommene

DISSERTATION

von

M.Sc. Susanne Obert

Tag der mündlichen Prüfung: 06.05.2021

Hauptreferent: $\quad$ Prof. Dr.-Ing. Martin Heilmaier

Institut für Angewandte Materialien (IAM)

Karlsruher Institut für Technologie (KIT)

Korreferentin: $\quad$ Prof. Dr.-Ing. habil. Manja Krüger

Institut für Werkstoff- und Fügetechnik

Otto-von-Guericke Universität Magdeburg 



\section{Abstract}

The performance of high-temperature materials has to be continuously improved in order to meet the demands for more efficiency and sustainability in structural high-temperature applications, like gas turbines. Since commercially applied, state-of-the-art Ni-based superalloys are already operating at their limits, due to the restriction by the solvus temperature of the strengthening $\gamma^{\prime}$ phase, the development of alternative materials is deemed mandatory. Hence, high-temperature materials enabling surface temperatures beyond $1100{ }^{\circ} \mathrm{C}$ during operation are targeted. Alloy design and selection especially face challenges in the development of both, chemical and mechanical resistance. In this regard, an adequate oxidation and sufficient creep resistance are of particular interest. Ti macroalloyed Mo-Si-based alloys have shown promising potential because of their high solidus temperatures in the range of $1800^{\circ} \mathrm{C}$ and beyond as well as considerably reduced density down to 6 to $7 \mathrm{~g} / \mathrm{cm}^{3}$, which is in striking contrast to typically $8.7 \mathrm{~g} / \mathrm{cm}^{3}$ of Ni-based superalloys. However, these alloys typically undergo catastrophic oxidation at temperatures below $1000{ }^{\circ} \mathrm{C}$ due to volatilisation of $\mathrm{MoO}_{3}$ leading to rapid mass loss. This phenomenon is well-known as pesting and is observed for pure Mo and Mo-based alloys. Nevertheless, in this work, pesting stability is achieved at $800{ }^{\circ} \mathrm{C}$ in novel eutectic and eutectic-eutectoid Mo-Si-Ti alloys, when a threshold concentration of nominal 40 to 43 at\% $\mathrm{Ti}$ is exceeded, while the Si content is kept between 20 to 26 at\%. These alloys are characterised by finescaled microstructures, consisting of Mo solid solution Moss and (Ti,Mo) ${ }_{5} \mathrm{Si}_{3}$ (eutectic) and/or Moss and (Mo,Ti) ${ }_{5} \mathrm{Si}_{3}$ (eutectoid). The excellent oxidation behaviour is attributed to the high Ti content dissolved in Moss enabling the formation of solid Ti-oxide, while retarding the evaporation of $\mathrm{MoO}_{3}$. Combined with around 50 vol\% of $\mathrm{M}_{5} \mathrm{Si}_{3}$ type silicide phases, thin mixed Ti-Si-oxide scales are formed, ensuring low mass changes. The oxidation resistance is maintained up to $1200^{\circ} \mathrm{C}$. Besides the importance of the Mo to Ti ratio for the pesting resistance, the ratio is decisive for the attained creep resistance, which is found to be solidus temperature-dependent. Thus, the Mo content needs to be maximised while meeting the Ti threshold. A further increase in solidus temperature is achieved by triggering primary solidification of $(\mathrm{Mo}, \mathrm{Ti})_{5} \mathrm{Si}_{3}$. The resulting alloys comprise up to $30 \mathrm{vol} \%$ primarily solidified $(\mathrm{Mo}, \mathrm{Ti})_{5} \mathrm{Si}_{3}$ and exhibit the best creep performance among all pestingresistant Mo-Si-Ti alloys developed in this work. 


\section{Kurzfassung}

Um den Anforderungen zur Effizienzsteigerung und Umsetzung von Nachhaltigkeitsstrategien für Anwendungen im Hochtemperaturbereich gerecht zu werden, steigt die Notwendigkeit, das Eigenschaftsprofil der eingesetzten Konstruktionswerkstoffe weiter zu verbessern. Da typische, kommerziell eingesetzte Ni-Basis-Superlegierungen bereits aufgrund der Löslichkeitstemperatur der $\gamma^{\prime}$ Verstärkungsphase an ihre Einsatzgrenze stoßen, ist die Entwicklung von neuen Hochtemperaturwerkstoffen für den Einsatz mit möglichen Oberflächentemperaturen oberhalb von $1100{ }^{\circ} \mathrm{C}$ unabdingbar. Die Legierungsentwicklung steht jedoch vor der Herausforderung, eine ausreichende Oxidationsbeständigkeit mit einer guten Kriechbeständigkeit zu kombinieren. In dieser Hinsicht erweisen sich Ti-makrolegierte Mo-Si-basierte Legierungen dank ihrer hohen Solidustemperatur im Bereich von $1800^{\circ} \mathrm{C}$ und darüber bei deutlich geringeren Dichten von 6 bis $7 \mathrm{~g} / \mathrm{cm}^{3} \mathrm{im}$ Vergleich zu Ni-Basis-Superlegierungen als vielversprechend. Von Nachteil ist jedoch das katastrophale Oxidationsverhalten bei Temperaturen unterhalb von $1000{ }^{\circ} \mathrm{C}$. Aufgrund der Bildung von flüchtigem $\mathrm{MoO}_{3}$ kommt es zu hohen Massenverlusten innerhalb kürzester Zeit. Dieses Phänomen wird als Pesting bezeichnet und ist bekannt dafür, bei reinem Molybdän und seinen Legierungen aufzutreten. In den neu entwickelten Mo-Si-Ti Legierungen kann dieses Pesting Verhalten jedoch unterbunden werden, wenn ein nomineller TiGehalt von mindestens 40 bis 43 at\% überschritten und gleichzeitig ein Si-Gehalt im Bereich von 20 bis 26 at\% eingestellt wird. Diese Legierungen zeichnen sich durch feinstrukturierte eutektische bzw. eutektisch-eutektoide Gefüge aus. Das Eutektikum besteht aus Mo-Mischkristall Moss und ( $\mathrm{Ti}, \mathrm{Mo})_{5} \mathrm{Si}_{3}$, während die eutektoide Reaktion in Moss und $(\mathrm{Mo}, \mathrm{Ti})_{5} \mathrm{Si}_{3}$ resultiert. Das Zusammenspiel aus dem Ti-reichen Moss und den $\mathrm{M}_{5} \mathrm{Si}_{3}$ Silizidphasen ermöglicht die Bildung von Ti-Si-Oxidschichten, die die Abdampfung von $\mathrm{MoO}_{3}$ deutlich erschweren und starke Massenveränderungen verhindern. Bei hohen Temperaturen von $1200^{\circ} \mathrm{C}$ liegt ebenfalls eine gute Oxidationsbeständigkeit vor. Das Verhältnis von Mo zu Ti ist jedoch nicht nur für die Oxidationsbeständigkeit ausschlaggebend, sondern auch für das Kriechverhalten, das stark mit der Solidustemperatur der Legierungen korreliert. Insofern führt die Maximierung des Mo-Gehaltes zur maximalen Ausnutzung des Kriechpotentials bei gleichzeitiger Einhaltung des notwendigen Ti-Gehaltes für Pesting Stabilität. Wird der Erstarrungsverlauf jedoch gezielt manipuliert, so dass (Mo,Ti) ${ }_{5} \mathrm{Si}_{3}$ als Verstärkungsphase primär erstarrt, so kann die Kriechbeständigkeit durch zusätzliche Erhöhung der Solidustemperatur, bei gleichzeitiger Beibehaltung der Pesting Stabilität, weiter verbessert werden. 


\section{Nomenclature}

\section{Abbreviations}

\begin{tabular}{|c|c|}
\hline Abbreviation & Description \\
\hline$a c$ & as-cast \\
\hline AcM & Arc Melting/arc-melted \\
\hline APT & Atom Probe Tomography \\
\hline as & as-sintered \\
\hline bcc & body centred cubic \\
\hline BSE & Backscattered Electrons \\
\hline Calphad & Calculation of Phase Diagrams \\
\hline calc. & calculated \\
\hline compr. & compressive \\
\hline CTE & Coefficient of Thermal Expansion \\
\hline $\mathrm{DC}$ & Dislocation Creep \\
\hline DOE & Design of Experiment \\
\hline $\mathrm{EBC}$ & Environmental Barrier Coating \\
\hline EBSD & Electron Backscatter Diffraction \\
\hline EDM & Electrical Discharge Machining \\
\hline EDX & Energy Dispersive X-Ray Spectroscopy \\
\hline exp. & experimental \\
\hline fcc & face centred cubic \\
\hline $\mathrm{g}$ & gaseous \\
\hline GB & Grain Boundary \\
\hline GIXRD & Grazing Incident X-Ray Diffraction \\
\hline HAADF & High-Angle Annular Dark-Field \\
\hline HIP & hot isostatically pressed \\
\hline$h t$ & heat-treated $\left(1300^{\circ} \mathrm{C}, 200 \mathrm{~h}\right.$ in $\left.\mathrm{Ar}\right)$ \\
\hline$h t^{*}$ & heat-treated $\left(1600^{\circ} \mathrm{C}, 150 \mathrm{~h}\right.$ in $\left.\mathrm{Ar}\right)$ \\
\hline
\end{tabular}




\begin{tabular}{|c|c|}
\hline$h t^{* *}$ & heat-treated $\left(1600{ }^{\circ} \mathrm{C}, 150 \mathrm{~h}+1400^{\circ} \mathrm{C}, 100 \mathrm{~h}\right.$ in $\left.\mathrm{Ar}\right)$ \\
\hline ICP-OES & Inductively Coupled Plasma Optical Emission Spectroscopy \\
\hline iso & isothermal \\
\hline $\mathrm{L}$ & Liquid \\
\hline M & Metal \\
\hline Moss & Mo Solid Solution \\
\hline $\mathrm{NH}$ & Nabarro-Herring \\
\hline ODS & oxide dispersion-strengthened \\
\hline PBR & Pilling-Bedworth Ratio \\
\hline $\mathrm{PM}$ & Powder Metallurgy \\
\hline PX & polycrystalline \\
\hline$R T$ & Room Temperature \\
\hline $\mathrm{S}, \mathrm{s}$ & solid (noun, adjective) \\
\hline $\mathrm{SAD}$ & selected area diffraction \\
\hline $\mathrm{SE}$ & Secondary Electrons \\
\hline SEM & Scanning Electron Microscopy \\
\hline STEM & Scanning Transmission Electron Microscopy \\
\hline SX & single-crystalline \\
\hline $\mathrm{TBC}$ & Thermal Barrier Coating \\
\hline TCP & topologically closed packed \\
\hline TEM & Transmission Electron Microscopy \\
\hline $\mathrm{v}$ & vitreous \\
\hline XRD & X-Ray Diffraction \\
\hline
\end{tabular}




\section{Symbols}

Latin symbo

a

b

$C_{0}$

C

$C_{C}$

$C_{D C}$

$C_{N H}$

$d$

$d$

$d^{d u p l}$

$d^{\text {int }}$

$d^{\text {top }}$

$d^{\text {total }}$

D

$D_{G B}$

$D_{L}$

$D_{S}$

$f$

G

G

$\Delta G$

$\Delta G^{0}$

k

$k^{*}$

$k_{1}$

$k_{2}$

$k_{n}$

$k_{w}$

$L$

$\Delta m$

$\Delta m_{\text {actual }}$

$m_{\text {air }}^{\text {alloy }}$

$m_{\mathrm{H}_{2} \mathrm{O}}^{\text {alloy }}$
Description

thermodynamic activity

Burgers vector

oxidant concentration at the oxide/atmosphere interface

material constant in power creep law

material constant in diffusional power creep law with diffu-

sion along grain boundaries according to Coble

material constant in dislocation power creep law

material constant in bulk diffusional power creep law ac-

cording to Nabarro-Herring

grain size

oxide scale thickness

thickness of the duplex Si-Ti-oxide scale

depth of the internal oxidation zone

thickness of the top $\mathrm{TiO}_{2}$ oxide scale

total oxide scale thickness

bulk diffusion coefficient

coefficient for diffusion along grain boundaries

diffusion coefficient within the liquid phase

diffusion coefficient within a solid phase

phase fraction of a specific phase

shear modulus

Gibbs free energy

change in Gibbs free energy

free standard reaction enthalpy

Boltzmann constant

linear oxide scale growth rate constant

linear weight change oxidation rate constant

parabolic weight change oxidation rate constant

oxide scale growth rate constant

weight change oxidation rate constant

overall length of the line (metallographic intersection

method)

(experimentally determined) specific mass change

actual mass change

weight of the sample in air

weight of the sample in ionised water
Unit

$\AA$

number $/ \mathrm{cm}^{3}$

$\mu \mathrm{m}$

$\mu \mathrm{m}$

$\mu \mathrm{m}$

$\mu \mathrm{m}$

$\mu \mathrm{m}$

$\mu \mathrm{m}$

$\mathrm{m}^{2} / \mathrm{s}$

$\mathrm{m}^{2} / \mathrm{s}$

$\mathrm{m}^{2} / \mathrm{s}$

$\mathrm{m}^{2} / \mathrm{s}$

$\mathrm{MPa}$

$\mathrm{J}$

$\mathrm{J}$

$\mathrm{J}$

$\mathrm{m}^{2} \mathrm{~kg} \mathrm{~s}^{-2} \mathrm{~K}^{-1}$

$\mathrm{ms}^{-1}$

$\left(\mathrm{mg} / \mathrm{cm}^{2}\right) \mathrm{s}^{-1}$

$\left(\mathrm{mg} / \mathrm{cm}^{2}\right)^{2} \mathrm{~s}^{-1}$

$\mathrm{m}^{\mathrm{n}} \mathrm{s}^{-1}$

$\left(\mathrm{mg} / \mathrm{cm}^{2}\right)^{\mathrm{w}} \mathrm{s}^{-1}$

$\mu \mathrm{m}$

$\mathrm{mg} / \mathrm{cm}^{2}$

mg

$\mathrm{mg}$

mg 


\begin{tabular}{|c|c|c|}
\hline$m_{M o}^{\text {vapour }}$ & specific mass change due to volatilisation of $\mathrm{MoO}_{3}$ & $\mathrm{mg} / \mathrm{cm}^{2}$ \\
\hline$m_{O}^{\text {duplex }}$ & $\begin{array}{l}\text { specific mass change due to } \mathrm{O} \text { incorporation during duplex } \\
\text { oxide scale growth }\end{array}$ & $\mathrm{mg} / \mathrm{cm}^{2}$ \\
\hline$m_{O}^{\text {internal }}$ & $\begin{array}{l}\text { specific mass change due to } \mathrm{O} \text { incorporation during internal } \\
\text { oxidation }\end{array}$ & $\mathrm{mg} / \mathrm{cm}^{2}$ \\
\hline$m_{O}^{\text {scale }}$ & $\begin{array}{l}\text { specific mass change due to } \mathrm{O} \text { incorporation during solid ox- } \\
\text { ide scale growth }\end{array}$ & $\mathrm{mg} / \mathrm{cm}^{2}$ \\
\hline$m_{o}^{\text {top }}$ & $\begin{array}{l}\text { specific mass change due to } \mathrm{O} \text { incorporation during top } \mathrm{TiO}_{2} \\
\text { oxide scale growth }\end{array}$ & $\mathrm{mg} / \mathrm{cm}^{2}$ \\
\hline$M_{x} O_{y}$ & $\begin{array}{l}\text { oxide of Metal } \mathrm{M} \text { with a stoichiometry of } x \text { metal atoms and } \\
y \text { oxygen atoms }\end{array}$ & - \\
\hline$n$ & exponent in the power creep law & - \\
\hline$n$ & exponent of oxide scale growth kinetics & - \\
\hline$n_{\text {Mo }}^{\text {vapour }}$ & amount of Mo oxidised to volatile $\mathrm{MoO}_{3}$ & $\mu \mathrm{mol} / \mathrm{cm}^{2}$ \\
\hline$n_{\text {Si,Ti }}^{\text {scale }}$ & amount of Si and Ti oxidised to solid oxide scales & $\mu \mathrm{mol} / \mathrm{cm}^{2}$ \\
\hline$N$ & $\begin{array}{l}\text { total number of intersections of respective line with phase } \\
\text { interfaces }\end{array}$ & - \\
\hline$N$ & number fraction of the phase regions for ellipsoid analysis & - \\
\hline$p$ & pressure & mbar \\
\hline$p_{i}$ & partial pressure of gaseous species $i$ & mbar \\
\hline$p_{i}{ }^{0}$ & standard pressure of gaseous species $i$ & mbar \\
\hline$P$ & interface boundary fraction & $\mu \mathrm{m}^{-1}$ \\
\hline$Q_{c}$ & apparent activation energy for creep & $\mathrm{kJ} / \mathrm{mol}$ \\
\hline$Q_{s d}$ & activation energy for self-diffusion in metals & $\mathrm{kJ} / \mathrm{mol}$ \\
\hline$R_{a d j}^{2}$ & coefficient of determination & - \\
\hline$t$ & time & $\mathrm{s}, \mathrm{h}$ \\
\hline$T$ & temperature & ${ }^{\circ} \mathrm{C}$ \\
\hline$T_{m}$ & melting point & ${ }^{\circ} \mathrm{C}$ \\
\hline$T_{\text {hom }}$ & homologous temperature & - \\
\hline$T_{\text {operating }}$ & operating temperature & ${ }^{\circ} \mathrm{C}$ \\
\hline$T_{\text {solidus }}$ & solidus temperature & ${ }^{\circ} \mathrm{C}$ \\
\hline$v$ & volume fraction & vol\% \\
\hline$v_{\mathrm{SiO}_{2}}^{\text {duplex }}$ & volume fraction of $\mathrm{SiO}_{2}$ within the duplex oxide scale & vol\% \\
\hline$v_{\mathrm{TiO}_{2}}^{\text {duplex }}$ & volume fraction of $\mathrm{TiO}_{2}$ within the duplex oxide scale & vol\% \\
\hline$w$ & exponent of weight change oxidation kinetics & - \\
\hline$x_{i}$ & atomic fraction of an element $i$ & at\% \\
\hline$x_{i}^{\text {phase }}$ & atomic fraction of element $i$ in respective phase & at $\%$ \\
\hline
\end{tabular}




\begin{tabular}{|c|c|c|}
\hline Greek symbol & Description & Unit \\
\hline$\alpha_{a}, \alpha_{c}$ & linear coefficient of thermal expansion along $a$ or $c$ axis & $\mathrm{K}^{-1}$ \\
\hline$\delta$ & grain boundary thickness & $\mathrm{nm}$ \\
\hline$\varepsilon$ & true strain & $\%$ \\
\hline$\varepsilon_{e}$ & engineering strain & $\%$ \\
\hline$\dot{\varepsilon}$ & true creep rate & $\mathrm{s}^{-1}$ \\
\hline$\dot{\varepsilon}_{C}$ & true grain boundary diffusional creep rate & $\mathrm{s}^{-1}$ \\
\hline$\dot{\varepsilon}_{D C}$ & true dislocation creep rate & $\mathrm{s}^{-1}$ \\
\hline$\dot{\varepsilon}_{I I}$ & stationary true creep rate & $\mathrm{s}^{-1}$ \\
\hline$\dot{\varepsilon}_{\min }$ & minimum true creep rate & $\mathrm{s}^{-1}$ \\
\hline$\dot{\varepsilon}_{N H}$ & true bulk diffusional creep rate & $\mathrm{s}^{-1}$ \\
\hline$\theta$ & $\begin{array}{l}\text { glancing angle with respect to incident X-Ray beam and re- } \\
\text { flecting crystallographic plane }\end{array}$ & $\circ$ \\
\hline$\rho$ & density & $\mathrm{g} / \mathrm{cm}^{3}$ \\
\hline$\sigma$ & true stress & $\mathrm{MPa}$ \\
\hline$\sigma_{e}$ & engineering stress & $\mathrm{MPa}$ \\
\hline$\sigma_{y}$ & yield strength & $\mathrm{MPa}$ \\
\hline$\omega$ & incident angle of GIXRD & $\circ$ \\
\hline$\Omega$ & volume of atom & $\mathrm{nm}^{3}$ \\
\hline
\end{tabular}




\section{Table of Contents}

$1 \quad$ Introduction and Motivation 1

2 Fundamentals $\quad 4$

2.1 History and Development of Mo-Si-Based Alloys 4

2.2 The Ternary Mo-Si-Ti System 10

2.3 Fundamentals on the Oxidation Behaviour 11

$2.4 \quad$ Fundamentals on the Creep Behaviour 26

$3 \quad$ Materials and Experimental Methods $\quad 34$

3.1 Thermodynamic Calculations 34

3.2 Materials Processing $\quad 35$

3.3 Microstructural Characterisation 36

3.3.1 Sample Preparation 36

3.3.2 Heat Treatments 37

$\begin{array}{lll}\text { 3.3.3 Chemical Analysis } & 37\end{array}$

3.3.4 Microscopic Analysis $\quad 37$

3.3.5 Atom Probe Tomography 39

$\begin{array}{lll}\text { 3.3.6 X-Ray Diffraction } & 39\end{array}$

3.4 Density Determination 40

3.5 Oxidation Testing 40

3.6 Creep Testing 40

4 Alloy Design and Development $\quad 42$

4.1 Interpretation of Thermodynamic Calculations 42

4.2 Thermodynamic Calculations and Alloy Selection 44

5 Microstructural Characterisation and Evaluation $\quad 48$

5.1 The Intermediate Eutectic-Eutectoid Alloy Series A and B 48

5.2 The $\left(\mathrm{Mo}, \mathrm{Ti}_{5}\right)_{5} \mathrm{Si}_{3}$-Containing Eutectic-Eutectoid Alloy Series C and D 52

5.3 The Chemical Composition of the Individual Phases 55

5.4 The Microstructural Stability at Elevated Temperatures $\quad 61$

6 Oxidation Behaviour $\quad 64$

6.1 The Intermediate Eutectic-Eutectoid Alloy Series A and B 64

6.1.1 Mass Changes and Oxide Scale Morphology at 800, 1100 and $1200^{\circ} \mathrm{C} \quad 64$

6.1.2 Contribution of Volatile and Solid Oxides to the Mass Change 73

6.1.3 Pre-Oxidation Experiments at 1100 and $1200^{\circ} \mathrm{C} \quad 76$ 
6.2 The (Mo,Ti) $)_{5} \mathrm{Si}_{3}$-Containing Eutectic-Eutectoid Alloy Series C and D 78

6.3 Microstructural and Chemical Requirements for Pesting Resistance 81

6.3.1 The Impact of the Microstructural Length Scale 81

6.3.2 The Impact of Phase Distribution and Composition 85

6.3.3 The Oxidation Behaviour of Moss at $800{ }^{\circ} \mathrm{C} \quad 87$

6.4 Analysis of the Oxide Scale Mock-Up and Oxidation Kinetics 89

6.4.1 Crystallography and Chemical Appearance of the Oxide Scales 90

6.4.2 The Oxide Scale Growth Kinetics 95

$\begin{array}{lll}7 & \text { Creep Behaviour } & 102\end{array}$

7.1 Assessment of the Creep Behaviour of the Eutectic-Eutectoid Alloys 102

7.2 Impact of Artificial Coarsening on the Creep Performance 110

$8 \quad$ Summary and Conclusion $\quad 114$

$\begin{array}{llr}9 & \text { Outlook } & 116\end{array}$

$\begin{array}{lr}\text { References } & 120\end{array}$

$\begin{array}{ll}\text { Appendix } & 143\end{array}$

$\begin{array}{ll}\text { List of Figures } & 172\end{array}$

$\begin{array}{ll}\text { List of Tables } & 179\end{array}$

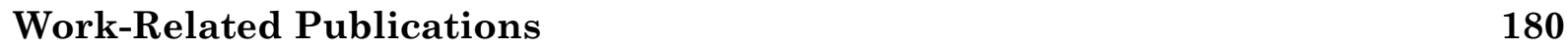

$\begin{array}{ll}\text { Eigenständigkeitserklärung } & 181\end{array}$

$\begin{array}{ll}\text { Acknowledgement } & 182\end{array}$ 



\section{Introduction and Motivation}

High-temperature structural materials have to fulfil manifold requirements in order to provide a high level of functionality and efficiency. Besides thermal and chemical stability of the microstructure and, thereby, resistance to oxidative and corrosive surroundings, mechanical high-temperature properties, like fatigue and creep strength, in conjunction with an adequate density, are essential. However, two of the major requirements, namely oxidation and creep resistance, are typically limited in all high-temperature alloy systems on Fe-, Co-, Ni- and Mo-basis developed so far [1-6]. The following well-known and established alloying systems serve as striking examples: Ferritic, stainless steels (Fe-Cr alloys) forming a $\mathrm{Cr}_{2} \mathrm{O}_{3}$ oxide layer, when exposed to oxidative environments, can only be operated up to $650^{\circ} \mathrm{C}$. This restriction is caused by insufficient creep resistance rather than by a potential lack of oxidation resistance [7, 8]. For comparison, the application of austenitic $\mathrm{Ni}$-Cr alloys is limited to maximum $950{ }^{\circ} \mathrm{C}$, as the formed $\mathrm{Cr}_{2} \mathrm{O}_{3}$ oxide scales do not provide sufficient oxidation protection at higher temperatures [9-13]. In contrast, $\mathrm{Ni}-\mathrm{Cr}-\mathrm{Al}$ alloys, on which $\mathrm{Al}_{2} \mathrm{O}_{2}$ (-containing) oxide scales lead to passivation, can be operated up to $1100{ }^{\circ} \mathrm{C}$ [14-16]. However, the excellent creep-resistance of the latter two systems obtained up to $900{ }^{\circ} \mathrm{C}$ is progressively decreasing with increasing temperature [17]. Conclusively, alloy design has faced challenges since decades $[13,18]$.

Besides these scientific challenges, the high-temperature material development is economically constrained by affordability, raw material availability and the product life cycle, which especially includes the efficiency during operation. The latter is highlighted in Fig. 1-1, which displays the specific core power as a function of the gas inlet temperature for an ideal gas turbine engine (black line) in comparison to the data of commercial engines (grey dots). Firstly, it is seen that the efficiency of gas turbine engines, which is related to the ideal one of the thermal (Carnot) engine [19], is improved with increasing gas inlet temperature, justifying the slogan "the hotter the better" [20]. However, the deviation from the ideal performance is increasing with rising temperature. The initial improvements (grey region in Fig. 1-1) have been realised by developing superior high-temperature materials, the "modern superalloys" [21]. These achievements led to today's high-performance, often directionally solidified, $\gamma^{\prime}$-strengthened (ordered $\mathrm{L}_{2}$ structure of type $\mathrm{Ni}_{3} \mathrm{Al}^{1}$

\footnotetext{
${ }^{1}$ Ordered fcc structure of space group P m $\overline{3} \mathrm{~m}$ (Pearson symbol cP4) with $\mathrm{Al}$ atoms occupying the cube corners and $\mathrm{Ni}$ atoms the face centres. $\mathrm{Al}$ is commonly substituted by other alloying elements like $\mathrm{Ta}$, $\mathrm{Ti}$ or $\mathrm{Nb}$. These $\gamma^{\prime}$ precipitates are coherent with the fcc $\gamma$ Ni solid solution matrix, p. 217 in Ref. [22] and p. 40-43 in Ref. [23].
} 
$[22,23])$ state-of-the-art Ni-based superalloys [17, 24]. However, their application is limited to surface temperatures of maximum $1150{ }^{\circ} \mathrm{C}$ in order to prevent microstructural instability by coarsening, rafting, exceeding the solvus temperature of the $\gamma^{\prime}$ phase as well as by topologically closed packed (TCP) phase formation [25-27]. Therefore, a further increase in operating temperature up to $1500{ }^{\circ} \mathrm{C}$ has only been achieved by structural and design innovations (red region in Fig. 1-1). These are mainly based on sophisticated cooling techniques (e.g. the implementation of macroscopic sub-structures of cooling channels) and the application of thermal barrier coating (TBC) systems. Conclusively, the target to further enhance the efficiency of high-temperature gas turbines prompts further research on light-weight advanced high-temperature materials, which can inherently withstand considerably higher operating temperatures.

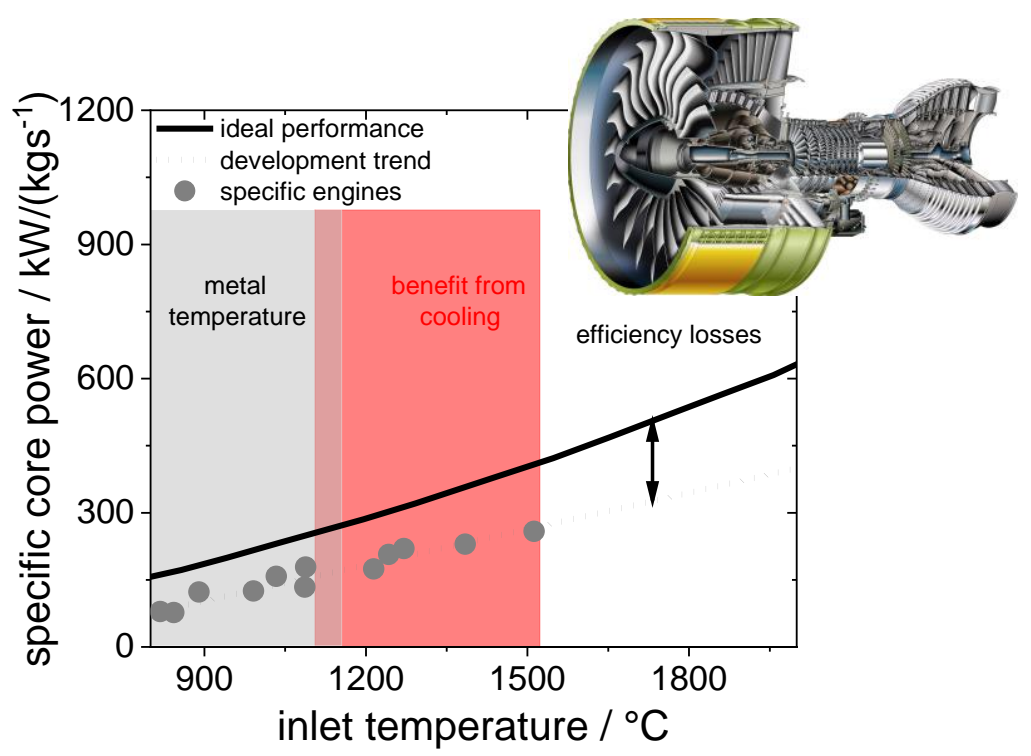

Fig. 1-1 Specific core power as a function of the turbine inlet temperature of commercial turbine engines (grey dots) compared to the ideal performance (black line); according to Ref. [20]. Top right inset: cutaway view image of a gas turbine [28].

Thus, at higher temperatures, only ceramic materials or alloys based on refractory metals like $\mathrm{Nb}$, Ta, $\mathrm{W}$ and Mo may serve as structural materials. While the first are inherently brittle, the latter typically undergo severe oxidation [29-31], which has disqualified both material classes for industrial application in ambient environment so far. In this regard, multiphase materials are mandatory in order to profit from high-temperature, oxidationresistant intermetallic phases and comparably ductile metallic phases. Thereby, oxidation protection necessitates the formation of oxidation-resistant oxide scales, like $\mathrm{Al}_{2} \mathrm{O}_{3}$ or $\mathrm{SiO}_{2}$, which provide protection up to $1300^{\circ} \mathrm{C}$, possibly even higher [10, 32]. These are either 
inherently formed by alloying additions like $\mathrm{Al}$ or $\mathrm{Si}$, or applied as coating [32-34]. However, $\mathrm{SiO}_{2}$ oxide scales are prone to volatility in the presence of water vapour [13, 35], which requires additional environmental barrier coatings (EBC). In this respect, Mo-Sibased alloy systems are promising, as the base refractory element Mo possesses a high melting temperature of $2623^{\circ} \mathrm{C}$ [36], and the silicide phases enable the formation of $\mathrm{SiO}_{2}$ beyond $1000^{\circ} \mathrm{C}$ [37-39]. However, so far, efforts of suppressing or counterbalancing the tendency of Mo to form volatile oxides have not been successful for temperatures below $1000{ }^{\circ} \mathrm{C}$ [4, 40-42]. Rather, Mo-Si-based alloys suffer from catastrophic oxidation in the intermediate temperature range [4, 40-42]. Besides their insufficient oxidation resistance, Mo-Si-B alloys have shown great potential for high-temperature applications because of their good creep resistance at $1200{ }^{\circ} \mathrm{C}$ [43-46]. Moreover, the thermal conductivity is four times greater than that of modern superalloys (ranging from 50 to $112 \mathrm{~W}(\mathrm{mK})^{-1}$ ) in the temperature range of 25 to $1370{ }^{\circ} \mathrm{C}$ [21], which enables quick heat conduction and thermal stress regulation. However, the density is considerably higher with $9.5 \mathrm{~g} / \mathrm{cm}^{3}$ [21] compared to $8.7 \mathrm{~g} / \mathrm{cm}^{3}$ of typical Ni-based superalloys [26]. When macro-alloyed with Ti, a significant reduction in density down to $7.7 \mathrm{~g} / \mathrm{cm}^{3}[4,47]$ and a further increase in creep resistance is achieved [4, 48]. But these Mo-Si-B-Ti alloys still do not exhibit an appropriate oxidation resistance in the intermediate temperature range $[4,48]$, emphasising the competing relation between oxidation and creep resistance.

Conversely, a novel two-phase eutectic Mo-Si-Ti alloy was found to exhibit good oxidation behaviour at $800^{\circ} \mathrm{C}$ [5], indicating further potential for achieving oxidation and creep resistance in Mo-Si-based alloys at low density. Thus, the objectives of this thesis are the design and development of Mo-Si-Ti alloys with a sufficient intrinsic oxidation behaviour accompanied by an adequate creep resistance. Scientific issues, like tailoring the microstructure and the understanding of the microstructure-property relationship, are addressed in detail with focus on oxidation and creep.

Firstly, Chap. 2 introduces into the fundamentals on Mo-Si-based alloy systems and their development leading to ternary Mo-Si-Ti alloys giving an overview on the current state of research. The used materials and applied methods are presented in Chap. 3. The alloy design guide line and selection supported by thermodynamic calculations is part of Chap. 4. Then, the achieved microstructures are presented and evaluated in Chap. 5. The results of the oxidation and creep experiments of the investigated alloys will be presented and discussed in Chaps. 6 and 7, respectively. Finally, a conclusive summary including a final evaluation and outlook are provided in Chaps. 8 and 9. 


\section{Fundamentals}

This chapter presents the essential physical and thermodynamic properties of Mo-Sibased alloys and the current research state of their development (Secs. 2.1 and 2.2). With regard to the main requirements for high-temperature applications, an introduction into the fundamentals of oxidation and creep behaviour is given and the performance potential of Mo-Si-based alloys, especially of Mo-Si-Ti alloys, is highlighted (Secs. 2.3 and 2.4).

\subsection{History and Development of Mo-Si-Based Alloys}

Mo-Si-based alloys have been subject of international research since the early $50 \mathrm{~s}$ and $60 \mathrm{~s}$ [49-51]. A wide range of different attempts has been undertaken with the aim of establishing and improving Mo-Si-based alloy systems by utilising the basic principles of physical metallurgy. Thereby, the ternary Mo-Si-B system is of great interest as Si and B are attractive elements for improving the oxidation resistance by forming solid oxide scales, like $\mathrm{SiO}_{2}$ and the low-viscous borosilicate $\mathrm{B}_{2} \mathrm{O}_{3}-\mathrm{SiO}_{2}$ [52]. The Mo-rich part of the ternary MoSi-B system is most relevant for high-temperature applications because these alloys possess high solidus temperatures in the range of $1900{ }^{\circ} \mathrm{C}$ [53]. This high-temperature capability is illustrated by the liquidus surface in Fig. 2-1, which declines from the high-melting Mo-corner and the Mo-B system to the binary Mo-Si side, as shown by the isotherms.

\section{Si}

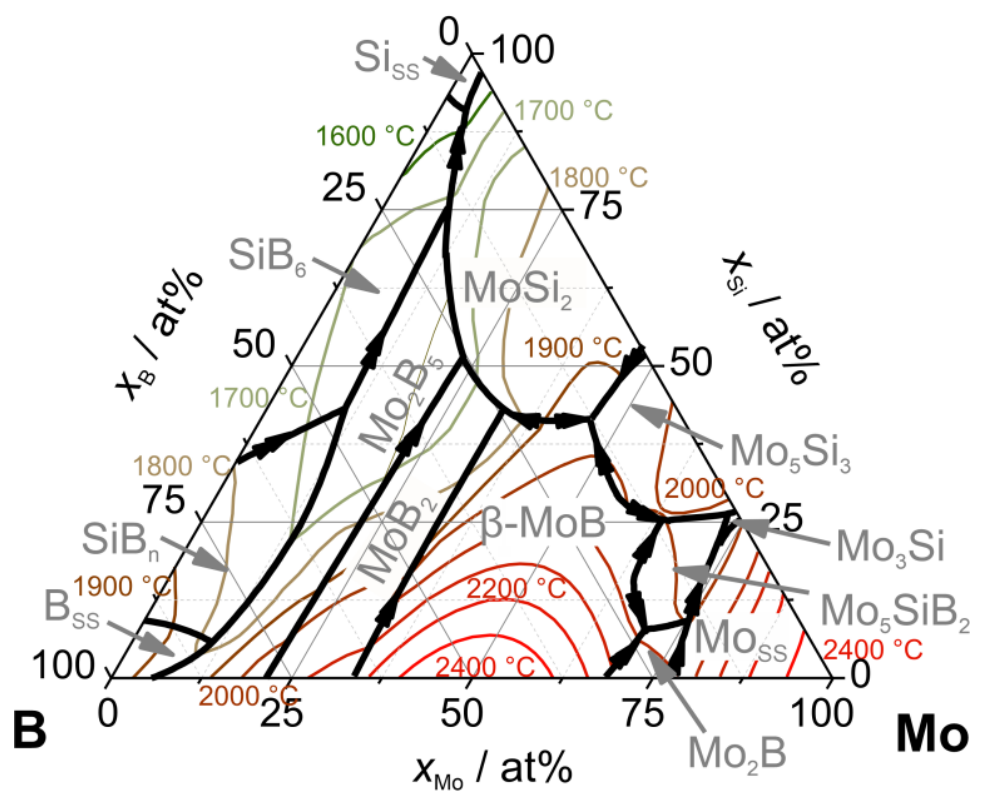

Fig. 2-1 Liquidus projection of the ternary Mo-Si-B system. Data taken from Ref. [54], schematic isotherms in $100 \mathrm{~K}$ steps calculated with Pandat. 
These high-melting Mo-Si-B alloys possess a broad chemical composition range up to 25 at\% Si and 20 at\% B, where Mo solid solution Moss is the primary solidifying phase. Besides the ternary $\mathrm{Mo}_{5} \mathrm{SiB}_{2}$ phase, all other primary solidifying phases originate from the binary systems. The solidification pathways of these alloys are determined by numerous phase reactions, like binary, or even ternary eutectic or peritectic reactions (see App. 1).

Thus, if appropriate amounts of Si and B are added, multiphase microstructures can be designed by taking advantage of the different solidification paths. This leads to two hightemperature stable phase regions of particular interest, which are highlighted in the isothermal section at $1600{ }^{\circ} \mathrm{C}$ in Fig. 2-2: (i) The classic Mo-Si-B alloys originally developed by Berczik in the late 90s [55, 56], which consist of Moss (bcc) and the intermetallic compounds Mos $\mathrm{Si}$ (A15) and $\mathrm{Mo5}_{5} \mathrm{SiB}_{2}$ (T2) (blue triangle in Fig. 2-2). These alloys profit from the ductility and increased fracture toughness of Moss and have shown promising creep performance and satisfactory oxidation behaviour in the temperature regime of 1000 to $1200{ }^{\circ} \mathrm{C}[45]$. However, these alloys suffer from pesting at temperatures below $1000{ }^{\circ} \mathrm{C}[4$, $40-42,53,57]$. For instance, initial mass losses of around -28 to $-37\left(\mathrm{mg} / \mathrm{cm}^{2}\right) \mathrm{h}^{-1}$ are observed in air at $800{ }^{\circ} \mathrm{C}[42,57]$. Therefore, these alloys are generally unsuitable for industrial applications, where operation occurs in a wide temperature range, unless inert atmosphere conditions are established.

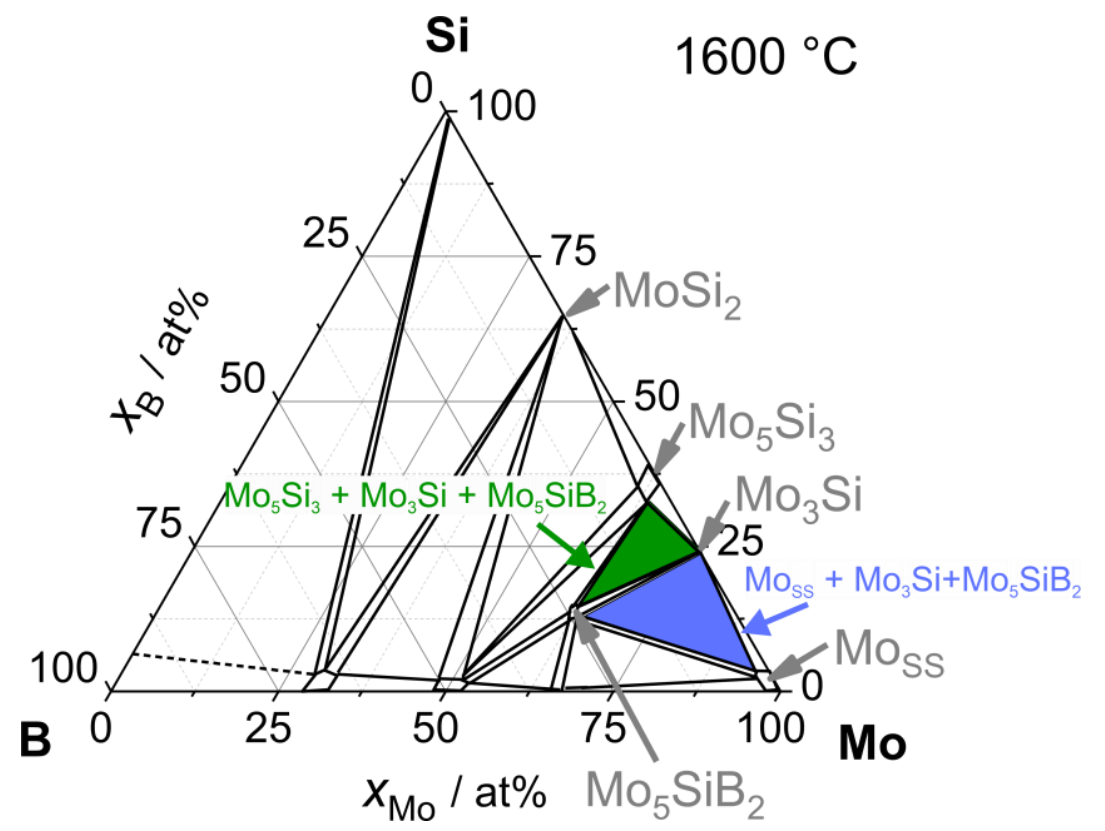

Fig. 2-2 Isothermal section of the ternary Mo-Si-B system at $1600{ }^{\circ} \mathrm{C}$. Phase equilibria of special interest are highlighted: Moss $+\mathrm{Mo}_{3} \mathrm{Si}+\mathrm{Mo5}_{5} \mathrm{SiB}_{2}$ (blue triangle), $\mathrm{Mo}_{5} \mathrm{Si}_{3}+\mathrm{Mo} \mathrm{Si}_{3}+\mathrm{Mo}_{5} \mathrm{SiB}_{2}$ (green triangle). Data taken from Ref. [58]. 
(ii) The other three-phase field solely consists of the intermetallic phases $\mathrm{Mo}_{5} \mathrm{Si}_{3}(\mathrm{~T} 1)+$ Mo3si (A15) + $\mathrm{Mo}_{5} \mathrm{SiB}_{2}$ (T2) and was investigated by Akinc et al. [52, 59] (green triangle in Fig. 2-2). These alloys were found to undergo catastrophic oxidation as well below $1000{ }^{\circ} \mathrm{C}$ with mass losses in the range of $-30\left(\mathrm{mg} / \mathrm{cm}^{2}\right) \mathrm{h}^{-1}[41]$ at $800{ }^{\circ} \mathrm{C}$. At increased temperatures, an adequate oxidation resistance is observed instead [41,60]. Additionally, these alloys typically possess an inferior fracture toughness due to the brittle nature of the intermetallic phases [61-64].

Since microstructural design aims to balance both, mechanical and chemical stability, new alloying strategies for Mo-Si-B-X alloys have emerged with the purpose of modifying the phase equilibrium regions. Therefore, in addition to the previously investigated phase fields, novel ones consisting of Moss $+\mathrm{Mo}_{5} \mathrm{Si}_{3}+\mathrm{Mo}_{5} \mathrm{SiB}_{2}$ and Moss $+\mathrm{Mo}_{5} \mathrm{SiB}_{2}+\mathrm{Ti}_{5} \mathrm{Si}_{3}$ have been established by alloying with $\mathrm{W} / \mathrm{Nb} / \mathrm{Ta}$ and $\mathrm{Hf} / \mathrm{Ti} / \mathrm{Zr}$, respectively $[21,42,65,66]$. In this respect, the development of the main promising concepts for Mo-Si-based alloys for high-temperature applications is illustrated in Fig. 2-3.

(a) Mo-Si-B

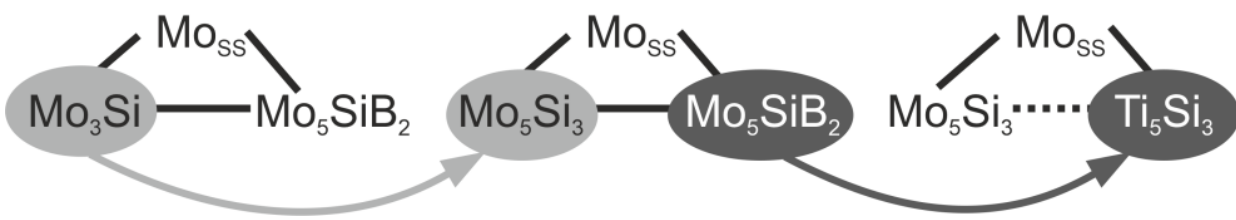

Fig. 2-3 Schematic overview of the main alloying concepts of Mo-Si-based alloys.

The main challenge is to prevent severe oxidation at temperatures below $1000{ }^{\circ} \mathrm{C}$ and to obtain an adequate oxidation resistance at elevated temperatures. This was not achieved for ternary Mo-Si-B alloys [42, 57], even though they profit from the quick passivation of the alloy substrate $[41,67,68]$ due to the reduction in oxide scale viscosity [69] at higher temperatures. Additionally, these alloys are characterised by higher densities in the range of $9.5 \mathrm{~g} / \mathrm{cm}^{3}$ [21] compared to commercially applied Ni-based superalloys, which makes them unattractive as structural material for moving parts. Besides this alloy design approach (a), namely alloying with B, a second approach (b) focused on additional alloying with Ti. This led to the substitution of poorly oxidation-resistant phases by Si-rich, more oxidation-resistant phases, like $\mathrm{Mo}_{3} \mathrm{Si}$ and $\mathrm{Mo5}_{5} \mathrm{Si}_{3}$, respectively. Furthermore, the alloy density was successfully lowered to $7.7 \mathrm{~g} / \mathrm{cm}^{3}[4,47]$. These Mo-Si-B-Ti alloys exhibit a suitable creep strength while possessing an improved oxidation resistance in the high tem- 
perature regime above $1000{ }^{\circ} \mathrm{C}$. However, minor oxidation resistance below $1000{ }^{\circ} \mathrm{C}$ is observed compared to the previously developed Mo-Si-B alloys. This is caused by the enhanced initial evaporation of $\mathrm{MoO}_{3}$ and the formation of a non-passivating porous $\mathrm{TiO}_{2}$ containing $\mathrm{B}_{2} \mathrm{O}_{3}-\mathrm{SiO}_{2}$ scale [47]. Additionally, manufacturing of these alloys proved to be problematic because of the narrow Moss $+\mathrm{Mo}_{5} \mathrm{Si}_{3}+\mathrm{Mo}_{5} \mathrm{SiB}_{2}$ three-phase field and the resulting difficulties of reproducibility. To overcome this problem, small additions of 2 at\% Fe were found to broaden the desired three-phase field [48]. However, while the resulting Mo-Si-B-Ti-Fe alloys exhibit significantly enhanced high-temperature oxidation behaviour due to the formation of a protective $\mathrm{SiO}_{2}-\mathrm{TiO}_{2}$ duplex scale at temperatures above $1000^{\circ} \mathrm{C}$, the oxidation resistance is still inadequate at lower temperatures [48, 70].

Although these results are promising for the development of alternative high-temperature materials, the applied alloy design approaches all have the increase in complexity of the achieved microstructures in common. Thus, the resulting multifaceted microstructureproperty relationships are difficult to understand. Therefore, the alloy design approach (c) targets the reduction in complexity of the alloy system by focusing on alloying with Ti and avoiding additional alloying elements. Within the ternary Mo-Si-Ti system profit is taken from eutectic and eutectoid phase reactions, which facilitate fine-scaled cast microstructures. These are believed to be beneficial for the oxidation resistance, as short diffusion paths for solid oxide forming elements, such as $\mathrm{Si}$ forming $\mathrm{SiO}_{2}$, are provided, which enable quick coverage of the alloy substrate. Thus, the addition of $\mathrm{B}$ is claimed to be redundant. However, first studies on two-phase Mo-Si-Ti alloys have shown, that these either exhibit an unexpected good oxidation resistance at $800{ }^{\circ} \mathrm{C}$ in the case of a binary eutectic alloy (comprising Moss and ( $\mathrm{Ti}, \mathrm{Mo})_{5} \mathrm{Si}_{3}$ ), or an adequate creep resistance in the case of a binary eutectoid alloy (comprising Moss and $\left(\mathrm{Mo}_{0}, \mathrm{Ti}_{5} \mathrm{Si}_{3}\right)$ [5]. The combination of both is still unachieved and, therefore, target of this research.

Besides the adjustment of the desired phase equilibria in Mo-Si-B, Mo-Si-B-Ti and Mo-Si$\mathrm{Ti}$ alloys, further alloy design strategies are pursued for optimisation of these multiphase alloys: (i) tailoring the volume fractions of the respective phases, (ii) modifying the microstructural morphology and length scale and (iii) improving the room and high-temperature properties of the phases by additional alloying. The strategies (i) and (ii) are typically realised by manipulating the solidification pathways by slightly changing the chemical composition, the selection of the manufacturing routes (e.g. powder metallurgical (PM) or cast process techniques (here arc melting (AcM)) and the enforced temperature profiles. These two strategies are, for instance, of key importance in the Mo-Si-B alloys for achieving both, 
an adequate room temperature $(R T)$ fracture toughness and sufficient high-temperature stability and oxidation resistance. With respect to the fracture toughness at $R T$, a high volume fraction of Moss is beneficial. Particularly as a continuous matrix with the silicide phases being embedded homogenously, Moss facilitates an improved RT fracture toughness [46, 71-74] in the range of 12 to $21 \mathrm{MPam}^{1 / 2}$ when representing around 30 to $50 \mathrm{vol} \%$ of the microstructure [46, 74]. However, an improvement in fracture toughness, achieved by an increased Moss fraction as continuous matrix, is coming at the expense of the oxidation behaviour and creep performance [46, 72]. A volume fraction of more than 50 vol\% intermetallic phases is required for the formation of an oxidation-resistant borosilicate oxide scale at higher temperatures [75]. Conversely, appropriately high Moss fractions lead to a decrease in brittle-to-ductile-temperature of more than $150 \mathrm{~K}$ (in alloy Mo-9Si$8 B)[72]$.

Typical representative alloys of the above presented alloy design concepts are contrasted in Fig. 2-4, revealing the notable differences in the obtained microstructures. It is obvious that PM routes lead to very fine-scaled microstructures, especially in the as-sintered (as) state, with homogenously distributed phase regions facilitating an improved oxidation resistance. In contrast, microstructures achieved by casting (e.g. AcM) are characterised by large dendrites and textures in the as-cast state ( $a c)$ due to (inhomogeneous) cooling. Long heat treatments at high temperatures are required in order to improve the microstructural homogeneity. The impact of the manufacturing route is clearly demonstrated by the threephase alloy Mo-9Si-8B (comprising Moss, Mos Si and $\mathrm{Mo}_{5} \mathrm{SiB}_{2}$ ). In the PM manufactured as variant, a very fine-scaled microstructure with a continuous Moss matrix is established (see Fig. 2-4a), whereas the microstructure is significantly coarser and textured in the $a c$ variant and especially, in the here presented example it is characterised by an intermetallic matrix (see Fig. 2-4b). The advancement to Mo-Si-B-Ti-(Fe) alloys is displayed in Fig. 2-4c. The representative alloy Mo-12.5Si-8.5B-27.5Ti-2Fe developed by Azim et al. [48] consists of Moss (39 vol\%), Mo5 $\mathrm{Si}_{3}, \mathrm{Mo}_{5} \mathrm{SiB}_{2}$ and small amounts of $\mathrm{Ti}_{5} \mathrm{Si}_{3}$. However, an additional heat treatment $\left(h t^{* *}: 1600^{\circ} \mathrm{C} 150 \mathrm{~h}+1400^{\circ} \mathrm{C} 100 \mathrm{~h}\right)$ is needed after casting in order to obtain the desired phase equilibrium. Contrary to this, fine-scaled two-phase alloys can be developed by AcM in the Mo-Si-Ti system. For instance, the binary eutectic alloy Mo-20Si-52.8Ti, composed of Moss and ( $\mathrm{Ti}, \mathrm{Mo})_{5} \mathrm{Si}_{3}$, reveals a fine fibrous microstructure in the $a c$ state (see Fig. 2-4d).

The strategy (iii) of alloying additional elements is mainly pursued to improve the ductility of Moss [75, 76]. This allows for a reduction in its volume fraction while maintaining an 
adequate fracture toughness, but decreasing the deteriorative impact on the oxidation resistance. Of particular relevance is $\mathrm{Si}$, which is a major solid solution strengthening element in Moss [77]. It can be dissolved up to maximum 4 at\% in thermodynamic equilibrium at $2025{ }^{\circ} \mathrm{C}$ [36]. In supersaturation at lower temperatures, it is known to segregate along the grain boundaries. This leads to disadvantageous low grain boundary cohesion and embrittlement $[71,76]$. In contrast, alloying elements, like $\mathrm{Zr}$, are found to be beneficial for the fracture toughness as grain boundary segregations are reduced and $\mathrm{O}$ residuals are gettered [46, 75, 76, 78, 79].
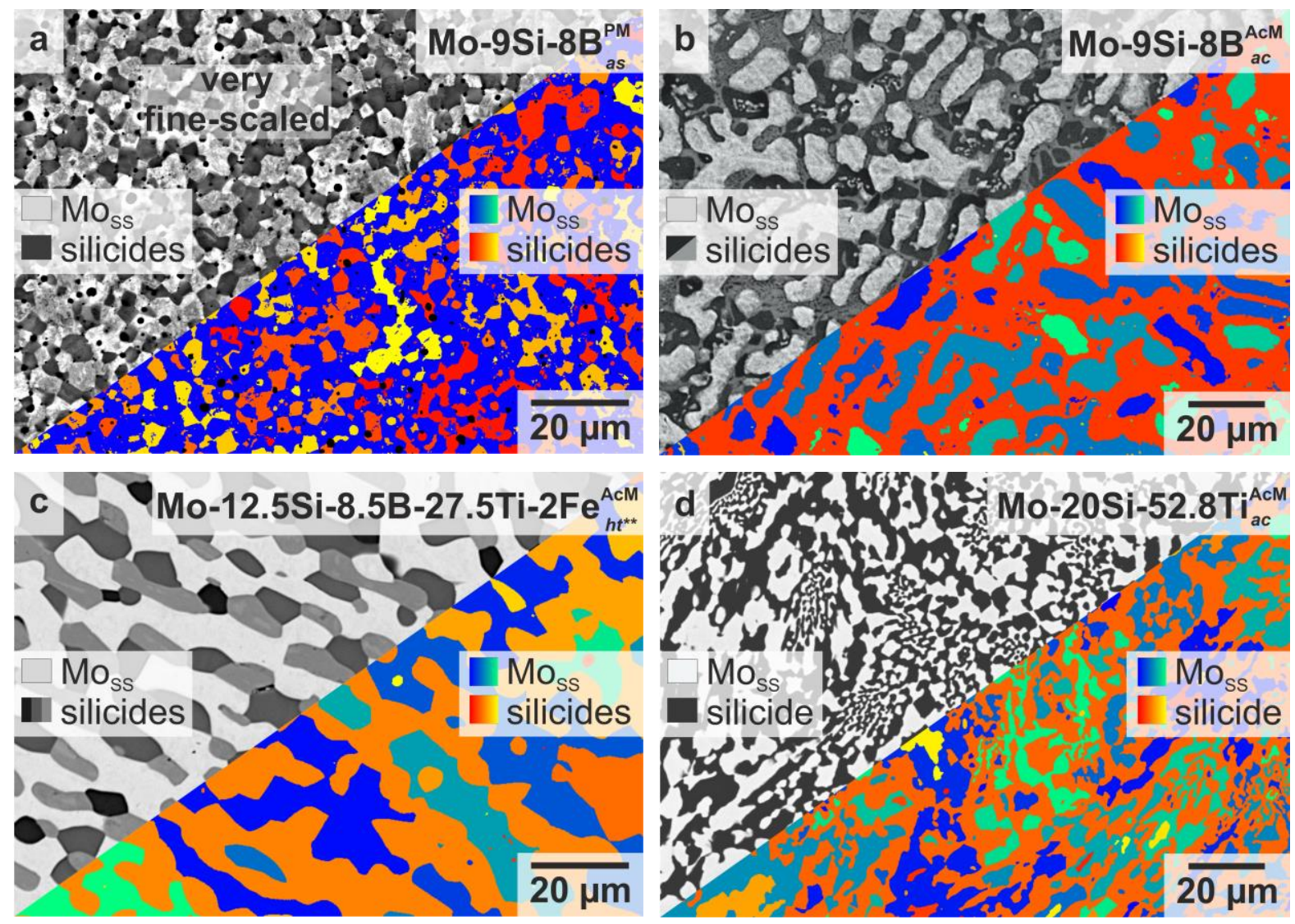

Fig. 2-4 BSE micrographs of alloy Mo-9Si-8B, PM-manufactured as-sintered, very fine-scaled (a) and AcM as-cast (b); alloy Mo-12.5Si-8.5B-27.5Ti-2Fe, AcM heat-treated (c) and alloy Mo-20Si-52.8Ti, AcM as-cast (d). Coloured proportions of the microstructures are included (Moss: blue to green, silicide phases: red to orange), connected pixel clusters are the same colour.

In essence, the strategies (i) and (ii) are of significant importance for the development of the Mo-Si-Ti alloys as potential alternative materials for high-temperature applications. Therefore, the ternary Mo-Si-Ti system will be discussed in detail in the following Sec. 2.2. 


\subsection{The Ternary Mo-Si-Ti System}

The study of the phase equilibria and the respective microstructures plays a crucial role for the development of Mo-Si-Ti alloys. Thereby, the metal-rich region of the ternary system with high liquidus/solidus temperatures is of main interest with regard to future hightemperature applications. The solidification characteristics within this ternary system are influenced by the invariant reactions of the binary systems, which evolve into it. This is indicated by the liquidus projection, which originates from the three corresponding binary systems (see Fig. 2-5). The four primary solidifying regions Moss, (Mo,Ti) 3 Si, (Mo,Ti) ${ }_{5} \mathrm{Si}_{3}$ and $(\mathrm{Ti}, \mathrm{Mo})_{5} \mathrm{Si}_{3}$ of major relevance are compared in Table 2-1 with respect to their physical characteristics.

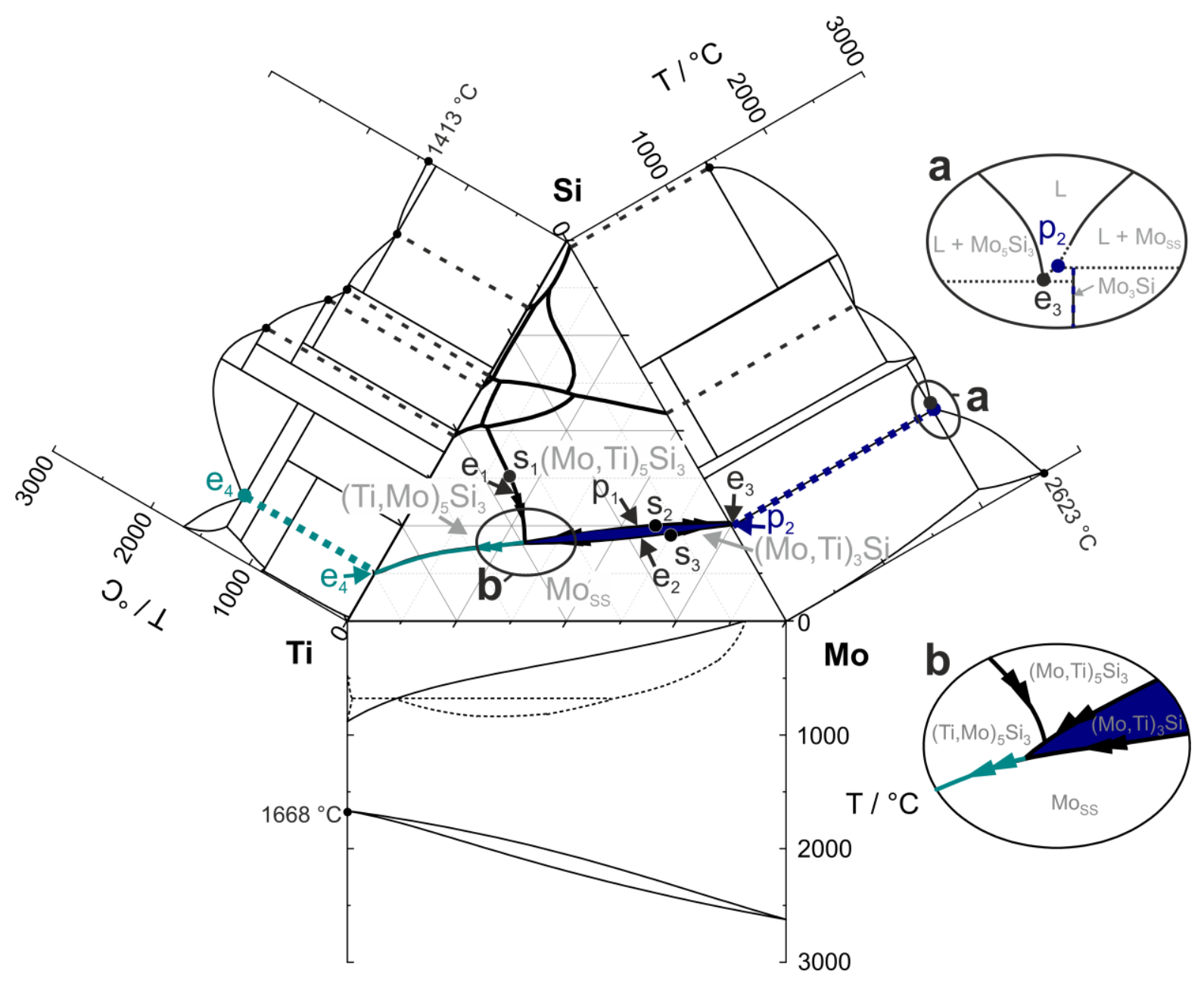

Fig. 2-5 Liquidus projection of the ternary Mo-Si-Ti system with the relevant metalrich section being labelled, including the binary systems. Zoomed-in views are provided in insets (a) and (b). Combination of thermodynamic calculations with Pandat and literature data [36, 80-83]. 
The respective ternary phases are substitutional solid solution phases of the binary intermetallic compounds. Mo and Ti substitute each other to a great extent on the respective lattice sites. Hence, (Mo,Ti) ${ }_{3} \mathrm{Si},(\mathrm{Mo}, \mathrm{Ti})_{5} \mathrm{Si}_{3}$ and $(\mathrm{Ti}, \mathrm{Mo})_{5} \mathrm{Si}_{3}$ (derived from $\mathrm{Mo}_{3} \mathrm{Si}_{1} \mathrm{Mo}_{5} \mathrm{Si}_{3}$ and $\left.\mathrm{Ti}_{5} \mathrm{Si}_{3}\right)$ are used for designation in the ternary system.

Table 2-1 Overview on the physical properties of the relevant phases in the ternary Mo-Si-Ti system.

\begin{tabular}{|c|c|c|c|c|}
\hline & $\begin{array}{c}\text { Mo } \\
\text { (Moss) }\end{array}$ & $\begin{array}{c}\mathrm{Mo}_{3} \mathrm{Si} \\
(\mathrm{Mo}, \mathrm{Ti})_{3} \mathrm{Si}\end{array}$ & $\begin{array}{c}\mathrm{Mo}_{5} \mathrm{Si}_{3} \\
(\mathrm{Mo}, \mathrm{Ti})_{5} \mathrm{Si}_{3}\end{array}$ & $\begin{array}{c}\mathrm{Ti}_{5} \mathrm{Si}_{3} \\
(\mathrm{Ti}, \mathrm{Mo})_{5} \mathrm{Si}_{3}\end{array}$ \\
\hline prototype & $\mathrm{W}$ & $\mathrm{Cr}_{3} \mathrm{Si}$ & $\mathrm{W}_{5} \mathrm{Si}_{3}$ & $\mathrm{Mn}_{5} \mathrm{Si}_{3}$ \\
\hline space group & I m $\overline{3}$ m (229) & $\mathrm{P}$ m $\overline{3} \mathrm{n}(223)$ & I 4/m c m (140) & $\mathrm{P} 63 / \mathrm{m} \mathrm{c} \mathrm{m} \mathrm{(193)}$ \\
\hline Strukturbericht & A2 & A15 & $\mathrm{D} 8_{\mathrm{m}}$ & $\mathrm{D} 88$ \\
\hline $\begin{array}{l}\text { lattice parame- } \\
\text { ter at } R T \text { / }\end{array}$ & $\begin{array}{c}a^{M o}=3.143- \\
3.147[84,85] \\
a^{T i}=3.280[83]\end{array}$ & $\begin{array}{c}a^{M o_{3} S i}=4.897 \\
{[86]}\end{array}$ & $\begin{array}{c}a^{\mathrm{Mo}_{5} S i_{3}}=9.249 \\
c^{M o_{5} S i_{3}}=4.925 \\
c / a=0.5325 \\
{[86-89]}\end{array}$ & $\begin{array}{c}a^{T i_{5} S i_{3}}=7.450 \\
c^{T i_{5} S i_{3}}=5.112 \\
c / a=0.6862 \\
{[90-92]}\end{array}$ \\
\hline $\begin{array}{l}\text { melting point / } \\
{ }^{\circ} \mathrm{C}\end{array}$ & $\begin{array}{c}T_{m}^{M o}=2623 \\
T_{m}^{T i}=1668 \\
{[36]}\end{array}$ & $\begin{array}{c}T_{m}^{\mathrm{Mo}_{3} \mathrm{Si}} \approx 2050 \\
{[53,80,93]}\end{array}$ & $\begin{array}{c}T_{m}^{\mathrm{Mo}_{5} \mathrm{Si}_{3}} \approx 2180 \\
{[36]}\end{array}$ & $\begin{array}{c}T_{m}^{\mathrm{Ti}_{5} S i_{3}}=2122 \\
\quad \text { (Pandat) }\end{array}$ \\
\hline $\begin{array}{l}\text { elemental } \\
\text { solubility }\end{array}$ & $\begin{array}{c}\text { Si: } 4 \text { to } 5 \text { at\% } \\
{[36,94,95]} \\
T>900{ }^{\circ} \mathrm{C}: \mathrm{Ti} \\
\text { and Mo total } \\
\text { miscibility }\end{array}$ & $\begin{array}{c}\text { Si: }(25 \pm 1) \text { at } \% \\
{[63]} \\
\text { Ti: } 28 \text { to } 30 \text { at } \% \\
{[4,66]}\end{array}$ & $\begin{array}{c}\text { Si: }(37.5 \pm 2 \text { to } \\
4) \text { at } \% \\
{[36,93,94,96]} \\
\text { Ti: } 40 \text { at\% } \\
\left(1600^{\circ} \mathrm{C}\right)[66]\end{array}$ & $\begin{array}{c}\text { Si: }(37.5 \pm 3) \text { at } \% \\
{[95,97]} \\
\text { Mo: } 12.5 \text { at\% } \\
\left(1600^{\circ} \mathrm{C}\right)[66]\end{array}$ \\
\hline density / g/cm³ & $\begin{aligned} \rho^{M o} & =10.28 \\
\rho^{T i} & =4.51\end{aligned}$ & 8.49 [98] & 8.19 [61] & 4.3 [99] \\
\hline $\begin{array}{l}R T \text { fracture } \\
\text { toughness } \\
\text { /MPam }^{1 / 2}\end{array}$ & $24[77]$ & 3 [63] & $2-2.5$ [100] & 2.1 [99] \\
\hline $\begin{array}{c}\text { coefficient of } \\
\text { thermal expan- } \\
\text { sion (CTE) } / 10^{-6} \\
\text { 1/K }\end{array}$ & $5.35[101]$ & $\begin{array}{c}\alpha_{a}=7.17 \\
\alpha_{c}=7.01 \\
\alpha_{c} / \alpha_{a}=0.98 \\
{[102,103]}\end{array}$ & $\begin{array}{c}\alpha_{a}=5.2 \text { to } 5.8 \\
\alpha_{c}=11.5 \text { to } 11.7 \\
\alpha_{c} / \alpha_{a}=2.0 \text { to } \\
2.2[100,104]\end{array}$ & $\begin{array}{c}\alpha_{a}=6.11 \\
\alpha_{c}=16.62 \\
\alpha_{c} / \alpha_{a}=2.72 \\
{[104]}\end{array}$ \\
\hline
\end{tabular}

The experimental evaluation of the phase equilibria in the ternary Mo-Si-Ti system was found to be in good agreement with the thermodynamic predictions by Yang et al. [105]. The corresponding binary and ternary reaction schemes are described in detail by Bondar and Lukas [93]. Among numerous phase reactions in the binary Mo-Si system, it is the 
peritectic reaction $\left(\mathrm{p}_{2}\right)$ at around $2050{ }^{\circ} \mathrm{C}[36,106]$, where the liquid $\mathrm{L}$ and Moss react to Mossi (blue circle and dashed line in Fig. 2-5a) [105], which is observed in the ternary system along the $\mathrm{p}_{2}-\mathrm{s}_{3}$ line as well:

$$
\text { peritectic }\left(\mathrm{p}_{2}\right): \mathrm{L}+\mathrm{Moss} \rightleftharpoons(\mathrm{Mo}, \mathrm{Ti})_{3} \mathrm{Si}
$$

Close to the chemical composition of the peritectic reaction and at only slightly lower temperatures, the following eutectic reaction ( $\left.\mathrm{e}_{3}\right)$ evolves from the binary Mo-Si system (at $\left.2020^{\circ} \mathrm{C}[36]\right)$ into the ternary system along the e 3 - s2 line $[93,105]$ :

$$
\text { eutectic }\left(\mathrm{e}_{3}\right): \mathrm{L} \rightleftharpoons(\mathrm{Mo}, \mathrm{Ti})_{5} \mathrm{Si}_{3}+(\mathrm{Mo}, \mathrm{Ti})_{3} \mathrm{Si}
$$

For the development of tailored Mo-Si-Ti alloys, the primary solidification region of $(\mathrm{Mo}, \mathrm{Ti})_{3} \mathrm{Si}$ is of special interest since it decomposes in a eutectoid reaction in the solid state [5] (see region highlighted in blue in Fig. 2-5):

$$
\text { eutectoid: }(\mathrm{Mo}, \mathrm{Ti})_{3} \mathrm{Si} \rightleftharpoons \mathrm{Moss}+(\mathrm{Mo}, \mathrm{Ti})_{5} \mathrm{Si}_{3}
$$

Moreover, multiple binary eutectic reactions lead to fine-scaled microstructures within the ternary system. The most relevant occurs along the eutectic ridge between the primary solidification region of Moss and ( $\mathrm{Ti}, \mathrm{Mo})_{5} \mathrm{Si}_{3}$ (green line in Fig. 2-5) [93], ending in the binary Ti-Si system ( $\mathrm{e}_{4}$, green circle and dashed line in Fig. 2-5).

$$
\text { eutectic }\left(\mathrm{e}_{4}\right): \mathrm{L} \rightleftharpoons \operatorname{Moss}+(\mathrm{Ti}, \mathrm{Mo})_{5} \mathrm{Si}_{3}
$$

Additionally, the following eutectic phase reaction $\left(\mathrm{e}_{1}\right)$ [93] occurs along the eutectic ridge between the primary solidification regions of $(\mathrm{Mo}, \mathrm{Ti})_{5} \mathrm{Si}_{3}$ and $(\mathrm{Ti}, \mathrm{Mo})_{5} \mathrm{Si}_{3}$, whose reaction temperature is maximum in the saddle point $\mathrm{s}_{1}$ [105].

$$
\text { eutectic }\left(\mathrm{e}_{1}\right) \mathrm{L} \rightleftharpoons(\mathrm{Mo}, \mathrm{Ti})_{5} \mathrm{Si}_{3}+(\mathrm{Ti}, \mathrm{Mo})_{5} \mathrm{Si}_{3}
$$

Two additional saddle points $\mathrm{s}_{2}\left(2118^{\circ} \mathrm{C}\right)$ and $\mathrm{s}_{3}\left(2114^{\circ} \mathrm{C}\right)$ were calculated by Yang et al. [105]. It is stated that $\mathrm{s}_{2}$ represents the transition from the eutectic reaction $\mathrm{e}_{3}$ to the peritectic reaction $\mathrm{p}_{1}[105]$ :

$$
\text { peritectic }\left(\mathrm{p}_{1}\right): \mathrm{L}+(\mathrm{Mo}, \mathrm{Ti})_{5} \mathrm{Si}_{3} \rightleftharpoons(\mathrm{Mo}, \mathrm{Ti})_{3} \mathrm{Si}
$$

The saddle point $\mathrm{s}_{3}$ is assigned to the transition from the peritectic reaction $\mathrm{p}_{2}$ to the eutectic reaction $\mathrm{e}_{2}[105]$ :

$$
\text { eutectic }\left(\mathrm{e}_{2}\right): \mathrm{L} \rightarrow \operatorname{Moss}+(\mathrm{Mo}, \mathrm{Ti})_{3} \mathrm{Si}
$$


Furthermore, two transition equilibria are proposed by Yang et al. [105] and dealt with in detail by Bondar and Lukas [93], which occur in the area where the primary solidification region of (Mo,Ti) ${ }_{3} \mathrm{Si}$ merges the eutectic ridge $\mathrm{e}_{4}$ (see Fig. 2-5b). The quaternary invariant reactions $\mathrm{u}_{1}\left(1926^{\circ} \mathrm{C}\right)$ and $\mathrm{u}_{2}\left(1930^{\circ} \mathrm{C}\right)$ of type II are expressed as follows [105]:

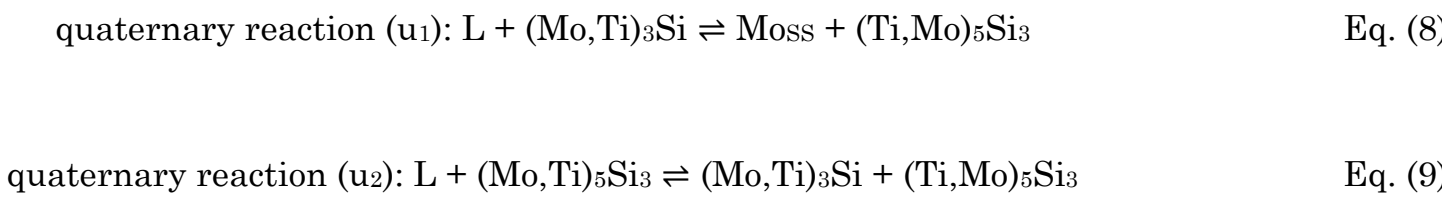

In order to assess the solid-state equilibria, the thermodynamic description at $1600{ }^{\circ} \mathrm{C}$ is given as isothermal section in Fig. 2-6. There are two three-phase equilibria highlighted in red and orange: Moss $+(\mathrm{Ti}, \mathrm{Mo})_{5} \mathrm{Si}_{3}+(\mathrm{Mo}, \mathrm{Ti})_{5} \mathrm{Si}_{3}$ and Moss $+\left(\mathrm{Mo}, \mathrm{Ti}_{5} \mathrm{Si}_{3}+(\mathrm{Mo}, \mathrm{Ti})_{3} \mathrm{Si}\right.$, respectively.

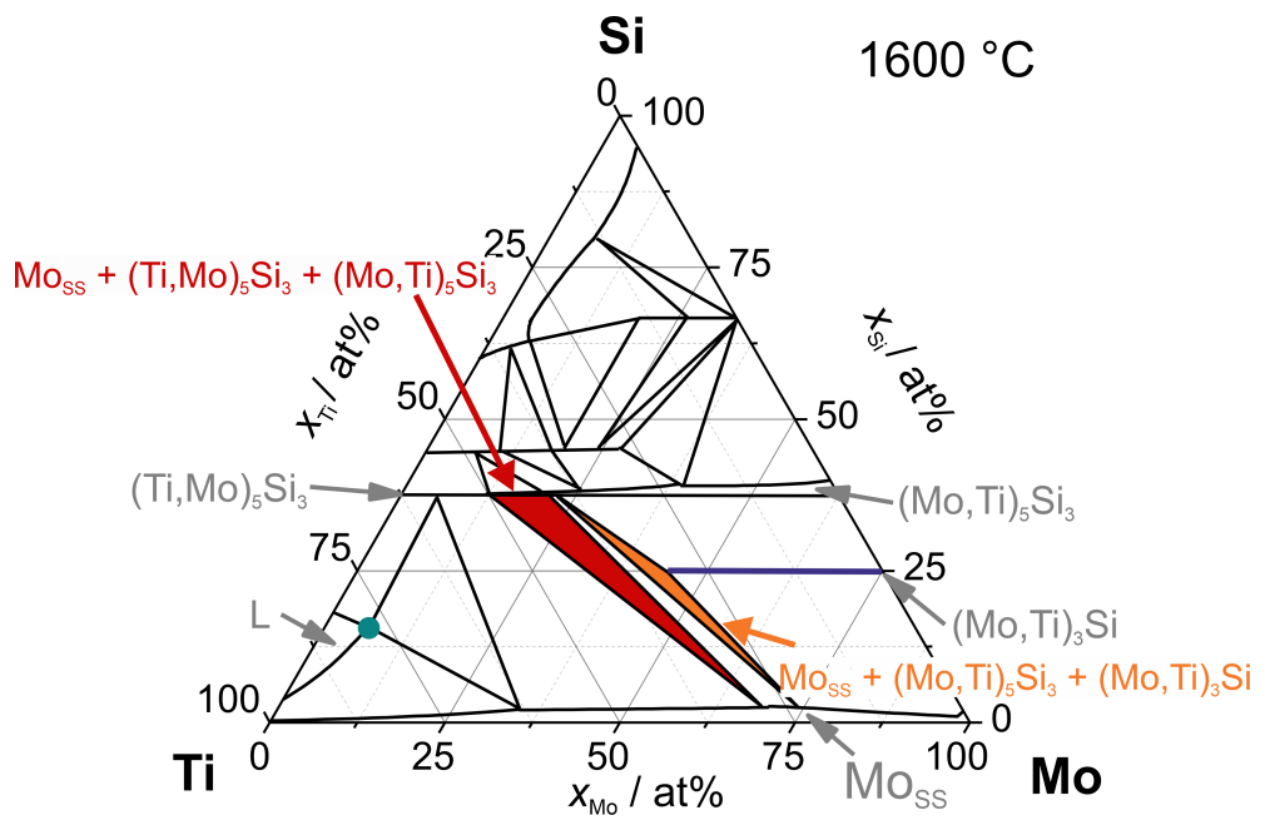

Fig. 2-6 Isothermal section of the ternary Mo-Si-Ti system at $1600{ }^{\circ} \mathrm{C}$ calculated with Pandat. Three-phase fields of special interest are highlighted. Red: Moss $+(\mathrm{Ti}, \mathrm{Mo})_{5} \mathrm{Si}_{3}+(\mathrm{Mo}, \mathrm{Ti})_{5} \mathrm{Si}_{3}$, orange: Moss $+(\mathrm{Mo}, \mathrm{Ti})_{5} \mathrm{Si}_{3}+(\mathrm{Mo}, \mathrm{Ti})_{3} \mathrm{Si}$. The $(\mathrm{Mo}, \mathrm{Ti})_{3} \mathrm{Si}$ phase region is highlighted by the blue line and the eutectic reaction $\mathrm{e}_{4}$ by the green circle in the Ti-rich corner.

It is seen that the $(\mathrm{Mo}, \mathrm{Ti})_{3} \mathrm{Si}$ phase is regarded as stoichiometric phase with a fixed $\mathrm{Si}$ content of 25 at\%. This is contradictory to experimental results published in Ref. [63]. If the temperature is decreased, the three-phase equilibrium Moss $+\left(\mathrm{Mo}, \mathrm{Ti}_{5}{ }_{5} \mathrm{Si}_{3}+(\mathrm{Mo}, \mathrm{Ti})_{3} \mathrm{Si}\right.$ slightly shifts towards the Mo-Si system by significantly narrowing until $1200{ }^{\circ} \mathrm{C}$ (not 
shown here). In contrast, the equilibrium Moss $+(\mathrm{Ti}, \mathrm{Mo})_{5} \mathrm{Si}_{3}+(\mathrm{Mo}, \mathrm{Ti})_{5} \mathrm{Si}_{3}$ phase field reveals an almost unchanged range when lowering the temperature to $1200^{\circ} \mathrm{C}$. This opens possibilities for alloy development targeting thermodynamic stable microstructures at high operating temperatures.

The solidification processing conditions control the solidification pathways and might suppress phase reactions by rapid cooling. The sluggish interdiffusion activities in Mo-Sibased alloys at high temperatures $[107,108]$ are, on the one hand demanding for achieving equilibrium conditions, but on the other hand advantageous for long-term high-temperature service.

\subsection{Fundamentals on the Oxidation Behaviour}

In the following section, approaches on how to describe and evaluate the oxidation behaviour, typical mechanisms and their characteristics are presented. In general, oxidation reactions are a type of high-temperature corrosion reactions and are defined as chemical reactions of (here) metal-based substrates $(\mathrm{M})$ with oxygen $(\mathrm{O})$ by forming oxides as reaction products $[109,110]$. These reaction products are gaseous or solid [110]. Oxidation resistance is principally achieved by the formation of a protective oxide scale. However, multiple characteristics of oxide scales determine whether passivation can be provided or not: (i) Thermodynamic stability of the formed oxides is mandatory even when the local chemical composition at the oxide scale/substrate interface is varying with ongoing oxidation. Otherwise "intrinsic chemical failure" [111] can occur. (ii) The growth kinetics are important to quickly form a continuous solid oxide scale, which allow for instantaneous coverage of the substrate. Subsequent to this initial stage of oxidation, a slow growing oxide scale is favourable. (iii) The adherence of the oxide scale is crucial for sufficient oxidation resistance since open pathways and spallation favour non-inhibited $\mathrm{O}$ ingress. This can be, for instance, caused by non-matching CTE of oxides and substrates, as internal stresses, provoked by thermal cycling, lead to cracking and decohesion of the oxide scale. Moreover, if the formed solid oxide scale reveals a different volume per unit area compared to the alloy substrate, buckling (volume expansion) or shrinkage (contraction) of the oxide scale on the substrate are caused. The corresponding ratio of the oxide scale volume and the substrate volume is known as the Pilling-Bedworth ratio (PBR), which can be related to a good adherence during thermal cycling [110]. (iv) Besides the aimed minimal porosity of the oxide scale (density), it is its functionality as diffusion barrier for both, $\mathrm{O}$ anions and metal cations, which especially leads to passivation and a diffusion-controlled oxidation 
rate. The $\mathrm{O}$ anions and metal cations are diffusing in- and outwards, respectively, depending on the fundamental diffusion mechanisms and on the defect structure of the oxide, see p. 72 in Ref. [112]. Thus, the interface, where the oxidation reactions are predominantly taking place, is determined by the faster diffusing species. This leads to two typical oxidation mechanisms: (i) Formation of external oxide scales at the oxide/atmosphere interface. (ii) Internal oxidation processes, where oxidation occurs at the oxide/substrate interface, see p. 245 in Ref. [109]. Both mechanisms are illustrated in Fig. 2-7, including typical ion transport directions. If the $\mathrm{O}$ inward diffusion in form of $\mathrm{O}^{2-}$ (see black arrow) is faster than the outward diffusion of metal cations (here $\mathrm{M}^{2+}$ ), then oxidation occurs preferentially at the oxide/substrate interface. This leads to an inward growth direction (Fig. 2-7a). In contrast, if the outward diffusion of the metal cations (blue arrow) is dominating and the $\mathrm{O}$ inward diffusion is slower, then the oxidation reactions take place at the oxide/atmosphere interface (see Fig. 2-7b) resulting in an externally growing oxide scale.

a

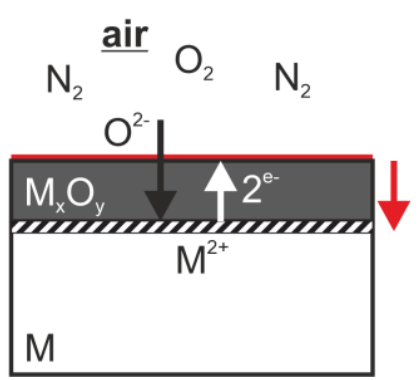

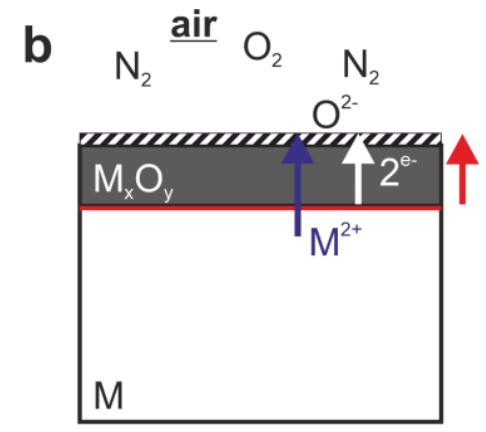

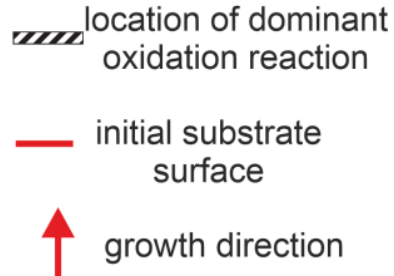

Fig. 2-7 Schematic transport mechanisms of oxidation reactions. According to p. 41 in Ref. [9].

The diffusion flux of the species depends on the chemical potential as thermodynamic driving force and on conditions like temperature, atmosphere and pressure. In general, an oxidation reaction leading to the oxide $\mathrm{M}_{x} \mathrm{O}_{y}$ can be expressed as (see p. 250 in Ref. [109]):

$$
\left(2 \frac{x}{y}\right) \mathrm{M}+\mathrm{O}_{2} \rightleftharpoons\left(\frac{2}{y}\right) \mathrm{M}_{x} \mathrm{O}_{y}
$$

The stability of metals, when exposed to a specific atmosphere with defined gas pressures, is characterised by the temperature-dependent free standard reaction enthalpy $\Delta G^{0}$ of the corresponding oxidation reactions [109]. These dependencies are plotted in so-called " $E l$ lingham-Richardson diagrams" [113] (see Fig. 2-8), which were first introduced by Ellingham in 1944 for the formation of oxides or sulphides of the respective metals [113]. Although these graphs do not provide any information on the oxidation kinetics, essential 
information is provided on whether specific oxidation reactions occur at a defined temperature $T$ and partial pressure $p$ (e.g. of $\mathrm{O}$ ) under thermodynamic equilibrium conditions [9, $112]$. When the oxidation reaction to a specific oxide $\mathrm{M}(+\mathrm{I})$-oxide reveals a lower $\Delta G$ than that for another $\mathrm{M}(+\mathrm{II})$-oxide ${ }^{2}$, then there is the tendency that the $\mathrm{M}(+\mathrm{I})$-oxide reduces the M(+II)-oxide [113]. This does not only depend on the valence state of the oxides, but also on the different metal cations, which represent the major cationic component. In this respect, this kind of plot displays the relative stabilities of different metals referring to their oxides. Typical oxides of $\mathrm{Si}$ and $\mathrm{Ti}$ are less stable than $\mathrm{Al}_{2} \mathrm{O}_{3}$, which is, hence, an attractive scale in a high variety of alloy systems, like Ti-Al- or Ni-Al-based alloys [114-118].

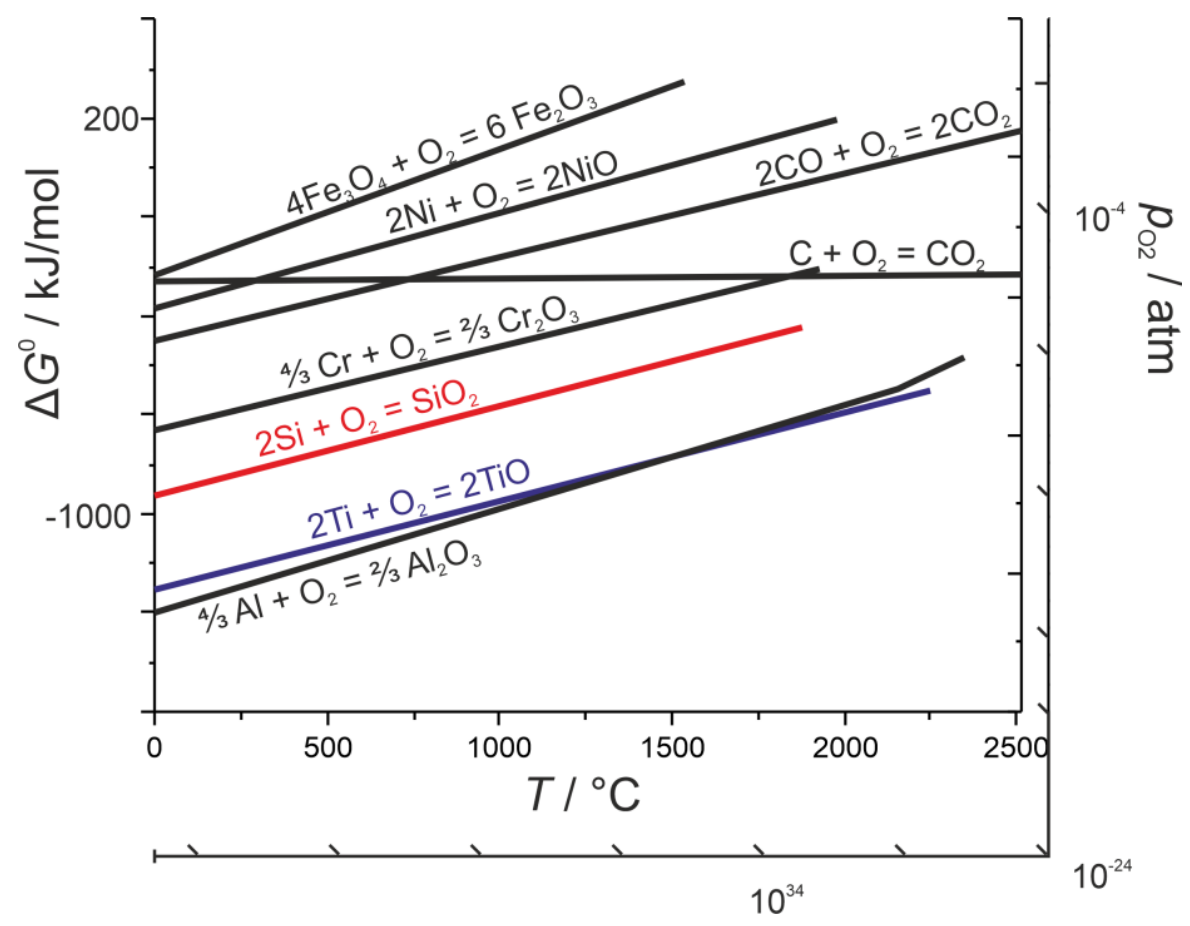

Fig. 2-8 Schematic Ellingham-Richardson plot. According to p. 23 in Ref. [9] and Ref. [119].

If the change in Gibbs free energy $\Delta G$ for a general oxidation reaction (see Eq. 11) is negative $(\Delta G<0)$, then oxidation will occur spontaneously, p. 17 in Ref. [9] and p. 1 in Ref. [112]:

$$
\Delta G=\Delta G^{0}+R T \ln \left(\frac{a_{\mathrm{M}_{x} 0_{y}}^{\frac{2}{y}}}{a_{\mathrm{M}}^{\frac{2 x}{y}} a_{\mathrm{o}_{2}}}\right)
$$

\footnotetext{
2 the curve of $\mathrm{M}(+\mathrm{I})$-oxide is more negative in Fig. 2-8
} 
Thus, the change in free energy is the driving force for reactions to take place. In this context, $a$ is the thermodynamic activity, which describes the deviation from the standard state of the respective species, p. 17 in Ref. [9]. Thereby, $a_{\mathrm{M}_{x} \mathrm{O}_{y}}$ is the thermodynamic activity of the oxide $\mathrm{M}_{x} \mathrm{O}_{y}$ formed in a stoichiometry of $x$ metal atoms and $y$ oxygen atoms on the metal $\mathrm{M}$; whereas, $a_{\mathrm{M}}$ is the activity of the metal itself. $a$ is defined as the ratio of the partial pressure $p_{i}$ of the gaseous species $i$ the metal $\mathrm{M}$ is exposed to and the analogous quantity corresponding to the standard state $p_{i}^{0}$, p. 17 in Ref. [9] (see Eq. 12).

$$
a=\frac{p_{i}}{p_{i}^{0}}
$$

Since the oxidation kinetics are essential for assessing the component design and predicting the component life in oxidative, corrosive or even more hazardous environments, oxidation experiments monitoring the actual mass change $\Delta m_{\text {actual }}$ as a function of test duration $t$ are mandatory. For comparative reasons, the actual mass change is normalised by the initial surface area $A$ of the oxidation sample, which leads to the specific mass change $\Delta m$. In general, the specific weight change kinetics can be expressed by the $w^{t h}$ power law (including the weight oxidation rate constant $k_{w}$ ):

$$
(\Delta m)^{w}=k_{w} t
$$

Idealised weight change kinetics with typical exponents of $w$ are displayed in Fig. 2-9.

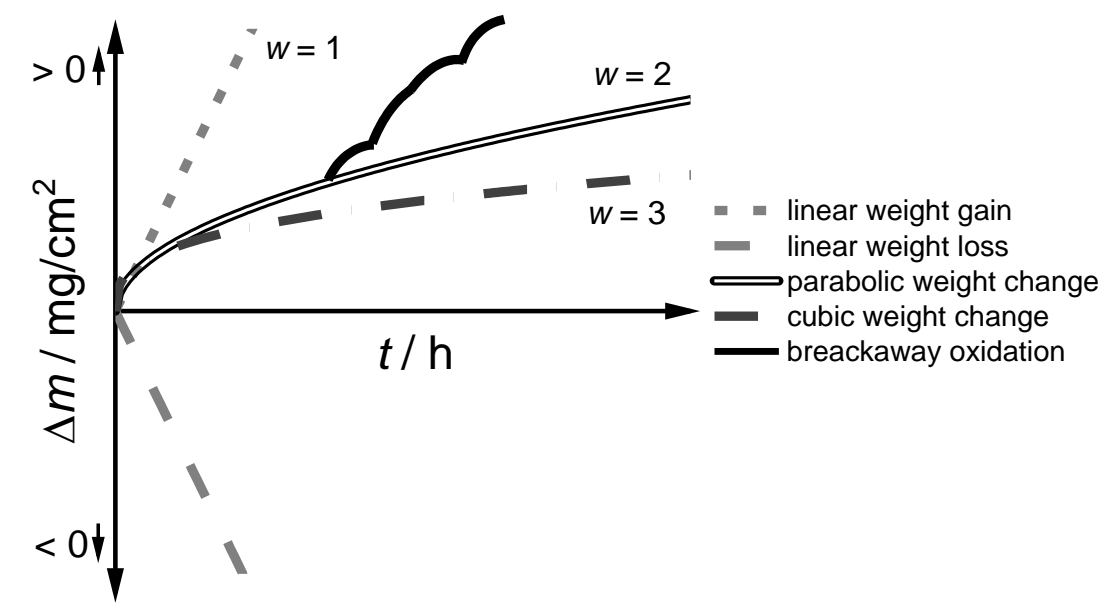

Fig. 2-9 Idealised specific weight change kinetics. According to p. 253 in Ref. [109].

In general, the observed mass changes are a balance of weight loss caused by the formation of volatile oxides and weight gain caused by solid oxide scale growth. However, such basic oxidation kinetics only serve as first indications for possible oxidation laws, as most multi- 
component alloys are usually multiphase and therefore exhibit complex phase- and sitespecific oxidation behaviour.

Linear oxidation with time $(w=1)$ can be associated to linear weight (i) gain or (ii) loss. Case (i) is observed when the forming oxide scale is not dense (e.g. porosity, cracks, volume differences or thermally induced stresses). This enables continuous $\mathrm{O}$ penetration towards the oxide scale/substrate interface. Case (ii) is observed when gaseous oxides are continuously evaporating. The rate-controlling processes are usually either surface-near reactions or diffusion activities in the gas phase, see p. 4 in Ref. [9]. The specific mass change can be expressed by means of introducing the linear oxidation rate constant $k_{1}$ in the following equation:

$$
\Delta m=k_{1} t
$$

In contrast, slow oxidation kinetics, like parabolic and cubic oxidation kinetics, with the oxidation rate constants $k_{2}$ and $k_{3}$, respectively (see Eq. 15 and 16), are favoured for industrial applications. These are present when the oxidation rate is diffusion-controlled (compared to the physical meaning of the equivalent oxide scale growth kinetics in the next paragraph).

$$
\begin{aligned}
& \Delta m=\sqrt{k_{2} t} \\
& \Delta m=k_{3} t^{\frac{1}{3}}
\end{aligned}
$$

The initially rapid weight gain is decelerated when the first layer of oxide is formed covering the substrate. Then the substrate and the atmosphere are separated by the oxide scale, see p. 8 in Ref. [9]. If the formed oxide scale exhibits a passivating character, further oxidation, occurring at the oxide scale/substrate interface or at the oxide scale/atmosphere interface, is diffusion-controlled by inward diffusion of $\mathrm{O}$ anions or outward diffusion of metal cations, respectively. However, if the oxide scale undergoes cracking or spallation, rapid $\mathrm{O}$ inward diffusion along new pathways or at the uncovered substrate surface leads to sudden increases in weight gain due to re-oxidation. This oxidation behaviour is called "breakaway oxidation", p. 253 in Ref. [109] and Ref. [120], and is observed for numerous metals like $\mathrm{Nb}$ and $\mathrm{Zr}[121,122]$ and alloy systems like Zr-based [122, 123] or Fe-Al-Cr alloys $[124,125]$. There are multiple effects causing breakaway oxidation: (i) Physical defects caused by different CTE of the substrate and the oxides gaining relevance during cyclic oxidation testing. (ii) Geometrical constraints caused by the volume of the oxide compared to the substrate, which leads to internal stresses and, thus, to buckling, cracking 
or decohesion of the oxide scale $(\mathrm{PBR} \neq 1)$ [110, 120]. (iii) The adherence of the oxide scale can be deteriorated by pore formation, agglomeration and/or segregation of impurities along the oxide scale/substrate interface. Breakaway oxidation might also lead to catastrophic oxidation when the oxide scale forming alloying element is completely consumed in the surface-near region. This is for instance observed in alumina forming $\mathrm{Fe}-\mathrm{Cr}$ - $\mathrm{Al}$ alloys at $1100{ }^{\circ} \mathrm{C}$ and beyond $[124,125]$. Temporarily, the breakaway oxidation can be alleviated by the self-healing capacity of the alloys due to the high surface-near concentration of the oxide scale forming element ${ }^{3}$. However, once the surface-near regions are depleted in this alloying element, non-protective, rapidly growing oxides are likely to form (e.g. Febased oxides) [124, 125].

Besides the evaluation of the specific mass change, the evolution of the oxide scale thickness in dependence of test duration, as well as the scale morphology are worth to ascertain in order to understand the oxidation mechanisms. This is of particular interest, as numerous processes, causing weight gain and/or loss, contribute to the overall specific mass change. Moreover, the initial surface area $A$, the actual weight change $m_{\text {actual }}$ is normalised by, is continuously changing (typically decreasing) with ongoing oxidation testing [126]. Therefore, the oxide scale thickness $d$ is often considered as a function of test duration for determining the oxide scale growth kinetics. The following equation, including the exponent $n$ and the scale growth oxidation rate constant $k_{n}$, allows for the general description of the oxide scale growth kinetics.

$$
d^{n}=k_{n} t
$$

Thereby, $n=1,2$ and 3 represents ideal cases with linear, parabolic and cubic oxide scale growth, respectively. The cubic and parabolic kinetics are either determined by ion diffusion along grain or phase boundaries [127-129] or by bulk diffusion through the formed oxide scale, p. 4 in Ref. [9]. The oxidation rate constants are temperature-dependent [130] and can be expressed by Eq. 18 [131]:

$$
k_{n=2}=\frac{2 D C_{0}}{N}
$$

Here, $D$ is the diffusion coefficient of the specie diffusing through the oxide scale, $C_{0}$ is the oxidant concentration at the oxide/atmosphere interface and $N$ is the number of oxidant species incorporated in the newly grown oxide per unit volume.

\footnotetext{
${ }^{3} \mathrm{In} \mathrm{Fe}-\mathrm{Cr}-\mathrm{Al}$ alloys enabled by the high $\mathrm{Al}$ content, which allows for the formation of $\mathrm{Al}_{2} \mathrm{O}_{3}[124,125]$.
} 
In the following, the oxidation behaviour of Mo will be reviewed, as its oxidation characteristics are important for the oxidation performance of Mo-based alloys. Mo undergoes catastrophic oxidation resulting in complete material disintegration at temperatures of around $500{ }^{\circ} \mathrm{C}$ and beyond [31, 132-134]. This phenomenon is caused by the formation of volatile $\mathrm{MoO}_{3}$. In the intermediate temperature range of 500 to $700{ }^{\circ} \mathrm{C}, \mathrm{MoO}_{3}$ evaporation is occurring simultaneously to the formation of porous, non-protective solid Mo-oxide scales, whereas at higher temperatures, $\mathrm{MoO}_{3}$ volatilisation is dominating $[133,135]$. This results in continuous rapid evaporation of $\mathrm{MoO}_{3}$ with linear weight losses in the range of $-984\left(\mathrm{mg} / \mathrm{cm}^{2}\right) \mathrm{h}^{-1}$ at $1100{ }^{\circ} \mathrm{C}$ [136]. However, this phenomenon is not only observed in pure Mo, but also in intermetallic compounds with Si, like MoSi2 [37, 38, 137, 138], below $1000^{\circ} \mathrm{C}$. The formation of mixed fast-growing, but porous Si-Mo oxide scales is outbalanced by the volatilisation of $\mathrm{MoO}_{3}$ [138]. The intense study on the oxidation behaviour of the silicides shaped the designation of this phenomenon as "pest" degradation $[139,140]$ or "pesting" [141].

The causes for pesting were firstly described by Westbrook in 1964 [139], who proposed a theory based on local intergranular oxidation attack due to accelerated diffusion of $\mathrm{O}$ along grain boundaries. Local enrichment of $\mathrm{O}$ and $\mathrm{N}$ during exposure to oxidative environments was regarded as root cause for grain boundary embrittlement and subsequent material disintegration. Moreover, several theories have argued that local stresses being caused by the volume expansion during oxide formation along pre-existing cracks or grain boundaries led to further crack formation, widening and growth and finally to sample disintegration [138, 142]. While the oxidation of Mo to (volatile) $\mathrm{MoO}_{3}$ leads to a volume expansion of $340 \%$ [138], the oxidation to solid $\mathrm{SiO}_{2}$ results in a volume expansion of only $180 \%$ [138]. Although the oxidation mechanisms have been widely studied since then, they are still not completely understood, as the oxidation behaviour is influenced by the chemical composition, impurities and the microstructure including defects [37, 130, 143]. This is shown in polycrystalline, relatively dense (> $95 \%$ ) and crack-free $\mathrm{MoSi}_{2}$, which does not suffer from pesting $[138,143]$. Research has been undertaken in order to establish an adequate pesting resistance. Thereby, (i) alloying elements like $\mathrm{Al}, \mathrm{Ti}$ and $\mathrm{Zr}$ were shown to enable the suppression of pesting in $\mathrm{Mo}(\mathrm{Si}, \mathrm{X})_{2}$ [142]. The improved oxidation resistance is attributed to the higher $\mathrm{O}$ affinity of the additional alloying elements compared to $\mathrm{Si}$ and to the lower volume expansion during formation of the respective oxides compared to (pure) $\mathrm{SiO}_{2}$ [142]. (ii) Pre-oxidation of $\mathrm{MoSi}_{2}$ at higher temperatures facilitates the formation of a continuous $\mathrm{SiO}_{2}$ oxide scale, which remains stable at lower temperatures of 
$500{ }^{\circ} \mathrm{C}$ and can withstand severe oxidation [143]. Nevertheless, $\mathrm{MoSi}_{2}$ and other Mo-silicides typically possess an improved oxidation behaviour at higher temperatures, as the formation of a protective $\mathrm{SiO}_{2}$ oxide scale is enabled, which retards the formation and volatilisation of Mo-oxides [37, 39]. This transition behaviour is determined by the growth kinetics of $\mathrm{SiO}_{2}$, which is considerably slower at lower temperatures, and by the presence of re-deposited vaporous Mo-oxides, which hinder the formation of a continuous $\mathrm{SiO}_{2}$ oxide scale [138]. The general oxidation reaction can be formulated as follows [39]:

$$
2 \mathrm{MoSi}_{2}+7 \mathrm{O}_{2} \rightarrow 2 \mathrm{MoO}_{3}+4 \mathrm{SiO}_{2}
$$

In essence, the formation of $\mathrm{MoO}_{3}$ and $\mathrm{SiO}_{2}$ is competing [38]. At high temperatures, $\mathrm{MoO}_{3}$ is evaporating instantaneously during the initial oxidation stage, causing rapid linear oxidation, while $\mathrm{SiO}_{2}$ nuclei formation commences [37]. Once being formed, the $\mathrm{SiO}_{2}$ nuclei grow laterally and cover the substrate surface. Thus, the available surface area for Mo oxidation is reduced and consequently, the oxidation rate decelerated. In the final oxidation stage, complete coverage/sealing of the surface by $\mathrm{SiO}_{2}$ is attained and further oxidation is controlled by $\mathrm{O}$ inward diffusion, as the oxidation reaction then preferentially occurs at the oxide/substrate interface [37].

In accordance to these observations, Mo-Si-based alloys suffer from the pesting phenomenon at temperatures below $1000^{\circ} \mathrm{C}$ as well $[4,40-42,48]$. The oxidation behaviour of the relevant individual phases being present in these alloy systems, especially in the ternary Mo-Si-Ti system, is summarised in Table 2-2. While pure Mo and its solid solutions (Moss) suffer from pesting at temperatures below $1000{ }^{\circ} \mathrm{C}$, there is an evident trend towards reduced pesting severity with decreasing Mo to Si ratio in the silicide phases. This is caused by the ability to form solid (s) oxides being enhanced by a higher Si content. At around 35 at\% $\mathrm{Si}$ and more, $\mathrm{SiO}_{2}$ formation is expected (at elevated temperatures) [136, 137, 144, 145]. At elevated temperatures, an improved oxidation behaviour is facilitated because of accelerated growth kinetics of $\mathrm{SiO}_{2}$ or $\mathrm{B}_{2} \mathrm{O}_{3}-\mathrm{SiO}_{2}$ (if $\mathrm{B}$ is present) [41, 42, 145]. Quick coverage of the substrate by fine-scaled microstructures or low-viscous oxide scales $\left(\mathrm{B}_{2} \mathrm{O}_{3}\right.$ $\mathrm{SiO}_{2}$ ) is beneficial and counterbalances the evaporation of gaseous (g) $\mathrm{MoO}_{3}$ [4, 41, 52]. If non-porous and well-adherent oxide scales are formed, the initial weight loss due to formation of volatile $\mathrm{MoO}_{3}$ is decelerated and the oxidation rate is diffusion-controlled by the inward diffusion of $\mathrm{O}$. 
Table 2-2 Overview on the oxidation behaviour of the relevant phases in Mo-Si-based alloy systems.

\begin{tabular}{|c|c|}
\hline & oxidation behaviour \\
\hline Mo & $T \geq 500{ }^{\circ} \mathrm{C}:$ pesting, formation of $\mathrm{MoO}_{3}(\mathrm{~g})[132,133,136,139]$ \\
\hline Moss & $\begin{array}{c}\text { no data reported in literature for }(\mathrm{Mo}, \mathrm{Ti})_{S S} \\
(\mathrm{Mo}, \mathrm{Si}, \mathrm{B}) \mathrm{ss}: \mathrm{T}=1100^{\circ} \mathrm{C} \text { : pesting, formation of } \mathrm{MoO}_{3}(\mathrm{~g})[136]\end{array}$ \\
\hline $\mathrm{Mo} 3 \mathrm{Si}$ & $\begin{array}{c}T \leq 1000^{\circ} \mathrm{C} \text { : pesting, formation of } \mathrm{MoO}_{3}(\mathrm{~g})[146] \\
T>1000^{\circ} \mathrm{C} \text { : rapid mass loss, formation of } \mathrm{MoO}_{3}(\mathrm{~g}) \text { and porous } \mathrm{SiO}_{2}(\mathrm{~s}) \text { scale } \\
{[136]}\end{array}$ \\
\hline$(\mathrm{Mo}, \mathrm{Ti})_{3} \mathrm{Si}$ & no data reported in liter \\
\hline $\mathrm{Mo}_{5} \mathrm{SiB}_{2}$ & $\begin{array}{l}T<1000^{\circ} \mathrm{C} \text { : no pesting, initial mass gain, subsequent continuous mass loss, for- } \\
\text { mation of } \mathrm{MoO}_{3}(\mathrm{~g}) \text { [68] } \\
T \geq 1000^{\circ} \mathrm{C} \text { : no pesting, initial rapid mass loss, steady state oxidation stage with } \\
\text { slow mass loss rate, formation of } \mathrm{B}_{2} \mathrm{O}_{3}-\mathrm{SiO}_{2} \text { scale (s), Mo-rich subscale [68] }\end{array}$ \\
\hline $\mathrm{Mo}_{5} \mathrm{Si}_{3}$ & $\begin{array}{c}T \leq 800^{\circ} \mathrm{C} \text { : pesting, formation of } \mathrm{MoO}_{3}(\mathrm{~g}) \text { and discontinuous, porous } \mathrm{SiO}_{2}(\mathrm{~s}) \\
\text { scale }[145] \\
T \geq 1000^{\circ} \mathrm{C} \text { : no pesting, considerable mass loss, formation of porous } \mathrm{SiO}_{2} \text { (s) scale } \\
{[67,145]}\end{array}$ \\
\hline$(\mathrm{Mo}, \mathrm{Ti})_{5} \mathrm{Si}_{3}$ & $\begin{array}{c}\text { improved oxidation behaviour }[40,70,147] \\
T=750-900{ }^{\circ} \mathrm{C}: \text { slow, parabolic oxidation, formation of } \mathrm{SiO}_{2}-\mathrm{TiO}_{2} \text { duplex scale } \\
{[147]} \\
T \geq 1100^{\circ} \mathrm{C} \text { : top } \mathrm{TiO}_{2}+\mathrm{SiO}_{2}-\mathrm{TiO}_{2} \text { duplex scale }\left(\mathrm{SiO}_{2} \text { matrix }\right)[147]\end{array}$ \\
\hline $\mathrm{Ti}_{5} \mathrm{Si}_{3}$ & $\begin{array}{c}T=1000^{\circ} \mathrm{C} \text { : accelerated oxidation, discontinuous crack-containing thin } \mathrm{SiO}_{2}(\mathrm{~s}) \\
\text { scale and TiN, TiSi2 subscales [148], high dependence on N, O, C impurities [148- } \\
151]\end{array}$ \\
\hline $\mathrm{Ti}_{5} \mathrm{Si}_{3.2}$ & $\begin{array}{c}T=1000^{\circ} \mathrm{C} \text { : outstanding oxidation resistance [148], formation of continuous, pas- } \\
\text { sivating } \mathrm{SiO}_{2} \text { scale (with some } \mathrm{TiO}_{2} \text { ) }[148,151]\end{array}$ \\
\hline$(\mathrm{Ti}, \mathrm{Mo})_{5} \mathrm{Si}_{3}$ & $\begin{array}{c}T=900{ }^{\circ} \mathrm{C} \text { : adequate oxidation resistance [152], formation of top } \mathrm{TiO}_{2}+\mathrm{SiO}_{2}- \\
\qquad \mathrm{TiO}_{2} \text { duplex scale ( } \mathrm{SiO}_{2} \text { matrix) }[153]\end{array}$ \\
\hline
\end{tabular}

The oxidation behaviour of the individual phases is principally not applicable to the multiphase Mo-Si-based alloys without any further considerations, since their oxidation behaviour is characterised by complex phase interactions and the superimposed, competing oxidation behaviour of the individual phases. Especially the different chemical composition, morphology, distribution and length scale of the respective microstructural constituents determine the different oxidation performance of the alloy concepts as displayed in the schematic overview in Fig. 2-10. 


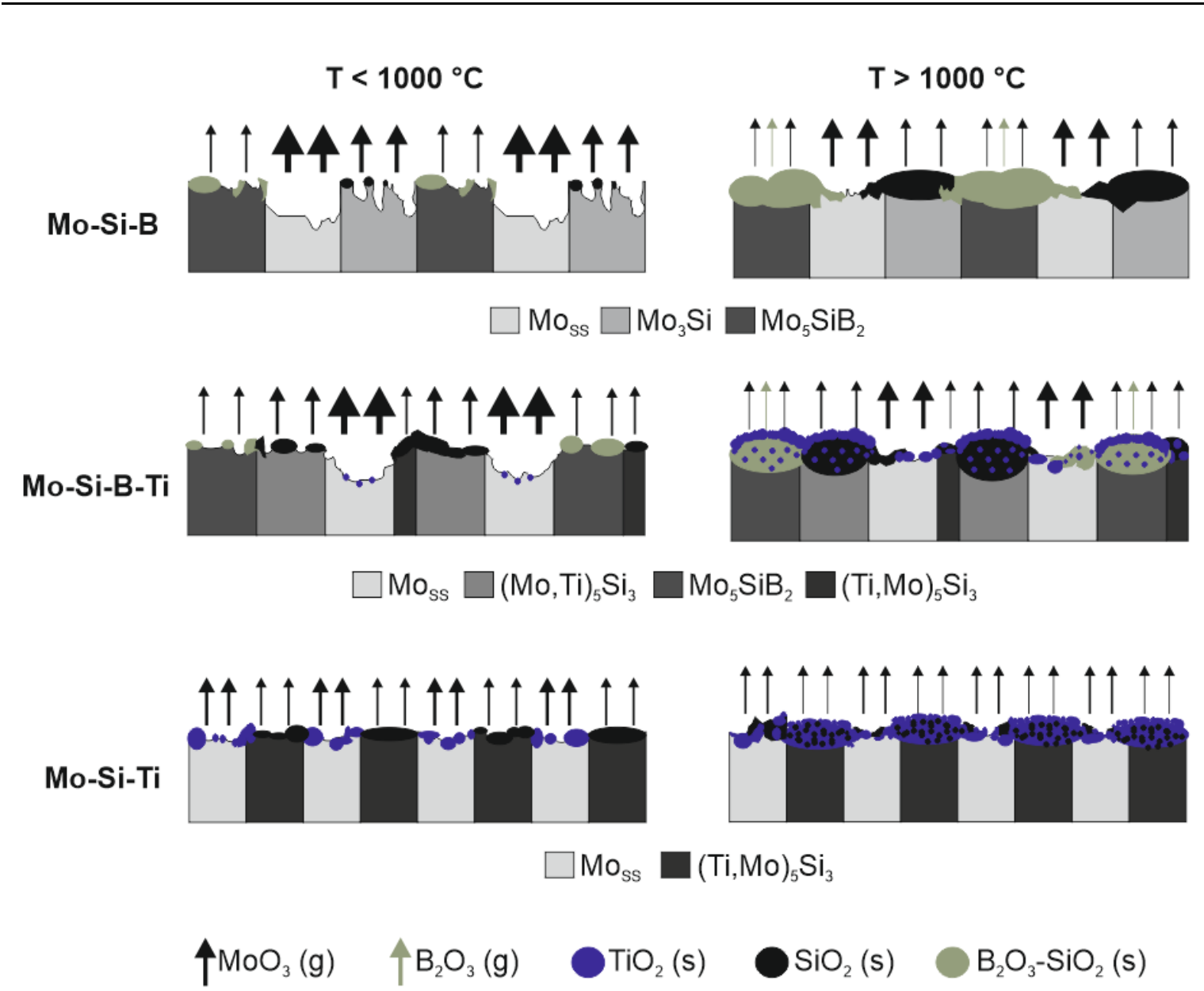

Fig. 2-10 Schematic overview on the oxidation mechanisms of typical Mo-Si-B and Mo-Si-B-Ti alloys compared to the novel eutectic Mo-Si-Ti alloy below and above $1000{ }^{\circ} \mathrm{C}$. According to observations made in Refs. [4, 5, 40, 47, 48].

Generally, the simultaneous formation of volatile $\mathrm{MoO}_{3}$ and solid oxide scale growth is characteristic of all Mo-Si-based alloy concepts. Thereby, the volatilisation of $\mathrm{MoO}_{3}$ is more pronounced at temperatures below $1000{ }^{\circ} \mathrm{C}$. This is caused by the diffusivity, the oxide growth kinetics and the oxide scale flowability, which are limited and/or non-inhibited $\mathrm{O}$ ingress is enabled by the discontinuous and porous nature of the oxide scales [41, 57]. This is seen in both, the classic three-phase Mo-Si-B alloys developed by Berczik [46, 154], and in the quaternary Mo-S-B-Ti alloys, which undergo catastrophic oxidation due to unhindered, continuous evaporation of $\mathrm{MoO}_{3}[4,47,48]$. At higher temperatures, the oxidation performance of the Mo-Si-based alloys is still dominated by the formation of volatile $\mathrm{MoO}_{3}$ throughout all present phases. But especially in the silicide phases, this is primarily occurring during the initial stage of oxidation until surface-near depletion in Mo [41, 155] leads to an appropriate amount and ratio of the solid oxide forming elements, like $\mathrm{Si}, \mathrm{B}$ and $\mathrm{Ti}$. Then, the oxidation rate is retarded and ideally $\mathrm{O}$ inward diffusion-controlled in the case of a protective oxide scale. Hence, steady state oxidation is achieved $[41,46,57$, 
$154,155]$. In the case of the Mo-Si-B alloys, a low-viscous $\mathrm{B}_{2} \mathrm{O}_{3}-\mathrm{SiO}_{2}$ oxide scale is formed, which quickly covers the silicide phases, but also the poorly oxidation-resistant phase Moss, preventing its ongoing oxidation to volatile $\mathrm{MoO}_{3}$. Thus, the oxidation resistance is improved with increasing volume fraction of the silicide phases [46, 75]. The B content is essential for achieving a reduction in oxide scale viscosity $[69,156]$, but however, leads to an accelerated $\mathrm{O}$ inward diffusion [57]. Additionally, at higher temperatures of $1200^{\circ} \mathrm{C}$, the B-containing alloys exhibit continuous mass loss, as oxidation rate-controlling evapo-

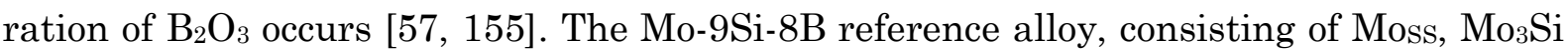
and $\mathrm{Mo}_{5} \mathrm{SiB}_{2}$, exhibits a total mass loss of $-94 \mathrm{mg} / \mathrm{cm}^{2}$ after $70 \mathrm{~h}$ of isothermal exposure to air at $820^{\circ} \mathrm{C}$ [155]. In contrast, at increased temperatures of 1100 and $1300{ }^{\circ} \mathrm{C}$ mass losses of -22 and $-40 \mathrm{mg} / \mathrm{cm}^{2}$, respectively, are attained after similar times [155]. At the latter parameter set, an average scale thickness of $30 \mu \mathrm{m}$ is observed [155]. Besides profiting from the quickly forming $\mathrm{B}_{2} \mathrm{O}_{3}-\mathrm{SiO}_{2}$ scale at higher temperatures, efforts have been undertaken by establishing solid oxide scales at lower temperatures on Mo-Si-B alloys by alloying with $\mathrm{Cr}$ or $\mathrm{Al}[42,155,157]$. However, these oxide scales are often porous and nonprotective leading to ongoing severe oxidation in the critical temperature range of $700-$ $900{ }^{\circ} \mathrm{C}$ [42]. Only with considerable alloying additions of for instance 25 at\% $\mathrm{Cr}$ to Mo-9Si8B continuous mixed oxide scales, like $\mathrm{Cr}_{2}\left(\mathrm{MoO}_{4}\right)_{3}$, can be formed [155]. Besides alloying additions, an accelerated formation of solid oxide scales and coverage of the alloy substrate has been targeted by developing finer microstructures. Thereby, 1 at\% $\mathrm{Zr}$ were added to alloy Mo-9Si-8B. Thereby, considerable grain refinement of the microstructure was achieved and when exposed to air at $1000{ }^{\circ} \mathrm{C}$, quick coverage of the alloy substrate reduced the initial weight loss by about two thirds [155]. However, at temperatures of $1150{ }^{\circ} \mathrm{C}$ and beyond, the $\mathrm{ZrO}_{2}$ particles, embedded in the $\mathrm{SiO}_{2}$ oxide scale, undergo the monoclinic tetragonal phase transformation accompanied by a substantial volume change. This significantly deteriorates the oxide scale performance [155]. Conclusively, while typical pesting behaviour is observed at lower temperatures, the oxidation performance of the Mo-Si-B alloys is adequate, but still to be improved at higher temperatures.

Therefore, Mo-Si-B-Ti alloys have been developed with the aim of substituting the minor oxidation-resistant phase Mo3Si by Si-richer $\mathrm{M}_{5} \mathrm{Si}_{3}$ silicides, in particular Mo5Si3. Especially high Ti-containing alloys profit from the oxidation-resistant variant $(\mathrm{Mo}, \mathrm{Ti})_{5} \mathrm{Si}_{3}$ in the temperature regime of 750 to $1360{ }^{\circ} \mathrm{C}[40,48]$. However, the phase equilibria are very difficult to adjust reproducibly in these quaternary alloys. Therefore, minor additions of Fe are needed [48]. Nonetheless, in the pesting-critical temperature regime, catastrophic oxidation to volatile $\mathrm{MoO}_{3}$ and locally porous $\mathrm{TiO}_{2}$ and $\mathrm{SiO}_{2}$ leads to linear weight loss and 
sample disintegration $[4,47]$. In contrast, the oxidation behaviour is improved at elevated temperatures, being characterised by slower initial oxidation rates compared to the typical Mo-Si-B alloys [4, 47]. The oxide scale is composed of outer, fast-growing, porous $\mathrm{TiO}_{2}$ particles. The gaps in between those are filled with some borosilicate (forming especially on the $\mathrm{Mos}_{5} \mathrm{SiB}_{2}$ phase) [47]. Underneath this continuous $\mathrm{TiO}_{2}$-rich oxide scale, a mixed $\left(\mathrm{B}_{2} \mathrm{O}_{3}-\right) \mathrm{SiO}_{2}$ duplex scale with embedded $\mathrm{TiO}_{2}$ particles is observed [4, 47, 158]. Inward diffusion of $\mathrm{O}$ is regarded as dominant diffusion mechanism [4, 47]. Thereby, it is of key importance that $\mathrm{SiO}_{2}$ is either present as matrix phase or as volumetric major phase (depending on the alloy composition) in the oxide scale. Otherwise a significant deterioration in oxidation behaviour is observed $[4,48]$. This is demonstrated in Mo-12.5Si-8.5B-27.5Ti, where the desired phase equilibrium is not established, meaning $(\mathrm{Mo}, \mathrm{Ti})_{3} \mathrm{Si}$ is present instead of $(\mathrm{Mo}, \mathrm{Ti})_{5} \mathrm{Si}_{3}$. After isothermal exposure to air at $1100{ }^{\circ} \mathrm{C}$ for $100 \mathrm{~h}$ a specific mass loss of $\approx-20 \mathrm{mg} / \mathrm{cm}^{2}$ is observed with an average scale thickness of $\approx 50 \mu \mathrm{m}$ [48]. In contrast, the specific mass loss of the Fe-containing variant Mo-12.5Si-8.5B-27.5Ti-2Fe stabilises at $\approx 0 \mathrm{mg} / \mathrm{cm}^{2}$ after $100 \mathrm{~h}$. Also, the oxide scale is significantly thinner with $\approx 25 \mu \mathrm{m}$ [48]. This results from the successfully established target phase equilibrium Moss + $(\mathrm{Mo}, \mathrm{Ti})_{5} \mathrm{Si}_{3}+\mathrm{Mo}_{5} \mathrm{SiB}_{2}+(\mathrm{Ti}, \mathrm{Mo})_{5} \mathrm{Si}_{3}$ [48]. However, if the temperature is further increased, the oxidation rate of the Mo-Si-B-Ti alloys is accelerated, as volatilisation of $\mathrm{B}_{2} \mathrm{O}_{3}$ and $\mathrm{MoO}_{3}$ occurs through open channels within the oxide scale [47]. Conclusively, these complex multiphase alloys only reveal an appropriate oxidation performance at elevated temperatures when numerous constraints are fulfilled.

In order to design alloys with simplified microstructures, two-phase Mo-Si-Ti alloys, comprising Moss and one silicide phase, have been developed [5]. Thereby, it is profited from Ti-rich $\mathrm{M}_{5} \mathrm{Si}_{3}$ silicides possessing an intrinsic adequate oxidation behaviour in the entire temperature range $[70,147,152,153]$, and of eutectic or eutectoid phase reactions facilitating fine-scaled microstructures. The fully eutectic alloy Mo-20Si-52.8Ti, consisting of Moss and (Ti,Mo) ${ }_{5} \mathrm{Si}_{3}$, was found to possess an outstanding oxidation behaviour even in the pesting regime at temperatures below $1000{ }^{\circ} \mathrm{C}$ [5]. A less than $10 \mu \mathrm{m}$ thick mixed $\mathrm{SiO}_{2}$ $\mathrm{TiO}_{2}$ oxide scale with a negligible specific mass change of $2 \mathrm{mg} / \mathrm{cm}^{2}$ is observed after isothermal exposure to air at $800{ }^{\circ} \mathrm{C}$ for $100 \mathrm{~h} \mathrm{[5].} \mathrm{At} \mathrm{elevated} \mathrm{temperatures,} \mathrm{an} \mathrm{outer} \mathrm{TiO}_{2}$ oxide scale is formed on top of a $\mathrm{SiO}_{2}-\mathrm{TiO}_{2}$ duplex scale. At $1100{ }^{\circ} \mathrm{C}$, a slight increase in mass change to $5 \mathrm{mg} / \mathrm{cm}^{2}$ [5] after $100 \mathrm{~h}$ is observed and the oxide scale thickness measures $20 \mu \mathrm{m}$ in total. However, since a fully eutectoid alloy Mo-21Si-34Ti, comprising Moss and (Mo,Ti) ${ }_{5} \mathrm{Si}_{3}$, suffers from pesting like the other Mo-Si-based alloying concepts [5], further investigation of the oxidation behaviour of the Mo-Si-Ti alloys is part of this thesis. 


\subsection{Fundamentals on the Creep Behaviour}

Creep is a thermally activated, time-dependent diffusion-controlled, irreversible deformation process under constant load and stress, respectively, at temperatures $T$ above 0.4 to 0.5 of the solidus temperature $T_{\text {solidus }}$, p. 1 in Ref. [159], [160]. Research on creep deformation and resulting fracture under tensile load dates back to the earlies 50s and 60s [160-163]. Up to nowadays, the creep resistance has emerged as significant property for high-temperature materials, as operating temperatures are continuously increasing. Moreover, creep deformation can already occur at stress levels below the macroscopic yield stress $\sigma_{y}$. Fundamentals of creep are briefly discussed in this section in the context of the phenomenological description by the power law and the corresponding creep mechanisms (dislocation and diffusion creep). For dislocation creep Fig. 2-11a displays the evolution of the strain $\varepsilon$ when a constant stress $\sigma$ is applied in dependence of time $t$. Three stages can be observed, which are referred to as primary (I), secondary (II) and tertiary creep (III). These are characterised by the varying deformation rate, the creep rate $\dot{\varepsilon}$, caused by changes in the internal, microstructural constitution (see Fig. 2-11b).
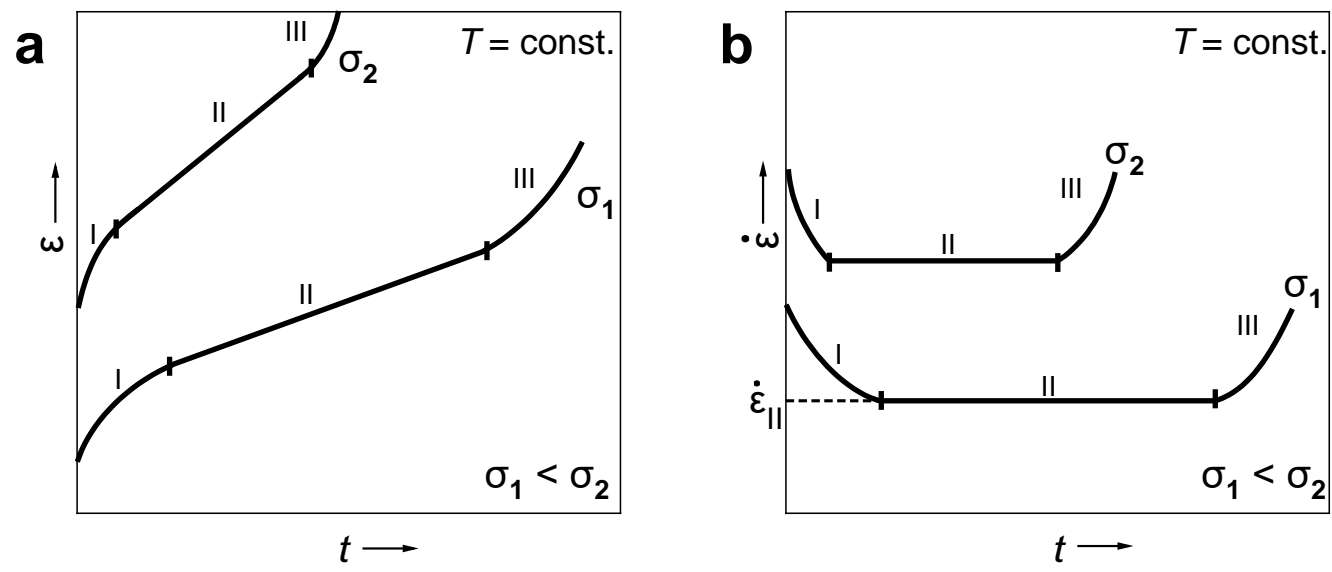

Fig. 2-11 Schematic evolution of the creep strain $\varepsilon$ as a function of time $t$ under constant tensile stress $\sigma_{i}$ (a) and the corresponding evolution of the creep rate $\dot{\varepsilon}$ with time (b). According to p. 282 in Ref. [164].

After an initial elastic deformation, primary creep occurs with decreasing creep rate due to dominant hardening/strengthening processes. These result from an increase in dislocation density caused by dislocation multiplication and interaction, either between them, or with obstacles other than dislocations [165], their rearrangement and the formation of subgrain structures [160]. When the hardening processes are outbalanced by dynamic recovery processes, such as dislocation annihilation (cross-slip of screw dislocations, climb of edge dislocations and glide of dislocations enabled by diffusion of point defects [166]), a 
temporary balance between hardening and softening can be attained, where the creep rate remains constant during plastic deformation, This is designated as "steady-state deformation" [166], or more accurately "quasi-stationary deformation" [167] when considering the difference between mechanical (constant mechanical parameters) and microstructural steady state. This stage is generally referred to as secondary creep stage with the constant secondary creep rate $\dot{\varepsilon}_{I I}[165,167]$. However, this kind of macroscopic steady state is not attained inevitably in every multiphase system. Rather a minimum in creep rate $\dot{\varepsilon}_{\text {min }}$ is reached because of microstructural instabilities not resulting in a linear relationship between the true strain $\varepsilon$ and time $t$ [5, 168-170]. When tensile stress is applied, a tertiary creep stage is eventually observed. The creep rate rapidly increases and finally rupture occurs due to degradation processes, like void formation and coalescence. Under compressive stress, this tertiary stage is usually not observed. However, the creep behaviour is typically analogous and the secondary creep rates are comparable for tensile and compressive loading [159, 171]. Generally, the creep behaviour is dependent on the applied stress and the prevalent temperature (see different stresses $\sigma_{1}<\sigma_{2}$ in Fig. 2-11). The empirical, microscopic relationship for the secondary creep rate has already been described by Mukherjee in 1968 and can be expressed as follows [160]:

$$
\dot{\varepsilon}_{I I}=C\left(\frac{\sigma}{G}\right)^{n} \exp \left(-\frac{Q_{c}}{k T}\right)
$$

Here, $C$ is a material constant, $G$ the shear modulus, $k$ the Boltzmann constant and $Q_{c}$ is the apparent activation energy for creep, which is often correlated to the activation energy for self-diffusion in metals $Q_{s d}[172,173]$. This relationship is well-known as the powerlaw creep with the stress exponent $n$, which allows for the determination of the dominant creep mechanism. For most pure metals and single-phase alloys $n$ is found to be in the range of 3 to 7 [160, 174], which corresponds to dislocation climb as dominant creep mechanism. Note that in this case, there is no dependency on the grain size ${ }^{4}[160]$, since it is the average dislocation spacing, which is the determining microstructural parameter [175] as will be discussed below in section (i) on dislocation creep.

Generally, multiple deformation mechanisms contribute to the creep deformation. Assuming that these mechanisms are dependent on each other, it is the slowest deformation mechanism, which is rate-controlling [171]. The typical creep deformation mechanisms are: (i) dislocation and (ii) diffusion creep in high-temperature regimes and (iii) dislocation

\footnotetext{
4 as long as the grain size is larger than the dislocation spacing [160, 175], which is typically $<1 \mu \mathrm{m}[176]$
} 
glide in low-temperature regimes. The first are based on high-temperature processes like slip (including activation of new slip systems), formation of subgrain structures (patterning of dislocations caused by dislocation-dislocation interaction) [171] and grain boundary sliding (shear accommodation at grain boundaries). In contrast, low-temperature deformation mechanisms are typically prevalent at high stress levels and are based on dislocation slip and deformation twinning [171]. This necessitates mobile dislocations of respective slip systems, which are able to pass obstacles like other dislocations, precipitates or impurity atoms by thermal activation [171]. In the following, both high-temperature creep mechanisms will be briefly discussed.

(i) Dislocation creep

Dislocation creep (DC) deformation is primarily active at elevated temperatures and intermediate stress levels due to considerable dislocation generation and reduction of their spacing. This high-temperature deformation mechanism is based on vacancy and interstitial atom diffusion fluxes allowing dislocation glide and climb. Climb is especially associated with the overcoming of obstacles. Dislocation glide is especially promoted at higher temperatures because further slip systems can be activated, which support continuous dislocation glide processes when barriers block the original slip plane [171, 177]. During the primary stage of creep, the creep rate is decreasing since the dislocation density is increasing because of dislocation multiplication. This leads to significant strengthening by dislocation interaction and pile-up. Since edge dislocations serve as vacancy sources and sinks, vacancy diffusion fluxes along the dislocation core or through the volume allow dislocations to climb. Thereby, dislocation substructures are generated [160, 171, 178]. Dislocation climb is rate-determining because it is slower than dislocation glide processes [171]. The strain rate is dependent on the vacancy flux between the climbing dislocations of different sign. Dislocation creep is generally assumed to be independent of the grain size [171], but however there are some exceptions reported, for instance in $\mathrm{Cu}$ [179]. Especially, when the average spacing between the dislocations is larger than half of the grain size, the dislocations do not predominantly interact with each other anymore, but with the grain boundaries. The secondary creep rate for dislocation creep can be expressed as [160]:

$$
\dot{\varepsilon}_{D C}=C_{D C}\left(\frac{D G b}{k T}\right)\left(\frac{\sigma}{G}\right)^{n}
$$

It is obvious that the stress-dependence is to the power of $n\left(\dot{\varepsilon} \propto \sigma^{n}\right)$, which is typically in the range of 3 to $7[160,174]$ as was already stated above. Additionally, besides the dependence of the material constant $C_{D C}$, the creep rate is a function of the volume diffusion coefficient $D$ and the burgers vector $b$. 
(ii) Diffusional creep

Diffusional creep is predominantly active at higher temperatures and comparably low stresses [164]. The deformation is based on stress-controlled diffusion activities of individual atoms and vacancies, and not on dislocation motion processes [180, 181]. Thereby, diffusive vacancy and opposite atom fluxes are generated by the gradients in chemical potential, caused by the inhomogeneous internal elastic stress state [171, 180]. The grain boundaries are of particular importance, as they act as source and sink for vacancies [181, 182]. Thus, the creep rate is dependent on the grain size $d$, namely proportional to $d^{-2}$, while only a linear stress dependency $(\dot{\varepsilon} \propto \sigma)$ is prevalent. The diffusion processes typically occur along the shortest pathways through the bulk material or along the grain boundaries. The bulk diffusion processes through the crystal lattice were assessed by Nabarro and Herring and studied in further research [163, 181-183]. Hence, this mechanism is referred to as "Nabarro-Herring creep" (NH), see p. 274 in Ref. [171]. The corresponding secondary creep rate is expressed as follows, see p. 285 in Ref. [164] and Ref. [180]:

$$
\dot{\varepsilon}_{N H}=C_{N H}\left(\frac{D}{k T}\right) \sigma \frac{\Omega}{d^{2}}
$$

Here, $\Omega$ is the volume of an atom with $\Omega=b^{3}$ and $C_{N H}$ a material constant. In contrast to the volume diffusion, diffusion processes along grain boundaries (GB) principally proceed faster, especially at intermediate and lower temperatures. They can become notable in fine-grained materials because of the increased grain boundary fraction. This is accompanied by their lower activation energies compared to lattice diffusion processes. These deformation processes are referred to as "Coble creep" $[184,185]$ according to the researcher Coble who investigated and described them in polycrystalline materials at higher temperatures in 1963 [186]. The respective secondary creep rate is proportional to $d^{-3}$ and expressed in Eq. 23, see p. 287 in Ref. [164]:

$$
\dot{\varepsilon}_{C}=C_{C}\left(\frac{D_{G B} \delta}{k T}\right) \sigma \frac{\Omega}{d^{3}}
$$

In this context, $\delta$ represents the thickness of the grain boundary ${ }^{5}$ [180] and $D_{G B}$ the diffusion coefficient for diffusion within the grain boundary. Although one may profit from strengthening by grain refinement at lower temperatures, finer grains are detrimental at high temperature. Especially for high-temperature material development singe-crystalline microstructures are of major interest, since polycrystals exhibit a minor creep resistance. This is because the grain boundaries act as accelerated diffusion paths, which

\footnotetext{
5 effective width where high-diffusivity is prevalent, usually set to 1 or several nm [187-189]
} 
facilitate faster dislocation annihilation [161] as well as early onset due to void and crack formation [190-193].

The volume and grain boundary diffusion creep mechanisms are principally occurring simultaneously. Then, the secondary creep rate is expressed as (see p. 287 in Ref. [164]):

$$
\dot{\varepsilon}_{I I}=\dot{\varepsilon}_{N H}+\dot{\varepsilon}_{C}=C_{N H}\left(\frac{D}{k T}\right) \sigma \frac{\Omega}{d^{2}}+C_{C}\left(\frac{D_{G B} \delta}{k T}\right) \sigma \frac{\Omega}{d^{3}}
$$

The individual contributions of the different creep deformation mechanisms are dependent on both, the microstructural features, particularly the grain size, and as already mentioned on the stress-temperature conditions. The latter can be addressed in deformation mechanisms maps, in which the respective dominant deformation regimes are illustrated (see Fig. 2-12a). Thereby, the deformation mechanism with the highest contribution to the overall deformation is regarded as dominant. These deformation maps were first introduced by Ashby in 1972 [180] and represent experimental data in dependence of the applied stress and temperature at a constant strain rate. The stress and the temperature are normalised by the shear modulus $G$ and the solidus temperature $T_{\text {solidus }}$ (or melting temperature $T_{m}$ for single component systems), respectively. Above the yield stress $\sigma_{y}$ plastic deformation occurs, which is based on dislocation glide. At homologous temperatures of 0.5 and beyond, the creep deformation mechanisms are active. The deformation mechanisms map of pure Mo is shown in Fig. 2-12b revealing its high creep resistance due to its high melting point. The stress exponent $n$ is reported to be 4.8, i.e. close to 5 [194].
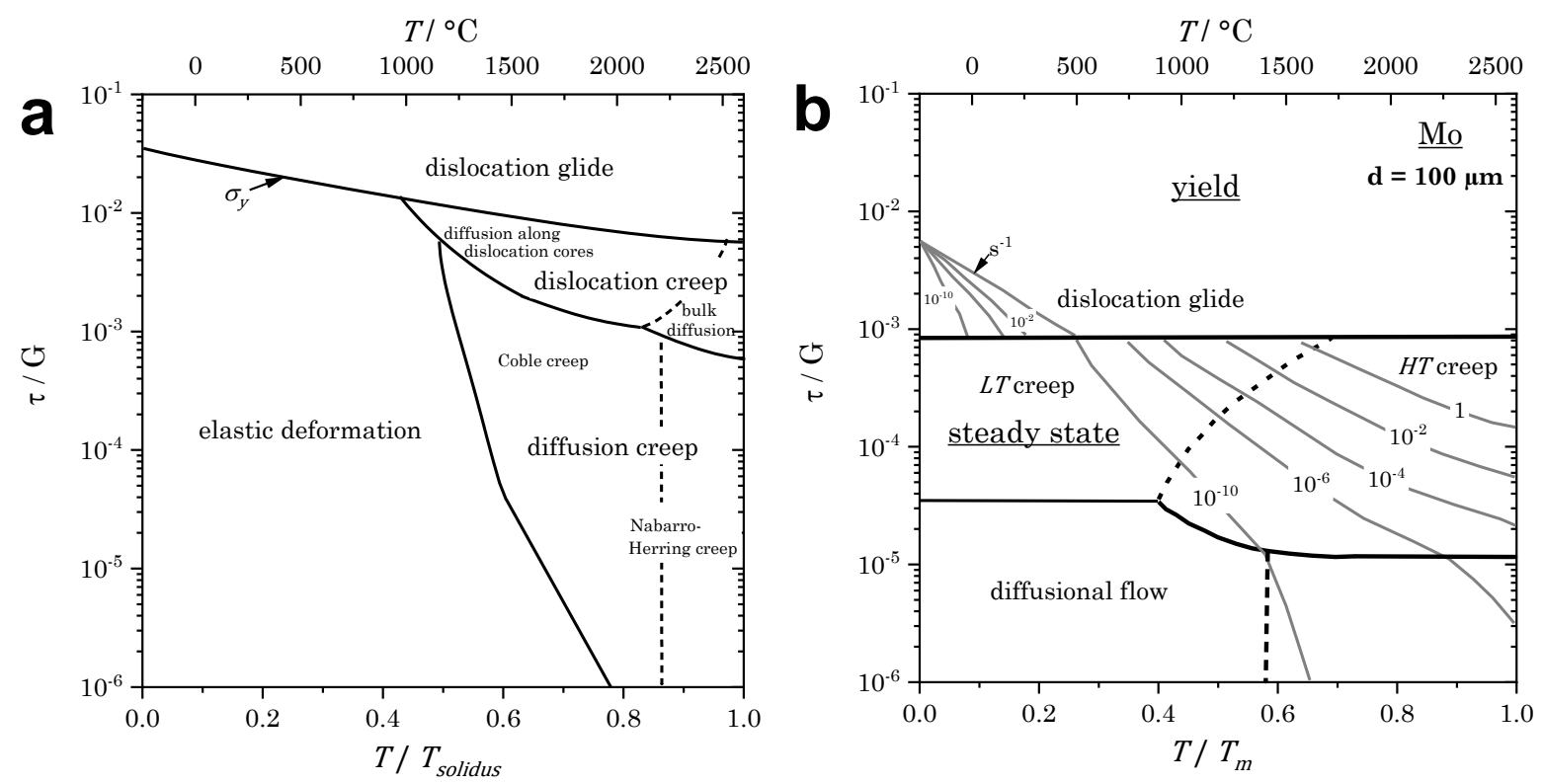

Fig. 2-12 Deformation mechanism maps: schematic (a) [180] and for pure Mo (b) [194]. 
In order to assess the creep behaviour of Mo-Si-based alloys, the creep performance of the relevant monolithic phases is summarised in Table 2-3. Among these, bcc-Mo possesses the highest creep resistance with a minimum creep rate in the range of $10^{-13} \mathrm{~s}^{-1}$ at $1200{ }^{\circ} \mathrm{C}$ and $100 \mathrm{MPa}$ [195]. In contrast, the silicides $\mathrm{Mo}_{5} \mathrm{Si}_{3}$ and $\mathrm{Ti}_{5} \mathrm{Si}_{3}$ exhibit minimum creep rates of about $10^{-7}$ and $10^{-6} \mathrm{~s}^{-1}$, respectively, at $1200{ }^{\circ} \mathrm{C}$ and $100 \mathrm{MPa}[99,196]$.

Table 2-3 Overview on the creep behaviour of the monolithic phases in Mo-Si-based alloys. *data for tensile test conditions. ${ }^{* *}$ calculation based on literature data. Secondary creep rates $\dot{\varepsilon}_{I I}$ are distinguished from the minimum creep rates $\dot{\varepsilon}_{\text {min }}$ by bold, blue letters.

\begin{tabular}{|c|c|c|c|}
\hline \multirow[b]{2}{*}{ phase } & \multicolumn{3}{|c|}{ creep behaviour } \\
\hline & $n /-$ & $\begin{array}{c}\dot{\varepsilon}_{\min } \text { or } \dot{\varepsilon}_{I I} / \mathrm{s}^{-1} \\
(\text { at } \sigma / \mathrm{MPa})\end{array}$ & $\begin{array}{l}Q_{c} / \mathrm{kJ} / \mathrm{mol} \\
(\text { at } \sigma / \mathrm{MPa})\end{array}$ \\
\hline Mo & $\begin{array}{c}3.85-\left.3.98\right|^{1600-2000}{ }^{\circ} \mathrm{C} * \\
{[195]}\end{array}$ & $\begin{array}{c}2.83 \times\left. 10^{-5}\right|_{10 \mathrm{MPa}} ^{180{ }^{\circ} \mathrm{C}} *[195] \\
1.0 \times\left. 10^{-13}\right|_{100 \mathrm{MPa}} ^{1200^{\circ} \mathrm{*}} * * \\
\text { accord. to Ref. [195] }\end{array}$ & $\begin{array}{c}\left.400\right|_{\text {n.a. }}[197] \\
362-\left.413\right|_{10 M P a} *[195]\end{array}$ \\
\hline$(\mathrm{Mo}, \mathrm{Si}, \mathrm{B})_{\mathrm{SS}}$ & $\left.5\right|^{1000-1300^{\circ} \mathrm{C} *[45]}$ & - & $\left.360\right|_{\text {n.a. }} *[45]$ \\
\hline (Mo,Si,Ti)ss & \multicolumn{3}{|c|}{ no data reported in literature } \\
\hline $\begin{array}{c}\mathrm{Mo} 3 \mathrm{Si} \\
(\mathrm{Mo}, \mathrm{Ti})_{3} \mathrm{Si}\end{array}$ & \multicolumn{3}{|c|}{ no data reported in literature } \\
\hline $\mathrm{Mo}_{5} \mathrm{Si}_{3}$ & $\left.1.9\right|^{1200^{\circ} \mathrm{C}}[196]$ & $\begin{array}{c}1.7 \times\left. 10^{-7}\right|_{140 \mathrm{MPa}} ^{1240^{\circ} \mathrm{C}}[67] \\
2.7 \times\left. 10^{-7}\right|_{100 \mathrm{MPa}} ^{1200^{\circ} \mathrm{C}}[196]\end{array}$ & $\left.399\right|_{140 \mathrm{MPa}} ^{1240-1320^{\circ} \mathrm{C}}[198]$ \\
\hline$(\mathrm{Mo}, \mathrm{Ti})_{5} \mathrm{Si}_{3}$ & \multicolumn{3}{|c|}{ no data reported in literature } \\
\hline $\mathrm{Ti}_{5} \mathrm{Si}_{3}$ & $\begin{array}{c}2.8-\left.3.0\right|^{800-1200{ }^{\circ} \mathrm{C}} \\
{[99,199,200]}\end{array}$ & $1 \times\left. 10^{-6}\right|_{100 \mathrm{MPa}} ^{1200}[\mathrm{C}]$ & $\begin{array}{c}\left.350\right|_{\text {n.a. }} ^{800-1200^{\circ} \mathrm{C}}[99] \\
\left.620\right|_{26 \mathrm{MPa}} ^{1200-1400^{\circ} \mathrm{C}}[200]\end{array}$ \\
\hline$(\mathrm{Ti}, \mathrm{Mo})_{5} \mathrm{Si}_{3}$ & \multicolumn{3}{|c|}{ no data reported in literature } \\
\hline $\mathrm{Mo}_{5} \mathrm{SiB}_{2}$ & $\begin{array}{c}4.3-\left.6.8\right|^{800-1200^{\circ} \mathrm{C}} \text { direc- } \\
\text { tion-dependent }[201]\end{array}$ & $3.0 \times\left. 10^{-8}\right|_{300 \mathrm{MPa}} ^{1500^{\circ} \mathrm{C}}[201]$ & $\begin{array}{l}400-\left.740\right|_{\text {n.a. }} ^{1500^{\circ} \mathrm{C}} \text { direc- } \\
\text { tion-dependent [201] }\end{array}$ \\
\hline
\end{tabular}

The creep strength of multiphase Mo-Si-B alloys depends on the volume fraction of the intermetallic phases and Moss, as these contribute individually to the effective creep deformation. An increased volume fraction of intermetallic phases (like $\mathrm{Mo}_{5} \mathrm{SiB}_{2}$ ) is beneficial for an improved creep resistance, while Moss, especially when being present as continuous matrix and not as particles in a coarse microstructure, deteriorates the creep resistance $[46,64,202]$. Thereby, the grain size plays a decisive role [200]. This is shown for the finescaled mechanically alloyed and hot-isostatically pressed (HIP) variant of Mo-9Si-8B alloy, which exhibits an inferior creep resistance to a coarser field-assisted sintered one [75]. However, additional alloying elements, like $\mathrm{Si}$, $\mathrm{Ti}$ and $\mathrm{Nb}$, which solid solution strengthen 
the Moss phase, are accounted for their beneficial impact on the creep resistance [4, 64]. This was shown for Mo-19.5Nb-12Si-8.5B, possessing a similar microstructure to Mo-12Si8.5B (Moss $+\mathrm{Mo} 3 \mathrm{Si}+\mathrm{Mo}_{5} \mathrm{SiB}_{2}$ ), but with partial substitution of Mo by Nb [64]. Thereby, Si was found to segregate along dislocations leading to beneficial pinning effects [45].

Fig. 2-13 presents a Norton plot for the comparative assessment of the creep resistance of typical Mo-Si-B, Mo-Si-B-Ti and novel Mo-Si-Ti alloys at $1200{ }^{\circ} \mathrm{C}$. With respect to potential application, the creep resistance of the three-phase Mo-Si-B alloys (black circles) is competitive to state-of-the-art Ni-based superalloys, like the $2^{\text {nd }}$ generation superalloy CMSX4 (orange diamonds) [71, 75]. Particularly at stress levels higher than $100 \mathrm{MPa}$, equal or even more than one order of magnitude lower minimum creep rates are attained in the Mo-Si-B alloys at $1200^{\circ} \mathrm{C}$. However, note that this testing temperature (and possible target temperature for future high-temperature applications) is already $100{ }^{\circ} \mathrm{C}$ beyond the maximum surface operating temperature of Ni-based superalloys.

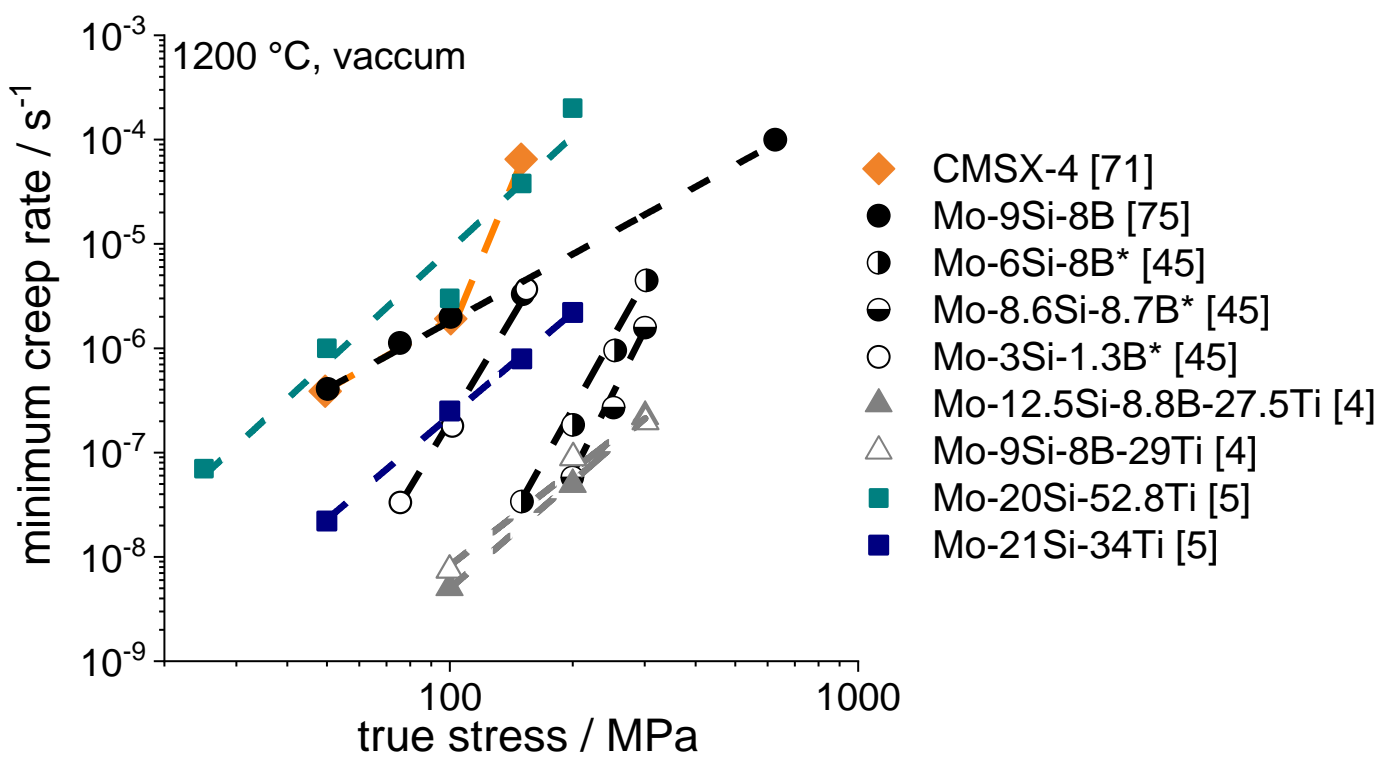

Fig. 2-13 Results of compressive and tensile (marked by *) creep tests as double logarithmic plot of minimum true creep rate vs. applied true stress of typical Mo-Si-B (black circles) and Mo-Si-B-Ti alloys (grey triangles) in comparison to novel Mo-Si-Ti alloys (coloured squares) and CMSX-4 (orange diamonds).

Typical multiphase Mo-Si-B alloys with silicide fractions of 35 to 50 vol\% (PM alloys Mo6Si-8B and Mo-8.6Si-8.7B [45]) exhibit stress exponents of 7 at $1200{ }^{\circ} \mathrm{C}$ in tension, revealing dislocation climb to be the dominant creep mechanism [45]. Other multiphase alloys, consisting of an intermetallic matrix (58 to 78 vol\%) with embedded Moss (AcM alloy Mo12Si-8.5B [202] and highly fine-scaled PM HIP alloy Mo-16.8Si-8.4B [203]) exhibit compressive stress exponents of 2.7 to 3.2 at $1300{ }^{\circ} \mathrm{C}[64,202,203]$. The apparent activation 
energies for creep were reported to be in the range of 295 to $360 \mathrm{~kJ} / \mathrm{mol}$ for these Mo-Si-B alloys [45, 202, 203]. The macro-alloyed Mo-Si-B-Ti alloys exhibit superior creep resistance to the Mo-Si-B alloys, namely minimum creep rates lower than $10^{-7} \mathrm{~s}^{-1}$ at $1200{ }^{\circ} \mathrm{C}$ and $100 \mathrm{MPa}$ (see grey triangles in Fig. 2-13). Stress exponents in the range of 3 to 3.5 indicate the creep deformation to be dislocation climb-controlled as well [4]. The improvement in creep resistance is mainly attributed to the solid solution strengthening of Moss by Ti, as the volume fraction of the intermetallics phases and the microstructural length scale are comparable [4]. The AcM alloys Mo-12.5Si-8.5B-27.5Ti and Mo-9Si-8B-29Ti with a volume fraction of 38 and 61 vol\% Moss, respectively, serve as examples with respective apparent activation energies for creep in the range of 350 to $550 \mathrm{~kJ} / \mathrm{mol}$ [4].

In contrast, the ternary Mo-Si-Ti alloys (coloured squares) exhibit a considerably minor creep resistance. However, significant differences in creep performance among the Mo-SiTi alloys (with similar fractions of 50 vol\% Moss) are evident. The pesting-resistant eutectic alloy Mo-20Si-52.8Ti (Moss + (Ti,Mo) $\left.{ }_{5} \mathrm{Si}_{3}\right)$ reveals one order of magnitude higher minimum creep rates compared to the eutectoid alloy Mo-21Si-34Ti (Moss + (Mo,Ti) $\left.{ }_{5} \mathrm{Si}_{3}\right)$ [5]. Thereby, the creep resistance of the eutectic alloy was stated to be determined by the least creep-resistant phase $(\mathrm{Ti}, \mathrm{Mo})_{5} \mathrm{Si}_{3}[5]$, whereas the eutectoid alloy reveals minimum creep rates comparable to the monolithic phase $\mathrm{Mo}_{5} \mathrm{Si}_{3}[67,196]$. However, when considering the solidus temperature of these alloys, it is found that the eutectic alloy had been tested at a higher homologous temperature [5]. Stress exponents in the range of 3.5 to 3.7 are comparable to the other Mo-Si-based alloys, again highlighting the dominance of dislocation climb [5]. The apparent activation energy for creep varied around 440 to $470 \mathrm{~kJ} / \mathrm{mol}$ [5].

For evaluation of the creep performance of these different Mo-Si-based alloy systems, the density has to be considered with regard to structural, rotating applications, in which the effective load is determined by the mass of the component. Thus, if the applied stress is normalised by the density, the Mo-Si-Ti alloys are most attractive because of their low densities in the range of 6.2 to $7.0 \mathrm{~g} / \mathrm{cm}^{3}$ [5]. In comparison, typical Mo-Si-B and Mo-Si-BTi alloys exhibit densities of 9.6 [34] and $7.8 \mathrm{~g} / \mathrm{cm}^{3}$ [4], respectively, in contrast to $8.7 \mathrm{~g} / \mathrm{cm}^{3}$ of typical Ni-based superalloys. In conclusion, the creep performance of all Mo-Si-based alloys is competitive to Ni-based superalloys. But with regard to their insufficient oxidation resistance at low temperatures (expect the eutectic Mo-Si-Ti alloy), they are still not qualified for industrial applications. Thus, the development of both, creep and oxidationresistant Mo-Si-Ti alloys will be pursued in this thesis. 


\section{Materials and Experimental Methods}

The development of novel Mo-Si-Ti alloys with tailored microstructures was first supported by thermodynamic calculations (Sec. 3.1), which facilitated the synthesis of specific promising alloys by arc melting (Sec. 3.2). Microstructural (Sec. 3.3) and physical (Sec. 3.4) characterisation methods, as well as oxidation (Sec. 3.5) and creep testing (Sec. 3.6) allowed for their detailed investigation and evaluation.

\subsection{Thermodynamic Calculations}

Thermodynamic calculations were performed within the ternary Mo-Si-Ti system with the aim of supporting the alloy design and predicting the respective phase equilibria. Therefore, the thermodynamic software package Pandat by CompuTherm LLC (version of 2018) was used in conjunction with the commercially available database PanMo2018a (detailed explanations can be found elsewhere [204-206]). The software is based on a Calphad (Calculation of Phase Diagrams) approach. Thereby, the Gibbs free energy $G$ for the individual phases is minimised to observe thermodynamic equilibrium. The thermodynamic data implemented in the database need to be critically reviewed and undergo continuous improvement by ongoing research to provide further and more accurate experimental data [81, 105, 207-209]. While Moss and the $\mathrm{M}_{5} \mathrm{Si}_{3}$ silicides were realised as phases with appropriate solubility ranges of the respective elements, the phase $(\mathrm{Mo}, \mathrm{Ti})_{3} \mathrm{Si}$ was implemented with a fixed Si content of 25 at\%. This is contradictory to experimental results on the monolithic phase $\mathrm{Mo}_{3} \mathrm{Si}$, which have proven that the $\mathrm{Si}$ content is lower and in the range of 24 at\% [63]. Therefore, in alloys with high $(\mathrm{Mo}, \mathrm{Ti})_{3} \mathrm{Si}$ volume fractions, the Si content needs to adjusted in experiments in order to achieve a reasonable prediction by the simulations.

The solidification calculations were performed in batches (batch calculations) on the basis of the design of experiment (DOE) principles [210]. This means that the input parameters used for the calculations, here the temperature $T$ and the concentration $x_{i}$ of the respective element $i$, were varied stepwise. For instance, the concentrations of Mo, Si and Ti were varied gradually with a step size of 0.2 at\% within a defined range (15 $\leq x_{T i} \geq 60$ at\%, $15 \leq x_{S i} \geq 30$ at\% and $x_{M o}$ accordingly). This overall composition range was subdivided into smaller ones (the batches) allowing prioritisation and tailored evaluation of composition regions of special interest (e.g. along the eutectic Moss-(Ti,Mo) ${ }_{5} \mathrm{Si}_{3}$ ridge).

The corresponding batch calculation runs were performed automatically, for both, equilibrium and Scheil conditions. In equilibrium, very slow cooling conditions allow for perfect 
liquid- and solid-state diffusion and, therefore, homogenous chemical compositions according to thermodynamic equilibrium. The resulting fractions of equilibrium phases can be determined by the Lever rule, see p. 208 in Ref. [211] (applied to the tie-triangle in ternary systems). However, for faster cooling conditions, the solid-state diffusion is considerably retarded and homogeneous composition of the solid phase according to thermodynamic equilibrium is not achieved. Non-equilibrium solidification is approximated by the Scheil model [212]. It is assumed that: (i) The diffusion is immediate in the liquid L (diffusion coefficient $D_{L} \rightarrow \infty$ ), which leads to homogeneous composition according to the thermodynamic equilibrium. (ii) The diffusion within the solid $\mathrm{S}$ is assumed to be negligible (diffusion coefficient $D_{S}=0$ ). (iii) Local equilibrium is present at the liquid/solid interface during the simulation. This model was initially developed for single-phase and binary alloys [212], but can be adopted for multiphase alloys as well [205, 206, 213].

Besides solidification simulations, isothermal sections and isopleths were calculated in order to analyse the simulated phase reactions. The atomic phase fractions $f$ of the distinct phases being provided by Pandat were converted to volumetric phase fractions by making use of the crystallographic data gained by X-ray diffraction measurements (XRD) and the experimentally determined alloy density.

\subsection{Materials Processing}

The investigated alloys were cast manufactured by arc melting (AcM) in an arc melter of type AM/0,5 by Edmund Bühler. The high-purity bulk elements Mo, Si and Ti (purity: 99.95, 99.99 and $99.8 \%$, respectively) were melted in a water-cooled, button-shaped $\mathrm{Cu}$ crucible in Ar. The Ar atmosphere of 600 mbar was established by multiple evacuating $\left(10^{-4}\right.$ mbar) and flooding steps. Pre-melting of a $\mathrm{Zr}$ sample reduced the concentration of potential $\mathrm{O}$ residuals below 240 ppm (determined by hot gas extraction, see Sec. 3.3.3). Repetitive arc melting of five times ensured a homogenous element distribution and the final weight loss was confirmed to be below $0.5 \mathrm{wt} \%$. Afterwards, the arc-melted buttons were re-melted into a nugget-shaped $\mathrm{Cu}$ crucible allowing more uniform cooling conditions. 


\subsection{Microstructural Characterisation}

\subsubsection{Sample Preparation}

The following samples were manufactured by electrical discharge machining (EDM):

(i) cross sections of $4 \mathrm{~mm}$ in thickness from the AcM nuggets for XRD analyses

(ii) cross sections of $4 \mathrm{~mm}$ in thickness from the AcM nuggets for microstructural analyses by scanning electron microscopy (SEM)

(iii) slices with a diameter of less than $3 \mathrm{~mm}$ and a thickness of around $2 \mathrm{~mm}$ for transmission electron microscopy (TEM)

(iv) $\quad(5 \times 5 \times 4) \mathrm{mm}^{3}$ oxidation test samples

(v) $\quad(5 \times 3 \times 3) \mathrm{mm}^{3}$ compression creep samples

Semi-automatic polishing and grinding machines equipped with a continuous water supply by Buehler were provided for the subsequent metallographic preparation:

(i) Sample preparation for XRD

For XRD analyses, bulk samples were investigated. Therefore, one face of the ED-machined slices was manually ground down to $\mathrm{SiC}$ grit P4000 and ultrasonically cleaned in ethanol.

(ii) Sample preparation for microstructural analyses by SEM

The samples intended for microstructural analysis were cold mounted in methyl-methacrylate resin (VariKEM 200 by Schmitz Metallographie) and step-wise ground and polished semi-automatically. The polishing steps were performed at $15 \mathrm{~N} /$ sample for a duration of 10 min by using diamond suspensions of 3 and $1 \mu \mathrm{m}$ particle size, respectively. Finally, appropriate surface quality was attained by polishing with colloidal suspension (OPS with pH of 9.8 by Struers) at $10 \mathrm{~N} / \mathrm{sample}$ for $20 \mathrm{~min}$. Samples with Moss as major phase were additionally vibratory-polished with OPS on Microcloth for $8 \mathrm{~h}$. For the analysis of mounted oxidation samples, an additional Au coating was applied by an Ar sputter devise.

(iii) Sample preparation for microstructural analyses by TEM

Thin slices were ground down to a thickness of less than $100 \mu \mathrm{m}$ with $\mathrm{SiC}$ grit P4000. Subsequently, they were jet-polished with an $\mathrm{H}_{2} \mathrm{SO}_{4}$-methanol electrolyte (ratio 1:4) at $15 \mathrm{~V}$ and room temperature in a TenuPol-5 by Struers until they were punctured. 
(iv-vi) Preparation of oxidation and compression creep samples

All surfaces of the oxidation samples and the front faces of the compression creep samples were ground to a final surface finish of SiC grit P2500. All samples were subsequently cleaned in ethanol in an ultrasonic bath. Thereby, special attention was paid to the compression creep samples in order to achieve plan parallel punch contact faces.

\subsubsection{Heat Treatments}

Heat treatments were performed subsequent to AcM in order to (i) achieve completion of the eutectoid decomposition of remaining (Mo,Ti) ${ }_{3} \mathrm{Si}$ in Ti-lean Mo-Si-Ti alloys or (ii) to homogenise and artificially coarsen the microstructure. These were conducted at (i) $1300^{\circ} \mathrm{C}$ for $200 \mathrm{~h}(h t)$ or (ii) $1600^{\circ} \mathrm{C}$ for $150 \mathrm{~h}\left(h t^{*}\right)^{6}$ in a HRTH $70-600 / 18$ tube furnace by Gero with a constant Ar (purity of $99.998 \%$ ) gas flow in the range of 1 to $3 \mathrm{ml} / \mathrm{min}$.

\subsubsection{Chemical Analysis}

The chemical composition of selective alloys was analysed in the $a c$ state and after $h t$. Weight loss during AcM, caused by likely evaporation of lower melting elements like Ti or $\mathrm{Si}$, and the amounts of interstitial impurities as take-up during processing were checked. Therefore, inductively coupled plasma optical emission spectroscopy (ICP-OES) was performed on ground and ultrasonically cleaned samples with a weight of (100 \pm 8$) \mathrm{mg}$ in conjunction with hot gas carrier extraction method determining $\mathrm{O}$ and $\mathrm{N}$. The $\mathrm{C}$ content was determined with a C/S-analyser. The resulting alloy composition was determined to vary less than around $0.1-0.2$ at\% from the initial nominal composition weighted in and the impurities were found to be about 0.005 at\% $\mathrm{C}, 0.004$ at\% $\mathrm{N}$ and 0.1 at\% $\mathrm{O}$.

\subsubsection{Microscopic Analysis}

Optical light microscopy was carried out by means of a stereomicroscope Aristomet by Leitz for macroscopic assessment of oxidised samples. Microstructures were analysed by SEM. Therefore, an EVO50 SEM by Zeiss equipped with an energy dispersive X-ray spectroscopy (EDX) system and an Auriga60 SEM by Zeiss equipped with an electron backscatter (EBSD) system were used. The SEM were operated at 20 and $10 \mathrm{kV}$, respectively. Be-

\footnotetext{
${ }^{6}$ Note that an additional heat treatment (iii) $1600{ }^{\circ} \mathrm{C}$ for $150 \mathrm{~h}+1400{ }^{\circ} \mathrm{C}$ for $100 \mathrm{~h}\left(h t^{* *}\right)$ was performed on a Mo-Si-B-Ti alloy for comparison (see for instance Fig. 2.4c and Fig. 9.2).
} 
sides secondary electron (SE) imaging, which allows for identification of topological characteristics like cracks and pores, backscatter electron (BSE) imaging was applied to distinguish and evaluate the individual phases by the $Z$-contrast. Additionally, orientation contrast imaging by BSE was performed on Moss as the major phase in order to identify different grains. In accordance to this, EDX analyses were performed for further characterisation of the chemical composition of the phases within the microstructures and oxide scales, whereas EBSD measurements allowed for the local assignment of the crystal structure of the respective phases.

For quantitative evaluation, representative BSE micrographs were used in order to determine the areal fractions of the respective phases and microstructural constituents. The different regions were either manually denoted (for instance in the case of eutectic and eutectoid regions) or determined by pixel sieve analysis by means of a Matlab code (in the case of large laterally expanded phases with a high $Z$-contrast). The evaluation was based on thresholding greyscale values and corresponding pixel analyses. This was performed with the image processing software Corel Photo Paint and ImageJ. The resulting areal fractions were assigned as volume fractions by assuming isometry and isotropy of the microstructures. The length scale of the multiphase microstructures was assessed in the $a c$ and after heat treatment ( $h t$ and $h t^{*}$ ) by determining the interface boundary fraction $P$ applying a linear intersection method, see p. 81 in Ref. [214], on representative BSE micrographs:

$$
P=2 \frac{N}{L}
$$

with the total number $N$ of intersections of the respective line with the phase boundaries, and the overall length of the lines $L$. Furthermore, 2D networks in the microstructures and oxide scales were studied. Therefore, pixel connectivity analyses were performed on binary greyscale BSE micrographs with a Matlab script according to Ref. [215]. Firstly, the 8-connected pixels were detected, then combined to clusters of pixels, which were finally colour-coded as phase-specific colour gradients.

Scanning transmission electron microscopy (STEM) was carried out for further microstructural characterisation on a Talos F200X FEI which was operated at $200 \mathrm{kV}$. For STEM high-angle annular dark-field (HAADF) imaging a camera length of $95 \mathrm{~mm}$ was used. Additionally, STEM-EDX analyses were performed in order to locally determine the chemical compositions of the fine-scaled microstructures. 


\subsubsection{Atom Probe Tomography}

In order to determine the chemical composition of selected oxide scales on an atomic level, atom probe tomography (APT) was performed. The preparation of the required tip-shaped specimens with apex diameters of maximum $100 \mathrm{~nm}$ was conducted by focused-ion beam (FIB) technique by means of a Strata dual beam SEM/FIB device by FEI. APT was conducted with a LEAP4000X device provided by Cameca, which was operated at a laser pulse rate of 100 or $125 \mathrm{kHz}$ under ultra-high vacuum of $10^{-10}$ Torr. $50 \mathrm{~K}$ were set as temperature and the control of the standing high voltage was in accordance to a detection rate of 0.3 to $0.5 \%$. 3D reconstruction of the tip-shaped specimens was performed by means of the software IVAS 3.6.14 by Cameca. The chemical composition was determined by applying peak deconvolution analysis tools in order to consider possible overlaps of peaks, like the overlap of $\mathrm{TiO}^{2+}$ and $\mathrm{O}_{2}{ }^{+}$at $32 \mathrm{Da}$. Attention is especially paid to the possible underestimation of O (see detailed discussion in Ref. [216]) during APT, which has been reported to be caused by the applied experimental conditions [217-220]. But this has been ensured not to be the case in the APT measurements presented in this thesis (analogous to APT results in Ref. [216]), as it is assumed that the experimental conditions remain unchanged and the $\mathrm{O}$ underestimation is expected to be consistent. The experimental conditions are mainly affected by the evaporation field, which is essentially determined by the laser pulse energy, the tip radius and the sample material. Variations of the evaporation fields lead to changes in (i) the fraction of pulses which cause multiple signals and/or (ii) the ratio of differently charged ions of the same species which are detected. By applying the software by Boll et al. [221], mass spectra, containing ions from single or multiple signals, were separated. Thereby, it was revealed that (i) the $\mathrm{O}$ content in total in the mass spectra, which derived from multiple signals, was lower compared to that originating from single signals and (ii) there was no disproportionally high amount of $\mathrm{O}$ or $\mathrm{O}_{2}$ ions. Thus, an underestimation of $\mathrm{O}$ during APT analysis is unlikely.

\subsubsection{X-Ray Diffraction}

X-ray diffraction (XRD) measurements were performed in order to determine the crystal structures of the present phases within the AcM alloys. Therefore, a D2 phaser by Bruker in Bragg-Brentano geometry, equipped with a $\mathrm{Cu}$ tube was used. The $\mathrm{Cu}$ tube was operated at $30 \mathrm{kV}$ and $10 \mathrm{~mA}$. The CuKa radiation was filtered by means of $\mathrm{Ni}$ foil and detected with a LynxEye line detector with a step size of $0.01^{\circ}$ in $2 \Theta$ with an accumulated time of $384 \mathrm{~s} / \mathrm{step}$. The determination of the lattice parameters was (i) based on the evaluation of the peak positions based on a Nelson Riley approach [222] for bcc phases and (ii) based on 
a modified least square fitting method [223] in the case of $\mathrm{M}_{5} \mathrm{Si}_{3}$ silicides. Furthermore, the crystal structures of representative oxide scales were evaluated by grazing incident XRD (GIXRD) with incident angles $\omega$ varying between 1.2 and $2.5^{\circ}$. Therefore, a SmartLab diffractometer by Rigaku, equipped with a HyPix-3000 detector and a CuKa radiation source working at $40 \mathrm{kV}$ and $30 \mathrm{~mA}$, was used. The step size in $2 \Theta$ was set to $0.01^{\circ}$. The sample was aligned by means of a variably adjusting stage, while setting the focus with a parallel beam and a $5^{\circ}$ soller slit in the primary beam path.

\subsection{Density Determination}

The density of the alloys was determined by the Archimedes method. Therefore, at least

five samples per alloy were weighed in air $\left(m_{\text {air }}^{\text {alloy }}\right)$ and in deionised water $\left(m_{\mathrm{H}_{2} \mathrm{O}}^{\text {alloy }}\right)$ at room temperature $R T$ with a Mettler AE240 balance. The density of the alloy $\rho_{\text {alloy }}$ is calculated by Eq. 26:

$$
\rho^{\text {alloy }}=\frac{\rho_{\mathrm{H}_{2} \mathrm{O}}^{R T}-m_{\text {ali }}^{\text {alloy }}}{m_{\text {air }}^{\text {alloy }}-m_{\mathrm{H}_{2} \mathrm{O}}^{\text {alloy }}}
$$

With the weight of the alloy in air $m_{\text {air }}^{\text {alloy }}$ and in ionised water $m_{\mathrm{H}_{2} \mathrm{O}}^{\text {alloy }}$.

\subsection{Oxidation Testing}

The oxidation experiments were conducted in cycles at 800,1100 and $1200{ }^{\circ} \mathrm{C}$ in muffle furnaces by Nabertherm and Gero in laboratory air. Oxidation cycles with durations of 1 , 5 and 10 h were performed multiple times, namely 20,6 and 5 times, respectively. Finally, the total test duration was $100 \mathrm{~h}$. Throughout testing, the samples were maintained in $\mathrm{Al}_{2} \mathrm{O}_{3}$ baskets, but were flipped around after each cycle in order to ensure homogenous oxidation. Cooling down to room temperature within 15 min was allowed between each cycle and the samples were weighed with a balance of precision $\pm 1 \mu \mathrm{g}$.

\subsection{Creep Testing}

The creep tests were performed with a universal testing machine of type Z100 by Zwick equipped with a vacuum furnace by Maytec under constant true compressive stress in the range of 50 to $300 \mathrm{MPa}$ at temperatures varying between 1050 to $1365^{\circ} \mathrm{C}$. The test temperatures were selected in order to determine the stress exponent $n$ at $1200{ }^{\circ} \mathrm{C}$, the apparent activation energy for creep for specific alloys and for comparing the creep performance 
at the same homologous temperature. During compression creep testing, the samples were loaded by $\mathrm{Si}_{3} \mathrm{~N}_{4}$ punches and the strain was measured by extensometer with three $\mathrm{Al}_{2} \mathrm{O}_{3}$ sticks. Two sticks are used to detect the distance to the upper crosshead and the third for the determination of the reference distance to the lower punch. In order to reduce friction impact, the punch contact faces of the compression creep samples were lubricated with hexagonal BN. Constant true stress $\sigma$ was applied by a computer-assisted closed loop mode. Uniform sample deformation is assumed. In conjunction with the engineering stress $\sigma_{e}$ and engineering strain $\varepsilon_{e}$, the true stress $\sigma$ can be expressed in Eq. 27. The respective true strain $\varepsilon$ was determined according to Eq. 28.

$$
\begin{aligned}
& \sigma=\sigma_{e}\left(1+\varepsilon_{e}\right) \\
& \varepsilon=\ln \left(1+\varepsilon_{e}\right)
\end{aligned}
$$

A uniform temperature distribution with less than $\pm 0.08^{\circ} \mathrm{Cmm}^{-1}$ deviation was verified by three thermocouples being contact-less positioned at equal distances within the testing zone. 


\section{Alloy Design and Development}

As has been shown (see Sec. 2.2), there are two alloys of major interest, namely a fully eutectic or fully eutectoid alloy, which either exhibit an outstanding oxidation behaviour in the pesting-critical temperature regime or an adequate creep resistance at $1200^{\circ} \mathrm{C}[5]$. These two alloys represent the basis of the here presented further Mo-Si-Ti alloy development and are referred to as reference alloys. The main objectives are the realisation of both, a sufficient oxidation resistance and an adequate creep resistance, by combining eutectic and eutectoid microstructures. Therefore, the alloy design of intermediate eutecticeutectoid alloys is guided by thermodynamic calculations within the relevant chemical composition range bordered by the two reference alloys. Efforts at achieving tailored microstructures with adjustable volume fractions of the respective microstructural constituents are presented. Thus, the solidification reactions, occurring in the metal-rich portion of the ternary Mo-Si-Ti system, are systematically analysed by studying both, equilibrium and Scheil conditions. The following scientific issues will be addressed:

(a) Do intermediate eutectic-eutectoid alloys exist in the Mo-rich section of the ternary system? Which chemical alloy compositions are promising for AcM?

(b) Can the volume fractions of the microstructural constituents be specifically tailored with respect to:

- minimisation of primarily solidified Moss?

- adjustment of eutectic and eutectoid volume fractions?

(c) Can the resulting microstructures be reliably predicted by the thermodynamic calculations?

(d) Are these microstructures fine-scaled as previously anticipated by the eutectic and eutectoid phase reactions?

\subsection{Interpretation of Thermodynamic Calculations}

The interpretation of the simulations performed in the ternary Mo-Si-Ti system is firstly based on the liquidus projection (already shown in Sec. 2.2 in Fig. 2-5) and on isothermal sections (see App. 2), which allow the identification of the implemented phase reactions prior to assessing the solidification pathways of individual alloys. The occurrence of several transition equilibria for thermodynamic equilibrium condition is predicted, especially of $\mathrm{u}_{1}$ at $1950{ }^{\circ} \mathrm{C}$ (as already introduced in Sec. 2.2): 
quaternary reaction $\left(\mathrm{u}_{1}\right): \mathrm{L}+(\mathrm{Mo}, \mathrm{Ti})_{3} \mathrm{Si} \rightleftharpoons \mathrm{Moss}+(\mathrm{Ti}, \mathrm{Mo})_{5} \mathrm{Si}_{3}$

Eq. (8)

However, these transition equilibria do not occur during AcM, as non-equilibrium conditions are caused by rapid cooling. Hence, the solidification follows faster reaction paths, like the primary solidification of (Mo,Ti) ${ }_{3} \mathrm{Si}$ and the eutectic reaction $\mathrm{e}_{4}$ (see Sec. 2.2):

$$
\text { eutectic }\left(\mathrm{e}_{4}\right): \mathrm{L} \rightleftharpoons \operatorname{Moss}+(\mathrm{Ti}, \mathrm{Mo})_{5} \mathrm{Si}_{3}
$$

This is clearly seen when comparing the solidification simulation for equilibrium and Scheil conditions for an intermediate alloy A1 (Mo-21Si-43.4Ti), which is located between the two reference alloys (see Fig. 4-1). While (Mo,Ti) ${ }_{3} \mathrm{Si}$ completely reacts according to $\mathrm{u}_{1}$ at $1950{ }^{\circ} \mathrm{C}$ for equilibrium conditions (see inset in Fig. 4-1a), it is predicted to be present with non-changing fraction once it is primarily solidified for Scheil conditions (see black line in Fig. 4-1b). The eutectic solidification of the residual melt is predicted to occur below $1950^{\circ} \mathrm{C}$ for both conditions, as the fractions of Moss (grey line) and (Ti,Mo) ${ }_{5} \mathrm{Si}_{3}$ (green line) are simultaneously increasing with decreasing fraction of the liquid (red line).
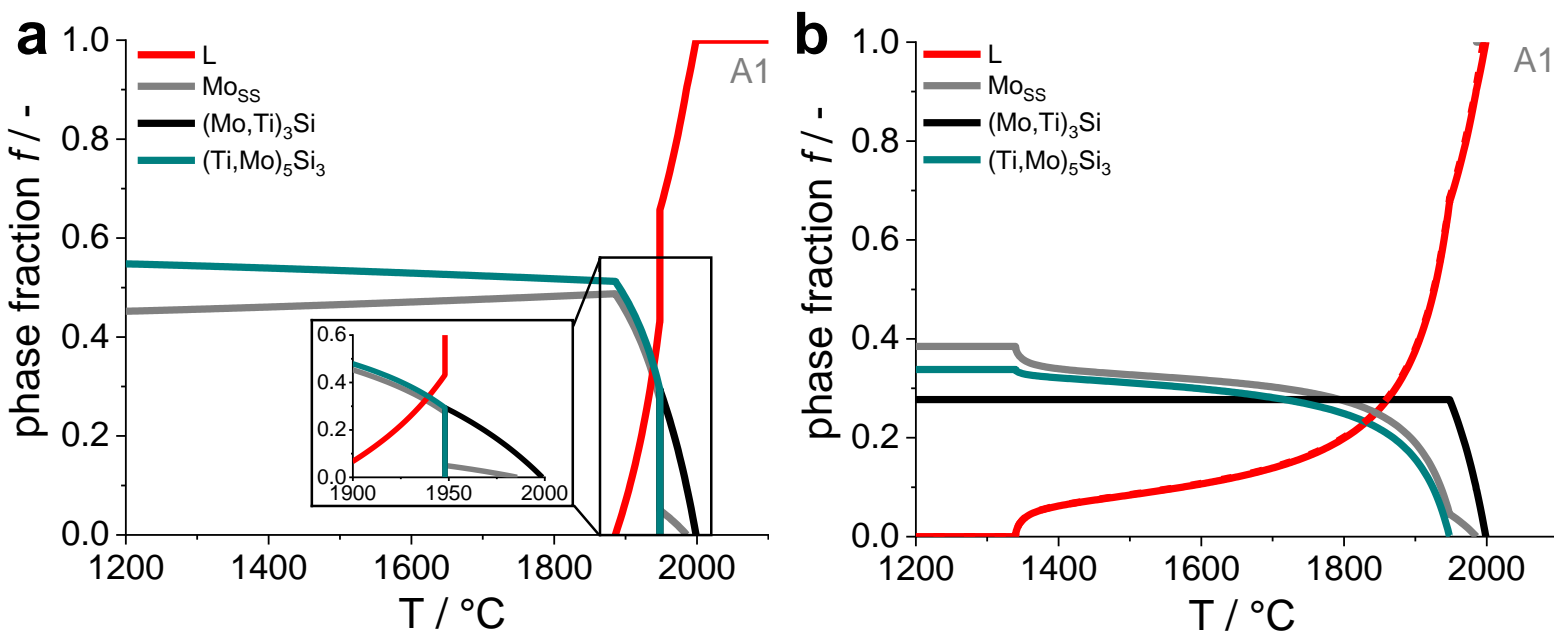

Fig. 4-1 Solidification simulation of alloy A1 (Mo-21Si-43.4Ti) for equilibrium (a) and Scheil conditions (b).

Since solid state reactions, like the eutectoid reaction (Eq. 3 in Sec. 2.2), cannot be represented by Scheil conditions, it assumed that the amount of (Mo,Ti) 3 Si (predicted for Scheil conditions) undergoes a eutectoid decomposition into Moss and (Mo,Ti) ${ }_{5} \mathrm{Si}_{3}$. This occurs during cooling, possibly already during ongoing solidification or during subsequent heat treatment in cast alloys. In particular, the eutectoid decomposition is dependent on the Ti content and on the temperature as predicted by thermodynamic calculations in equilibrium (see App. 3). The higher the Ti content of the alloy, the higher is the temperature at 
which the eutectoid decomposition of $(\mathrm{Mo}, \mathrm{Ti})_{3} \mathrm{Si}$ starts (can be recognised by the presence of Moss and (Mo,Ti) $)_{5} \mathrm{Si}_{3}$ in the solidification simulation). Note that (Mo,Ti) ${ }_{3} \mathrm{Si}$ is represented by Pandat as stoichiometric compound and, therefore, its primary solidifying region might not be depicted correctly.

Conclusively, the phase fractions of the simulated alloys are extracted from the Scheil simulations, whereas the solidus temperature $T_{\text {solidus }}$ and the chemical composition (at $T_{\text {solidus }}$ ) of the respective phases are determined by calculations in equilibrium condition.

\subsection{Thermodynamic Calculations and Alloy Selection}

Batch calculations (see Sec. 3.1) of solidification pathways of numerous Mo-Si-Ti alloys were performed in the relevant chemical composition range, framed by the eutectic and eutectoid reference alloys, with the purpose of addressing the question whether the volume fractions of the microstructural constituents can be specifically tailored (from a simulation point of view). Therefore, different targets are defined in order to adjust eutecticeutectoid microstructures with the aim of achieving oxidation and creep resistance, thus investigating:

(i) eutectic-eutectoid Mo-Si-Ti alloys with varying amount of eutectic volume fractions and some primarily solidified Moss

(ii) eutectic-eutectoid Mo-Si-Ti alloys with minimised or completely reduced fraction of primarily solidified Moss because Moss is the pesting-critical phase [132, 133, 136]

(iii) eutectic-eutectoid alloys with some amount of primarily solidified (Mo,Ti) ${ }_{5} \mathrm{Si}_{3}$ as it is known to be pesting- and creep-resistant $[67,196,198]$

Based on the thermodynamic simulations, the following alloy candidates (see Table 4-1), were found to be promising to meet the targets (the alloy compositions of alloys A1, B1, $\mathrm{AB}$, alloys $\mathrm{C}$ and $\mathrm{D}$ are analogous to the ones investigated in Refs. [215, 224, 225]). These are categorised as different alloy series A to D, which are illustrated in the metal-rich portion of the liquidus projection in Fig. 4-2. Generally, the variation in Ti content among those alloy series does not only directly affect the $T_{\text {solidus }}$ but determines the phase of primary solidification in conjunction with an appropriate Si content (provided that the inaccurate implementation of the (Mo,Ti) ${ }_{3} \mathrm{Si}$ phase by Pandat is considered). 
Table 4-1 Comparison of the alloys selected for investigation.

\begin{tabular}{|c|c|c|c|c|}
\hline$\#$ & $\begin{array}{c}\text { nominal alloy com- } \\
\text { position / at\% }\end{array}$ & $T_{\text {solidus }} /{ }^{\circ} \mathrm{C}$ (calc.) & $\begin{array}{c}\text { primarily solidify- } \\
\text { ing phase (calc.) }\end{array}$ & $\rho / \mathrm{g} / \mathrm{cm}^{3}$ (exp.) \\
\hline eutectic & Mo-20Si-52.8Ti & 1723 & - & $6.2[5]$ \\
\hline C2 & Mo-21Si-47Ti & 1827 & $(\mathrm{Mo}, \mathrm{Ti})_{3} \mathrm{Si}$ & $6.30 \pm 0.15$ \\
\hline C1 & Mo-21.6Si-44.2Ti & $1877[225]$ & - & $6.44 \pm 0.14[225]$ \\
\hline A1 & Mo-21Si-43.4Ti & $1885[225]$ & $(\mathrm{Mo}, \mathrm{Ti})_{3} \mathrm{Si}$ & $6.49 \pm 0.11[224]$ \\
\hline A2 & Mo-20.5Si-43.4Ti & 1882 & Moss & $6.53 \pm 0.02$ \\
\hline AB & Mo-21.5Si-41.5Ti & 1916 & $(\mathrm{Mo}, \mathrm{Ti})_{3} \mathrm{Si}$ & $6.62 \pm 0.07$ \\
\hline B1 & Mo-21Si-38.7Ti & 1948 & $(\mathrm{Mo}, \mathrm{Ti})_{3} \mathrm{Si}$ & $6.84 \pm 0.05[224]$ \\
\hline B2 & Mo-20.25Si-38.7Ti & 1942 & $\mathrm{Moss}$ & $6.83 \pm 0.06$ \\
\hline eutectoid & Mo-21Si-34Ti & 1948 & - & $7.0[5]$ \\
\hline D1 & Mo-26Si-40Ti & $1947[225]$ & $(\mathrm{Mo}, \mathrm{Ti})_{5} \mathrm{Si}_{3}$ & $6.42 \pm 0.05[225]$ \\
\hline D2 & Mo-26Si-44Ti & $1915[225]$ & $(\mathrm{Mo}, \mathrm{Ti})_{5} \mathrm{Si}_{3}$ & $6.24 \pm 0.08[225]$ \\
\hline
\end{tabular}

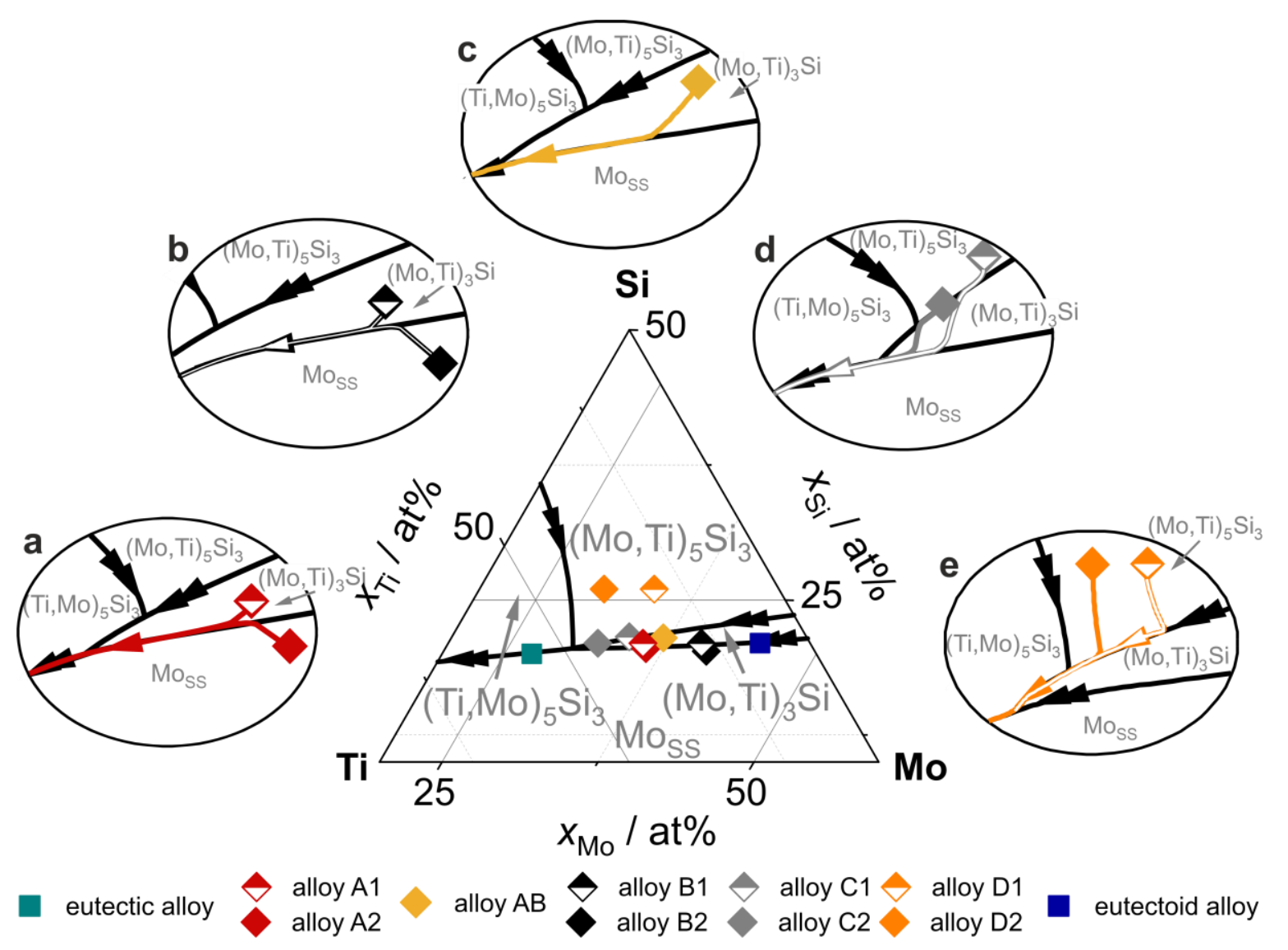

Fig. 4-2 Calculated metal-rich portion of the ternary Mo-Si-Ti liquidus projection (according to Ref. [224]), including insets (a-e) with schematic detailed views of the composition profile of the liquid (coloured lines) during solidification in Scheil condition. The investigated alloys are highlighted by coloured symbols. 
Alloy series A and B were selected in order to address target (i). Both are characterised by chemical compositions close to the (Mo,Ti) ${ }_{3} \mathrm{Si}$-Moss ridge and solidification pathways propagating along it (see composition profile of the liquid L during solidification in schematic zoomed-in views in Fig. 4-2a and b). Their main difference is the nominal Ti content (series A: Ti-rich vs. series B: Ti-lean) and the fraction of eutectoid regions (see Scheil simulations in Fig. 4-3a and b). Alloy series $\mathrm{A}$ is predicted to be composed of around $25 \%$ eutectoid regions (fraction of $(\mathrm{Mo}, \mathrm{Ti}){ }_{3} \mathrm{Si}$ ) in comparison to $45 \%$ in alloy series $\mathrm{B}$. The difference of the alloy variants 1 and 2 (solid and dashed lines in Fig. 4-3a and b), which is attained by slight variations in Si content, is reasoned by the varying amount of primarily solidified Moss (yellow circle). Note that the Moss phase fraction, solidifying until the eutectic solidification starts, is assigned as primary, even when simultaneous solidification of (Mo,Ti) ${ }_{3} \mathrm{Si}$ is predicted. This is justified by the inaccurate implementation of the region of primary $(\mathrm{Mo}, \mathrm{Ti})_{3} \mathrm{Si}$ solidification. In between these two alloy series, alloy $\mathrm{AB}$ represents a medium Ti-containing alloy (see Fig. 4-2c), but with similar volume fractions of microstructural constituents to alloy series A (see App. 4 for solidification simulations).

In order to avoid any primary solidification of Moss and, thus, meeting objective (ii), the alloy series $\mathrm{C}$ was developed. The alloy compositions are located closely to the (Mo,Ti) ${ }_{5} \mathrm{Si}_{3}-$ $(\mathrm{Mo}, \mathrm{Ti})_{3} \mathrm{Si}$ ridge and the composition of the liquid follows the (Mo,Ti) ${ }_{3} \mathrm{Si}-\mathrm{Moss}$ ridge similarly as for the alloy series A and B (for Scheil conditions), after having passed the primary solidification region of (Mo,Ti) 3 Si (see Fig. 4-2d). The variants 1 and 2 are here distinguished by a significantly different fraction of (Mo,Ti) ${ }_{3} \mathrm{Si}$ and, thus, presumably of eutectoid regions (see solid and dashed lines in Fig. 4-3c). This is caused by differently extended temperature ranges during which the liquid proceeds through the (Mo,Ti) ${ }_{3} \mathrm{Si}$ region (even observed for Scheil conditions).

The additional alloy series D, dedicated to objective (iii), is considerably enriched in Si in order to trigger the primary solidification of $(\mathrm{Mo}, \mathrm{Ti})_{5} \mathrm{Si}_{3}$ (see Fig. 4-2e). The solidification pathways propagate along the $(\mathrm{Mo}, \mathrm{Ti})_{5} \mathrm{Si}_{3}-(\mathrm{Mo}, \mathrm{Ti})_{3} \mathrm{Si}$ ridge for Scheil conditions, which is unique for this alloy series among all investigated ones. The variants 1 and 2 are also distinguished by a considerably varying amount of $(\mathrm{Mo}, \mathrm{Ti})_{3} \mathrm{Si}$ and, therefore, presumably eutectoid volume fractions (see solid and dashed lines in Fig. 4-3d).

While the primary solidification of the respective phase can be directly extracted from the liquidus projection, the type of subsequent solidification sequences along the two-phase ridges, which border the $(\mathrm{Mo}, \mathrm{Ti})_{3} \mathrm{Si}$ region of primary solidification ((Mo,Ti) ${ }_{3} \mathrm{Si}-\mathrm{Moss}$ and $\left.(\mathrm{Mo}, \mathrm{Ti})_{5} \mathrm{Si}_{3}-(\mathrm{Mo}, \mathrm{Ti})_{3} \mathrm{Si}\right)$ is still under debate $[93,105,226]$. In principal, the occurrence of 
two simultaneously solidifying phases would imply a eutectic(-) or peritectic(-like) reaction. For instance $\mathrm{L} \rightarrow \mathrm{Moss}+(\mathrm{Mo}, \mathrm{Ti})_{3} \mathrm{Si}$ along the $(\mathrm{Mo}, \mathrm{Ti})_{3} \mathrm{Si}-\mathrm{Moss}$ ridge or $\mathrm{L}+(\mathrm{Mo}, \mathrm{Ti})_{5} \mathrm{Si}_{3}$ $\rightarrow(\mathrm{Mo}, \mathrm{Ti})_{3} \mathrm{Si}$ along the $(\mathrm{Mo}, \mathrm{Ti})_{3} \mathrm{Si}-(\mathrm{Mo}, \mathrm{Ti})_{5} \mathrm{Si}_{3}$ ridge towards the Ti-rich side (see liquidus projection in Fig. 2-5 in Sec. 2.2) for equilibrium conditions. However, neither the here presented Scheil solidification simulations, nor the simulations for equilibrium conditions (see App. 5) allow for a distinct determination of the occurring phase reactions throughout the entire solidification process. Thus, the resulting microstructures of the AcM alloys have to be evaluated in the following Secs. 5.1 and 5.2.
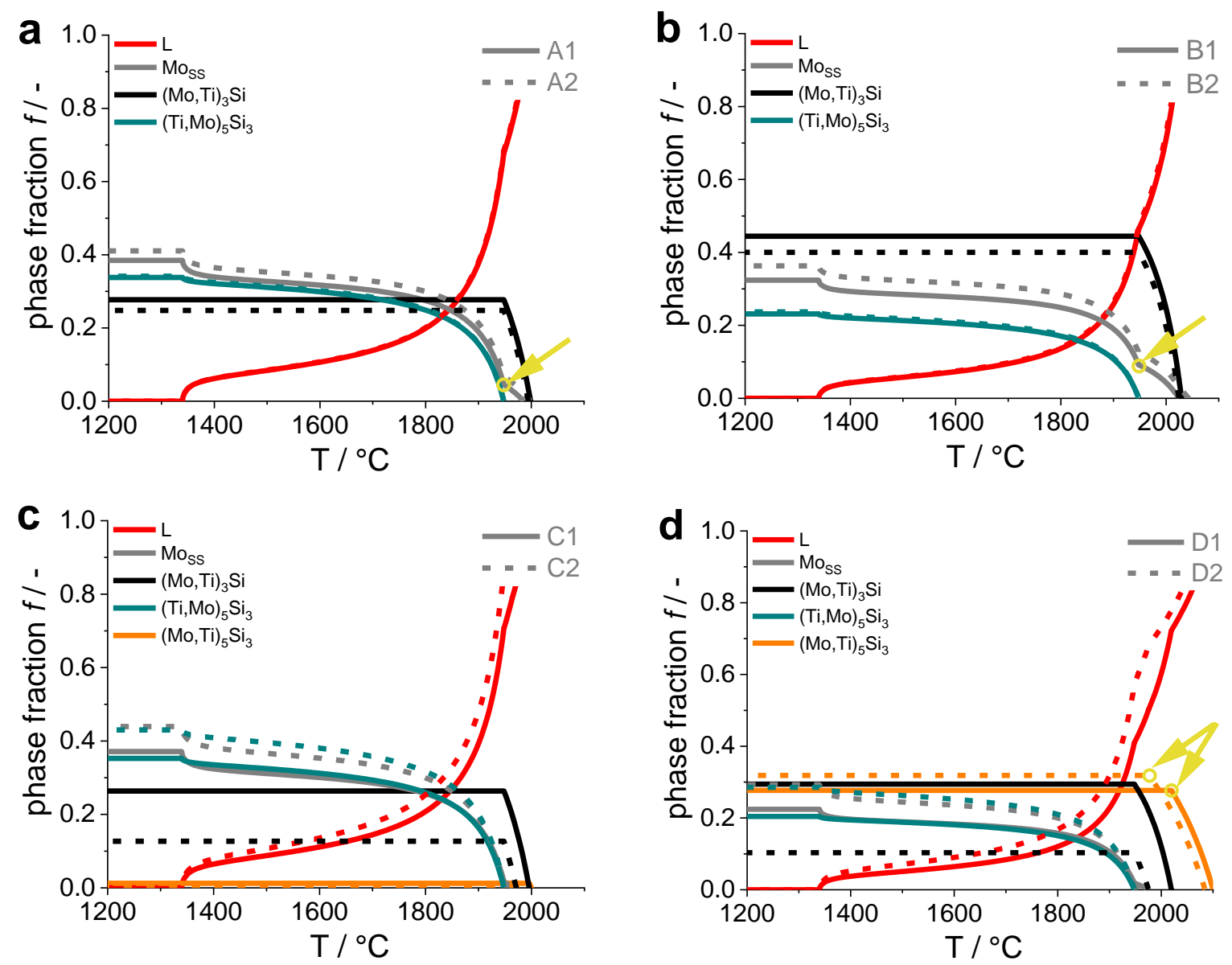

Fig. 4-3 Scheil solidification simulations for alloy series A (a), B (b), C (c) and D (d). The alloy variants 1 are symbolised by solid lines, whereas the variants 2 by dotted lines. The phase fraction assigned as primarily solidified (Moss in alloy series $\mathrm{A}$ and $\mathrm{B},(\mathrm{Mo}, \mathrm{Ti})_{5} \mathrm{Si}_{3}$ in alloy series $\left.\mathrm{D}\right)$ is highlighted by the yellow circle and arrow. 


\section{Microstructural Characterisation and Evaluation}

\subsection{The Intermediate Eutectic-Eutectoid Alloy Series A and B}

The microstructures of the alloy series A and B are compared to the eutectic and eutectoid reference alloys in as-cast ( $a c)$ and heat-treated $(h t)$ condition (see Fig. 5-1). The reference alloys are characterised by fine-scaled, two-phase microstructures with mostly lamellar, but also partially degenerated morphology, being composed of Moss and ( $\mathrm{Ti}, \mathrm{Mo})_{5} \mathrm{Si}_{3}$ or (Mo,Ti) ${ }_{5} \mathrm{Si}_{3}$ (see Fig. 5-1a and b). Moss and the respective silicide phase are present at a ratio of about $1: 1$, as was also reported in Ref. [5]. In comparison, the intermediate alloys reveal eutectic-eutectoid microstructures with some amount of primarily solidified Moss. The distinction between eutectic and eutectoid regions is based on (i) the morphology of the microstructural constituents and (ii) on the observed $Z$-contrast in BSE mode of the silicides. As the eutectoid regions originate from former ( $\mathrm{Mo}, \mathrm{Ti})_{3} \mathrm{Si}$, they are assumed to be dendritic in shape, while the eutectic regions, originating from the final solidification of the residual melt, are assumed to be interdendritic. This is further supported by the different grey level in BSE contrast of ( $\mathrm{Ti}, \mathrm{Mo})_{5} \mathrm{Si}_{3}$ (dark grey) and (Mo,Ti) ${ }_{5} \mathrm{Si}_{3}$ (bright grey) within the eutectic and eutectoid regions. The difference in grey level is attributed to the different content of $\mathrm{Ti}$ and Mo, which occupy the respective lattice sites in the corresponding $\mathrm{M}_{5} \mathrm{Si}_{3}$ silicide, while the Si content is almost independent of the silicide type.

In the Ti-rich alloy series $\mathrm{A},(\mathrm{Mo}, \mathrm{Ti})_{3} \mathrm{Si}$ underwent complete eutectoid decomposition during AcM (see Fig. 5-1c and d). Thus, no additional heat treatment is required. The microstructures do not provide further indications what kind of solidification reaction has occurred, when the composition of the melt proceeds along the Moss-(Mo,Ti) ${ }_{3} \mathrm{Si}$ ridge. As no eutectic microstructure of lamellar Moss $+(\mathrm{Mo}, \mathrm{Ti})_{3} \mathrm{Si}$ can be identified, it is likely that this solidification sequence is suppressed by the fast cooling conditions. Additionally, there are no obvious morphological differences observed between alloys A1 and A2, even though their chemical compositions are predicted to be located in different regions of primary solidification (see Fig. 4-2a). This supports the former definition of the primarily solidified fraction of Moss (yellow circle in Fig. 4-3a, fraction of Moss, which solidified previously to the simultaneous solidification of Moss and (Ti,Mo) ${ }_{5} \mathrm{Si}_{3}$ according to the eutectic reaction).

The Ti-lean alloys, like the eutectoid reference alloy and the alloy series B, are characterised by residual (Mo,Ti) ${ }_{3} \mathrm{Si}$ in ac condition (see Fig. 5-1e and g). Hence, a subsequent heat treatment is mandatory to achieve complete eutectoid decomposition (see Fig. 5 - $1 \mathrm{f}$ and h). 

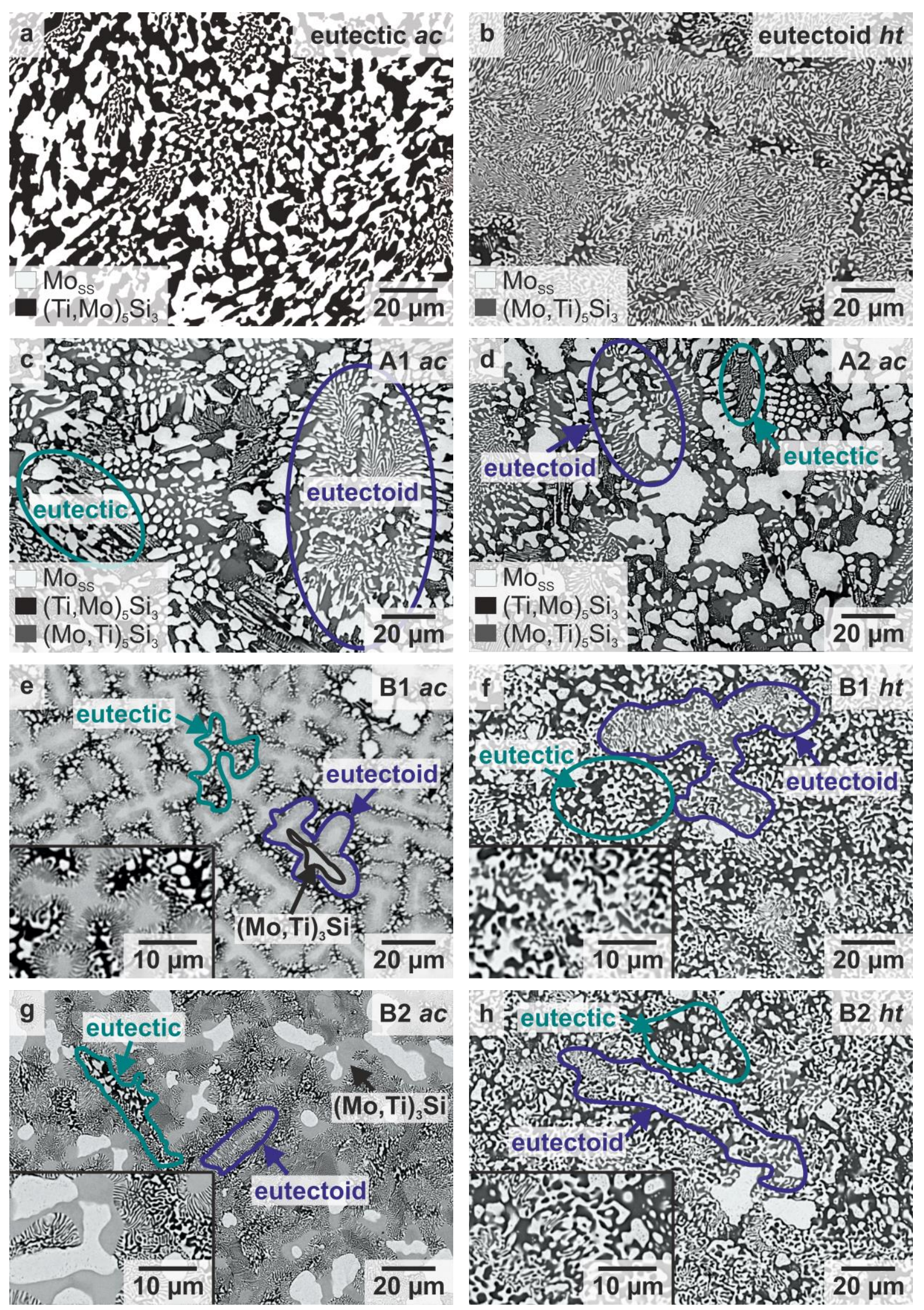

Fig. 5-1 BSE micrographs of the eutectic (a) and eutectoid (b) alloys, alloy series A (c and d) and B (e to h) in the $a c$ and/or $h t$ condition $\left(1300^{\circ} \mathrm{C}, 200 \mathrm{~h}\right)$. Micrographs c and f according to Ref. [224]. 
The alloy variants 1 and 2 of alloy series B reveal differences in the morphology of primarily solidified Moss and (Mo,Ti) ${ }_{3} \mathrm{Si}$ in the ac condition. Alloy B1, which is, based on the liquidus projection by Pandat, located in the primary solidification region of (Mo,Ti) ${ }_{3} \mathrm{Si}$, reveals (Mo,Ti) ${ }_{3} \mathrm{Si}$ dendrites and some globular Moss regions, which seem to be independently formed from (Mo,Ti) ${ }_{3} \mathrm{Si}$ (see Fig. 5-1e). The (Mo,Ti) $)_{3} \mathrm{Si}$ dendrites reveal seams of a lamellar microstructure, which might be caused by (i) the eutectic reaction $\mathrm{L} \rightarrow$ Moss + $(\mathrm{Mo}, \mathrm{Ti})_{3} \mathrm{Si}$, which is favoured along already pre-existing phase boundaries of previously solidified (Mo,Ti) ${ }_{3} \mathrm{Si}$ (by heterogenous nucleation), or (ii) by partial eutectoid decomposition of $(\mathrm{Mo}, \mathrm{Ti})_{3} \mathrm{Si} \rightarrow \mathrm{Moss}+(\mathrm{Mo}, \mathrm{Ti})_{5} \mathrm{Si}_{3}$ leaving residual $(\mathrm{Mo}, \mathrm{Ti})_{3} \mathrm{Si}$ cores behind (the label in Fig. 5-1e corresponds to option (ii)). Because of the fine-scaled microstructures, it is not possible to determine the silicide phases by means of SEM analyses, which do not provide sufficient chemical resolution for investigation of the phase compositions. In contrast, TEM, enabling high resolution analyses, does not only allow for determination of the chemical composition, but also of the crystal structure. However, because of the small investigated volumes, no statistical, sound conclusions can be drawn on the overall microstructures. Therefore, only a qualitatively discourse can be provided here. Either option (i) or (ii) would enable the formation of the microstructure seen after heat treatment, as the formed lamellar microstructure coarsens, while the residual fraction of $(\mathrm{Mo}, \mathrm{Ti})_{3} \mathrm{Si}$ decomposes by the eutectoid reaction (see Fig. 5-1f).

Unlike alloy B1, alloy B2 is located in the primary solidification region of Moss, which is experimentally confirmed by the considerable amount of globularly solidified Moss regions (see Fig. 5-1g). Interestingly, (Mo,Ti) ${ }_{3} \mathrm{Si}$ is solidified along the phase boundaries of Moss, which suggests the partial peritectic reaction $\mathrm{L}+\mathrm{Moss} \rightarrow(\mathrm{Mo}, \mathrm{Ti})_{3} \mathrm{Si}$ to take place. The morphological differences of alloys B1 and B2 in the ac condition are not observed after the heat treatment anymore (see Fig. 5-1f and h). This leads to the assumption that the different phase fractions of globular/dendritic Moss and/or (Mo,Ti) ${ }_{3} \mathrm{Si}$ observed in the $a c$ alloy series B, which presumably originated from different initial phase reactions, might could have been observed in the alloy series A as well, if the eutectoid decomposition had been partially suppressed after AcM. Therefore, the divergence from the thermodynamic equilibrium reaction along the $(\mathrm{Mo}, \mathrm{Ti}){ }_{3} \mathrm{Si}$-Moss ridge seems not to be solely influenced by the cooling conditions during AcM (which are assumed to be comparable for all alloy series), but also by the starting point (alloy composition) determining from which region of primary solidification the ridge is reached. 
In comparison, the primary solidification of Moss is suppressed in the medium Ti-containing alloy $\mathrm{AB}$. The resulting $a c$ microstructure is characterised by comparably large eutectoid dendrites of lateral expansion of more than $60 \mu \mathrm{m}$ and interdendritic eutectic regions (see Fig. 5-2a). Only a small fraction of residual (Mo,Ti) ${ }_{3} \mathrm{Si}$ is observed in the centre of the eutectoid regions. Besides the absence of primarily solidified Moss, the morphology in the $a c$ state is likely to have originated from solidification sequences comparable to alloy B1. This is reasonable when comparing the composition of the liquid during solidification, which proceeds similarly through the phase regions for alloys AB and B1 (see Fig. 4-2b and c). After heat treatment, the microstructure is characterised by interpenetrating finescaled eutectic-eutectoid regions (see Fig. 5-2b).
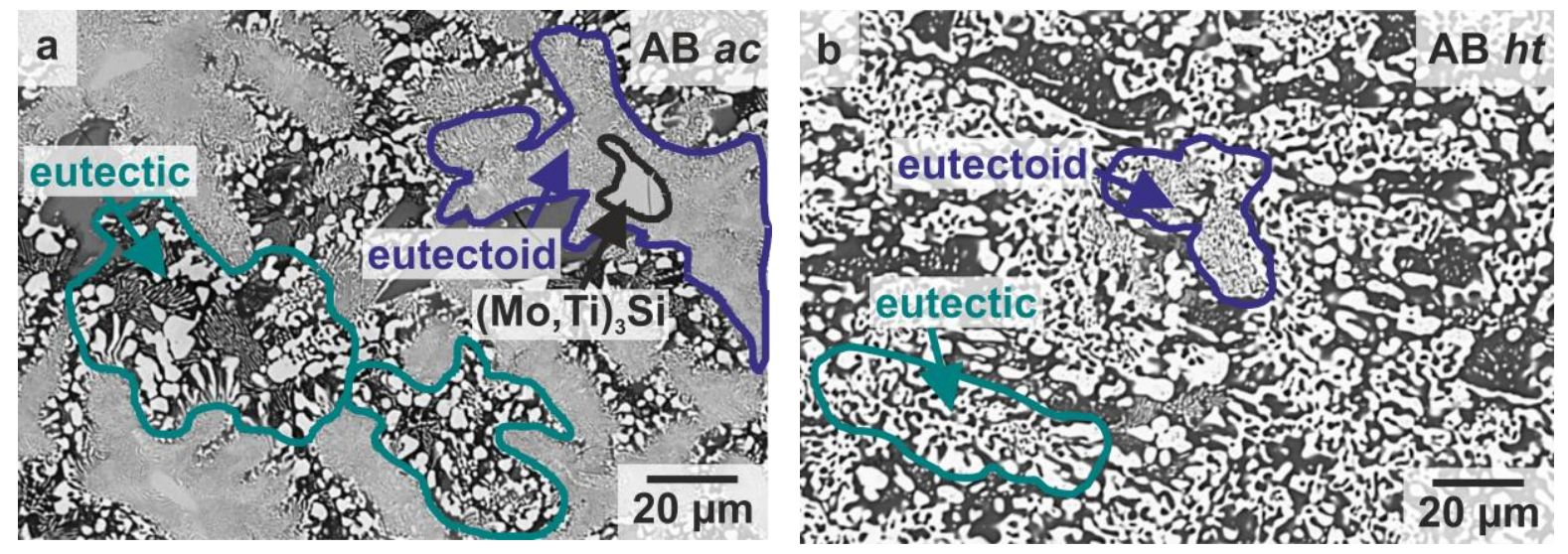

Fig. 5-2 BSE micrographs of alloy AB in the $a c$ (a) and $h t$ (b) condition.

Conclusively, most investigated intermediate alloys comprise primarily solidified Moss to some extent (except alloy AB), even then, when the primarily solidifying phase is predicted to be (Mo,Ti) ${ }_{3} \mathrm{Si}$ by thermodynamic calculations (alloys A1 and B1). This confirms that the transition between the primary solidification regions Moss and (Mo,Ti) ${ }_{3} \mathrm{Si}$ is not precisely predicted. However, the experimentally determined amount of primarily solidified Moss is in good agreement with the predicted volume fraction of solidified Moss until the eutectic reaction starts (assigned as primary as well), as shown in the comparative summary of the experimentally determined volume fractions and the thermodynamic predictions in Fig. 5-3. 


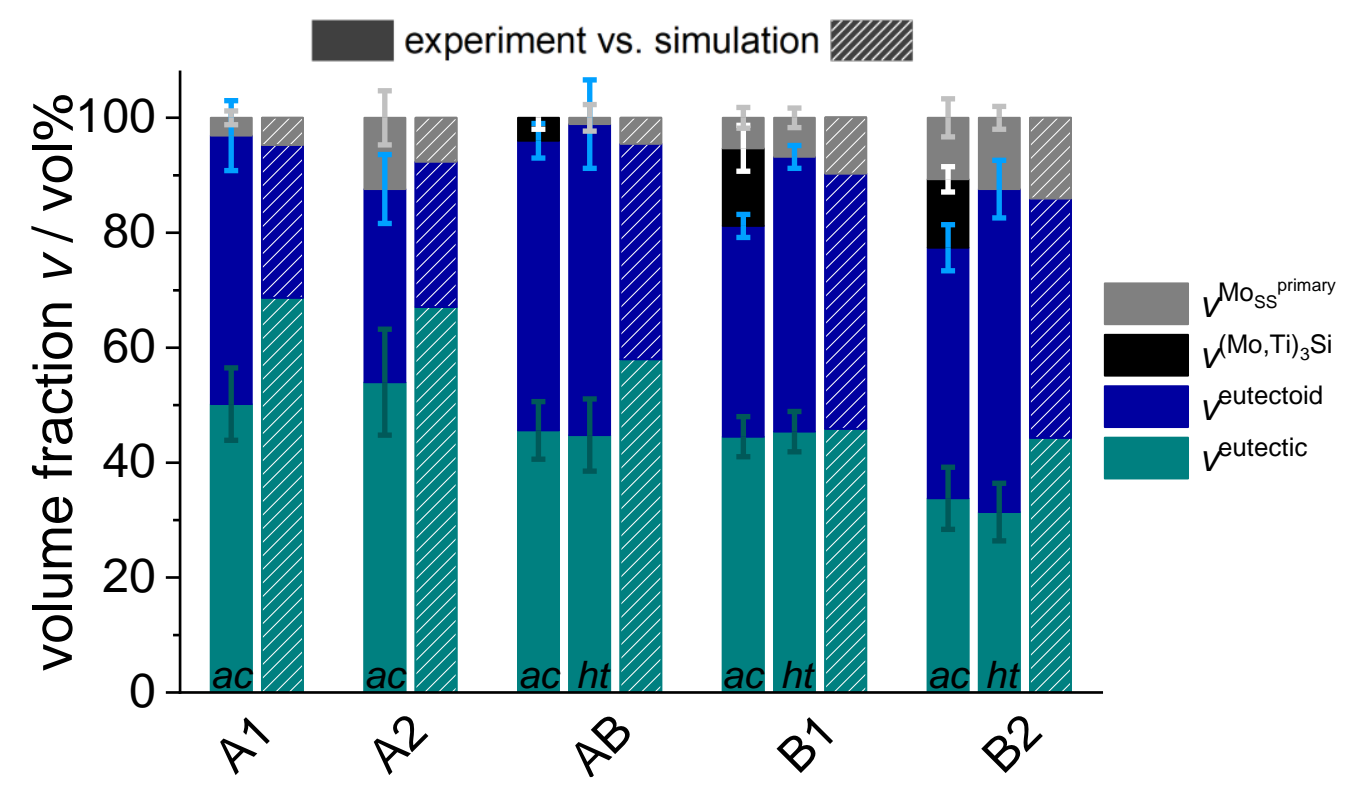

Fig. 5-3 Experimentally determined (filled bars) and thermodynamic (hatched bars) volume fractions $v$ of the microstructural constituents in the investigated alloys of series $\mathrm{A}$ and $\mathrm{B}$ and alloy $\mathrm{AB}$ in $a c$ and $h t$ condition. Data of alloys $\mathrm{A} 1 a c$ and B1 $h t$ are taken from Ref. [224].

Especially, the increase in volume fraction of primarily solidified Moss of (3 \pm 1$)$ vol\% (A1) [224] and (7 \pm 2$)$ vol\% (B1) [224] in the alloy variants 1 up to (12 \pm 5$)$ vol\% (A2) and $(11 \pm 3)$ vol\% (B2) in the alloy variants 2 meets the thermodynamic predictions. Although there is some discrepancy in the volume fraction of the eutectic and eutectoid regions between the experiment and simulation results, it is concluded that, when considering the standard deviations and the accuracy of the distinction of the eutectic and eutectoid regions, trends can be extracted from the thermodynamic simulations in order to guide the alloy development.

\subsection{The (Mo, $\left.\mathrm{Ti}_{5}\right)_{5} \mathrm{Si}_{3}$-Containing Eutectic-Eutectoid Alloy Series $\mathrm{C}$ and $\mathrm{D}$}

The adjustment of the alloy composition leads to the alloy series $\mathrm{C}$ and $\mathrm{D}$ with varying amounts of $(\mathrm{Mo}, \mathrm{Ti})_{3} \mathrm{Si}$ or $(\mathrm{Mo}, \mathrm{Ti})_{5} \mathrm{Si}_{3}$ as primarily solidifying phase (see also thermodynamic calculations in Fig. 4-3c and d). The alloy series $\mathrm{C}$ is characterised by homogenously distributed, interpenetrating eutectic and eutectoid regions with small (see alloy C1, Fig. 5-4a) to none amounts of $(\mathrm{Mo}, \mathrm{Ti})_{5} \mathrm{Si}_{3}$ regions in the $a c$ condition (see alloy C2, Fig. 5-4b). Thus, the target of a solely eutectic-eutectoid alloy without any further solidified phases is realised in alloy $\mathrm{C} 2$, serving as Ti-rich reference to the (Mo,Ti) ${ }_{5} \mathrm{Si}_{3}$-containing alloys 
(series D). Regarding the solidification sequences, the attained microstructures do not provide further clarification what kind of phase reaction occurs along the (Mo,Ti) ${ }_{5} \mathrm{Si}_{3}$ $(\mathrm{Mo}, \mathrm{Ti})_{3} \mathrm{Si}$ ridge, as was already questioned in Sec. 4.2. However, it is likely that the composition of the liquid (see Fig. 4-2d) passes the (Mo,Ti) $)_{5} \mathrm{Si}_{3}-(\mathrm{Mo}, \mathrm{Ti})_{3} \mathrm{Si}$ ridge (after primary solidification of $(\mathrm{Mo}, \mathrm{Ti})_{5} \mathrm{Si}_{3}$ in alloy $\mathrm{C} 1$ ) that quickly during solidification (within $10 \mathrm{~K}$ referring to the Scheil and equilibrium calculations), so that the potential solidifying microstructural constituents are skipped and therefore not observed in the BSE micrographs after AcM. Subsequent propagation of the composition of the liquid through the solidification region of $(\mathrm{Mo}, \mathrm{Ti})_{3} \mathrm{Si}$ is expected to lead to the dendritic solidification of (Mo,Ti) ${ }_{3} \mathrm{Si}$ and following eutectoid decomposition during and/or after final eutectic solidification.

Microstructural analyses of the alloy series D reveal eutectic-eutectoid matrices with embedded $(\mathrm{Mo}, \mathrm{Ti})_{5} \mathrm{Si}_{3}$ particles of different length scale and volume fraction (see Fig. 5-4c and d). The composition of the liquid proceeds through the primary region of $(\mathrm{Mo}, \mathrm{Ti})_{5} \mathrm{Si}_{3}$ for a comparably long temperature range of almost $80 \mathrm{~K}$ in both, equilibrium and Scheil condition (see Fig. 4-3d). Thus, it is evidently that the present $(\mathrm{Mo}, \mathrm{Ti})_{5} \mathrm{Si}_{3}$ regions originate from this solidification sequence. The assumption made for the alloy series $\mathrm{C}$ regarding the skipping of the $(\mathrm{Mo}, \mathrm{Ti})_{5} \mathrm{Si}_{3}-(\mathrm{Mo}, \mathrm{Ti})_{3} \mathrm{Si}$ ridge, might also be applied to the alloy series $\mathrm{D}$. The composition of the liquid proceeds along this ridge only for another approximate $50 \mathrm{~K}$ until the (Ti,Mo) ${ }_{5} \mathrm{Si}_{3}-\mathrm{Moss}$ ridge is reached and subsequently the eutectic ridge, along which the final solidification occurs (see Fig. 4-2e). Interestingly, the region of (Mo,Ti) ${ }_{3} \mathrm{Si}$ is not passed by the composition of the liquid, so the question arises by which kind of solidification sequence/phase reaction the eutectoid regions are formed. As the composition of the liquid propagates towards the Ti-rich side of the ternary liquidus projection, the peritectic reaction $\mathrm{L}+(\mathrm{Mo}, \mathrm{Ti})_{5} \mathrm{Si}_{3} \rightarrow(\mathrm{Mo}, \mathrm{Ti})_{3} \mathrm{Si}$ is likely to occur along the $(\mathrm{Mo}, \mathrm{Ti})_{5} \mathrm{Si}_{3}-$ $(\mathrm{Mo}, \mathrm{Ti})_{3} \mathrm{Si}$ ridge. This seems reasonable as the eutectoid regions are often in contact with $(\mathrm{Mo}, \mathrm{Ti})_{5} \mathrm{Si}_{3}$ regions and especially in alloy $\mathrm{D} 2$, where the lamella growth direction seems to be perpendicular to the $(\mathrm{Mo}, \mathrm{Ti})_{5} \mathrm{Si}_{3}$ phase boundary (see inset of Fig. $5-4 \mathrm{~d}$ ). Thus, the phase fraction of $(\mathrm{Mo}, \mathrm{Ti})_{5} \mathrm{Si}_{3}$ is likely to decrease again during ongoing solidification. This cannot be predicted by Scheil calculations, as peritectic reactions require solid-state diffusion, which is not considered. In contrast, the calculations in equilibrium (see App. 5d) predict a reduction in $(\mathrm{Mo}, \mathrm{Ti})_{5} \mathrm{Si}_{3}$ phase fraction with ongoing solidification of $(\mathrm{Mo}, \mathrm{Ti})_{3} \mathrm{Si}$ with decreasing temperature. 

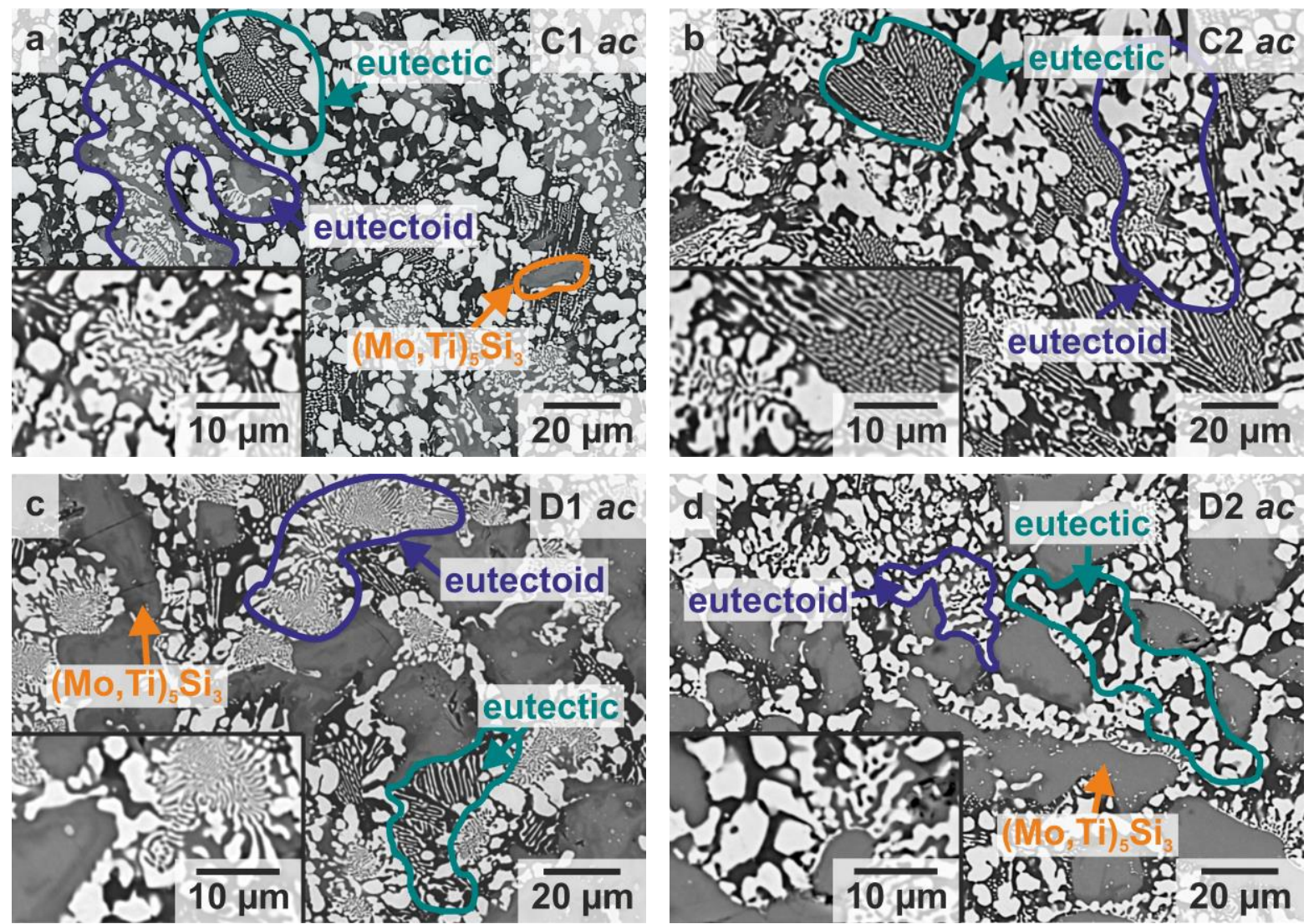

Fig. 5-4

BSE micrographs of the (Mo,Ti) $5 \mathrm{Si}_{3}$-containing alloy series $\mathrm{C}(\mathrm{a}$ and $\mathrm{b}$ ) and D (c and d) in the $a c$ condition. c and d according to Ref. [225].

Furthermore, it is striking that no residual $(\mathrm{Mo}, \mathrm{Ti})_{3} \mathrm{Si}$ is observed within alloy series $\mathrm{C}$ and D. Consequently, the eutectoid reaction has already been completed during AcM. This is comparable to the observations made for the Ti-rich alloy series A. These are generally in agreement with the dependence of the eutectoid reaction on the temperature and $\mathrm{Ti}$ content as already discussed in Sec. 4.1 on the basis of thermodynamic predictions.

The corresponding experimentally determined volume fractions of the microstructural constituents are presented in Fig. 5-5. Although the originally targeted difference of a systematically varying content of eutectoid regions between the alloy variants 1 and 2 in alloy series $\mathrm{C}$ is achieved, there is some divergence of approximately 5 to $10 \mathrm{vol} \%$ between the experimental results and the thermodynamic predictions (including standard deviations). However, the observed deviations are consistent among the alloys of series $\mathrm{C}$ and the trends of the major and minor microstructural constituents are valuable. Therefore, target-oriented tailoring of microstructures is allowed. Nevertheless, the volume fraction of the microstructural constituents of alloy series D are very well predicted. This is somehow surprising, as the anticipated occurrence of the peritectic reaction $\mathrm{L}+(\mathrm{Mo}, \mathrm{Ti})_{5} \mathrm{Si}_{3} \rightarrow$ $(\mathrm{Mo}, \mathrm{Ti})_{3} \mathrm{Si}$ is not considered for Scheil conditions. 


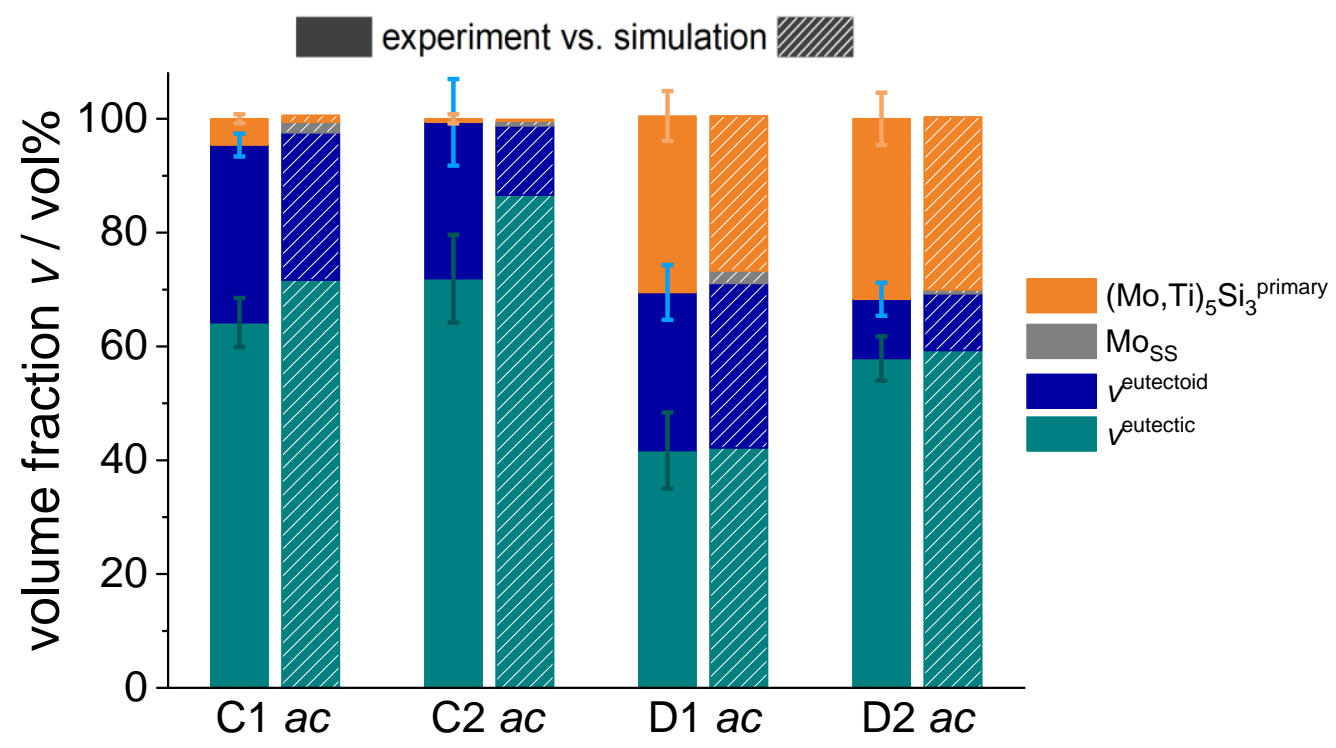

Fig. 5-5 Experimentally determined volume fractions (filled bars) of the microstructural constituents in the alloy series $\mathrm{C}$ and $\mathrm{D}$ in ac condition in comparison to the thermodynamically predicted values for Scheil condition. Data of alloys C1, D1 and D2 according to Ref. [225].

The microstructural evaluation of the investigated alloys reveals that the targets, defined in Sec. 4.2, are achieved: Target (i) focusing on eutectic-eutectoid Mo-Si-Ti alloys with adjustable volume fractions of eutectic regions and primarily solidified Moss and target (ii), which aimed at the minimisation and reduction of the latter, are realised by the intermediate eutectic-eutectoid alloy series A, B and C. The eutectic volume fraction can be adjusted in the range of 32 (alloy B2) over 54 (alloy A2) to 70 vol\% (alloy C2) and the amount of primarily solidified Moss from less than 1 vol\% (alloy AB, C1 and C2) over 3 (alloy A1) to $13 \mathrm{vol} \%$ (alloy A2). Moreover, target (iii) aiming variable contents of ( $\mathrm{Mo}, \mathrm{Ti})_{5} \mathrm{Si}_{3}$ regions within a eutectic-eutectoid microstructure is achieved in alloy series D with up to $30 \mathrm{vol} \%$ of $(\mathrm{Mo}, \mathrm{Ti}){ }_{5} \mathrm{Si}_{3}$ regions (alloy $\left.\mathrm{D} 2\right)$.

\subsection{The Chemical Composition of the Individual Phases}

To further identify the phases, present in the attained microstructures, XRD measurements were performed in the $a c$ and $h t$ condition for all alloy series A to D (see App. 6 for diffraction patterns of alloys A1, B1, C1 and D1). Besides bcc Moss, both silicide phases, (Ti,Mo) ${ }_{5} \mathrm{Si}_{3}$ of hexagonal $\mathrm{Mn}_{5} \mathrm{Si}_{3}$-type (D88) and (Mo,Ti) ${ }_{5} \mathrm{Si}_{3}$ of tetragonal $\mathrm{W}_{5} \mathrm{Si}_{3}$-type, were confirmed. (Mo,Ti) ${ }_{3} \mathrm{Si}$ (A15) was identified in the Ti-medium and Ti-lean alloys AB, B1 and $\mathrm{B} 2$ in the $a c$ condition. Further on, the lattice parameters of the respective phases were 
determined. Especially, the determination of the lattice parameters of Moss allows for the evaluation of the phase-specific Ti content when compared to literature data on lattice parameters of single-phase bcc Mo-Ti alloys as shown in Fig. 5-6 [224]. Thereby, the impact of $\mathrm{Si}$ on the lattice parameter of Moss is considered to be (i) similar among all alloys, namely in the range of $3-4$ at\% as predicted by thermodynamic calculations at the beginning of solidification, and (ii) negligible in the investigated alloys [224]. The first consideration is regarded as reasonable as the AcM route leads to fast cooling conditions and potentially to supersaturation of Moss in $\mathrm{Si}$. The second consideration is based on studies by Sturm et al. in Ref. [77]. They reported an insignificant decrease in lattice parameter in Mo-Si solid solutions by $0.2 \%$ when up to 3.34 at\% $\mathrm{Si}$ are added. This evaluation only holds true for average, global Ti contents in Moss including the overall microstructure. This means that primarily solidified Moss regions, as well as Moss lamellae within eutectic and eutectoid regions are considered. Within the latter, local varying Ti contents might be present, especially in the alloy series A, B and C. These differences will be assessed in detail later by locally resolving methods.

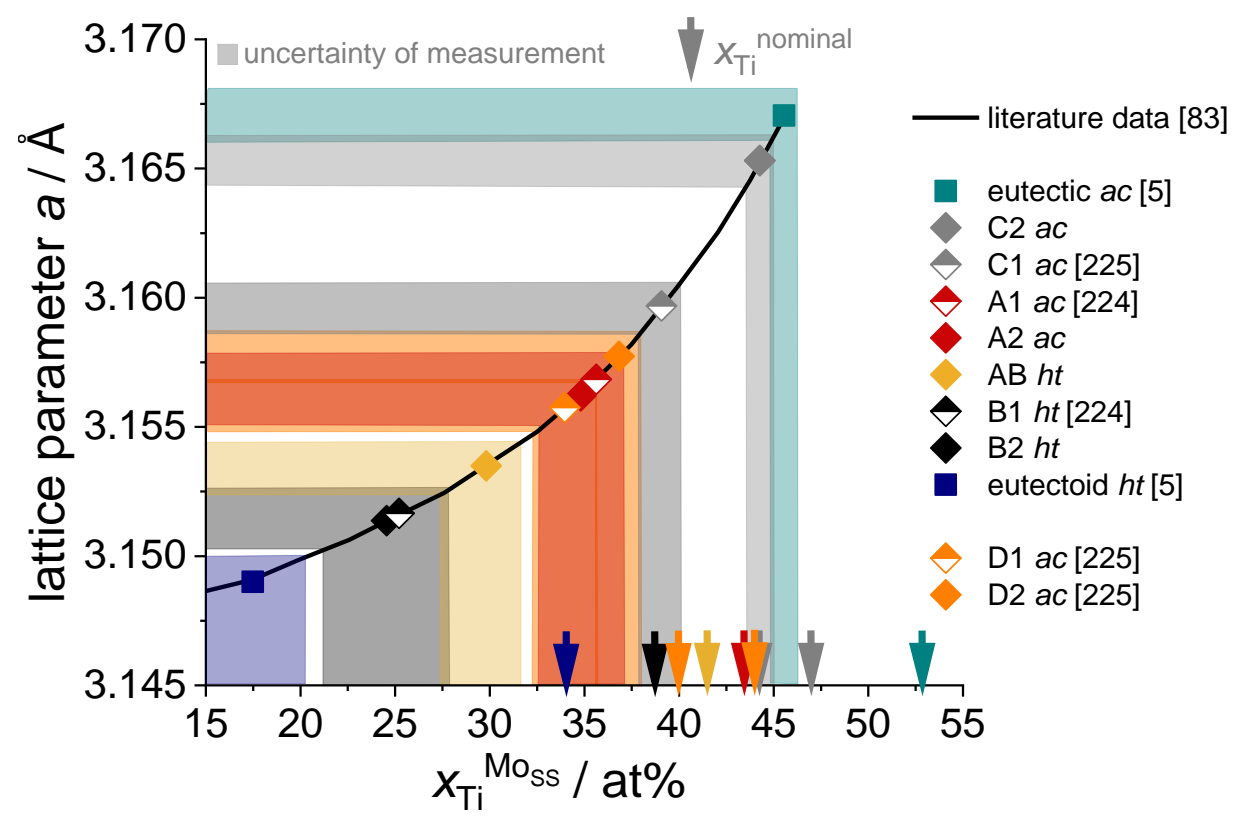

Fig. 5-6 Experimentally determined lattice parameters of Moss in the alloys A to D including the eutectic and eutectoid reference alloys compared to literature data of binary bcc Mo-Ti solid solutions (black line) taken from Ref. [83]. The estimated uncertainty of measurement is $0.001 \AA$ as indicated by the semitransparent regions. The nominal $\mathrm{Ti}$ content of the alloys is given by the coloured arrows along the abscissa. According to Ref. [224]. 
Fig. 5-6 shows that both, the lattice parameter of Moss (ordinate axis) and the nominal (total) Ti content (arrows on the abscissa), are framed by the eutectic and eutectoid reference alloys. Thereby, the global Ti content in Moss is consistently lower compared to the nominal Ti content in all investigated alloys. This reveals that Ti is considerably dissolved in the $\mathrm{M}_{5} \mathrm{Si}_{3}$ silicides [224].

It is seen that the evolution of the lattice parameters and the corresponding Ti content in Moss are very well in line with the variation of the nominal Ti content for all investigated alloys with similar nominal Si content of around 21 at\% (reference alloys and alloy series A to $\mathrm{C}$ ). The Moss being present in the eutectic alloy is the Ti-richest with 45 at\% Ti, while it is decreasing over 35 and 25 at\% in the alloy series A and B, respectively, to 17 at\% Ti in the eutectoid alloy [224]. For the high (Mo,Ti) ${ }_{5} \mathrm{Si}_{3}$-containing alloy series D (higher nominal Si content of 26 at\%), alloy D1 is exceptional as it possesses a comparably high Ti content in Moss of 34 at\% compared to only 40 at\% nominal. However, the assumed uncertainty of the determination of the lattice parameters of $0.001 \AA$ results in an uncertainty of the Ti content of 1.4 to more than 5 at\% in the eutectic and eutectoid reference alloys, respectively.

The lattice parameters $a$ and $c$ of the silicide phases $(\mathrm{Ti}, \mathrm{Mo})_{5} \mathrm{Si}_{3}$ and $(\mathrm{Mo}, \mathrm{Ti})_{5} \mathrm{Si}_{3}$ were determined as well. Neither the comparison of the absolute parameters (see App. 7), nor of the $c / a$ ratio (see App. 8) with the experimentally determined Mo content $x_{M o}^{M_{5} S i_{3}}$ in the respective $\mathrm{M}_{5} \mathrm{Si}_{3}$ silicide, or the nominal Mo content, revealed any distinct dependency. Even the comparison with literature data does not allow for any sound conclusions.

As the site-specific chemical composition, especially of the pesting-critical Moss, is a crucial parameter for the assessment of the oxidation behaviour [224] as will be shown later, the reliable, local determination is of key importance. But this is problematic as the fine-scaled morphology of Moss and the silicides within the eutectic and eutectoid regions necessitates the investigation of small volumes in order to minimise interferences with adjacently located regions. However, local resolving techniques do not allow for statistical findings. Thus, standard-related EDX measurements were conducted for primarily solidified and/or large laterally expanded Moss and silicide regions. Additionally, local resolving STEMEDX analyses were performed for selected alloys, namely the eutectic reference alloy, the intermediate eutectic-eutectoid alloy B1 and the eutectoid reference alloy (see also Ref. [215]). The eutectic-eutectoid alloy B1 was analysed in the ac condition as unambiguous 
assignment of the eutectic and eutectoid regions was supported by the distinctive morphology of the respective microstructural regions. The corresponding STEM-EDX maps are depicted in Fig. 5-7. There is no difference observed in element distribution when comparing Moss or the silicides in the eutectic and eutectoid regions in all investigated alloys [215]. But cuboidal and spherical precipitates were observed within Moss in the eutectoid alloy (see Fig. 5-7d) [215]. While the cuboidal precipitates were found to be rich in Ti and $\mathrm{Si}$, the spherically shaped ones were found to be Mo-rich (see App. 9 for element quantification) [215]. These precipitates likely originate from the supersaturation of Moss after AcM and formed during the subsequent heat treatment $h t$ at $1300{ }^{\circ} \mathrm{C}$ for $200 \mathrm{~h}$.
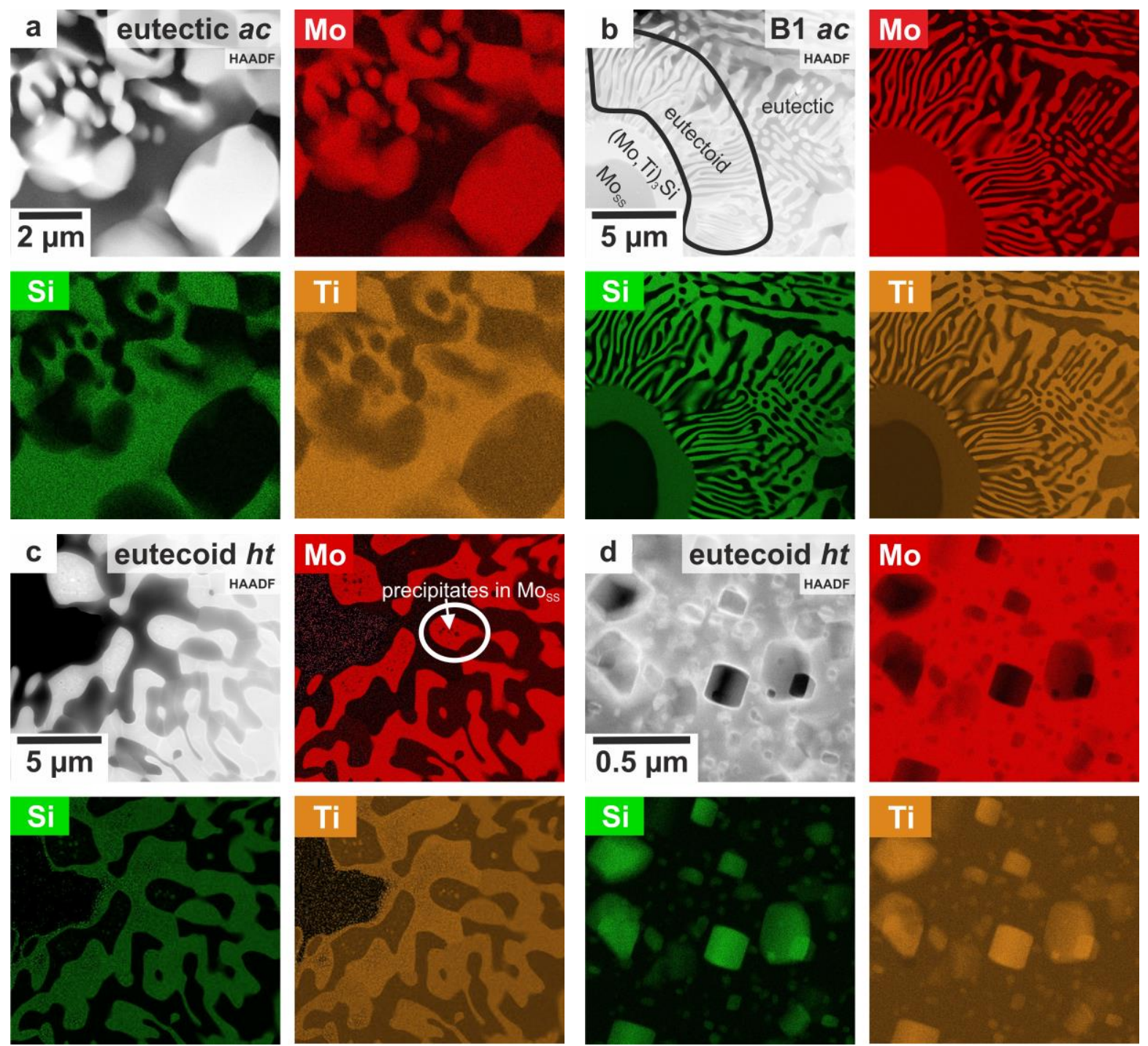

Fig. 5-7 HAADF images and corresponding STEM-EDX maps of the constitutional elements Mo (red), Si (green) and Ti (orange) of the eutectic reference alloy in $a c$ condition (a), alloy B1 in $a c$ condition (b) and the eutectoid reference alloy in $h t$ condition (precipitates in Moss circled in white) (c), including a more detailed analysis of the precipitates in Moss (d). According to Ref. [215]. 
Additional line scans in representative areas were performed for further analysis and are compared to the experimental results gained by standardised EDX and to the thermodynamic predictions in Fig. 5-8 (detailed experimental STEM-EDX values are listed in App. 9, [215]).
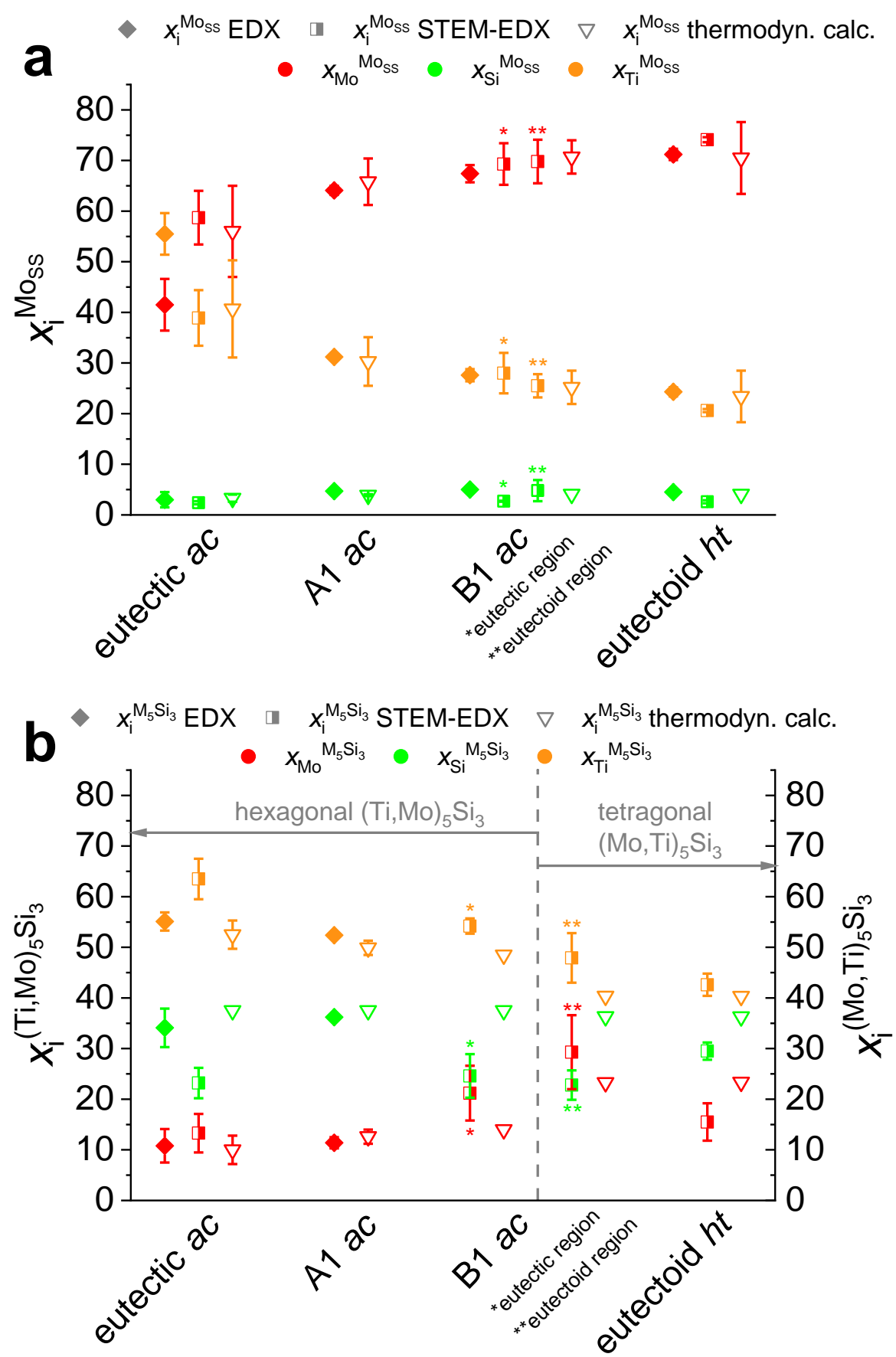

Fig. 5-8 Comparison of the phase-specific chemical composition of Moss (a), (Ti,Mo) ${ }_{5} \mathrm{Si}_{3}$ and $(\mathrm{Mo}, \mathrm{Ti})_{5} \mathrm{Si}_{3}$ (b) in the eutectic reference alloy, alloys A1, B1 and the eutectoid reference alloy determined by standard-related EDX (diamond symbols), STEM-EDX (half-opened squares, data according to Ref. [215]) and thermodynamic calculations for equilibrium (opened triangles). 
Note the range in chemical composition, predicted by the thermodynamic calculations, which stems from the change in chemical composition during solidification when the temperature decreases from liquidus to solidus temperature. The primary focus is placed on the site-specific Ti content in Moss (see orange data points in Fig. 5-8a) being present in the eutectic or eutectoid regions and on the Mo to Ti ratio in the $\mathrm{M}_{5} \mathrm{Si}_{3}$ silicides (see red and orange data points in Fig. 5-8b). As was already revealed by XRD analysis (see Fig. 5-6), a considerable difference is found in the Ti content dissolved in Moss of around $(39 \pm 9)$ at $\%$ in the eutectic reference alloy compared to $(21 \pm 0)$ at $\%$ in the eutectoid reference alloy by STEM-EDX [215]. In contrast, there is no considerable difference found in the intermediate eutectic-eutectoid alloy B1 within the range of scatter, as Moss comprises (28 \pm 4$)$ and (26 \pm 2$)$ at\% $\mathrm{Ti}$ in the eutectic and eutectoid region, respectively [215]. The $\mathrm{M}_{5} \mathrm{Si}_{3}$ silicides cannot be assigned unambiguously to either $\mathrm{Mn}_{5} \mathrm{Si}_{3}$-type (Ti,Mo) ${ }_{5} \mathrm{Si}_{3}$ or $\mathrm{W}_{5} \mathrm{Si}_{3}$-type $(\mathrm{Mo}, \mathrm{Ti})_{5} \mathrm{Si}_{3}$ based on the determined chemical compositions. Even the evaluation of TEM diffraction patterns of the $\mathrm{M}_{5} \mathrm{Si}_{3}$ silicides in the respective regions only confirmed the presence of hexagonal $\mathrm{Mn}_{5} \mathrm{Si}_{3}$-type (Ti,Mo) ${ }_{5} \mathrm{Si}_{3}(\mathrm{D} 88$ ) in the eutectic region (see App. 10), while the identification of the crystal structure remained impossible in the finescaled eutectoid region [215].

However, XRD measurements revealed the presence of both, (Ti,Mo) ${ }_{5} \mathrm{Si}_{3}$ and $(\mathrm{Mo}, \mathrm{Ti})_{5} \mathrm{Si}_{3}$ (see App. 6). This leads to the assumption that the Mo-lean $\mathrm{M}_{5} \mathrm{Si}_{3}$ silicide is (Ti,Mo) ${ }_{5} \mathrm{Si}_{3}$, although the difference in Mo content in $(\mathrm{Ti}, \mathrm{Mo})_{5} \mathrm{Si}_{3}$ and $(\mathrm{Mo}, \mathrm{Ti})_{5} \mathrm{Si}_{3}$ is not consistent among the investigated alloys. For instance, a Mo content of 13 to 21 at\% is determined for (Ti,Mo) ${ }_{5} \mathrm{Si}_{3}$ (see eutectic alloy and alloy B1 in Fig. 5-8) and 15 to 29 at\% for (Mo,Ti) ${ }_{5} \mathrm{Si}_{3}$ (see eutectoid alloy and alloy B1 in Fig. 5-8). These observations reveal the difficulty of assessing the transition from hexagonal $(\mathrm{Ti}, \mathrm{Mo})_{5} \mathrm{Si}_{3}$ to tetragonal $(\mathrm{Mo}, \mathrm{Ti})_{5} \mathrm{Si}_{3}$ which is still under debate in literature [89, 93, 105]. For instance, a Mo content of 26.4 at\% was reported to be dissolved in hexagonal (Ti,Mo)5Si3 in alloy Mo-40Ti-30Si [152]. Thermodynamic calculations in the pseudo-binary system $\mathrm{Ti}_{5} \mathrm{Si}_{3}-\mathrm{Mo}_{5} \mathrm{Si}_{3}$ predict a two-phase region of $(\mathrm{Ti}, \mathrm{Mo})_{5} \mathrm{Si}_{3}$ and $(\mathrm{Mo}, \mathrm{Ti})_{5} \mathrm{Si}_{3}$ at a maximum Mo content of $18 \mathrm{at} \%$ in $(\mathrm{Ti}, \mathrm{Mo})_{5} \mathrm{Si}_{3}$ at temperatures close to liquidus [93] (see App. 11). With decreasing temperature, the amount of Mo dissolved in (Ti,Mo) ${ }_{5} \mathrm{Si}_{3}$ is predicted to be decreasing [93]. At $1600{ }^{\circ} \mathrm{C}$, an isothermal section of the Mo-Si-Ti system, presented by Yang et al. in Ref. [105], reveals the maximum Mo content in (Ti,Mo) ${ }_{5} \mathrm{Si}_{3}$ to be 12.5 at\%, while the maximum $\mathrm{Ti}$ content in $(\mathrm{Mo}, \mathrm{Ti})_{5} \mathrm{Si}_{3}$ is reported to be 40 at\%. In comparison, the thermodynamic calculations for equilibrium reveal Mo contents of 14 to 9 at\% in $(\mathrm{Ti}, \mathrm{Mo})_{5} \mathrm{Si}_{3}$ in the intermediate alloys $\mathrm{A} 1$ and $\mathrm{B} 1$ with decreasing temperature from liquidus to solidus temperature, in contrast to 13 to 7 at\% 
Mo in hexagonal (Ti,Mo) ${ }_{5} \mathrm{Si}_{3}$ in the eutectic reference alloy. For tetragonal $\left(\mathrm{Mo}, \mathrm{Ti}_{5} \mathrm{Si}_{3}, \mathrm{Mo}\right.$ contents of 29 to 23 at\% (eutectoid alloy) and 24 to 18 at\% (alloy B1) are predicted with decreasing temperature from liquidus to solidus temperature.

\subsection{The Microstructural Stability at Elevated Temperatures}

Fine-scaled microstructures are attained in the intermediate alloy series A to D due to the eutectic and eutectoid phase reactions as revealed by the assessment of the phase boundary fraction $P$ in Fig. 5-9. The influence of different heat treatments on the ac microstructure is studied (ac: grey squares; $h t: 1300{ }^{\circ} \mathrm{C}, 200 \mathrm{~h}$ : black triangles; $h t^{*}: 1600{ }^{\circ} \mathrm{C}, 150 \mathrm{~h}$ : blue circles). In the Ti-rich alloys, like the eutectic reference alloy and the alloy series $\mathrm{A}$ and $\mathrm{C}$, where the eutectoid reaction has already been completed during AcM, an additional heat treatment at $1300{ }^{\circ} \mathrm{C}$ for $200 \mathrm{~h}(h t)$ does neither have a significant impact on the microstructural length scale, nor on the volume fraction of the microstructural constituents (not shown here). In contrast, in the Ti-medium and -lean alloys (alloy AB, alloy series $\mathrm{B}$ and the eutectoid reference alloy), which still comprise residual ( $\mathrm{Mo}, \mathrm{Ti})_{3} \mathrm{Si}$ after AcM, a subsequent, appropriate heat treatment at $1300{ }^{\circ} \mathrm{C}$ for $200 \mathrm{~h}$ triggers the completion of the eutectoid decomposition leading to more fine-scaled microstructures with increased phase boundary fractions $\left(>0.5 \mu \mathrm{m}^{-1}\right)$ compared to the Ti-rich alloys. Besides the completion of the eutectoid decomposition of the residual (Mo,Ti) ${ }_{3} \mathrm{Si}$, coarsening of the former solidified eutectic and already formed eutectoid regions is observed.

In order to evaluate the high-temperature microstructural stability of the investigated alloys, an additional heat treatment was applied at $1600{ }^{\circ} \mathrm{C}$ for $150 \mathrm{~h}\left(h t^{*}\right)$. Thereby, the ratio of Moss and the silicide phases remains unaltered in all investigated alloys. However, the Ti-rich eutectic-eutectoid alloys $\mathrm{A} 1$ and $\mathrm{C} 1$ are not in thermodynamic equilibrium in $a c$ condition and, thus, undergo further phase reactions at $1600{ }^{\circ} \mathrm{C}$ as confirmed by XRD measurements (see App. 12). After $h t^{*}$ only Moss and (Ti,Mo) ${ }_{5} \mathrm{Si}_{3}$ were detected, but no $(\mathrm{Mo}, \mathrm{Ti})_{5} \mathrm{Si}_{3}$. This is in agreement with the thermodynamic calculations at $1600{ }^{\circ} \mathrm{C}$ for equilibrium conditions (see App. 13a), only predicting the presence of Moss and (Ti,Mo) ${ }_{5} \mathrm{Si}_{3}$ for alloys with more than 40 at\% nominal Ti content. Thus, the additional heat treatment at $1600^{\circ} \mathrm{C}$ is the driving force for phase transformations to take place in alloys $\mathrm{A} 1$ and $\mathrm{C} 1$ until a complete two-phase Moss $+(\mathrm{Ti}, \mathrm{Mo})_{5} \mathrm{Si}_{3}$ microstructure is achieved. However, the eutectic reference alloy (already consisting of Moss and (Ti,Mo) ${ }_{5} \mathrm{Si}_{3}$ ) and the Ti-lean eutectic-eutectoid alloys, as well as the eutectoid reference alloy (Ti content $<40$ at\%), reveal 
stable phase equilibria and, thus, no phase reactions take place at $1600{ }^{\circ} \mathrm{C}$ (see XRD pattern of alloy B1 in App. 14a). For comparison, the alloys of series D comprise the same microstructural constituents after $h t^{*}$ as in ac condition with comparable phase ratios, as XRD measurements confirm the expected presence of Moss, (Ti,Mo) ${ }_{5} \mathrm{Si}_{3}$ and (Mo,Ti) ${ }_{5} \mathrm{Si}_{3}$ (see App. 15b) and thermodynamic calculations predict the respective volume fractions (see App. 13b). Thus, there is no change in volume fraction of the microstructural constituents observed in both reference alloys, alloy series B and D after $h t^{*}$. Therefore, these alloys undergo considerable coarsening while $h t^{*}$. In contrast, in the Ti-rich, intermediate Mo-Si-Ti alloys (series A and C) microstructural coarsening occurs only after phase equilibrium is established at $1600{ }^{\circ} \mathrm{C}$. Conclusively, considerable coarsening of the microstructures is observed for all alloys (see App. 15 for BSE micrographs and Fig. 5-9 blue circles). Accordingly, high-temperature microstructural stability is achieved in the Ti-rich eutecticeutectoid alloys up to $1300{ }^{\circ} \mathrm{C}$ as well as in the reference alloys and Ti-lean alloys even up to $1600^{\circ} \mathrm{C}$. Nonetheless, the comparison with representative Mo-Si-based alloys reveals that the Mo-Si-Ti alloys are similarly or even more fine-scaled than (heat-treated) AcM Mo-Si-B-Ti alloys and the typical PM as-sintered (as) Mo-Si-B alloy Mo-9Si-8B.

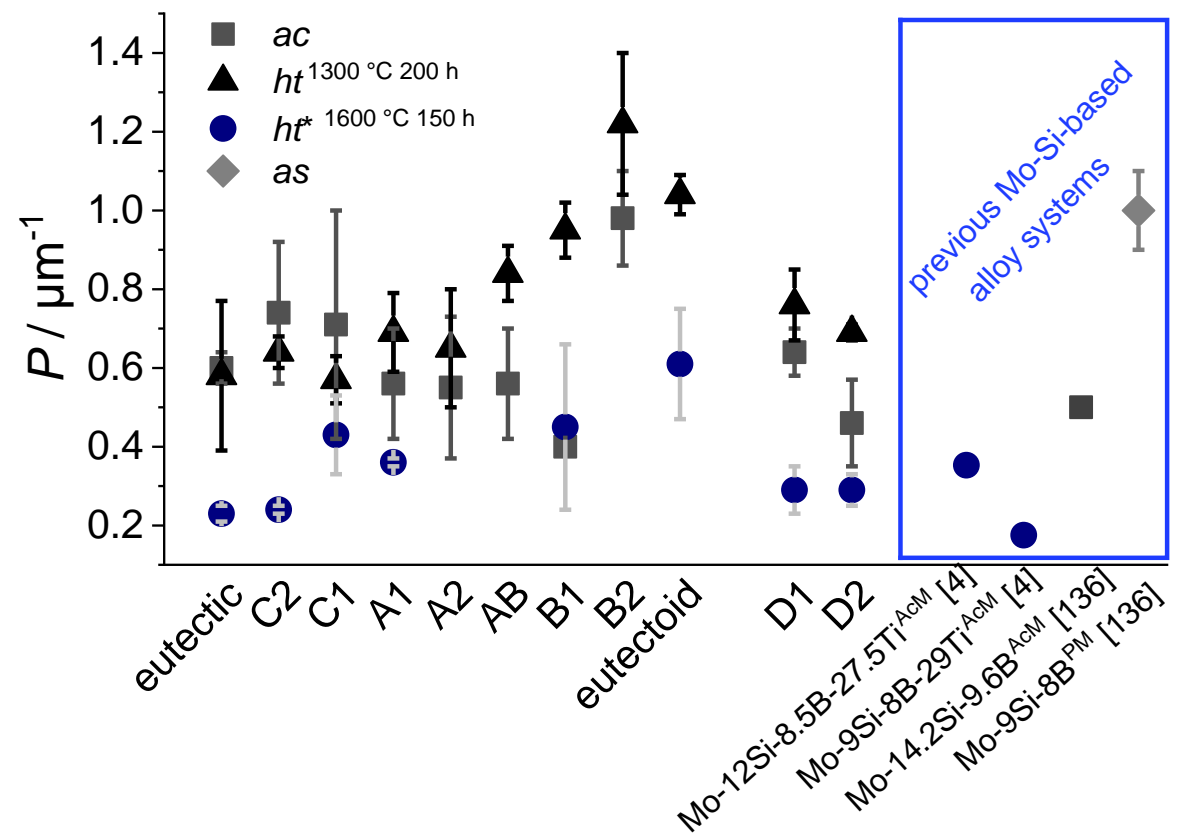

Fig. 5-9 Interface boundary fraction $P$ of the investigated alloys in the $a c$ state and after specific heat treatments including the eutectic and eutectoid reference alloys (data for $a c$ and selected $h t$ variants according to Refs. [215, 224] and of the eutectic reference alloy in $a c$ and $h t^{*}$ condition according to Ref. [215]) and other typical Mo-Si-based alloy systems (data taken from Refs. [4, 136]). Note that the applied $h t^{*}$ was performed subsequent to $h t$ on the Ti-lean alloys B1 and the eutectoid alloy. 
Conclusively, the initially expressed scientific issues (see Chap. 4) on the microstructural characterisation and evaluation of the developed Mo-Si-Ti alloys have been addressed in detail in this chapter. The following conclusions can be drawn: (i) Intermediate eutecticeutectoid Mo-Si-Ti alloys exist in the metal-rich section of the ternary Mo-Si-Ti system and can be cast manufactured. (ii) The volume fractions of the microstructural constituents can be specifically tailored and (iii) reasonably well-predicted by thermodynamic calculations. (iv) The resulting microstructures are fine-scaled because of the eutectic and eutectoid phase reactions. 


\section{Oxidation Behaviour}

This chapter includes published research by Obert et al. [215, 216, 224, 225] on the oxidation behaviour of the here presented Mo-Si-Ti alloys. Respective data, figures and argumentations are referenced or cited when being based on or extracted from them, respectively.

All aforementioned alloy series A to D, including the eutectic and eutectoid reference alloys, were subjected to cyclic oxidation testing at 800,1100 and $1200{ }^{\circ} \mathrm{C}$. Thereby, $800{ }^{\circ} \mathrm{C}$ represents a critical temperature in the pesting regime. $1100{ }^{\circ} \mathrm{C}$ allows for direct comparison to commercially applied Ni-based superalloys, which are typically operated at this temperature (surface temperature). $1200{ }^{\circ} \mathrm{C}$ is selected as potential higher operating temperature. As there are no differences observed in oxidation behaviour at 1100 and $1200{ }^{\circ} \mathrm{C}$, the results for $1100{ }^{\circ} \mathrm{C}$ are only shortly presented and provided in full detail in the appendix. Firstly, the intermediate eutectic-eutectoid alloy series A and B will be evaluated (Sec. 6.1) (data according to Ref. [224]). The oxidation behaviour of the alloy series C (data for $800{ }^{\circ} \mathrm{C}$ according to Ref. [215]) and the high (Mo,Ti) $)_{5} \mathrm{Si}_{3}$-containing alloys of series $\mathrm{D}$ will be assessed separately in Sec. 6.2 (data according to Ref. [225]). The requirements for suppression of pesting are investigated in Sec. 6.3. Finally, analyses of the formed oxide scales and their scale growth kinetics are presented in Sec. 6.4.

\subsection{The Intermediate Eutectic-Eutectoid Alloy Series A and B}

\subsubsection{Mass Changes and Oxide Scale Morphology at 800,1100 and $1200^{\circ} \mathrm{C}$}

The specific weight changes of the alloy series A and B and of both reference alloys during cyclic exposure to laboratory air at 800,1100 and $1200{ }^{\circ} \mathrm{C}$ are displayed in Fig. 6-1. At least three samples were tested for each condition, but only one representative sample is shown for simplicity (see App. 16 for results of all samples). The following conclusions are drawn from these oxidation experiments: (i) The oxidation behaviour of both reference alloys, the eutectic and the eutectoid [224], is in good agreement with the results previously reported by Schliephake et al. [5]. Thus, the findings are statistically verified. The eutectic alloy is characterised by low specific mass changes in the entire temperature regime of $(0.1 \pm 0.1) \mathrm{mg} / \mathrm{cm}^{2}$ at $800^{\circ} \mathrm{C},(1.8 \pm 0.1) \mathrm{mg} / \mathrm{cm}^{2}$ at $1100{ }^{\circ} \mathrm{C}$ and $(3.1 \pm 0.1) \mathrm{mg} / \mathrm{cm}^{2}$ at $1200^{\circ} \mathrm{C}$ after $100 \mathrm{~h}$ [224]. In contrast, the eutectoid alloy shows typical catastrophic oxidation behaviour at $800{ }^{\circ} \mathrm{C}$ with significant mass loss of more than $-150 \mathrm{mg} / \mathrm{cm}^{2}$ after 
$20 \mathrm{~h}$. At higher temperatures, the mass change is slightly increased compared to the eutectic alloy with considerable scatter between the samples (see App. 16b and c) leading to an average mass change of $(-17.6 \pm 7.2)$ and $(-14.8 \pm 15.0) \mathrm{mg} / \mathrm{cm}^{2}$ [224] at 1100 and $1200{ }^{\circ} \mathrm{C}$, respectively. (ii) The oxidation behaviour of the intermediate alloy series A and B clearly differs from each other, but can be related to the oxidation behaviour observed for the eutectic and eutectoid reference alloys [215]. The alloy series B, as well as the medium-Ti alloy $\mathrm{AB}$, suffer from pesting at $800{ }^{\circ} \mathrm{C}$ like the eutectoid alloy and most other Mo-Si-based alloys [47, 227]. However, the severity of pesting is reduced with increasing nominal Ti content of the investigated alloys as shown by the reduction in mass losses. These saturate after 15 to $20 \mathrm{~h}$ at $(-60.0 \pm 1.7) \mathrm{mg} / \mathrm{cm}^{2}$ (alloy $\mathrm{AB}$ ) [215], $(-120.1 \pm$ $22.0) \mathrm{mg} / \mathrm{cm}^{2}$ (alloy B1) [215] and (-148.0 \pm 85.7$) \mathrm{mg} / \mathrm{cm}^{2}$ (alloy B2), which are lower than $(-167.2 \pm 12.3) \mathrm{mg} / \mathrm{cm}^{2}$ of the eutectoid reference alloy [215] but still too high. In contrast, alloy series A exhibits acceptable mass changes in the range of $(-2.0 \pm 1.9) \mathrm{mg} / \mathrm{cm}^{2}$ (alloy A1) [224] to $(-6.1 \pm 6.5) \mathrm{mg} / \mathrm{cm}^{2}$ (alloy A2), which is in the order of the first pesting-resistant eutectic reference alloy [5]. At 1100 and $1200^{\circ} \mathrm{C}$, both alloy series show similar oxidation behaviour to the eutectic and eutectoid reference alloys with reasonable mass changes of $(2.7 \pm 1.9) \mathrm{mg} / \mathrm{cm}^{2}$ (alloy A1) [224], $(-1.1 \pm 5.8) \mathrm{mg} / \mathrm{cm}^{2}$ (alloy A2), $(1.0 \pm 1.7) \mathrm{mg} / \mathrm{cm}^{2}$ (alloy $\mathrm{AB}),(-13.2 \pm 19.5) \mathrm{mg} / \mathrm{cm}^{2}$ (alloy B1) [224] and (-10.6 \pm 5.9$) \mathrm{mg} / \mathrm{cm}^{2}$ (alloy B2) after $100 \mathrm{~h}$ at $1200^{\circ} \mathrm{C}$. However, there is some scatter in mass change observed, which is likely to be caused by local microstructural inhomogeneity in the $a c$ and $h t$ condition.

When comparing the oxidation behaviour of the eutectic-eutectoid Mo-Si-Ti alloys to the one observed for an un-coated single-crystalline Ni-based superalloy (here standard CMSX-47, half-opened green circles in Fig. 6-1a and b) at 800 and $1100{ }^{\circ} \mathrm{C}$, it is revealed that: (i) CMSX-4 is very oxidation-resistant at $800{ }^{\circ} \mathrm{C}$ without showing any considerable mass change after $100 \mathrm{~h}$ [229], which is comparable to the behaviour observed for the eutectic reference alloy. (ii) At $1100^{\circ} \mathrm{C}, \mathrm{CMSX}-4$ exhibits negligible mass changes of less than $0.1 \mathrm{mg} / \mathrm{cm}^{2}$ in total $[228,230]$, which is one order of magnitude lower than the typical absolute amount of mass change of $\approx \pm 2 \mathrm{mg} / \mathrm{cm}^{2}$ observed for the pesting-resistant Mo-Si$\mathrm{Ti}$ alloys (eutectic reference alloy and alloys A). The outstanding oxidation resistance of CMSX-4 is attributed to the formation of a continuous $\mathrm{Al}_{2} \mathrm{O}_{3}$ scale [228].

\footnotetext{
${ }^{7}$ common alloy composition according to Ref. [228]
} 

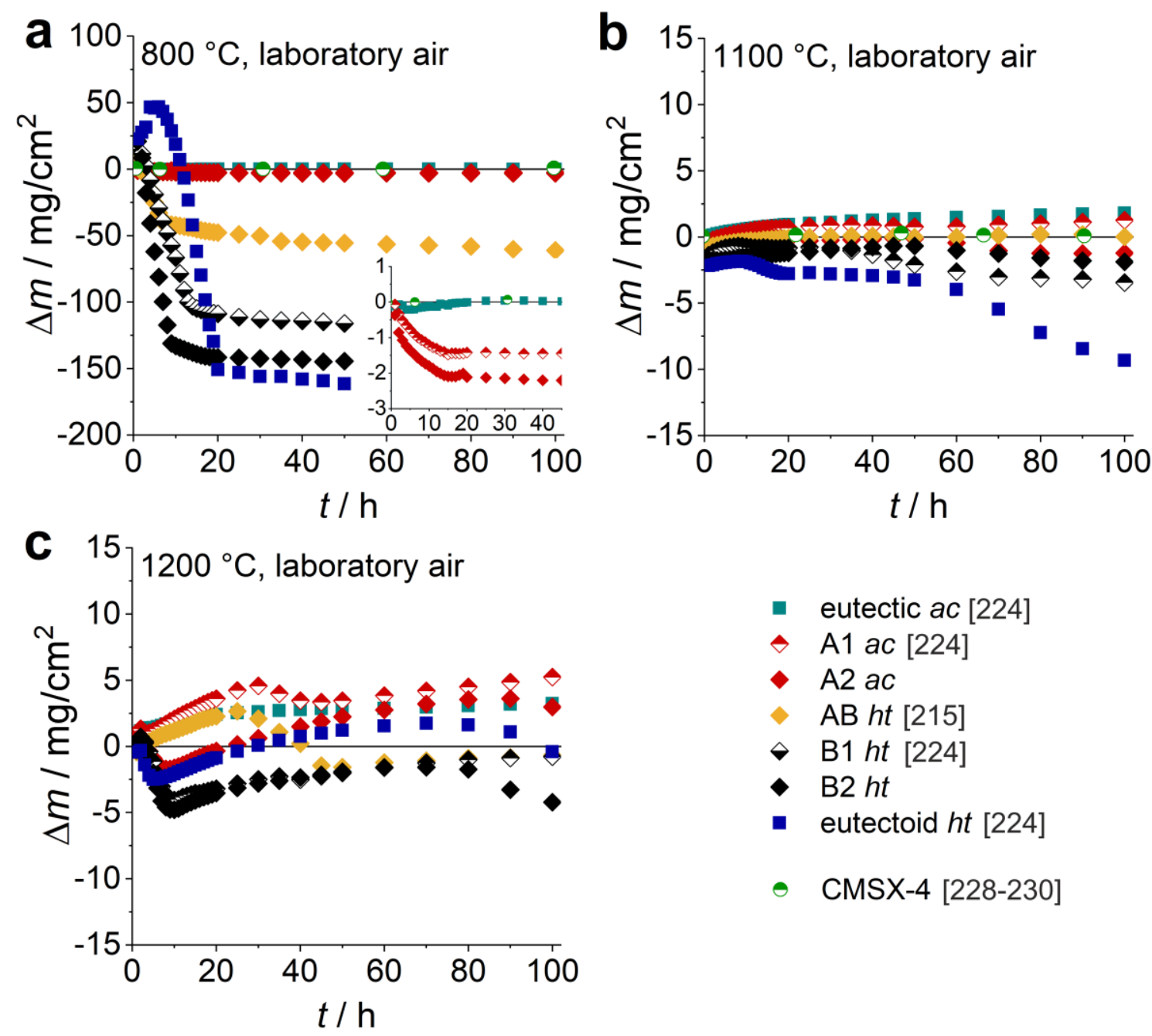

Fig. 6-1 Specific weight change $\Delta m$ as a function of oxidation time $t$ during cyclic oxidation of the alloy series A and B in comparison to the eutectic and eutectoid reference alloys at $800{ }^{\circ} \mathrm{C}(\mathrm{a}), 1100$ (b) and $1200^{\circ} \mathrm{C}$ (c). Data on the reference alloys, alloys A1 and B1 according to Ref. [224], data on alloy AB at $800{ }^{\circ} \mathrm{C}$ according to Ref. [215]. Data of CMSX-4 are included for comparison at 800 [229] (isothermal test conditions) and $1100{ }^{\circ} \mathrm{C}[228,230]$.

Cross sections of oxidised samples of alloy series A and B were analysed by SEM in order to investigate the oxide scale morphology. For comparison the eutectic and eutectoid reference alloys were investigated as well. At $800^{\circ} \mathrm{C}$, the eutectic alloy is characterised by a $(5 \pm 1) \mu \mathrm{m}$ [224] thick, mixed $\mathrm{SiO}_{2}-\mathrm{TiO}_{2}$ oxide scale without any indications for internal oxidation, while the eutectoid alloy exhibits catastrophic oxidation according to the pesting phenomenon [224] (see App. 17). These results are in good agreement with Ref. [5]. In contrast, an outer $\mathrm{TiO}_{2}$-rich oxide scale is formed on alloy $\mathrm{A} 1$ during the initial oxidation, 
which is characterised by locally poor adherence and cracks along the oxide/substrate interface (see Fig. 6-2a). Significant selective internal oxidation is observed, which occurs preferentially in Moss in eutectoid regions located close to the substrate surface. This reveals the strikingly different oxidation behaviour of the eutectic and eutectoid microstructures in the pesting regime [224]. When located at the substrate surface, the high Ti content within Moss leads to quick coverage of the surface with $\mathrm{TiO}_{2}$ while enabling further O inward diffusion [224]. The subjacent Moss regions mainly oxidise to Ti-oxides with some embedded Si-oxide islands, while the $\mathrm{M}_{5} \mathrm{Si}_{3}$ silicide networks remain intact without significant oxidation [224]. However, some enclosed porosity of less than $3 \mathrm{vol} \%$ is present in the internal oxidation zone, indicating that formed volatile $\mathrm{MoO}_{3}$ is entrapped [224]. Thus, the oxidation behaviour of Moss is remarkable, as it does not undergo complete volatilisation as would be caused by sole $\mathrm{MoO}_{3}$ formation [133, 136, 231]. Nevertheless, as the specific mass losses stabilise after $20 \mathrm{~h}$, the evaporation of $\mathrm{MoO}_{3}$ is presumably balanced by the formation of solid $\mathrm{TiO}_{2}$, which is facilitated by the quick outward diffusion of Ti cations [224].

After $100 \mathrm{~h}$, the morphology of the oxide scale is comparable to the initial appearance, except the internal oxidation is more equal when comparing the eutectic and eutectoid regions (see Fig. 6-2b). The top $\mathrm{TiO}_{2}$ oxide scale grew to a thickness of $(4 \pm 2) \mu \mathrm{m}$, while the internal oxidation zone is with $(23 \pm 10) \mu \mathrm{m}$ significant in depth. Generally, the same observations apply to the oxide scale morphology of alloy A2 (see App. 18a), except the increased average depth of internal oxidation with a considerable scatter of (46 \pm 25$) \mu \mathrm{m}$. This is most likely caused by the local microstructural inhomogeneity being increased in alloy A2 by the (by a factor of 3) increased volume fraction of primarily solidified Moss, which oxidises faster than the $\mathrm{M}_{5} \mathrm{Si}_{3}$ silicides. This is in good agreement with the increased mass change in alloy A2, when compared to alloy A1, highlighting the detrimental effect of laterally expanded Moss regions. However, both alloys exhibit pesting resistance, which is mainly attributed to the high average, global Ti content in Moss of approximately 35 at\% (see Fig. 5-6) [224]. For comparison, the pesting-resistant eutectic alloy comprises 45 at\% $\mathrm{Ti}$ in Moss, while the eutectoid alloy, suffering from pesting, only contains 17 at\% $\mathrm{Ti}$ in Moss [224]. Thus, it is demonstrated that the site-specific local Ti content in Moss lamellae in eutectic and eutectoid regions is of key importance, as these oxidise at different rates. By comparison, considering the STEM-EDX results on a representative intermediate eutectic-eutectoid alloy [215] (see Fig. 5-8, alloy B1 ac), there is no definite difference in Ti content dissolved in Moss lamellae in eutectic and eutectoid regions identified (see Sec. $5.3)$. 

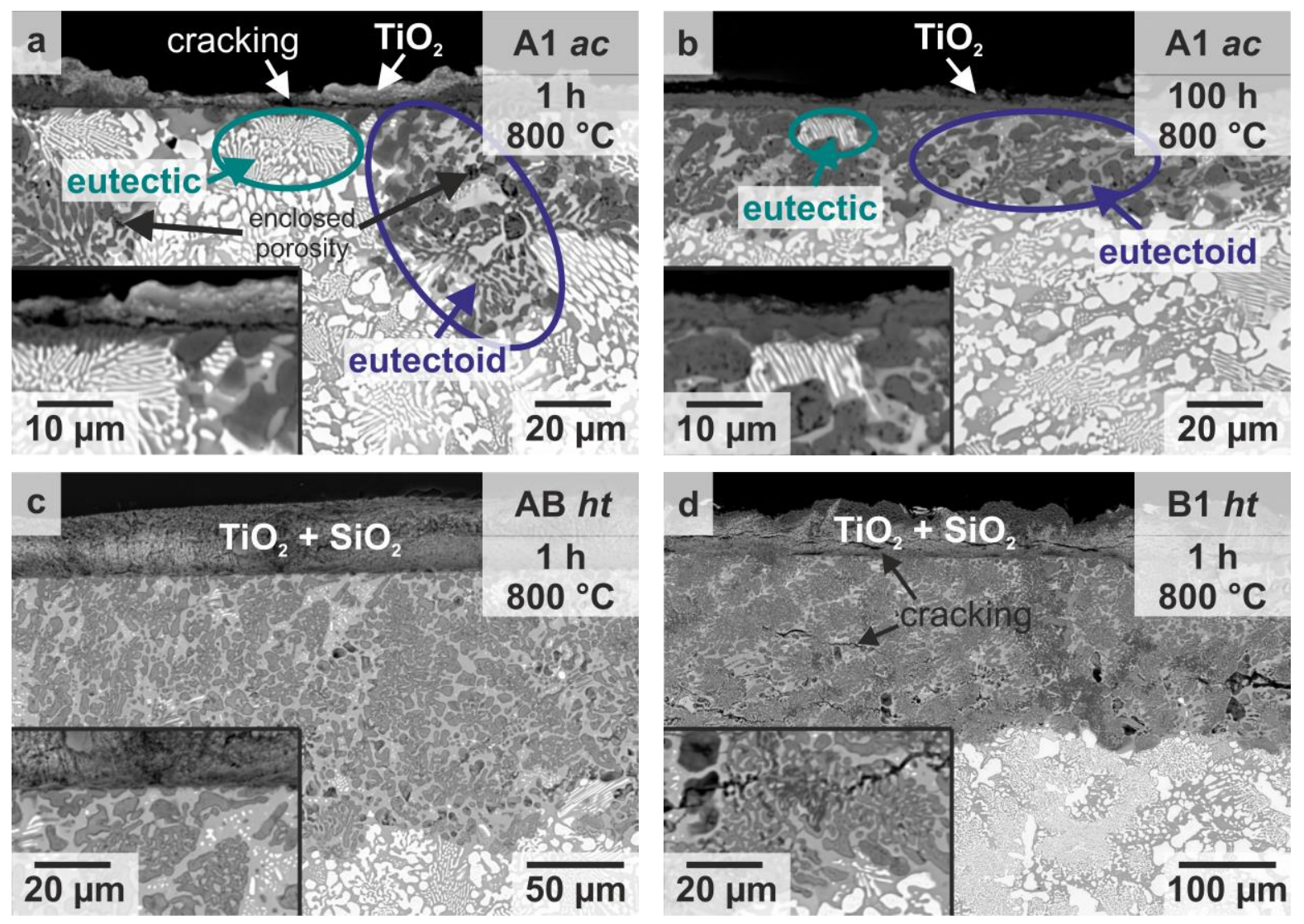

Fig. 6-2 Representative BSE micrographs of the investigated alloys after cyclic oxidation at $800^{\circ} \mathrm{C}$ in laboratory air for 1 and $100 \mathrm{~h}$, respectively: alloy $\mathrm{A} 1 \mathrm{ac}$ (a and b), alloy AB $h t$ (c) and alloy B1 $h t$ (d). (a, b, d) according to Ref. [224].

In contrast, the insufficient oxidation resistance of the Ti-medium and -lean alloy series $\mathrm{AB}$ and $\mathrm{B}$ is not only dominated by significant mass losses due to evaporation of $\mathrm{MoO}_{3}$, but also by thick porous, oxide scale formation as revealed by microstructural analyses (see Fig. 6-2c and d). The intense oxidation, even after the first hour of exposure to air, presumably results in significant changes in volume. Thus, cracking occurs in both, the external Si-/Ti-oxide scales and the internal oxidation zone due to thermal cycling.

A decrease in severity of the pesting behaviour is observed with increasing nominal Ti content as highlighted by the reduction in depth of the internal oxidation from (166 \pm 43) $\mu \mathrm{m}$ in the Ti-lean alloy B1 to $(146 \pm 12) \mu \mathrm{m}$ in the medium-Ti alloy AB after $1 \mathrm{~h}$ at $800^{\circ} \mathrm{C}$. This is also accompanied by less local spallation. The latter is especially highlighted when comparing the results to the eutectoid reference alloy, which significantly suffers from spallation and already partial material disintegration after $1 \mathrm{~h}$ of oxidation at $800^{\circ} \mathrm{C}$ (see App. 17c). After $100 \mathrm{~h}$ of oxidation, the eutectoid reference alloy is completely disintegrated [224] (see App. 17d), while the samples of alloy AB and alloy series $B$ remain intact, but with significant cracking of the oxide scales (crack length in the order 
of several millimetres) resulting in local decohesion (see App. 18b and c). Additionally, there is no difference in oxidation behaviour observed in the eutectic and eutectoid regions in these alloys. On the one hand, the impact of additionally primarily solidified Moss is observed in alloy B2 as the overall mass loss is increased by about $25 \%$ compared to alloy B1 after $100 \mathrm{~h}$. But on the other hand, this impact is regarded to be minor because of the generally insufficient oxidation behaviour and the similar, severe cracking of the oxide scales (see App. 18d). Conclusively, alloy AB and the alloy series B were neither found to be oxidation-resistant themselves, nor that the volume fraction of the eutectic regions prevents pesting at $800^{\circ} \mathrm{C}[215,224]$.

This is attributed to the remarkably low global Ti content in Moss in the eutectic and eutectoid regions (being 30 and 25 at\% in $\mathrm{AB}$ and $\mathrm{B}$, respectively, as compared to 35 at\% in the pesting-resistant alloy series A) retarding or inhibiting solid Ti-oxide formation due to the reduced Ti activity, which might have compensated the volatilisation of $\mathrm{MoO}_{3}$. Thus, the existence of a Ti threshold of 35 at\% in Moss (or 43 at\% nominal Ti content) is postulated to determine whether pesting can be prevented or not [215, 224]. Additionally, note that the volume fraction and distribution of the binary eutectic regions might be anticipated to be decisive for the suppression of pesting, as these are almost present as connected networks in the alloy series A [224]. This morphology might facilitate quick oxide scale formation leading to coverage of the substrate surface and bridging of less oxidationresistant eutectoid regions. However, the volume fraction of eutectic was found to be comparable for the pesting-resistant alloy A1 with $(50 \pm 6)$ vol\% and the non-oxidation-resistant alloys $\mathrm{AB}$ and $\mathrm{B} 1$ with (45 \pm 6$)$ and (45 \pm 3 ) vol\%, respectively (see Fig. 5-3) [215].

In order to investigate the impact of the cyclic test conditions on the pesting behaviour, additional isothermal oxidation tests were performed at $800{ }^{\circ} \mathrm{C}$ for alloys A1 and B1. Even though no difference in mass change was observed after $100 \mathrm{~h}$ of oxidation, less cracks were present within the oxide scales. This resulted in less deep internal oxidation of alloy A1 (see App. 19), but still catastrophic oxidation of alloy B1. This leads to the assumption that pesting of alloy B1 is not only caused by cracking due to thermal cycling, but probably mainly due to the volume change during oxidation and the resulting internal stresses, which lead to internal cracking and non-hindered $\mathrm{O}$ ingress.

At elevated temperatures of 1100 and $1200{ }^{\circ} \mathrm{C}$, the oxide scales formed on both intermediate alloy series $\mathrm{A}$ and $\mathrm{B}$ are characterised by continuous, mixed $\mathrm{SiO}_{2}-\mathrm{TiO}_{2}$ oxide scales without any indications of a difference in oxidation behaviour of eutectic and eutectoid regions. Fig. $6-3$ depicts the cross sections after 1 and $100 \mathrm{~h}$ of cyclic oxidation at $1200^{\circ} \mathrm{C}$ 
(see App. 20 oxide scales formed after $100 \mathrm{~h}$ at $1100^{\circ} \mathrm{C}$ ). While the oxide scales formed after the first hour of oxidation reveal an intermixed morphology of $\mathrm{SiO}_{2}$ and $\mathrm{TiO}_{2}$ with $\mathrm{TiO}_{2}$-enriched surface-near regions in alloys A1 and B1 (see Fig. 6-3a and c), a clear separation in a top $\mathrm{TiO}_{2}$ oxide scale and an underlying $\mathrm{SiO}_{2}-\mathrm{TiO}_{2}$ duplex scale has occurred after $100 \mathrm{~h}$ (see Fig. 6-3b and d) [224]. The same observations apply to the eutectic and eutectoid reference alloys, which are in good agreement with Ref. [5], and to the alloy variants A2 and B2 with increased volume fractions of primarily solidified Moss, as well as to the Ti-medium alloy $\mathrm{AB}$ (see App. 22). The total oxide scale thickness significantly increases from $(7 \pm 2)$ and $(13 \pm 5) \mu \mathrm{m}$ after $1 \mathrm{~h}$ to $(70 \pm 10)$ and $(75 \pm 25) \mu \mathrm{m}$ after $100 \mathrm{~h}$ of cyclic oxidation at $1200^{\circ} \mathrm{C}$ in alloys $\mathrm{A} 1$ and B1, respectively [224].
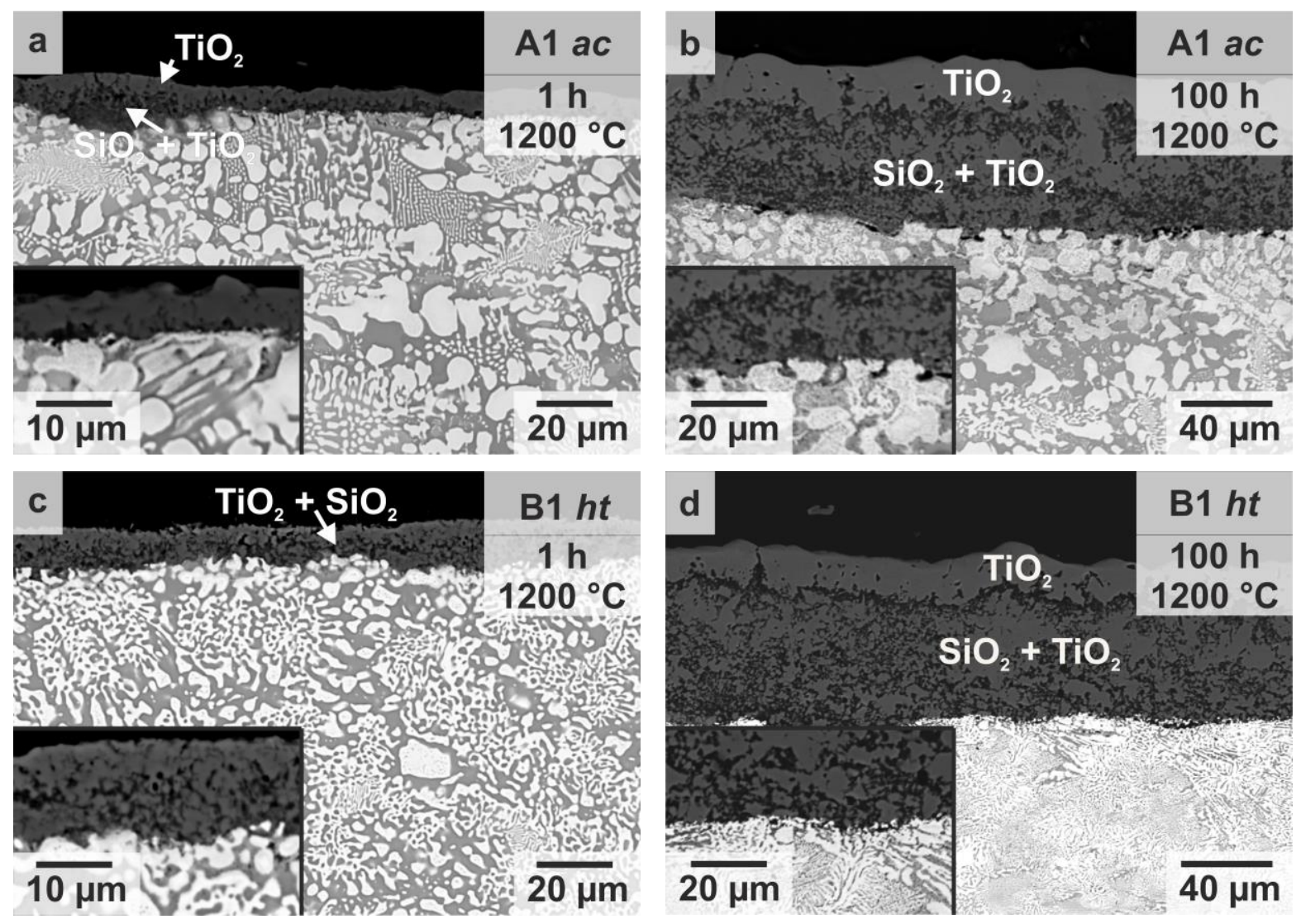

Fig. 6-3 Cross sectional BSE micrographs of alloy A1 $a c$ after 1 (a) and $100 \mathrm{~h}$ (b) and of alloy $\mathrm{B} 1 \mathrm{ht}$ after 1 (c) and $100 \mathrm{~h}(\mathrm{~d})$ of cyclic oxidation at $1200{ }^{\circ} \mathrm{C}$ in laboratory air. (b, d) according to Ref. [224].

The oxide scale evolution is evaluated at $1200^{\circ} \mathrm{C}$ by (i) addressing the oxide scale thickness after $100 \mathrm{~h}$ (the oxide scale growth kinetics are discussed in Sec. 6.4) and (ii) the respective volume fraction of $\mathrm{SiO}_{2}$ within the $\mathrm{SiO}_{2}-\mathrm{TiO}_{2}$ duplex scale in Fig. 6-4 (see App. 21 for results at $1100^{\circ} \mathrm{C}$ ). The following conclusions are made: (i) The oxide scale thickness 
in total tends to increase with decreasing nominal Ti content of the alloys. This is highlighted by the eutectic reference alloy, which possesses a thin oxide scale of $(60 \pm 13) \mu \mathrm{m}$ (52.8 at\% Ti nominal), in comparison to that of the eutectoid reference alloy with $(79 \pm$ 11) $\mu \mathrm{m}$ in thickness (34 at\% Ti nominal). The intermediate alloys A1 and B1 range in between further pronouncing this trend. (ii) The degree of internal oxidation shows the same tendency of increasing depth with decreasing nominal Ti content, namely from $(9 \pm 3) \mu \mathrm{m}$ in the eutectic reference alloy to $(56 \pm 15) \mu \mathrm{m}$ in the eutectoid reference alloy over $(34 \pm$ 10) and (53 \pm 11$) \mu \mathrm{m}$ in alloys $\mathrm{A} 1$ and B1, respectively. (iii) The increase in volume fraction of primarily solidified Moss (alloys A2 and B2) leads to rather thick oxide scales and internal oxidation zones compared to the generally observed trend from Ti-rich to Ti-lean alloys. This confirms the detrimental effect of Moss even at high temperatures, at which the evaporation of Moss is assumed to be outbalanced by the formation of solid oxide scales. (iv) There is no correlation between either a less nominal Ti content in the alloy substrate, or a reduction of internal oxidation depth with an increase in volume fraction of $\mathrm{SiO}_{2}$ in the $\mathrm{SiO}_{2}-\mathrm{TiO}_{2}$ duplex scale. The volume fraction of $\mathrm{SiO}_{2}$ is rather found to vary inconsistently with the nominal Ti content of the alloys. It is maximum in the eutectic and eutectoid reference alloy with $(52 \pm 6)$ and $(47 \pm 7)$ vol\%, respectively, compared to minimum $(39 \pm$ 3) vol\% in alloy B2.

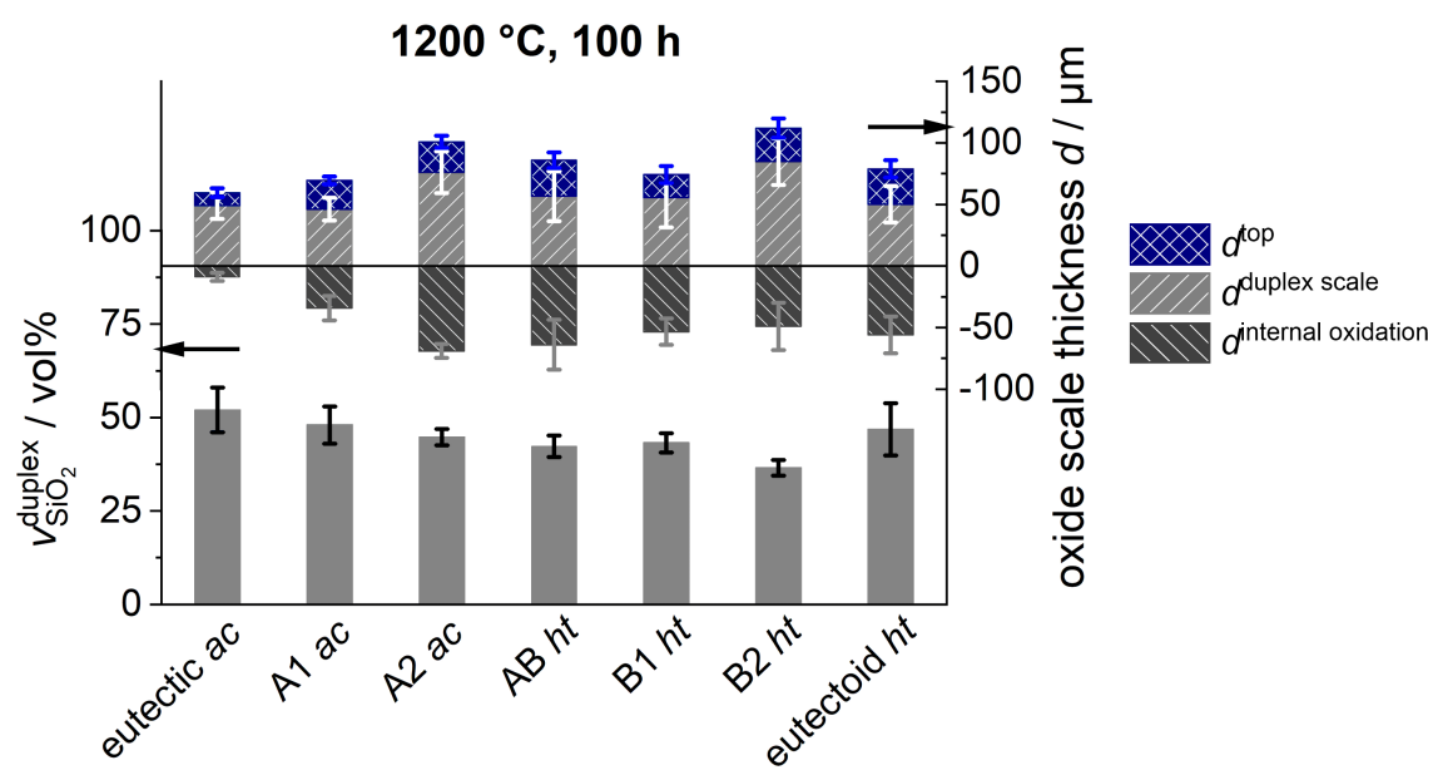

Fig. 6-4 Thickness of the sub-oxide scales (upper bar chart) compared to the volume fraction of $\mathrm{SiO}_{2}$ in the $\mathrm{SiO}_{2}-\mathrm{TiO}_{2}$ duplex scale (lower bar chart) after $100 \mathrm{~h}$ at $1200{ }^{\circ} \mathrm{C}$. Data of alloys A1, B1 and reference alloys according to Ref. [224]. 
In order to draw conclusions on the matrix forming oxide within the duplex scale, further morphological characteristics have to be considered, besides the volume fraction of the respective oxides [224]. 2D pixel cluster analyses were performed for both reference alloys and alloys A1 and B1 (see Fig. 6-5) [224]. The pixel clusters corresponding to $\mathrm{SiO}_{2}$ are coloured in warm colours (red to yellow) and the ones belonging to $\mathrm{TiO}_{2}$ in cold colours (blue to green). Connected clusters are highlighted by one respective colour.
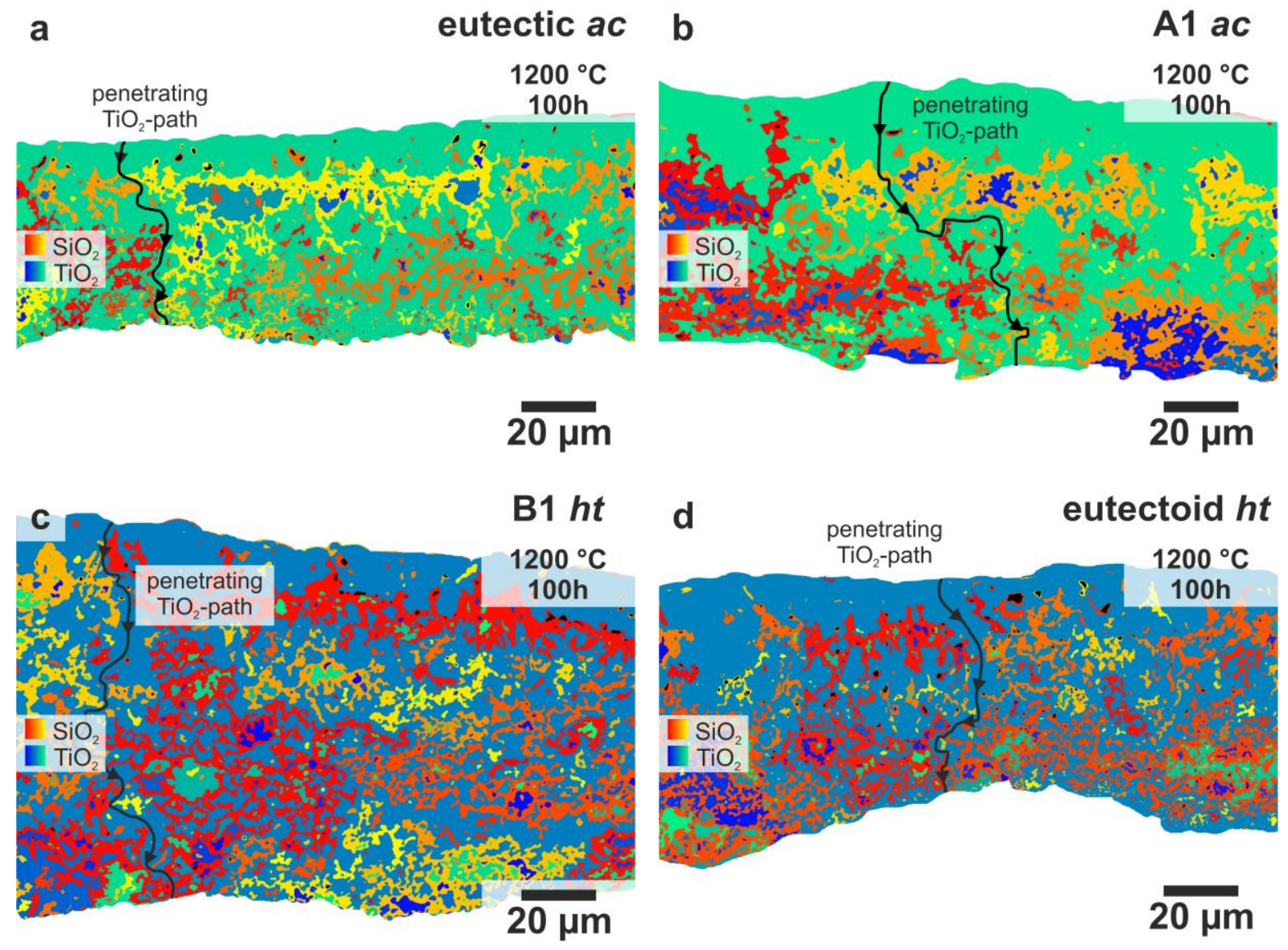

Fig. 6-5 Colour-coded images of the oxide scales formed on the eutectic alloy in $a c$ condition (a), alloy A1 ac (b, according to Ref. [224]), alloy B1 $h t$ (c) and the eutectoid reference alloy in $h t$ condition (d) after $100 \mathrm{~h}$ at $1200^{\circ} \mathrm{C} . \mathrm{SiO}_{2}$ is highlighted by warm colours (red to yellow) while $\mathrm{TiO}_{2}$ is highlighted by cold colours (blue to green). The connected pixels are coloured in the same colour. Exemplary penetrating $\mathrm{TiO}_{2}$ pathways are symbolised by black, arrowed lines.

It is found that $\mathrm{TiO}_{2}$ forms large clusters, which penetrate the $\mathrm{SiO}_{2}-\mathrm{TiO}_{2}$ duplex scale down to the substrate in all alloys. In contrast, the $\mathrm{SiO}_{2}$ clusters are of small lateral expansion, rather isolated distributed and are rarely in contact with the substrate surface. Thus, an interconnected 2D network structure of $\mathrm{TiO}_{2}$ is present in all investigated Mo-Si-Ti alloys, 
independent of both, their $\mathrm{Ti}$ content in the alloy substrate and the pesting resistance at $800{ }^{\circ} \mathrm{C}$. This leads to the assumption that $\mathrm{TiO}_{2}$ might be the matrix forming oxide within the duplex scale [224], which however, requires analyses in 3D to be proven. Conclusively, the importance of $\mathrm{SiO}_{2}$ as matrix forming oxide or as oxide with a high volume fraction in the scale seems to be less relevant for good oxidation resistance [224]. This is contrary to previous research on $\mathrm{Ti}_{5} \mathrm{Si}_{3 \pm \mathrm{x}}$ at $1000{ }^{\circ} \mathrm{C}$ [151], on $(\mathrm{Mo}, \mathrm{Ti})_{5} \mathrm{Si}_{3}$ in the temperature range of 750 to $1300{ }^{\circ} \mathrm{C}[70,147]$ and on Mo-Si-B-Ti-Fe alloys at $1100{ }^{\circ} \mathrm{C}$ [48], in which the importance of $\mathrm{SiO}_{2}$ as matrix forming oxide was pointed out. Hence, the $\mathrm{SiO}_{2}-\mathrm{TiO}_{2}$ duplex scale does not necessarily have to be composed of a $\mathrm{SiO}_{2}$ matrix at $1200{ }^{\circ} \mathrm{C}$ in Mo-Si-Ti alloys in order to enable reasonable oxidation resistance [224]. Furthermore, it is supposed that this trend might be transferred as a general result to 1100 and even $800{ }^{\circ} \mathrm{C}$.

\subsubsection{Contribution of Volatile and Solid Oxides to the Mass Change}

Unambiguously, a further understanding of the oxidation mechanisms of the investigated alloys is of main interest at the pesting-critical temperature of $800^{\circ} \mathrm{C}$. But the alloys either exhibit pesting-stability, being accompanied by the formation of very thin oxide scales, or catastrophic oxidation, being characterised by immense oxide scale growth, cracking and material disintegration. Hence, a quantitative evaluation of the similarities and differences among all alloy series is not possible at this temperature [224]. Therefore, the following analysis approach is applied to the results obtained at $1200{ }^{\circ} \mathrm{C}$ after 1,10 and $100 \mathrm{~h}$ of cyclic oxidation. The trend is regarded to hold true for $800{ }^{\circ} \mathrm{C}$ as well by assuming comparable nature of the present oxidation processes. Thereby, the quantification of the species Mo, Ti and Si oxidising to vaporous and solid oxides, respectively, is targeted for both reference alloys and alloy series A and B.

Generally, the experimentally determined specific weight change $\Delta m$ (normalised by the initial surface area $A$ of the respective sample) is defined by the following individual contributions: (i) mass gain $m_{O}^{\text {scale }}$ due to $\mathrm{O}$ incorporation during solid oxide scale growth. (ii) mass loss $m_{M o}^{\text {vapour }}$ caused by volatilisation of $\mathrm{Mo}$ as $\mathrm{MoO}_{3}$ (see Eq. 29 [224]).

$$
\begin{gathered}
\Delta m=m_{O}^{\text {scale }}+m_{M o}^{\text {vapour }} \\
\text { with } m_{O}^{\text {scale }} \geq 0 \text { and } m_{\text {Mo }}^{\text {vapour }} \leq 0
\end{gathered}
$$

Especially, as evaporating Mo possesses a significantly higher molar mass compared to O, which is incorporated while oxidising with $\mathrm{Si}$ and $\mathrm{Ti}$ to solid oxides, the molar masses of 
the oxidised amounts $n_{M o}^{\text {vapour }}, n_{S i}^{\text {scale }}$ and $n_{T i}^{\text {scale }}$ have to be considered (see App. 23 and Ref. [224] for detailed equations). As the mock-up of the formed oxide scales at $1200{ }^{\circ} \mathrm{C}$ is known in detail by the previously presented microstructural investigations (see Fig. 6-4), $m_{O}^{\text {scale }}$ can be determined by utilising the thickness $d$ of the sub-oxide scales $\left(d^{\text {top }}\right.$ : top $\mathrm{TiO}_{2}$ scale; $d^{\text {duplex }}: \mathrm{SiO}_{2}-\mathrm{TiO}_{2}$ duplex scale) and the volume fraction $v$ of the respective oxides $\left(v_{\mathrm{SiO}_{2}}^{\text {duplex }} ; v_{\mathrm{TiO}_{2}}^{\text {duplex }}\right)[224]$. Note that the microstructural data and the experimentally determined mass change of one and the same sample were used for calculating each mass loss. Based on the attained results, $m_{M o}^{\text {vapour }}$ can be calculated by rearranging Eq. 29 [224]. The following assumptions are included in this analysis: (i) Neglect of the internal oxidation, although its impact is not considered to be negligible (it will be addressed separately at the end of this section) [224]. (ii) Outward growth of the $\mathrm{TiO}_{2}$ top oxide scale and (iii) inward growth of the $\mathrm{SiO}_{2}-\mathrm{TiO}_{2}$ duplex scale, as has been confirmed for the three-phase MoSi-B-Ti alloy system in Ref. [47].

It is found that the evaporation of $m_{M o}^{\text {vapour }}$ is more dominant with decreasing nominal Ti content throughout the alloy series after $100 \mathrm{~h}$ at $1200^{\circ} \mathrm{C}$, as its absolute value is minimum in the eutectic alloy with $(-7 \pm 2) \mathrm{mg} / \mathrm{cm}^{2},(-10 \pm 2) \mathrm{mg} / \mathrm{cm}^{2}$ in alloy A1 and increases to $(-32 \pm 6)$ and $(-29 \pm 4) \mathrm{mg} / \mathrm{cm}^{2}$ in alloy B1 and the eutectoid reference alloy, respectively [224]. The corresponding results for the amounts and ratio of reacted, metallic species are displayed in Fig. 6-6 for 100 h of cyclic oxidation (see App. 24 for results after 1 and 10 h).

\section{$1200^{\circ} \mathrm{C}, 100 \mathrm{~h}$}

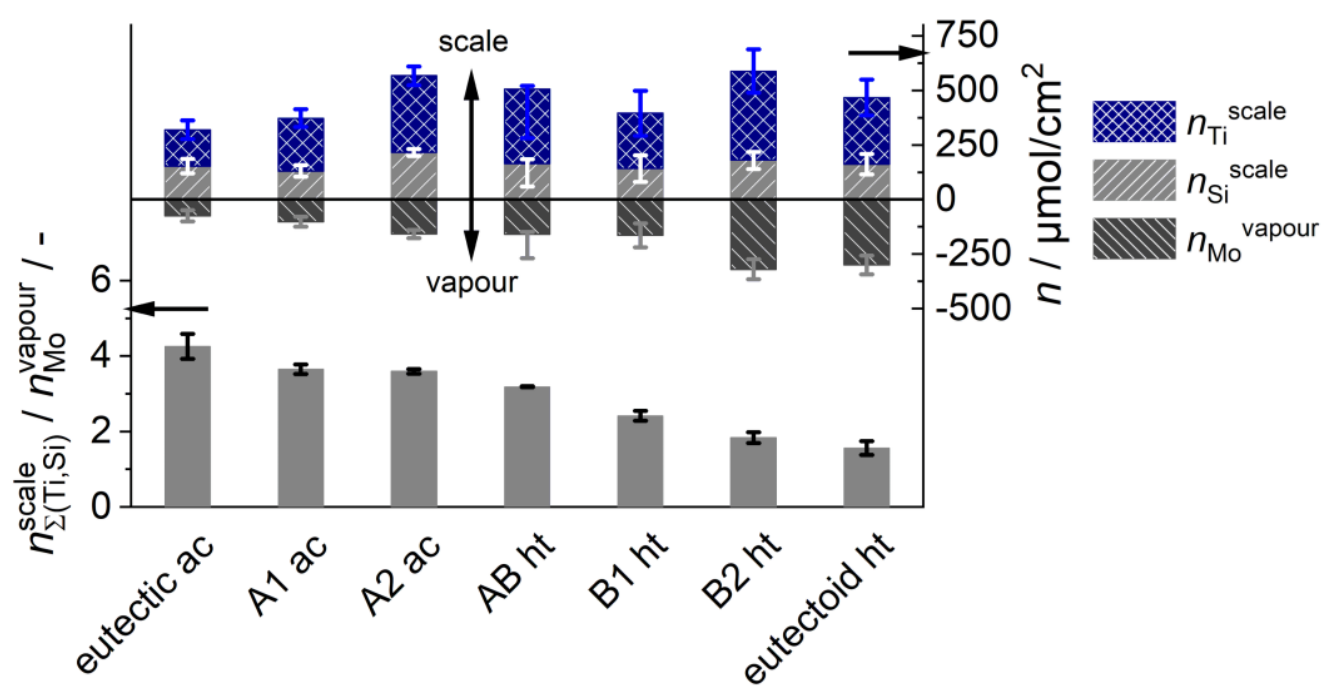

Fig. 6-6 Calculated quantity of the oxidised species $\mathrm{Ti}$ and $\mathrm{Si}$, forming solid oxides, and of oxidised Mo, evaporating as volatile $\mathrm{MoO}_{3}$, after $100 \mathrm{~h}$ at $1200{ }^{\circ} \mathrm{C}$ (upper bar chart) and the ratio of the respective species (lower bar chart). According to Ref. [224]. 
Note that the consideration of the standard deviation of the measured sub-oxide scale thicknesses allows a conservative estimate of the limits of this calculation approach as displayed by the error bars. It is revealed that the amount of oxidised Si is almost unaffected by the chemical composition of the alloy substrate as it varies in the range of 130 to $220 \mu \mathrm{mol} / \mathrm{cm}^{2}$ without any indications of a specific trend. In contrast, the average amount of reacted $\mathrm{Ti}$ increases consistently with decreasing nominal $\mathrm{Ti}$ content, namely from $(160 \pm 40) \mu \mathrm{mol} / \mathrm{cm}^{2}$ (eutectic alloy), through $(240 \pm 40) \mu \mathrm{mol} / \mathrm{cm}^{2}$ (alloy A1) to $(250 \pm 150) \mu \mathrm{mol} / \mathrm{cm}^{2}$ (alloy B1) and $(300 \pm 70) \mu \mathrm{mol} / \mathrm{cm}^{2}$ (eutectoid alloy) [224] ${ }^{8}$. In this regard the alloy variants A2 and B2 with increased volume fractions of primarily solidified Moss represent exceptions, as these reveal disproportionally high amounts of oxidised Ti $\left(>350 \mu \mathrm{mol} / \mathrm{cm}^{2}\right.$ ). In contrast, the absolute amount of evaporated Mo significantly increases with decreasing nominal Ti content [224]. Explicitly from $(-75 \pm 25) \mu \mathrm{mol} / \mathrm{cm}^{2}$ in the eutectic to $(-300 \pm 50) \mu \mathrm{mol} / \mathrm{cm}^{2}$ in the eutectoid alloy. The ratio of oxidised $\mathrm{Ti}$ and $\mathrm{Si}$ atoms to evaporated Mo atoms (see lower bar chart in Fig. 6-6) confirms that the evaporation of $\mathrm{Mo}$ in form of $\mathrm{MoO}_{3}$ gains dominance with decreasing nominal Ti content. Additionally, the ratio of oxidised species correlates well with the ratio of the nominal composition of the alloy substrate, which reduces from 2.7 (eutectic alloy), through 1.8 (alloy A1) and 1.5 (alloy B1) to 1.2 (eutectoid alloy) [224]. However, it is considerably lower than the ratio observed for the oxidation processes in the Ti-rich alloys (4.2 (eutectic alloy) to 3.6 (alloy A1)), indicating that the oxidation consumes more $\mathrm{Ti}$ and Si than provided by the alloy substrate in these alloys. Conclusively, it is suggested that the Mo volatilisation is more pronounced in Ti-lean alloys, probably caused by the less passivating character of the formed oxide scales.

This calculation approach is conservative, as the internal oxidation is neglected. If the impact of internal oxidation would have been considered, then the absolute value of $m_{M o}^{\text {vapour }}$ would be reduced leading to a further increase in the obtained ratios, as the experimentally observed mass change would be the same [224]. Hence, the argumentation would be further shifted towards an intense oxide scale formation.

Taking into account that the experimentally determined specific mass changes are a function of oxidation time (see Fig. 6-1c and App. 24), it is obvious that the Ti-rich alloys exhibit different oxidation characteristics when compared to the Ti-lean alloys. Especially, the eutectic reference alloy reveals a constant mass change after $50 \mathrm{~h}$ [224] and it seems as if the solid oxide scale growth is dominant. Contrary to these observations, the mass change

\footnotetext{
${ }^{8}$ but note the overlap in amount of reacted Ti among the alloys when considering the standard deviations
} 
of the eutectoid alloy is still varying after $100 \mathrm{~h}$ of oxidation [224], with a typical decline in mass change indicating ongoing evaporation of $\mathrm{MoO}_{3}$. In conclusion, the oxide scales formed on the eutectic alloy and on the alloy series A are regarded as passivating, whereas on alloy $\mathrm{AB}$, alloy series $\mathrm{B}$ and the eutectoid alloy the oxide scales do not seem to be dense. These observations can be transferred to lower temperatures, especially to $1100{ }^{\circ} \mathrm{C}$, as confirmed by applying the same approach to the experimental results gained at $1100{ }^{\circ} \mathrm{C}$ (see App. 25). Additionally, it is supposed that these conclusions hold true for observations made at $800^{\circ} \mathrm{C}$ as well, highlighting the pesting resistance of the Ti-rich alloys.

\subsubsection{Pre-Oxidation Experiments at 1100 and $1200^{\circ} \mathrm{C}$}

The differing passivating character of the oxide scales formed at 1100 and $1200{ }^{\circ} \mathrm{C}$ and their preventive potential against cyclic oxidation at $800{ }^{\circ} \mathrm{C}$ is revealed by pre-oxidation experiments at 1100 and $1200{ }^{\circ} \mathrm{C}$ [224]. Isothermal pre-oxidation at $1100{ }^{\circ} \mathrm{C}$ for $10 \mathrm{~h}$ of alloy $\mathrm{A} 1$ leads to the formation of a mixed $\mathrm{SiO}_{2}-\mathrm{TiO}_{2}$ oxide scale with a thickness of $(10 \pm 5) \mu \mathrm{m}[224]$, which neither shows any further scale growth during cyclic oxidation at $800{ }^{\circ} \mathrm{C}$ for $100 \mathrm{~h}$, nor significant internal oxidation (see Fig. 6-7a) as has been observed for non-pre-oxidised samples (see Fig. 6-2a). The mass changes are slightly positive in the range of $3 \mathrm{mg} / \mathrm{cm}^{2}$ [224] (see Fig. 6-8, half-opened red diamond symbols). A comparable oxide scale with $(11 \pm 2) \mu \mathrm{m}$ in thickness is formed on alloy $\mathrm{B} 1$ at $1100{ }^{\circ} \mathrm{C}$ after $10 \mathrm{~h}$, which slightly grows to a thickness of $(16 \pm 8) \mu \mathrm{m}$ during oxidation at $800{ }^{\circ} \mathrm{C}$ (see Fig. 6-7b). Additionally, considerably low mass changes of $(-2 \pm 1) \mathrm{mg} / \mathrm{cm}^{2}$ are observed after $100 \mathrm{~h}$ (see Fig. 6-8, half-opened black diamond symbols) confirming the suppression of pesting and, thus, the passivating character of the oxide scale formed previously at $1100{ }^{\circ} \mathrm{C}$.
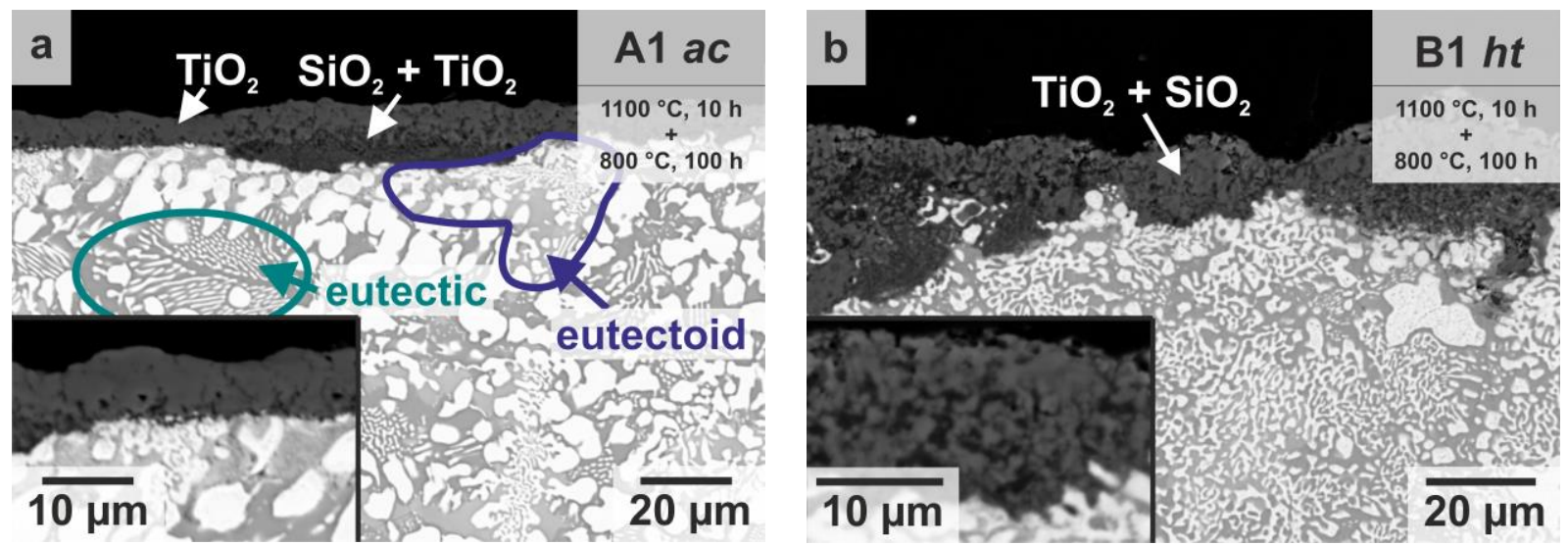

Fig. 6-7 BSE micrographs of isothermally pre-oxidised samples $\left(1100^{\circ} \mathrm{C}, 10 \mathrm{~h}\right)$ and subsequent cyclic oxidation at $800^{\circ} \mathrm{C}$ for $100 \mathrm{~h}$ of alloys $\mathrm{A} 1 \mathrm{ac}$ (a, according to Ref. [224]), and B1 ht (b). 


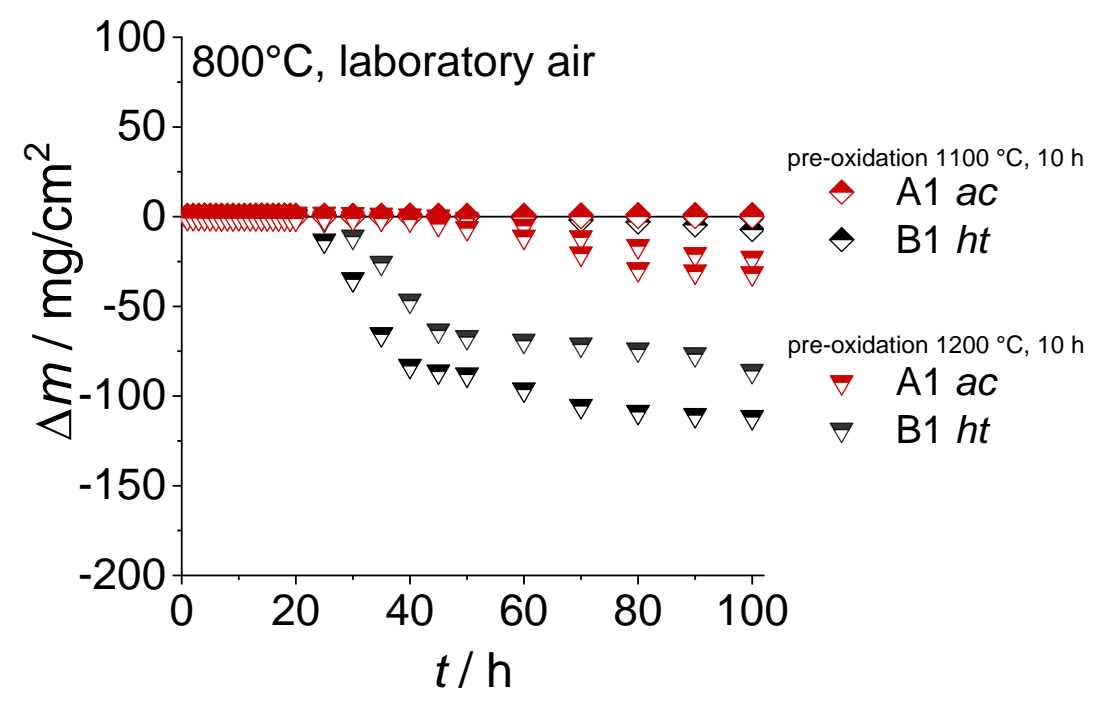

Fig. 6-8 Specific weight change of alloys A1 $a c$ and B1 $h t$ at $800{ }^{\circ} \mathrm{C}$ after $10 \mathrm{~h}$ of isothermal pre-oxidation at 1100 (diamond symbols) and $1200{ }^{\circ} \mathrm{C}$ (triangular symbols). Note that two samples per each testing condition are shown.

In contrast, when pre-oxidised at $1200{ }^{\circ} \mathrm{C}$ (oxide scale thickness $(41 \pm 12) \mu \mathrm{m}$ ), alloy A1 shows higher mass losses in the range of -20 to $-30 \mathrm{mg} / \mathrm{cm}^{2}$ during cyclic oxidation at $800{ }^{\circ} \mathrm{C}$ in comparison to pre-oxidation at $1100{ }^{\circ} \mathrm{C}$ (see Fig. 6-8, half-opened red triangular symbols). Additionally, the outer oxide scale considerably grows during exposure to $800{ }^{\circ} \mathrm{C}$ to an approximate thickness of some $100 \mu \mathrm{m}$ and suffers delamination (see Fig. 6-9a), while the internal oxidation zone is deeper compared to non-pre-oxidised samples. The non-protective character of the oxide scale formed at $1200{ }^{\circ} \mathrm{C}$ under pesting conditions is even more pronounced in alloy B1. Samples of B1, pre-oxidised for $10 \mathrm{~h}$ at $1200^{\circ} \mathrm{C}$ (oxide scale thickness $(24 \pm 6) \mu \mathrm{m})$, underwent pesting after $20 \mathrm{~h}$ when cyclically exposed to $800{ }^{\circ} \mathrm{C}$ (see Fig. 6-8, half-opened black triangular symbols). After $100 \mathrm{~h}$, the sample is completely oxidised and reveals severe cracking and delamination (see Fig. 6-9b).

This indicates that the passivating potential of the oxide scales is influenced by their thickness when cyclic oxidation conditions are prevalent. The oxide scales are prone to crack initiation, growth and spallation at critical thicknesses (> 25 and $40 \mu \mathrm{m}$ in alloys B1 and A1, respectively), which are here attained in the $1200{ }^{\circ} \mathrm{C}$ pre-oxidised samples during subsequent cyclic oxidation at $800{ }^{\circ} \mathrm{C}$. This observation might be attributed to a mismatch in CTE of the substrate and the formed oxide scales (see Sec. 6.4.1 for further discussion of the CTE), which becomes significant with increasing scale thickness. Thus, thicker oxide scales are more likely to suffer from decohesion and delamination. This is the case for the oxide scales formed during pre-oxidation at $1200^{\circ} \mathrm{C}$ after $10 \mathrm{~h}$, which are by a factor of 2 -3 thicker than the scales formed at $1100{ }^{\circ} \mathrm{C}$ (see App. 26). Then, these scales presumably 
grew to a critical value after around 20 or $40 \mathrm{~h}$ in alloys B1 and A1, respectively, where cracking occurred allowing $\mathrm{O}$ ingress, Mo outward diffusion and $\mathrm{MoO}_{3}$ volatilisation.
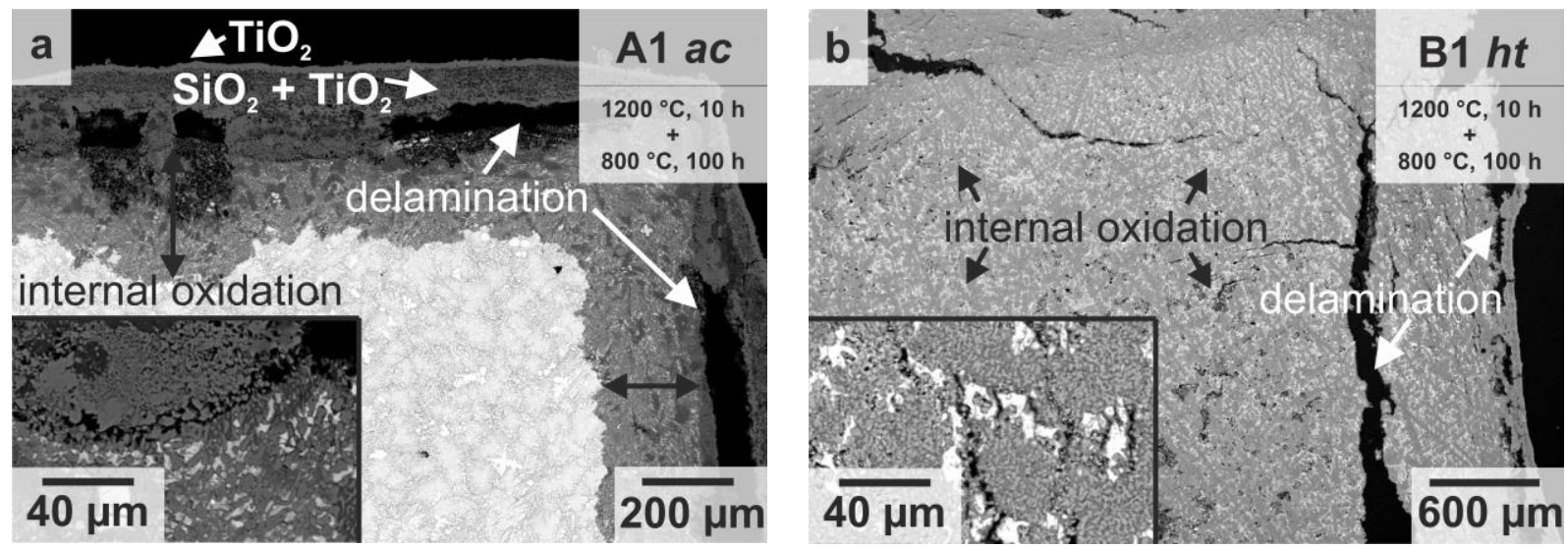

Fig. 6-9 BSE micrographs of isothermally pre-oxidised samples of alloys A1 ac (a) and $\mathrm{B} 1 \mathrm{ht}(\mathrm{b})$ and subsequent cyclic oxidation at $800^{\circ} \mathrm{C}$ for $100 \mathrm{~h}$.

Finally, the investigation of the oxidation behaviour of the alloy series A and B in comparison to the eutectic and eutectoid reference alloys has shown that (i) the oxide scale morphology of the investigated alloys is comparably fine-scaled like the alloy substrate microstructures. (ii) The oxide scale formation and growth are not only a function of test temperature, but also of the nominal alloy composition, as the novel eutectic-eutectoid alloys series A exhibits pesting resistance at $800{ }^{\circ} \mathrm{C}$. The obtained pesting stability is attributed to a threshold in nominal Ti content of 43 at\% [215, 224]. (iii) The impact of Moss in form of globularly shaped primarily solidified precipitates is detrimental, especially in the pesting regime at $800{ }^{\circ} \mathrm{C}$.

\subsection{The (Mo, $\left.\mathrm{Ti}_{5}\right)_{5} \mathrm{Si}_{3}$-Containing Eutectic-Eutectoid Alloy Series C and D}

The findings on the oxidation behaviour of the alloy series C and D are in good agreement with the ones presented in Sec. 6.1. All alloys reveal pesting stability with low mass changes of $(-10.0 \pm 9.0) \mathrm{mg} / \mathrm{cm}^{2}$ (alloy C2 ac) [215], $(0.2 \pm 0.1) \mathrm{mg} / \mathrm{cm}^{2}$ (alloy C1 ac) [215], $(-5.7 \pm 9.7) \mathrm{mg} / \mathrm{cm}^{2}$ (alloy D1 $a c$ ) and $(0.2 \pm 0.0) \mathrm{mg} / \mathrm{cm}^{2}$ (alloy D2 ac) [225] after $100 \mathrm{~h}$ of cyclic oxidation at $800{ }^{\circ} \mathrm{C}$ in laboratory air (see Fig. 6-10a). Note the considerable scatter of data in alloys $\mathrm{C} 2$ and D1, which is caused by individual oxidation samples showing increased, but still adequate absolute mass changes (maximum -12 and $-17 \mathrm{mg} / \mathrm{cm}^{2}$, respectively, after $100 \mathrm{~h}$ ). This is presumably caused by local microstructural inhomogeneities and cracks within the silicide regions being present prior to oxidation testing (see App. 27). 

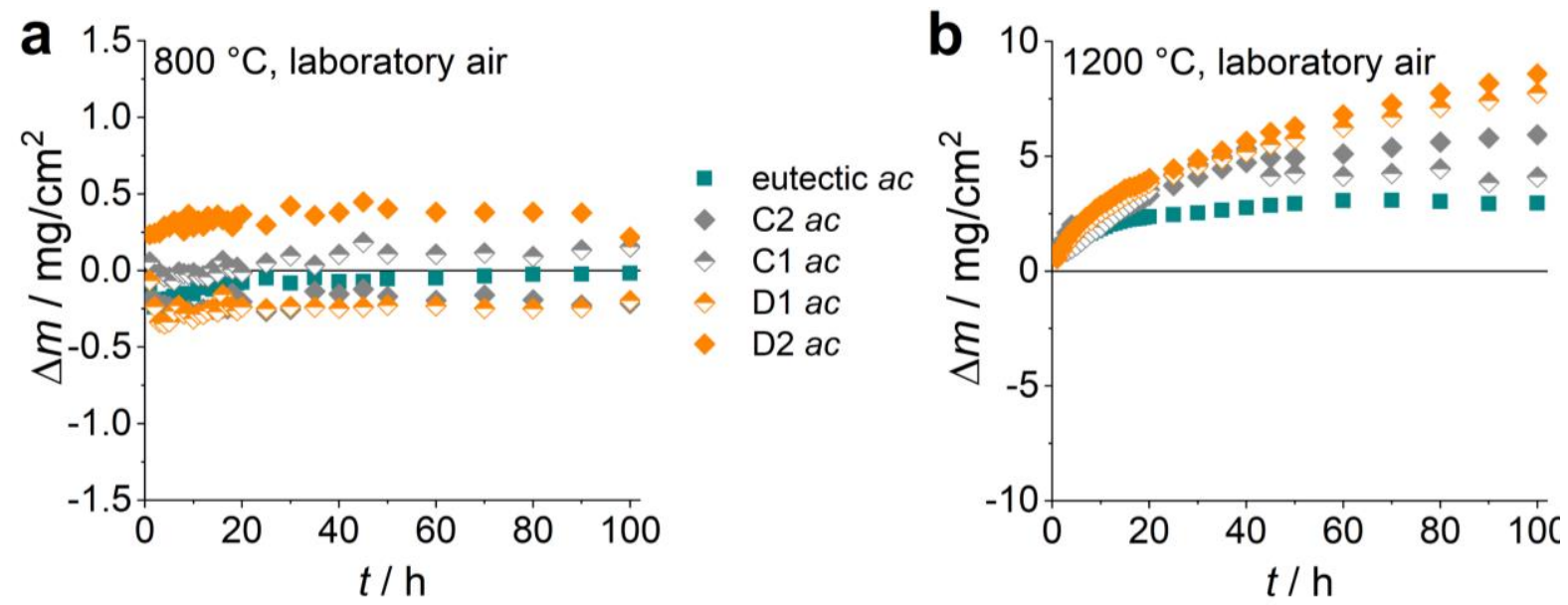

Fig. 6-10 Specific mass change $\Delta m$ as a function of test duration $t$ of the alloy series $\mathrm{C}$ and D during cyclic oxidation at 800 (a) and $1200^{\circ} \mathrm{C}$ (b) in laboratory air, including the eutectic reference alloy for comparison. Data of alloy series $\mathrm{C}$ and D taken from Refs. [215, 225] and of the eutectic alloy from Ref. [224]. (Only one representative oxidation sample is shown, results of three tested ones are provided in App. 28.)

The determined threshold of nominal 43 at\% Ti or 35 at\% Ti in Moss for pesting resistance can be applied for the low $(\mathrm{Mo}, \mathrm{Ti})_{5} \mathrm{Si}_{3}$-containing eutectic-eutectoid alloy series $\mathrm{C}$ as well. The alloys $\mathrm{C} 1$ and $\mathrm{C} 2$ reveal a thin $\mathrm{SiO}_{2}-\mathrm{TiO}_{2}$ mixed oxide scale with similar morphology as observed for the eutectic reference alloy (see Fig. 6-11a) being less than 4 and $7 \mu \mathrm{m}$ thick, respectively. The high $(\mathrm{Mo}, \mathrm{Ti})_{5} \mathrm{Si}_{3}$-containing alloy series $\mathrm{D}$ is found to be pestingresistant, too, even alloy D1 with only 40 at\% nominal Ti content. This is attributed to the high volume fraction of pesting-resistant $(\mathrm{Mo}, \mathrm{Ti})_{5} \mathrm{Si}_{3}$, the lower volume fraction of Moss and especially to the considerable high Ti concentration of 34 (alloy D1) and 37 at\% (alloy D2) in Moss (see Fig. 5-6). The cross sections of the oxidised samples reveal phase-specific oxidation behaviour at $800{ }^{\circ} \mathrm{C}$. While the surface-near regions of $(\mathrm{Mo}, \mathrm{Ti})_{5} \mathrm{Si}_{3}$ slowly oxidise outwards to form a $(4 \pm 2) \mu \mathrm{m}$ thin $\mathrm{SiO}_{2}$-rich oxide scale [225], the eutectic and eutectoid regions are characterised by more intense in- and outward oxidation yielding mixed $\mathrm{SiO}_{2}$ $\mathrm{TiO}_{2}$ scales with an increased thickness of (12 \pm 4$) \mu \mathrm{m}$ (see Fig. 6-11b). Although, local cracking along the oxide scale/substrate interface and within surface-near (Mo,Ti) ${ }_{5} \mathrm{Si}_{3}$ regions is observed, no severe oxidation attack occurs. The crack formation is possibly triggered by internal stresses due to thermal cycling. Conclusively, the oxidation results on alloy series D lead to the suggestion that the volume fraction of the microstructural constituents, particularly of Moss and (Mo,Ti) ${ }_{5} \mathrm{Si}_{3}$, effects the pesting resistance in Mo-Si-Ti alloys. 

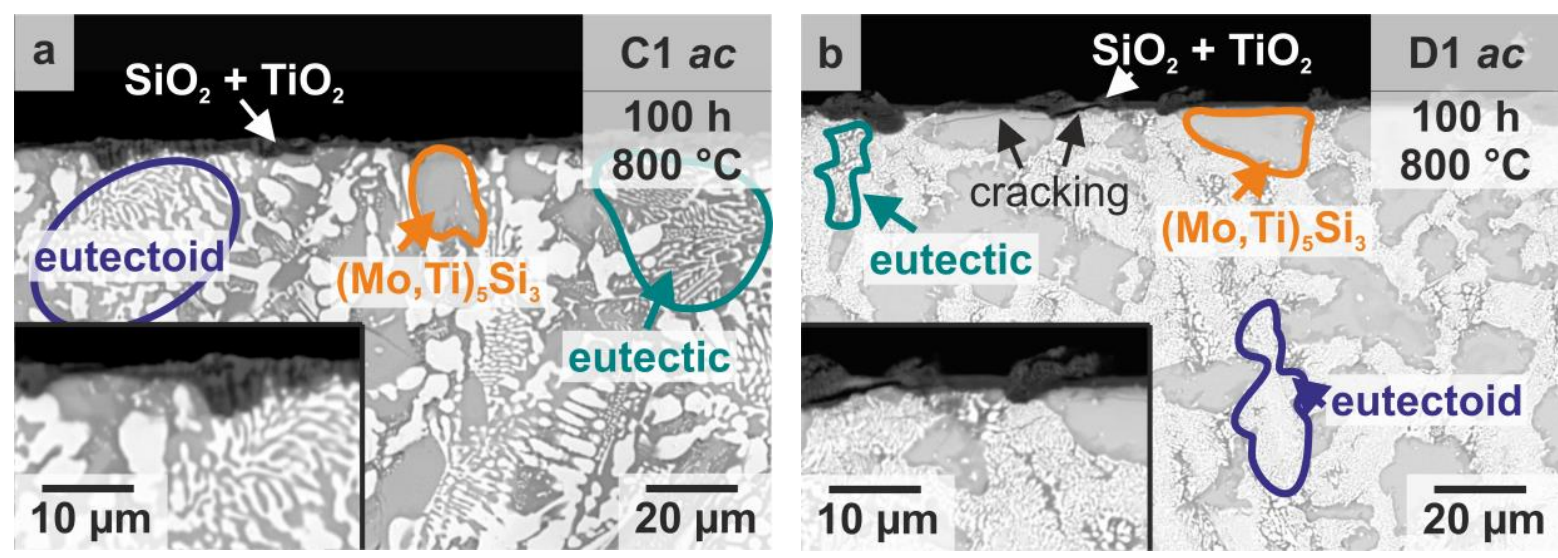

Fig. 6-11 BSE micrographs of the cross sections of cyclically oxidised samples of alloys $\mathrm{C} 1$ (a) and D1 (b) after $100 \mathrm{~h}$ at $800^{\circ} \mathrm{C}$ (the ones for alloys $\mathrm{C} 2$ and $\mathrm{D} 2$ are appended in App. 29).

At 1100 and $1200{ }^{\circ} \mathrm{C}$, similar oxidation behaviour compared to the eutectic and eutectoid reference alloys, as well as to the alloy series A and B, is observed. The mass changes were acceptable, namely $(-0.3 \pm 9.2) \mathrm{mg} / \mathrm{cm}^{2} \quad$ (alloy $\left.\mathrm{C} 2\right), \quad(1.2 \pm 5.3) \mathrm{mg} / \mathrm{cm}^{2} \quad$ (alloy $\left.\mathrm{C} 1\right)$, $(8.0 \pm 0.2) \mathrm{mg} / \mathrm{cm}^{2}$ (alloy D1) [225] and $(8.8 \pm 0.2) \mathrm{mg} / \mathrm{cm}^{2}$ (alloy D2) [225] after $100 \mathrm{~h}$ of oxidation at $1200^{\circ} \mathrm{C}$ (see Fig. 6-10b). The oxide scale morphology is also characterised by an outer $\mathrm{TiO}_{2}$ oxide scale and an underlying $\mathrm{SiO}_{2}-\mathrm{TiO}_{2}$ duplex scale (representative BSE micrographs of the oxide scales formed at $1200^{\circ} \mathrm{C}$ after $100 \mathrm{~h}$ are provided in App. 30). The total oxide scale thickness was found to be in the same order of approximately 40 to $60 \mu \mathrm{m}$ like the one formed on the eutectic reference alloy (see Fig. 6-12). However, the top $\mathrm{TiO}_{2}$ oxide scale was considerably thicker in the alloys containing primarily solidified

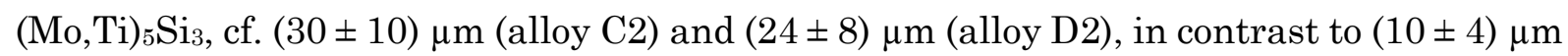
in the eutectic reference alloy. Additionally, a decrease in volume fraction of $\mathrm{SiO}_{2}$ within the duplex scale down to $(42 \pm 6)$ vol\% (alloy C2) and (33 \pm 7) vol\% (alloy D2) [225] was observed. This is likely to be caused by the high content of silicide phases, especially (Mo,Ti) $)_{5} \mathrm{Si}_{3}$, in the range of 72 to 74 vol\% in alloys D2 and D1 [225], respectively, in comparison to only 50 vol\% silicide phases in the eutectic-eutectoid alloy series. The silicide phases oxidise considerably slower to $\mathrm{SiO}_{2}$ (and potentially $\mathrm{TiO}_{2}$ ) than Moss to volatile $\mathrm{MoO}_{3}$ and solid Ti-oxides. Thus, the fast-growing $\mathrm{TiO}_{2}$ is responsible for the lower amount of $\mathrm{SiO}_{2}$ within the duplex oxide scale. Moreover, intense internal oxidation is observed in alloy series $\mathrm{C}$ and especially $\mathrm{D}$, which might be attributed to the high $\mathrm{TiO}_{2}$ fraction within the duplex oxide scale, enabling faster inward diffusion of $\mathrm{O}$. 


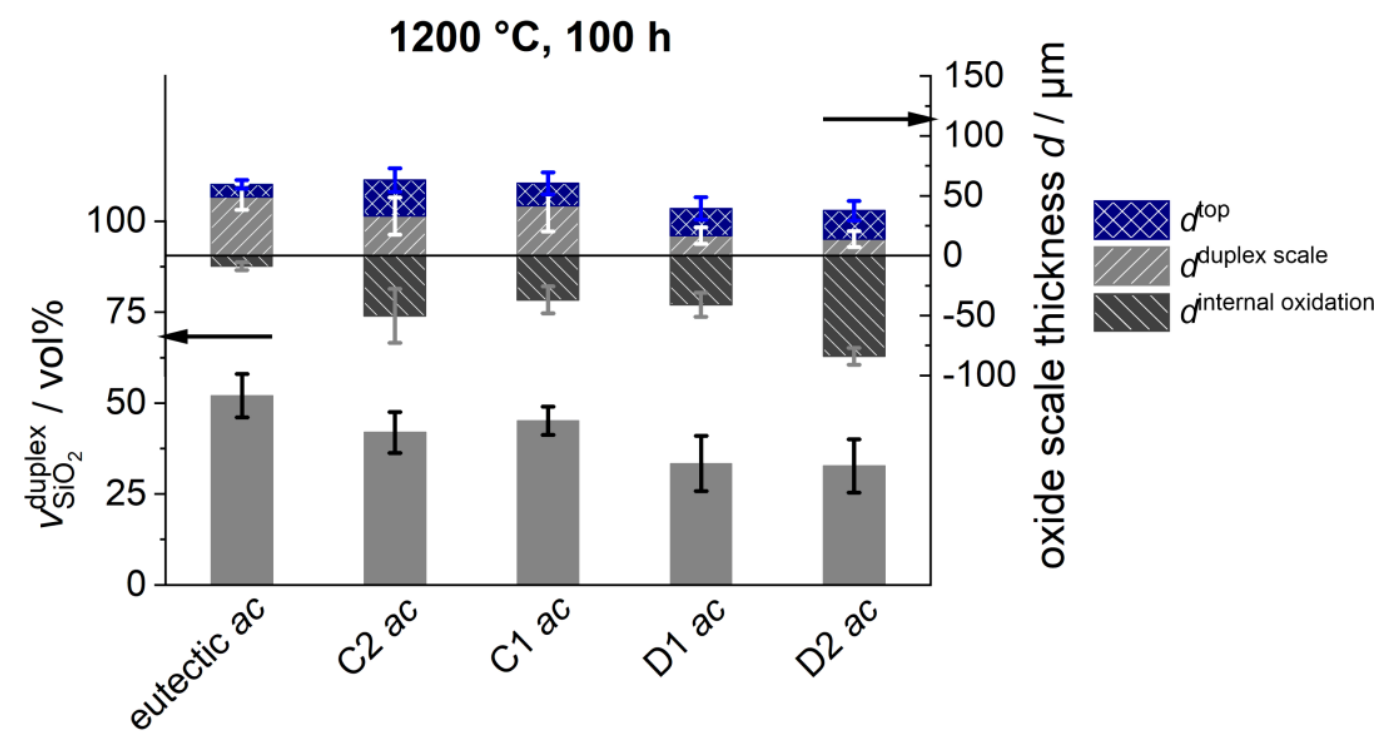

Fig. 6-12 Comparison of the sub-oxide scale thicknesses (upper bar chart) and the volume fraction of $\mathrm{SiO}_{2}$ within the $\mathrm{SiO}_{2}-\mathrm{TiO}_{2}$ duplex scale (lower bar chart) of the alloy series $\mathrm{C}$ and $\mathrm{D}$ including the eutectic reference alloy after $100 \mathrm{~h}$ of cyclic oxidation at $1200^{\circ} \mathrm{C}$. Data on the eutectic alloy taken from Ref. [224] and data on alloys C1 and D according to Ref. [225].

\subsection{Microstructural and Chemical Requirements for Pesting Resistance}

The investigation of the oxidation behaviour of the eutectic-eutectoid alloy series A to D, indicated that the suppression of pesting is mainly dominated by the Ti content in the alloy substrate, especially in the pesting-critical phase Moss. In the following, the role of the microstructural length scale and the volume fraction of the eutectic-eutectoid microstructural constituents will be studied, besides the chemical requirements of the individual phases.

\subsubsection{The Impact of the Microstructural Length Scale}

In principle, a fine microstructural length scale is beneficial, as it provides short diffusion paths for elements forming passivating oxide scales, like Si. However, quick coverage and sealing of surface-near less oxidation-resistant phases, like Moss, is only enabled in MoSi-based alloys at high temperatures, when the $\mathrm{SiO}_{2}$ oxide scale viscosity is sufficiently reduced [232]. This is typically achieved by alloying with B in order to form a low-viscous borosilicate scale [69] beyond $1000{ }^{\circ} \mathrm{C}$ in the transient stage of oxidation $[41,67,68]$. Thus, conventional Mo-Si-based alloys still suffer from pesting at $800{ }^{\circ} \mathrm{C}$, even when being considerably fine-scaled down to $1 \mu \mathrm{m}^{-1}$ phase boundary fraction $[4,136,155]$. Moreover, $\mathrm{TiO}_{2}$ 
is crystalline and non-flowing in the entire temperature range and cannot be accounted for viscous covering of the alloy substrate. Therefore, the impact of the microstructural length scale on the pesting resistance is studied for the artificially coarsened eutectic alloy and alloy A1. Considerable coarsening up to $(0.23 \pm 0.03)$ [215] and $(0.35 \pm 0.01) \mu \mathrm{m}^{-1}$ is achieved in these heat-treated $\left(h t^{*}\right)$ variants at $1600{ }^{\circ} \mathrm{C}$ for $150 \mathrm{~h}$, respectively (see Fig. 5-9 for comparison of the phase boundary fractions and Fig. 6-13 for the obtained microstructures after $\left.h t^{*}\right)$. It is assumed that Moss is the matrix forming phase in the eutectic reference alloy as it is present as 2D network structure after $h t^{*}$ (see Fig. 6-13a).
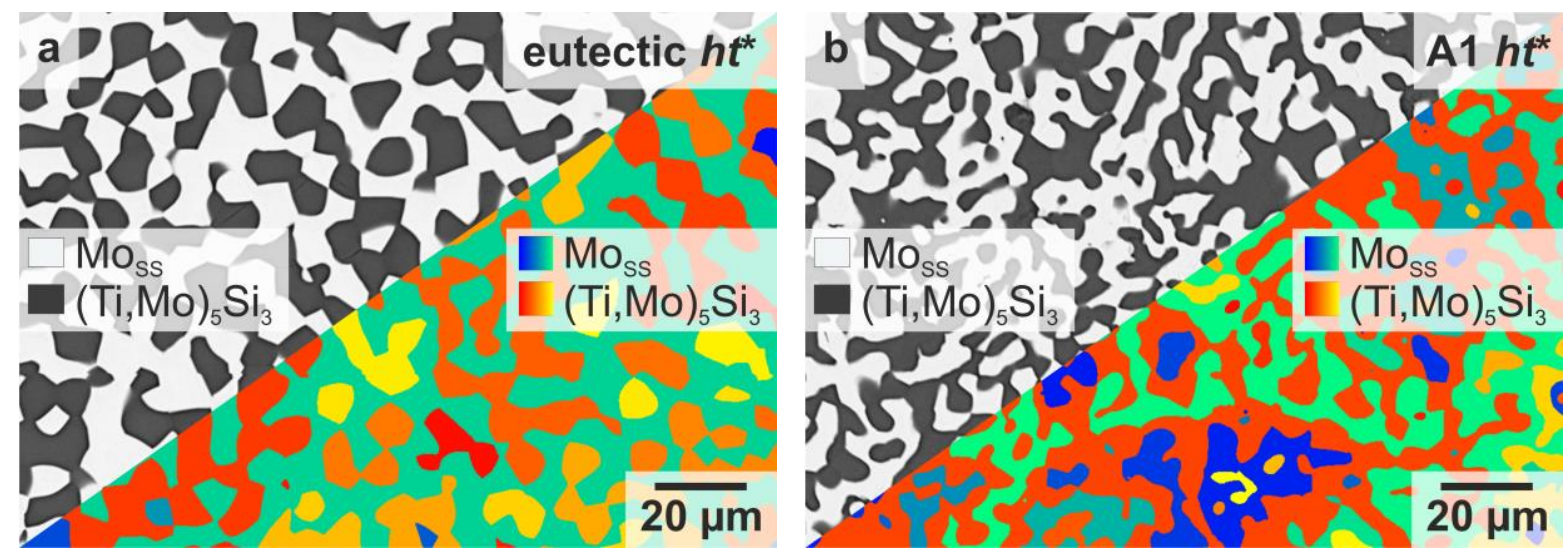

Fig. 6-13 BSE micrographs of the eutectic alloy (a) and alloy A1 (b) after heat treatment $\left(h t^{*}\right)$ at $1600{ }^{\circ} \mathrm{C}$ for $150 \mathrm{~h}$. Corresponding coloured portions of the microstructures are included (Moss is highlighted by cold colours from blue to green, while (Ti,Mo) ${ }_{5} \mathrm{Si}_{3}$ is highlighted by warm colours from red to yellow).

The eutectic alloy does not undergo any phase transformation during the additionally applied heat treatment as confirmed by the unaffected volume fraction of the present phases [215] and XRD (see App. 12a). In contrast, the microstructure of alloy A1 $h t^{*}$ predominantly comprises Moss and (Ti,Mo) ${ }_{5} \mathrm{Si}_{3}$, and almost none (Mo,Ti) ${ }_{5} \mathrm{Si}_{3}$ as revealed by XRD analysis (see App. 12b). These observations are in good agreement with the thermodynamic calculations for equilibrium conditions, which predict the two-phase equilibrium of Moss and (Ti,Mo) ${ }_{5} \mathrm{Si}_{3}$ to be present at $1600{ }^{\circ} \mathrm{C}$ (see App. 13a).

The oxidation resistance of the $a c$ and coarsened $h t^{*}$ variant of the eutectic alloy is exceptionally good in the entire investigated temperature range of 800 to $1200{ }^{\circ} \mathrm{C}$ under cyclic conditions (see Fig. $6-14$ for results at $800{ }^{\circ} \mathrm{C}$, whereas the results at 1100 and $1200{ }^{\circ} \mathrm{C}$ are provided in App. 31a) [215]. Small specific mass changes of (0.04 \pm 0.12$)$ and $(-0.55 \pm 0.04) \mathrm{mg} / \mathrm{cm}^{2}$ are characteristic of both, the $a c$ and $h t^{*}$ variant, respectively, after 
$100 \mathrm{~h}$ [215]. In contrast, alloy A1 exhibits an oxidation behaviour dependent on its prevalent condition. While good pesting resistance with mass changes of $(-2.0 \pm 1.9) \mathrm{mg} / \mathrm{cm}^{2}$ [224] is attained in the $a c$ condition after $100 \mathrm{~h}$ of cyclic oxidation, severe pesting behaviour with mass losses of $(-60 \pm 3) \mathrm{mg} / \mathrm{cm}^{2}$ is observed in the $h t^{*}$ condition.

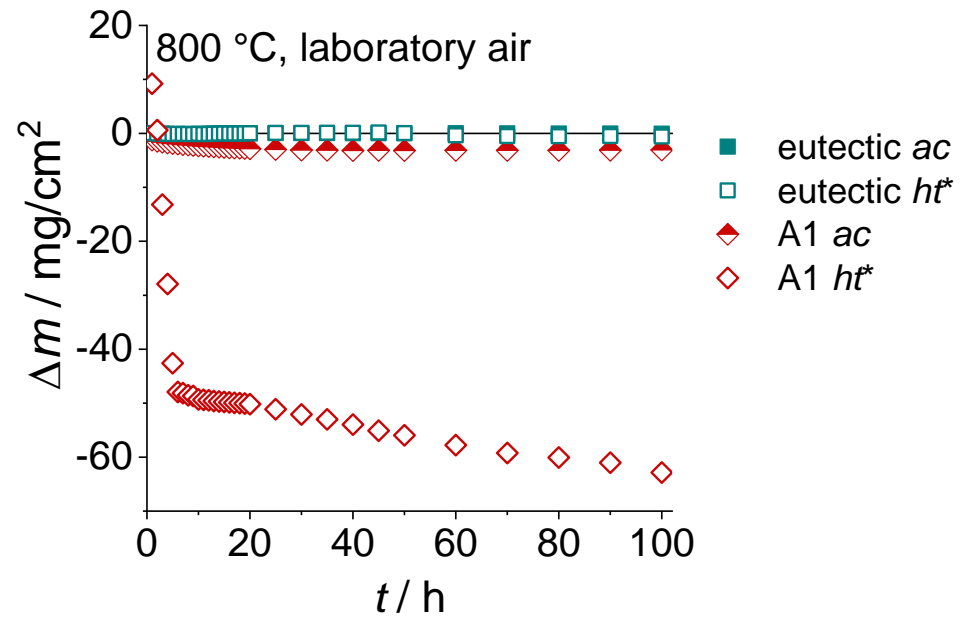

Fig. 6-14 Specific weight change during cyclic oxidation at $800{ }^{\circ} \mathrm{C}$ of the eutectic alloy and alloy A1 in $a c$ and $h t^{*}\left(1600^{\circ} \mathrm{C}, 150 \mathrm{~h}\right)$ condition, respectively. Data of the eutectic alloy in $a c$ condition taken from Ref. [224] and in $h t^{*}$ condition from Ref. [215].

The corresponding microstructures of the oxide scales formed at $800{ }^{\circ} \mathrm{C}$ on the coarsened variants are depicted in Fig. 6-15. In $h t^{*}$ condition, the oxidation of the eutectic alloy is site-specific and more complex than in ac condition, as the difference in oxidation rate of the individual phases is more pronounced [215]. Therefore, a distinction in oxidation behaviour of the individual phases is possible by means of SEM imaging (see Fig. 6-15a). This is not possible in the $a c$ condition, as the fine-scaled microstructure facilitates the instantaneous formation of an intermixed $\mathrm{SiO}_{2}-\mathrm{TiO}_{2}$ oxide scale (see App. 17a and b), as was also reported in Ref. [5]. In $h t^{*}$ condition, Moss rapidly oxidises to $\mathrm{TiO}_{2}$ with small $\mathrm{SiO}_{2}$ precipitates being distributed inhomogeneously. Due to the coarsened microstructure, the internal oxidation attack is directly guided towards the alloy substrate by the laterally expanded Moss regions [215]. In contrast, the surface-near (Ti,Mo) ${ }_{5} \mathrm{Si}_{3}$ regions are characterised by slow oxidation to a thin top oxide scale comprising mainly $\mathrm{TiO}_{2}$ (see BSE contrast and research on the oxidation behaviour of (Ti,Mo) $\left.{ }_{5} \mathrm{Si}_{3}[152,153]\right)$. However, significant cracking is observed in the surface-near $(\mathrm{Ti}, \mathrm{Mo})_{5} \mathrm{Si}_{3}$ regions. It is most likely that this is caused by the cyclic test conditions for several reasons: (i) Cracking within $(\mathrm{Ti}, \mathrm{Mo})_{5} \mathrm{Si}_{3}$ is mainly observed near the substrate surface and not in the substrate core of the oxidation sample, which is in agreement with the low amount of cracks being present 
prior to oxidation testing [215]. (ii) The CTE of $\mathrm{Ti}_{5} \mathrm{Si}_{3}$ is strongly anisotropic [233, 234], favouring internal stresses during thermal cycling. (iii) Isothermal oxidation testing at $800{ }^{\circ} \mathrm{C}$ for $100 \mathrm{~h}$ reveals significantly less cracking in the surface-near (Ti,Mo) ${ }_{5} \mathrm{Si}_{3}$ regions and, therefore, a reduced depth of internal oxidation (see Fig. 6-15b) [215].
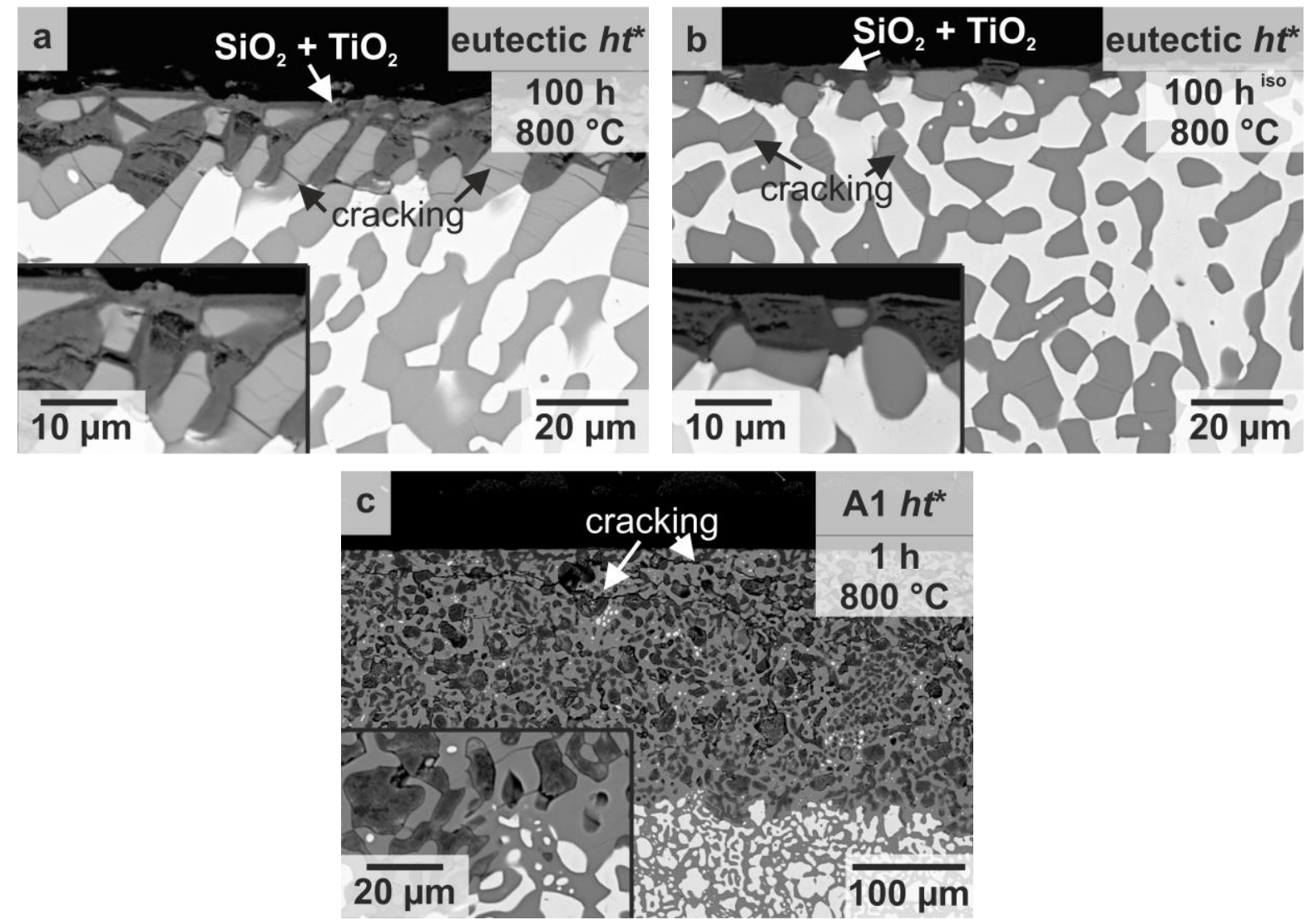

Fig. 6-15 Cross sectional BSE micrographs of oxidation samples of the eutectic alloy $h t^{*}$ during cyclic (a) and isothermal (iso) (b) oxidation at $800{ }^{\circ} \mathrm{C}$ for $100 \mathrm{~h}$ and of alloy $\mathrm{A} 1 h t^{*}$ after cyclic oxidation at $800^{\circ} \mathrm{C}$ for $1 \mathrm{~h}(\mathrm{c}) .(\mathrm{a}, \mathrm{b})$ according to Ref. [215].

However, despite cracking within $(\mathrm{Ti}, \mathrm{Mo})_{5} \mathrm{Si}_{3}$, neither spallation nor partial material disintegration occurs, as oxidation to $\mathrm{TiO}_{2}$ only occurs along the crack flanks and is inhibited within a small surrounding volume [215]. Additionally, cracking mainly occurs along the $c$-axis of $(\mathrm{Ti}, \mathrm{Mo})_{5} \mathrm{Si}_{3}$ and is therefore independent of the orientation of the silicide regions. Thus, direct oxidation attack through the entire length of the silicide regions is not enabled. In accordance with this observation, the internal oxidation of Moss is stopped, so the internal corrosion zone is less than $20 \mu \mathrm{m}$ deep after $100 \mathrm{~h}$. This is due to the fact that Moss does not represent the matrix phase and $(\mathrm{Ti}, \mathrm{Mo})_{5} \mathrm{Si}_{3}$ regions terminate the respective pathways towards the substrate (see evolution of the oxide scale thickness with time in comparison to the $a c$ variant in App. 32) [215]. The observed oxidation behaviour of the 
$(\mathrm{Ti}, \mathrm{Mo})_{5} \mathrm{Si}_{3}$ regions is in good agreement with previously published studies on the oxidation behaviour of a (Ti,Mo) ${ }_{5} \mathrm{Si}_{3}$-based Mo-Si-Ti alloy [152]. Low specific mass changes of about $1.1 \mathrm{mg} / \mathrm{cm}^{2}$ [153] and a thin oxide scale (<10 $\mu \mathrm{m}$ thickness) [152] were reported after $100 \mathrm{~h}$ of isothermal oxidation in air at $900{ }^{\circ} \mathrm{C}$. The oxide scale was found to be composed of a top $\mathrm{TiO}_{2}$ oxide scale and an underlying $\mathrm{SiO}_{2}-\mathrm{TiO}_{2}$ duplex scale, with $\mathrm{SiO}_{2}$ as matrix forming oxide [152]. Thereby, the Mo content (26.4 at\% Mo in Ref. [152]) was found not to deteriorate the oxidation resistance when compared to the oxidation behaviour of monolithic $\mathrm{Ti}_{5} \mathrm{Si}_{3}[148-151,235]$.

In contrast to the eutectic alloy, alloy $\mathrm{A} 1 h t^{*}$ undergoes catastrophic oxidation being mainly characterised by rapid inward oxidation ( $>200 \mu \mathrm{m}$ after $1 \mathrm{~h}$ ) of $\mathrm{Moss}_{\text {so }} \mathrm{TiO}_{2}$ and presumably $\mathrm{MoO}_{3}$, as significant porosity is observed in the former Moss network structure (see Fig. 6-15c). Additionally, the (Ti,Mo) ${ }_{5} \mathrm{Si}_{3}$ regions cannot provide passivation, which is presumably caused by too slow solid oxide formation and, thus, passivation. However, it is confirmed by XRD (see App. 33) that the Ti content in Moss remains nearly unaffected by the additional heat treatment $h t^{*}$ of alloy A1 (slight increase from 35 at $\%$ in $a c$ to 37 at\% in $h t^{*}$ condition). This indicates that the pesting resistance is more sensitive to the critical Ti content (in the alloy substrate or in Moss, respectively), when the microstructural length scale is increased. Moreover, the excellent oxidation behaviour of the eutectic alloy, in both $a c$ and $h t^{*}$ condition, is not determined by the fine-scaled microstructure. This leads to the conclusion that the pesting resistance is not determined by viscous oxide scale flow covering the substrate surface, but possibly by surface diffusion-controlled processes in coarsened microstructures, when the Ti content is in a critical range. Therefore, as the chemical conditions are presumably accounted to be decisive for the pesting resistance, these will be discussed in the following.

\subsubsection{The Impact of Phase Distribution and Composition}

As was already shown in Sec. 4.2, the variation in nominal Ti content of the Mo-Si-Ti alloys results in a shift in solidification paths leading to different primarily solidifying phases and eutectic/eutectoid volume fractions. Therefore, the investigation of the oxidation behaviour of the alloy series A to D allows for a systematic study of the impact of the volume fraction of the microstructural constituents and of the chemical composition of the individual phases on the oxidation behaviour (see Fig. 6-16). As has already been described in Sec. 5.3, the composition of the $\mathrm{M}_{5} \mathrm{Si}_{3}$ silicides is characterised by comparable Ti to Mo ratios. Since both phases, $(\mathrm{Ti}, \mathrm{Mo})_{5} \mathrm{Si}_{3}$ and $(\mathrm{Mo}, \mathrm{Ti})_{5} \mathrm{Si}_{3}$, reveal pesting resistance $[147,152]$, 
the site-specific composition of Moss is of particular interest. The Si content in Moss is consistently $3-4$ at\% for all alloys, which is close to the maximum solubility in thermodynamic equilibrium [36], whereas the Ti content varies significantly. The eutectic-eutectoid alloy series $\mathrm{A}$ to $\mathrm{C}$, including the eutectic and eutectoid reference alloys, can be compared directly, as these reveal a comparable nominal Si content (alloys to the left in Fig. 6-16) [215]. The Si-rich, high (Mo,Ti) ${ }_{5} \mathrm{Si}_{3}$-containing alloy series D is included separately (alloys to the right in Fig. 6-16).

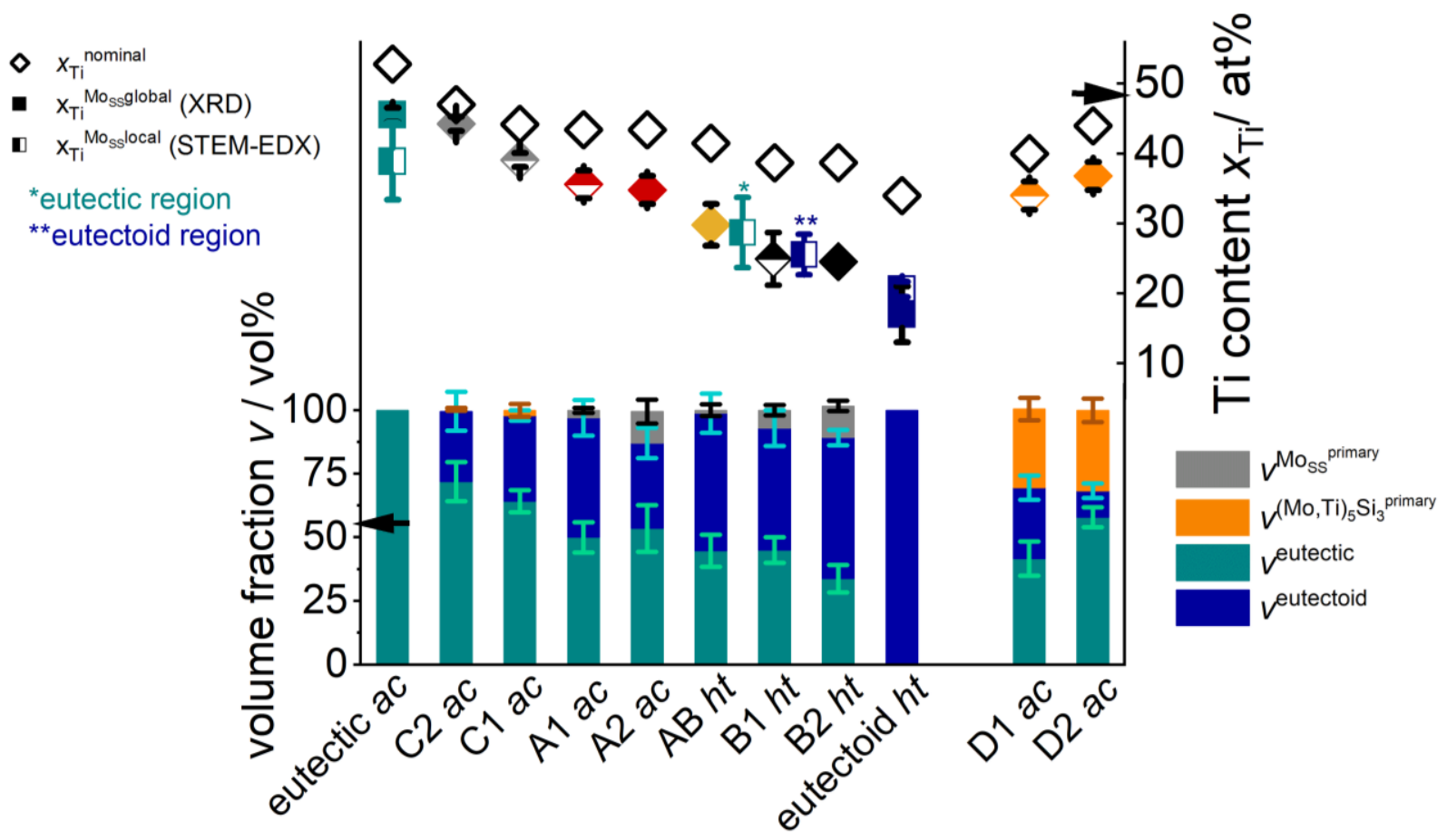

Fig. 6-16 Nominal Ti content (opened diamonds) vs. the Ti content in Moss being either determined globally via XRD (coloured symbols analogous to Fig. 4-2, or locally via STEM-EDX (half-opened squares) for the investigated alloys in correlation with the volume fraction of the microstructural constituents/phases. According to Ref. [215], except results on alloy C1 and alloy series D, which are according to Ref. [225].

In essence, the volume fraction of the eutectic microstructure is reduced with decreasing Ti content. However, in the intermediate alloys A1 ac, AB $h t$ and B1 $h t$, among which only alloy A1 $a c$ is pesting-resistant, the volume fraction is similar within the scatter of data. Thus, the volume fraction of the eutectic microstructure does not have an influence on the pesting resistance, as already stated in Sec. 6.1 [215]. Nevertheless, the difference in Ti content in Moss, which is determined by the nominal Ti content, is prominent throughout all alloy series. Conclusively, the previously anticipated threshold of nominal 43 at\% Ti 
and 35 at\% $\mathrm{Ti}$ in Moss for suppression of pesting is confirmed for the eutectic-eutectoid alloy series [215, 224]. In the alloy series $\mathrm{D}$, this threshold seems to be even more reduced down to 40 at\% Ti nominal and 34 at\% Ti in Moss, possibly caused by the high fraction of $(\mathrm{Mo}, \mathrm{Ti})_{5} \mathrm{Si}_{3}$ itself being pesting-resistant.

\subsubsection{The Oxidation Behaviour of Moss at $800^{\circ} \mathrm{C}$}

In order to verify the impact of the Ti content in Moss on the pesting behaviour, the cyclic oxidation behaviour of bcc Moss with different Ti contents (20 to 50 at\%) is assessed at $800{ }^{\circ} \mathrm{C}$ [215]. Thereby, alloy Mo-20Ti represents the 'worst case' composition which is comparable to the Ti-lean Moss present in the eutectoid reference alloy. In contrast, alloy Mo40Ti-3Si (partial Si enrichment along the grain boundaries) resembles the most promising composition, even with considerable Si content, similar to the Ti-rich Moss present in the eutectic reference alloy. The results of the cyclic oxidation tests are shown in Fig. 6-17.

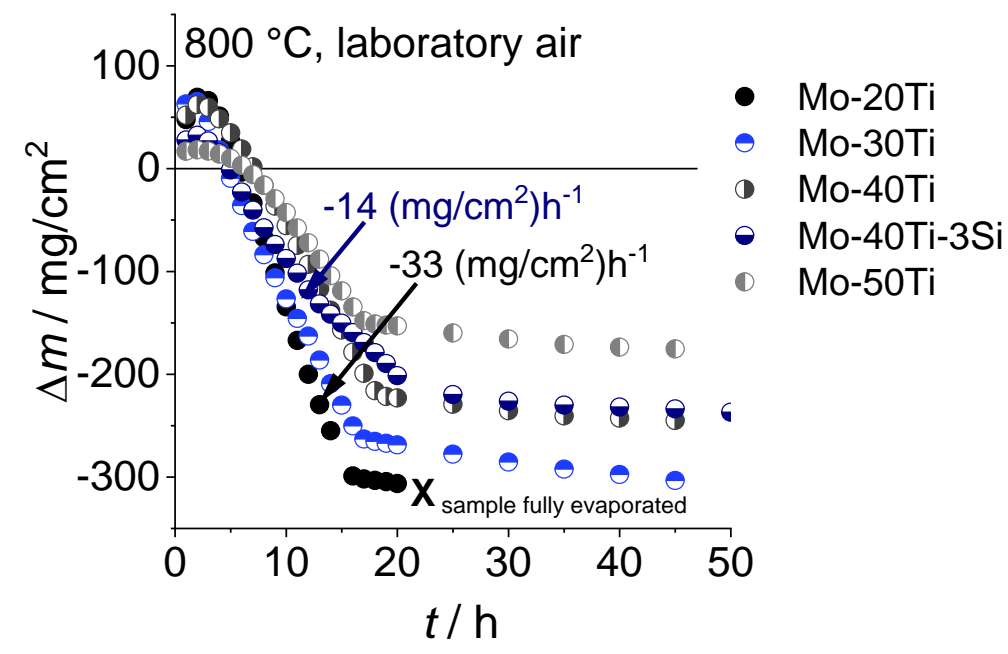

Fig. 6-17 Specific weight change of bcc Mo-Ti(-Si) alloys during cyclic oxidation at $800{ }^{\circ} \mathrm{C}$ in laboratory air (one representative sample is shown among three tested in total for each alloy). According to Ref. [215].

Although all Moss show typical pesting behaviour, it is demonstrated that the oxidation rate is significantly reduced with increasing Ti content. Alloy Mo-20Ti oxidises fastest with an oxidation rate of $-33\left(\mathrm{mg} / \mathrm{cm}^{2}\right) \mathrm{h}^{-1}$, whereas alloy Mo-40Ti-3Si exhibits an oxidation rate decelerated down to $-14\left(\mathrm{mg} / \mathrm{cm}^{2}\right) \mathrm{h}^{-1}[215]$. The initially observed peak in mass gain is most likely to be caused by the formation of solid Ti-oxides. These undergo cracking due to cyclic thermal impact during ongoing oxidation testing, which then allows unhindered $\mathrm{O}$ uptake and accelerated oxidation to volatile $\mathrm{MoO}_{3}$ resulting in rapid mass loss. Besides the reduction in oxidation rates, it is the maintained material integrity of the Ti-rich Moss, 
which clearly differentiates the pesting behaviours (see Fig. 6-18) [215]. Alloy Mo-20Ti mainly oxidises to volatile $\mathrm{MoO}_{3}$, which partially re-deposits on the sample surface in form of less-adherent, needle-shaped Mo-oxides (highlighted by white arrows in Fig. 6-18a). During $1 \mathrm{~h}$ of oxidation, the sample is already significantly consumed and only a less than $10 \mu \mathrm{m}$ thick Ti-oxide scale covers the substrate surface beneath the re-condensed Mo-oxides (highlighted by black arrows in Fig. 6-18a) [215]. This leads to complete evaporation

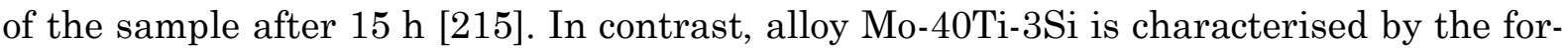
mation of inward growing, highly porous, but solid Ti-oxides (highlighted by black arrows in Fig. 6-18b) [215]. The porosity is likely to be caused by the formation and evaporation of $\mathrm{MoO}_{3}$, which also re-deposits moderately at the sample surface (highlighted by the white arrow in Fig. 6-18b) [215]. However, the sample stays intact and does not suffer material disintegration. The Si-enriched grain boundaries do not exhibit any specific oxidation behaviour, but along the surface-near grain boundaries oxidation occurs leaving pores behind.
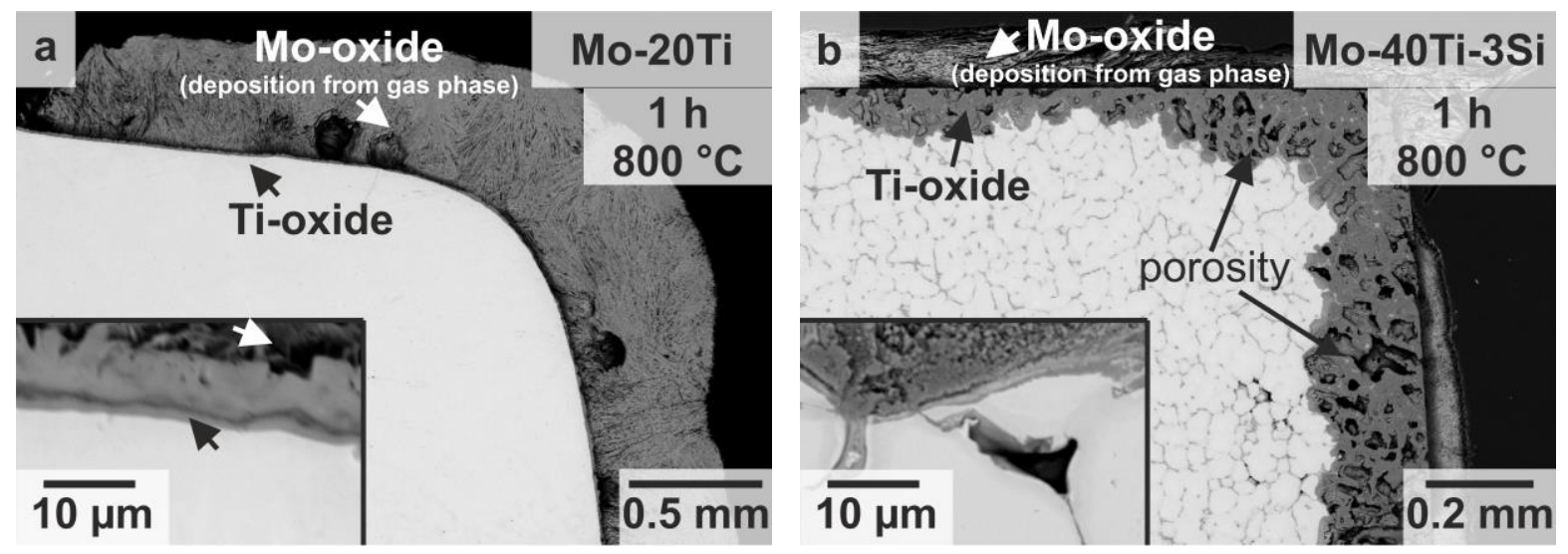

Fig. 6-18 BSE micrographs of alloy Mo-20Ti (a) and Mo-40Ti-3Si (b) after $1 \mathrm{~h}$ of oxidation at $800{ }^{\circ} \mathrm{C}$ in laboratory air. According to Ref. [215].

Although, the oxidation behaviour of pure Mo (and Mo-silicides) has been discussed in detail in literature (see Sec. 2.3), no data has been reported on Mo-Ti alloys so far. Thus, the present investigations indicate that there is no pesting resistance in monolithic, Ticontaining Moss up to 50 at\% Ti. A significant reduction in $\mathrm{MoO}_{3}$ evaporation with increasing Ti content is found instead [215]. While the equilibria in the ternary Mo-Si-O have been studied in detail at $800{ }^{\circ} \mathrm{C}$ [236], only little is reported on the isothermal sections in the Ti-rich Mo-Ti-O system [237, 238]. However, it is assumed that the fraction of $\mathrm{MoO}_{3}$ is reduced for the same $\mathrm{O}$ partial pressure and similar Ti or Si contents in equilibrium, when comparing Mo-Ti and Mo-Si alloys. Thus, the evaporation of $\mathrm{MoO}_{3}$ is likely to be less pronounced in Ti-rich Moss. 
Regarding the protective potential of oxide scales formed on the respective substrate, the Pilling-Bedworth ratio (PBR) is often utilised for comparing their adhesion on single-phase metals and alloys [110]. A PBR of 1 is considered as ideal, as full coverage of the substrate is enabled [110]. However, besides good scale adhesion, a dense oxide scale mock-up is required for oxidation resistance, which needs to be considered additionally. The application of the PBR to multiphase alloys, like the here investigated Mo-Si-Ti alloys, is complicated and has to be discussed with precaution. However, when studying the modified, Tidependent PBR (see Ref. [239] for detailed description) only for the Moss phase being present in the corresponding eutectic-eutectoid alloys, it is obvious that the observed $\mathrm{Ti}$ threshold is reflected as well (see App. 34). The obtained results are in good agreement with the oxidation study on Ti-rich Mo-Si-B-TiC alloys by Hatakeyama et al. in Ref. [239], who reported pesting stability for a minimum nominal Ti content of 46 at\% and a respective PBR of 0.87 to 1.16. Contrary, pesting was observed for an alloy comprising only 40 at\% nominal $\mathrm{Ti}$ and a corresponding PBR of 0.67 in Ref. [239]. However, for the here presented Mo-Ti alloys, PBR values of 0.8 (40 at\% Ti) and 1.0 (50 at\% Ti) are attained, which suggest good adhesion and probably oxidation resistance. But all Mo-Ti alloys suffer from pesting. Thus, the modified PBR allows for a qualitative comparison of the investigated alloys and is not a specific indicator whether pesting can be suppressed or not, as the density of the scale and diffusion characteristics for ions within the oxide scale need to be taken into account.

\subsection{Analysis of the Oxide Scale Mock-Up and Oxidation Kinetics}

Despite the above presented findings, the reasons for the passivating character of the oxide scales formed on the pesting-resistant eutectic alloy (and eutectic-eutectoid alloys) at 800 and $1200{ }^{\circ} \mathrm{C}$ still remain unsolved. Especially, the considerable fraction of $\mathrm{TiO}_{2}$, which is present as connected network in the duplex scale at $1200^{\circ} \mathrm{C}$, is questionable. Generally, $\mathrm{TiO}_{2}$ is known for its minor oxidation resistance due to scale cracking and spallation [240243]. Therefore, this section addresses the crystallographic and chemical appearance, as well as the growth kinetics of the formed oxide scales on the eutectic reference alloy. In the previous sections, the oxides within the scales were regarded to be amorphous $\mathrm{SiO}_{2}$ and rutile $\mathrm{TiO}_{2}$. This assignment was based on the $Z$-contrast in BSE micrographs, XRD results of the oxidised samples of the eutectic alloy, alloys A1 and D2 (see App. 35) and on observations made by several researches on Mo-Si-(B)-Ti alloys [4, 5, 47, 48]. However, the oxides will be precisely investigated in the following section and will, therefore, be referred to as $\mathrm{Si}$ - and Ti-oxide (oxide with $\mathrm{Si}$ and $\mathrm{Ti}$ as major cationic component, respectively). 
These terms are only used for a general qualitatively distinction and are not to be mistaken with oxidation levels or stoichiometry relations.

\subsubsection{Crystallography and Chemical Appearance of the Oxide Scales}

GIXRD measurements of oxidation samples of the $a c$ eutectic alloy oxidised at 800 and $1200{ }^{\circ} \mathrm{C}$ confirm the presence of mainly rutile $\mathrm{TiO}_{2}$, $\mathrm{Ti}(+\mathrm{IV})$-oxide (space group $\mathrm{P} 42 / \mathrm{m} \mathrm{n} \mathrm{m}$ ) and some cristobalite $\mathrm{SiO}_{2}$, $\mathrm{Si}\left(+\mathrm{IV}\right.$ )-oxide (space group $\mathrm{P} 4_{1} 2_{1} 1$ ) (see Fig. 6-19) [216].

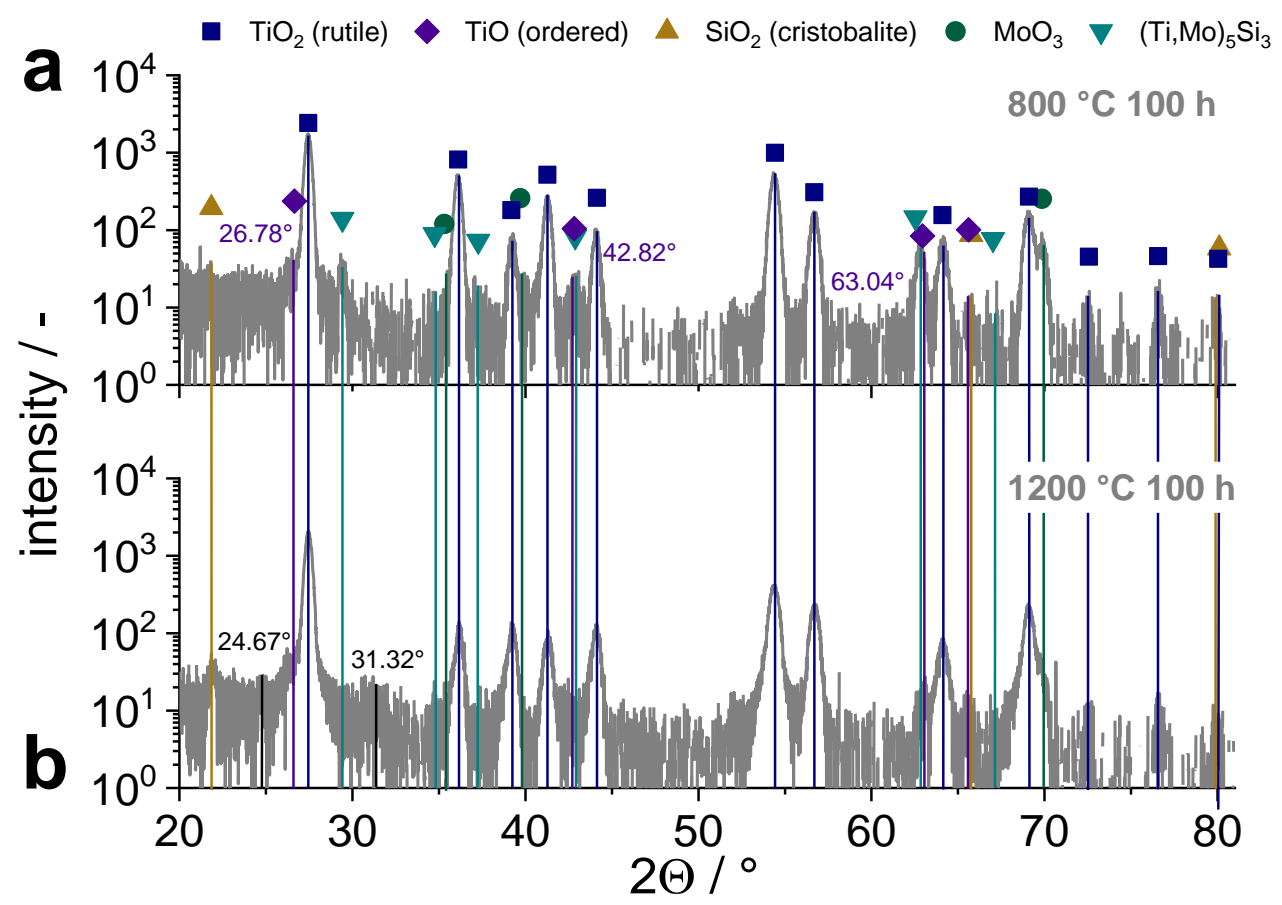

Fig. 6-19 GIXRD pattern at an incident angle $\omega=1.2^{\circ}$ of the oxidised samples of the $a c$ eutectic alloy after $100 \mathrm{~h}$ at 800 (a) and $1200^{\circ} \mathrm{C}(\mathrm{b})$. Intensities are plotted in log scale. According to Ref. [216].

In contrast, BSE analyses have revealed a considerable volume fraction of (52 \pm 6$)$ vol\% $\mathrm{SiO}_{2}$ [224] within the duplex oxide scale formed at $1200{ }^{\circ} \mathrm{C}$. Thus, it is assumed that $\mathrm{SiO}_{2}$ is mainly present in amorphous condition, which is in accordance to the EBSD results in Ref. [5]. Additionally, D88 (Ti,Mo) ${ }_{5} \mathrm{Si}_{3}$ (space group P 63/m c m) peaks are identified, especially in the $800{ }^{\circ} \mathrm{C}$ oxidation sample. This is attributed to the high penetration depth of the incident beam (incident angle $\omega=1.2^{\circ}$ ) exceeding the comparably low oxide scale thickness of $(5 \pm 1) \mu \mathrm{m}[224]$ and, thus, the sub-oxide scale region is also detected. In this regard, one would expect peaks referring to Moss as well. But this phase oxidises faster and deeper while the (Ti,Mo) ${ }_{5} \mathrm{Si}_{3}$ regions can withstand the oxidation attack (compare to BSE micrographs in App. 17a and b). Moreover, some weak peaks of both oxidation samples (800 and 
$1200^{\circ} \mathrm{C}$ ) can be assigned to ordered $\mathrm{TiO}$ (space group C $12 / \mathrm{m} \mathrm{1}$ ) [216]. While the peaks at $2 \Theta=42.82,63.04$ and $65.57^{\circ}$ are superimposed by $(\mathrm{Ti}, \mathrm{Mo})_{5} \mathrm{Si}_{3}$ (particularly in the case of the $800^{\circ} \mathrm{C}$ sample) or cristobalite $\mathrm{SiO}_{2}$, the peak at $26.78^{\circ}$ might only correspond to the plane group (111) of ordered $\mathrm{TiO}$ [216]. Although, further characteristic peaks belonging to $\mathrm{TiO}$, for instance at $2 \Theta=30.29$ and $46.74^{\circ}$ (plane groups (111) and (021)), which could be accounted for a representative fraction of TiO, were not identified [216]. Moreover, some weak peaks indicate the presence of $\mathrm{MoO}_{3}$ (space group $\mathrm{P} \mathrm{n} \mathrm{m} \mathrm{a),} \mathrm{which} \mathrm{can} \mathrm{be} \mathrm{explained}$ by the partial incorporation of condensed $\mathrm{MoO}_{3}$ on the oxide/atmosphere interface into the oxide scale during ongoing oxidation [216]. For the sample oxidised at $1200{ }^{\circ} \mathrm{C}$, two weak peaks at $2 \Theta=24.67$ and $31.32^{\circ}$ remain unassigned, as these neither match to any of the here discussed crystal structures nor to further considered ones (see App. 36) [216].

The chemical composition of the Ti- and Si-oxide is determined by APT. The characteristic and representative parts of the respective mass spectra of the oxides are displayed in Fig. 6-20 [216]. As the tips manufactured from the Si-oxide region of the $800{ }^{\circ} \mathrm{C}$ oxide scale could not be analysed because of mechanical instabilities, only the Ti-oxide region (Tioxide $800^{\circ} \mathrm{C}$ ) was evaluated [216]. Moreover, the top Ti-oxide region, as well as the Siand Ti-oxide regions within the duplex oxide scale formed at $1200{ }^{\circ} \mathrm{C}$ were investigated (top Ti-oxide $1200^{\circ} \mathrm{C}$, Si-oxide $1200^{\circ} \mathrm{C}$ and Ti-oxide $1200^{\circ} \mathrm{C}$ ). The mass spectra of the (top) Ti-oxide regions of the oxide scales formed at 800 and $1200{ }^{\circ} \mathrm{C}$ exhibit similar peaks, besides the ones corresponding to $\mathrm{Al}^{+/ 2+}(13.5$ and $27 \mathrm{Da})$ and $\mathrm{AlO}^{2+}(21.5 \mathrm{Da})$, which are unique for the top Ti-oxide region of the $120{ }^{\circ} \mathrm{C}$ oxide scale (see Fig. 6-20a and b) [216]. These peaks are presumably caused by reactions with the $\mathrm{Al}_{2} \mathrm{O}_{3}$ crucible, where the oxidation samples were maintained in during oxidation. The main peak of $\mathrm{Si}^{+}$(28 $\mathrm{Da}$ ) was identified in both spectra, but no other O-containing Si-peaks were found. Additionally, no peaks corresponding to Mo were identified. The peak at $32 \mathrm{Da}$ is primarily related to $\mathrm{TiO}^{2+}$ ions, but it contains significant contribution of $\mathrm{O}_{2}{ }^{+}$, as indicated by the side peak of $\mathrm{O}_{2}{ }^{+}$at $34 \mathrm{Da}$. After these considerations and the application of peak deconvolution, the chemical compositions were determined (see Table 6-1) [216]. Thereby, it is assumed that the $O$ content is not underestimated as already discussed in the experimental methods in Sec. 3.3.5.

At $800^{\circ} \mathrm{C}$, it is found that the top Ti-oxide region has a composition of $\mathrm{TiO}_{2.1}, \mathrm{Ti}(+\mathrm{IV})$ oxide, which is in very good agreement to rutile $\mathrm{TiO}_{2}$, $\mathrm{Ti}(+\mathrm{IV})$-oxide, confirmed by GIXRD [216]. The mass spectra of the underlying duplex oxide scale exhibit the same characteristic peaks as found for the Ti-oxide formed at $800{ }^{\circ} \mathrm{C}$, including a small peak of $\mathrm{Si}^{+}$at 
28 Da (see Fig. 6-20c and d) [216]. However, no Mo was identified as well, while the top Ti-oxide region possesses a comparable composition of $\mathrm{TiO}_{2.2}$, $\mathrm{Ti}(+\mathrm{IV})$-oxide to the Ti-oxide region formed at $800{ }^{\circ} \mathrm{C}$, the Ti-oxide region within the duplex oxide scale exhibits a stoichiometry of $\mathrm{TiO}_{1.4}$ [216]. For comparison, the top oxide scale was unambiguously confirmed to be rutile $\mathrm{TiO}_{2}$, Ti(+IV)-oxide by EBSD analyses in Ref. [5], but only some Tioxide regions were assigned to rutile within the duplex oxide scale in Ref. [5]. The numerous non-indexed, sub-surface regions were assumed to be amorphous $\mathrm{SiO}_{2}$ [5]. Considering the APT results, it is likely that these non-indexed regions represent a Ti-oxide other than rutile-type.

The mass spectrum of the Si-oxide region is characterised by peaks corresponding to $\mathrm{Si}$ and $\mathrm{O}$ or combinations of both (see Fig. 6-20d) without any indications of $\mathrm{Al}$ or Mo [216]. Here, the peak at $32 \mathrm{Da}$ is mainly related to $\mathrm{O}_{2}{ }^{+}$ions. Additionally, some peaks $(31,31.5$, 32.5 and $33 \mathrm{Da}$ ) were assigned to $\mathrm{TiO}^{2+}$ ions [216]. By means of peak deconvolution, the $\mathrm{Ti}$ content was found to be approximately $0.4 \%$. The stoichiometry of the Si-oxide was determined to be $\mathrm{SiO}_{1.6}$, which is relatively close to $\mathrm{Si}(+\mathrm{IV})$-oxide [216]. Conclusively, the $\mathrm{O}$ content is comparably low, like for the Ti-oxide region within the duplex oxide scale.
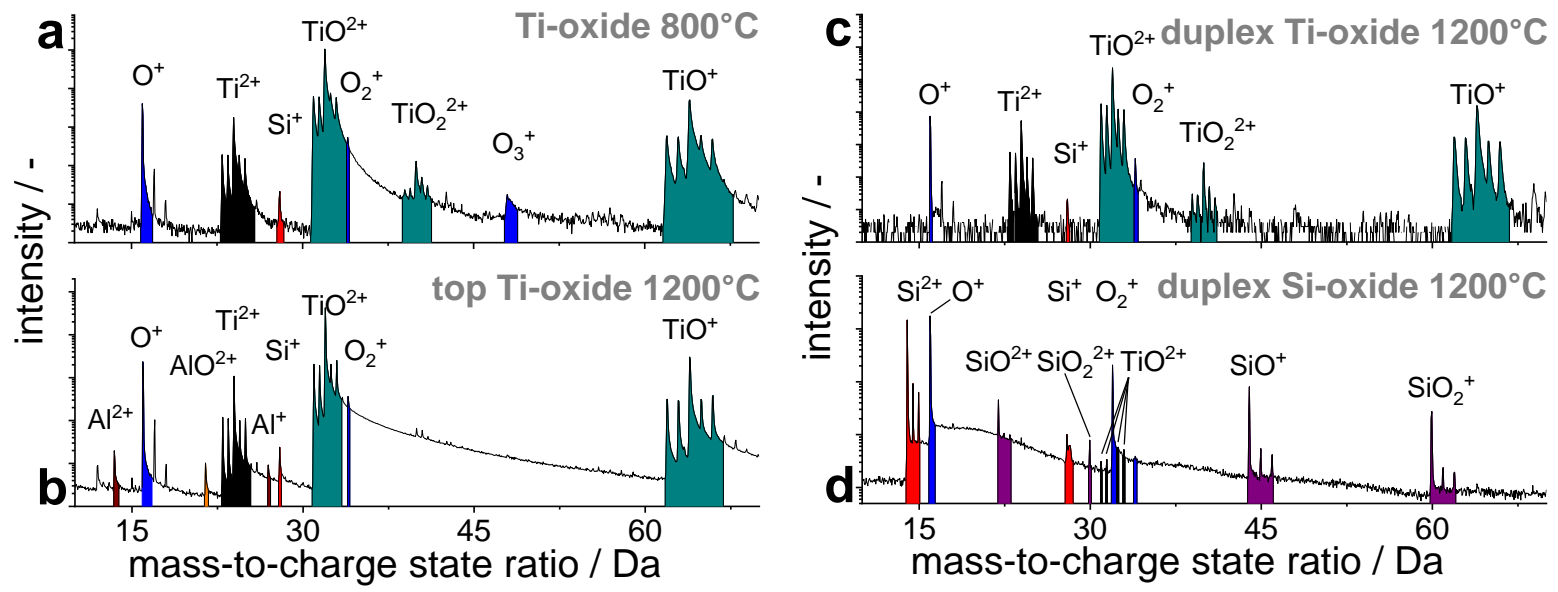

Fig. 6-20 Characteristic parts of the mass spectra of a Ti-oxide region of the oxide scale formed at $800{ }^{\circ} \mathrm{C}$ after $100 \mathrm{~h}$ (a), of the top oxide scale formed at $1200{ }^{\circ} \mathrm{C}$ after $100 \mathrm{~h}(\mathrm{~b})$ and of a Ti-oxide (c) and Si-oxide region (d) of the underlying duplex scale of the eutectic alloy. According to Ref. [216]. 
Table 6-1 Chemical composition of the different oxide regions determined by APT after peak deconvolution [216].

\begin{tabular}{|c|c|c|c|c|c|c|}
\hline / at\% & $\mathrm{Ti}$ & $\mathrm{Si}$ & $\mathrm{O}$ & $\mathrm{Al}$ & \multicolumn{2}{|c|}{$\begin{array}{l}\text { stoichiometry and oxidation levels } \\
\text { of possible oxides }\end{array}$} \\
\hline Ti-oxide $800^{\circ} \mathrm{C}$ & 32.4 & $<0.1$ & 67.6 & - & $\mathrm{TiO}_{2.1}$ & $\mathrm{Ti}(+\mathrm{IV})$ \\
\hline top Ti-oxide $1200{ }^{\circ} \mathrm{C}$ & 31.7 & $<0.1$ & 68.3 & $<0.1$ & $\mathrm{TiO}_{2.2}$ & $\mathrm{Ti}(+\mathrm{IV})$ \\
\hline Ti-oxide duplex $1200^{\circ} \mathrm{C}$ & 41.0 & $<0.1$ & 59.0 & - & $\begin{array}{c}\mathrm{TiO}_{1.4} \\
\mathrm{Ti}_{2} \mathrm{O}_{2.9} \\
\mathrm{Ti}_{3} \mathrm{O}_{4.3} \\
\rightarrow \mathrm{Ti}_{x} \mathrm{O}_{y}\end{array}$ & $\begin{array}{c}\mathrm{Ti}(+\mathrm{II}) \text { or } \mathrm{Ti}(+\mathrm{III}) \\
\mathrm{Ti}(+\mathrm{III}) \\
\mathrm{Ti}(+\mathrm{IV} /+\mathrm{III}) \\
\rightarrow \mathrm{Ti}(+2 y / x) \text {-oxide }\end{array}$ \\
\hline Si-oxide duplex $1200^{\circ} \mathrm{C}$ & 0.4 & 38.0 & 61.6 & - & $\mathrm{SiO}_{1.6}$ & $\mathrm{Si}(+\mathrm{IV})$ \\
\hline
\end{tabular}

The stoichiometry of the Ti-oxide within the duplex oxide scale still remains under discussion and is, thus, designated as $\operatorname{Ti}(+2 y / x)$-oxide [216]. On the one hand it is most likely to be of rutile crystal structure, but on the other hand the experimentally determined chemical composition is not in agreement with the stoichiometry range of thermodynamically stable rutile, which is reported to be $\mathrm{TiO}_{1.96}$ to $\mathrm{TiO}_{2}$ [244, 245]. In contrast, the chemical composition is close to $\mathrm{Ti}_{2} \mathrm{O}_{3}$, $\mathrm{Ti}(+\mathrm{III})$-oxide and only off-set to the homogeneity range by $0.06\left(\mathrm{Ti}_{2} \mathrm{O}_{2.92}\right.$ to $\left.\mathrm{Ti}_{2} \mathrm{O}_{3.02}[244,246]\right)$. However, corundum $\mathrm{Ti}_{2} \mathrm{O}_{3}$ could not be identified by GIXRD. Also, the presence of amorphous $\mathrm{Ti}_{2} \mathrm{O}_{3}$ is rather unlikely, as it is only reported to be present as intermediate oxide layer between $\mathrm{TiO}$ and a top $\mathrm{TiO}_{2}$ oxide scale during spontaneous oxidation of pure $\mathrm{Ti}$ at $R T$ [247, 248]. From a thermodynamic point of view, the Ti-oxide, prevalent within the oxide scale, is most likely to be $\mathrm{Ti}_{3} \mathrm{O}_{5}, \mathrm{Ti}$ (+IV/+III)-oxide even when $\mathrm{Ti}_{3} \mathrm{O}_{5}$ does not exhibit an appropriate solubility range [244, 249]. This conclusion is based on isothermal sections of the ternary Ti-Si-O and Mo-Si-O system shown in Fig. 6-21. The eutectic alloy substrate, comprising Moss and (Ti,Mo) ${ }_{5} \mathrm{Si}_{3}$, is considerably enriched in $\mathrm{O}$ during oxidation (see dotted grey line). Thus, it is most likely to oxidise to solid $\mathrm{SiO}_{2}, \mathrm{Ti}_{3} \mathrm{O}_{5}$ and volatile $\mathrm{MoO}_{3}$ at the substrate surface, while the composition of the duplex oxide scale changes with increasing $\mathrm{O}$ content (analogous to an increasing oxygen partial pressure) and oxide scale thickness to $\mathrm{SiO}_{2}$ and $\mathrm{TiO}_{2}$. The top $\mathrm{TiO}_{2}$ oxide scale is most probably determined by oxide scale growth kinetics due to its high diffusivity for Ti cations [250] and its fast-growing characteristics [47, 147]. 

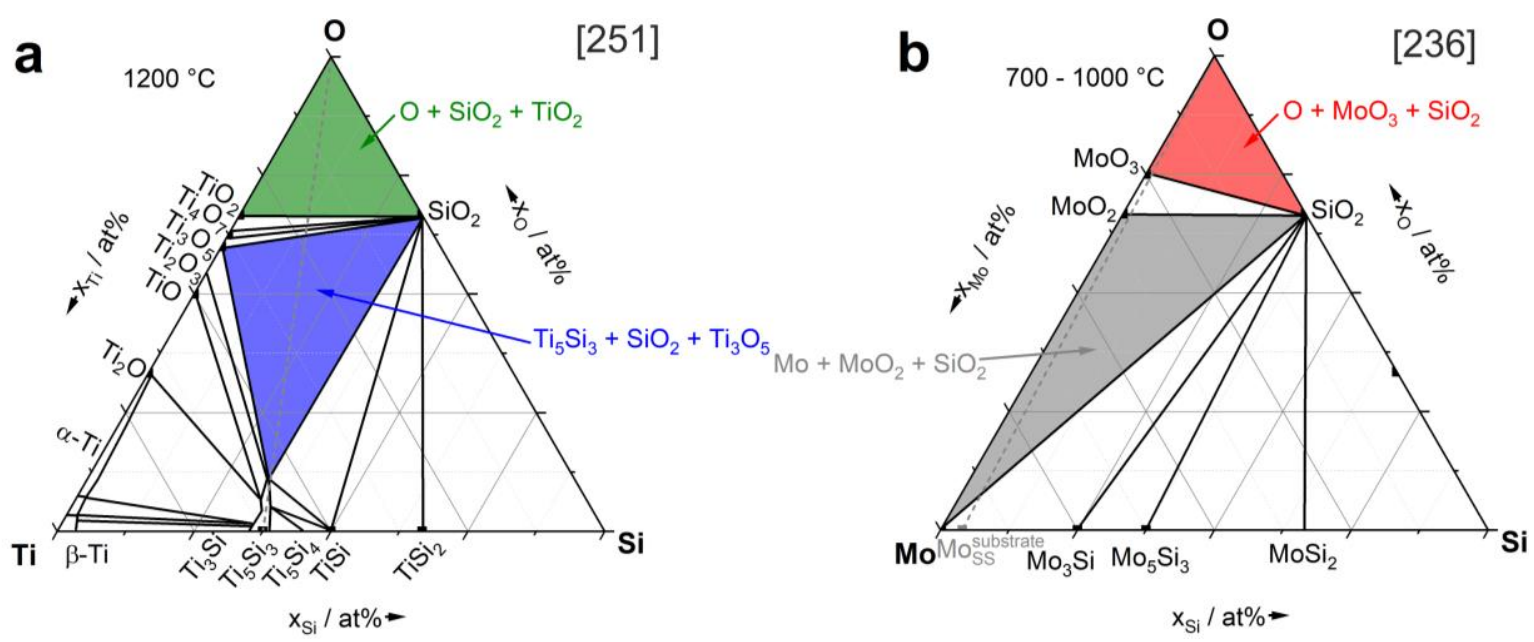

Fig. 6-21 Isothermal sections of the ternary Ti-Si-O system at $1200^{\circ} \mathrm{C}$ (a) and the ternary Mo-Si-O system at 700 to $1000^{\circ} \mathrm{C}$ (b). According to Refs. [236, 251].

Nevertheless, it is still questionable, why the high fraction of the Ti-oxide is not detrimental for the oxidation behaviour, as pure $\mathrm{Ti}$ and its alloys are known to exhibit modest oxidation resistance at temperatures beyond $600{ }^{\circ} \mathrm{C}$ caused by the formation of poorly adherent and porous oxide scales [130, 231, 242, 252]. However, a reduction in oxidation rate is reported for $\mathrm{Ti}-x \mathrm{Si}\left(x=3\right.$ to 13 at\%) alloys at 500 to $850{ }^{\circ} \mathrm{C}[242,253]$. Depending on the $\mathrm{Si}$ content, $\mathrm{Si}$ is either homogenously distributed within the rutile $\mathrm{TiO}_{2}$ oxide scale or embedded as particles with diameters less than $1 \mu \mathrm{m}[242,253]$. The improvement of the oxidation behaviour is attributed to a change in internal oxide architecture, which prevents spallation [70]. Several reasons are proposed: (i) Retardment of the O inward diffusion and reduction of the $\mathrm{O}$ penetration depth [253]. (ii) Deceleration of the oxidation rate due to a reduction of the $\mathrm{O}$ vacancy sites in rutile $\mathrm{TiO}_{2}$ caused by $\mathrm{Si}$ ion occupation [253]. (iii) Formation of a dense duplex oxide scale containing $\mathrm{SiO}_{2}$, which prevents recrystallisation and stratification of $\mathrm{TiO}_{2}[242,253]$. Regarding the APT results, the Si content in the Ti-oxide formed on the eutectic alloy is less than 0.1 at\%. Thus, it is questionable, whether this low amount can be accounted for the good oxidation behaviour. However, for comparison, in $\mathrm{Ti}-\mathrm{Nb}$ alloys $\mathrm{Nb}^{5+}$ ions were reported to substitute $0.14 \%$ of the $\mathrm{Ti}^{4+}$ ions within the $\mathrm{TiO}_{2}$ oxide scale leading to a decelerated oxidation at 900 and $1000{ }^{\circ} \mathrm{C}$ in air [254]. Additionally, the good corrosion resistance ${ }^{9}$ of alloy Ti-6Al-6Nb was attributed to the partial substitution of $\mathrm{Ti}$ ions of different oxidation states (e.g. $\mathrm{Ti}^{3+}, \mathrm{Ti}^{4+}$ ) by $\mathrm{Nb}^{5+}$ ions in $\mathrm{TiO}_{2}$ reducing the concentration of $\mathrm{O}$ vacancy sites [255].

\footnotetext{
9 in salt solution as described in Ref. [255] at $R T$
} 
Additionally, as the oxide scales formed on the eutectic alloy are crack-free, it might be assumed that the CTE of the oxide scales and of the eutectic alloy substrate are matching better than in the case of Ti(-based alloys) and its oxide scales. However, literature data (provided in Table 6-2) reveal that there is no considerable difference in CTE. $\mathrm{TiO}_{2}$ exhibits a CTE of $9.4 \times 10^{-6} \mathrm{~K}^{-1}$ in average at roughly $300{ }^{\circ} \mathrm{C}$ [256], which is different to the eutectic reference alloy by around $1.6 \times 10^{-6} \mathrm{~K}^{-1}$ at $300{ }^{\circ} \mathrm{C}$ [216]. For comparison, typical CTE of TiSi-based alloys vary by comparable 1.5 to $2.3 \times 10^{-6} \mathrm{~K}^{-1}$ at this temperature [257]. Thus, it is concluded that the interaction of the Ti- with the Si-oxide enables the excellent oxidation behaviour.

Table 6-2 CTE data of $\mathrm{Ti}, \mathrm{Mo}, \mathrm{Ti}_{5} \mathrm{Si}_{3}, \mathrm{TiO}_{2}, \mathrm{SiO}_{2}$ and the eutectic reference alloy, as well as Ti-Si-based alloys.

\begin{tabular}{|c|c|c|c|}
\hline & $\mathrm{CTE} / 10^{-6} \mathrm{~K}^{-1}$ & $T /{ }^{\circ} \mathrm{C}$ & Ref. \\
\hline $\mathrm{Ti}$ (hdp) & 10.5 & 20 to 700 & {$[258]$} \\
\hline $\mathrm{Mo}$ (bcc) & 5.6 & 1000 & {$[259]$} \\
\hline $\mathrm{Ti}_{5} \mathrm{Si}_{3}$ (D88) & $\begin{array}{c}a \text { axis: } 5.1 \\
c \text { axis: } 22.2\end{array}$ & 26 to 1000 & {$[234]$} \\
\hline $\mathrm{TiO}_{2}$ (rutile) & $\begin{array}{c}a \text { axis: } 8.1 \\
c \text { axis: } 10.6\end{array}$ & 276 & {$[256]$} \\
\hline $\mathrm{SiO}_{2}$ (vitreous) & 0.5 & $R T$ to 300 & {$[260]$} \\
\hline $\begin{array}{c}\text { eutectic refer- } \\
\text { ence alloy }\end{array}$ & 7.0 to 9.1 & 300 to 1200 & {$[216]$} \\
\hline $\mathrm{Ti}_{-}$-Ti5Si3 alloy & 10.1 to 13.8 & 200 to 1000 & {$[257]$} \\
\hline Ti-7.5Si-1Al & 11.0 to 14.6 & 200 to 1000 & {$[257]$} \\
\hline
\end{tabular}

\subsubsection{The Oxide Scale Growth Kinetics}

In the following, the oxide scale growth kinetics of the pesting-resistant ac eutectic reference alloy is assessed by evaluating the thickness of the (sub-)oxide scales formed during cyclic oxidation at $1200^{\circ} \mathrm{C}$ as a function of time in double logarithmic manner (see Fig. 6-22a) [216]. The general power fit function for the oxide scale thickness $d$, expressed in Eq. 17 (see Sec. 2.3), is applied to these experimental values with the exponent $n$ being (i) fixed to 2 (equal to parabolic oxide scale growth [261]) and (ii) variably adjusted for best fit quality (see dotted lines in Fig. 6-22). It is found that the oxide scale growth in total obeys to parabolic oxidation, as well as the growth of the duplex scale [216]. Thus, the overall oxide scale growth is determined by the evolution of the duplex scale. Additionally, the subtraction of both parabolically shaped functions of oxide scale thickness $\left(d_{\text {total }}\right.$ and 
$\left.d_{\text {duplex }}\right)$ result in a parabolic curve as well. This might correspond to the growth function of the top $\mathrm{TiO}_{2}$ oxide scale $d_{\text {top }}$. Conclusively, the oxide growth kinetics of the eutectic alloy is parabolic at $1200{ }^{\circ} \mathrm{C}$ and, thus, diffusion rate-controlled by either diffusion of the oxidant (O anions) or the reactants (metals cations) through the (sub-)oxide scales [216].

In order to evaluate whether a transition in oxidation kinetics occurs with decreasing temperature, the oxide scale thickness in total at $1200{ }^{\circ} \mathrm{C}$ is compared to observations made at 1100 and $800{ }^{\circ} \mathrm{C}$ (see Fig. 6-22b) [216].
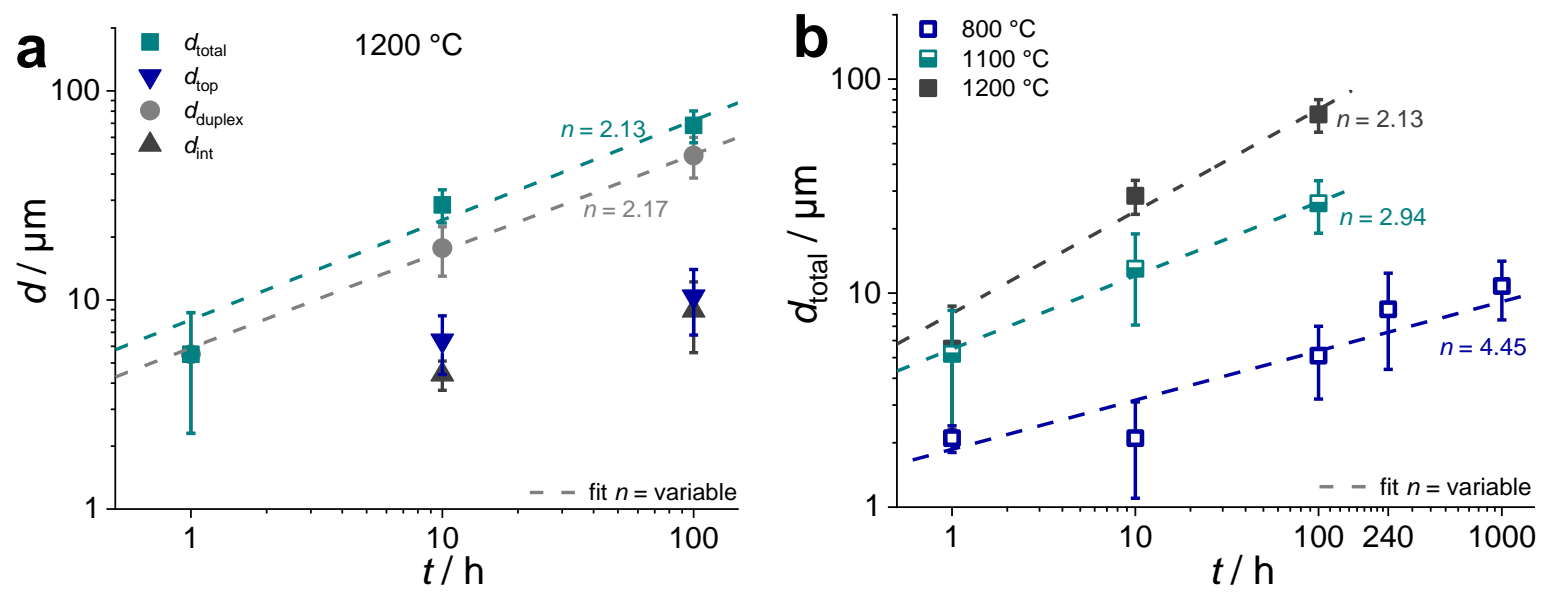

Fig. 6-22 Evolution of the (sub-)oxide scale thicknesses $d\left(d_{\text {total }}, d_{\text {top }}\right.$ of the top Tioxide, $d_{\text {duplex }}$ of the underlying duplex scale, $d_{\text {int }}$ of the internal oxidation zone) at $1200{ }^{\circ} \mathrm{C}$ as a function of exposure time $t$ (a), including fit functions according to Eq. 17 with $n$ being adjusted variably (dotted lines). For comparison, $d_{\text {total }}$ is plotted in logarithmic manner as a function of $t$ for 800, 1100 and $1200^{\circ} \mathrm{C}$ and fitted accordingly (b). All data are from the eutectic reference alloy according to Ref. [216].

This reveals that the oxide scale thickness (including the internal oxidation zone) is considerably higher at 1100 and $1200^{\circ} \mathrm{C}$, namely $(26 \pm 7)$ and $(68 \pm 11) \mu \mathrm{m}$, respectively, compared to only $(5 \pm 1) \mu \mathrm{m}$ at $800{ }^{\circ} \mathrm{C}$ [224]. Thus, at least 5 times thicker oxide scales are formed at elevated temperatures (see oxide scale evolution as a function of temperature in App. 37). This is attributed to thermally activated diffusion processes. For instance, the estimated diffusion distance of $\mathrm{Ti}^{4+}$ cations in $\mathrm{TiO}_{2}, \mathrm{Ti}(+\mathrm{IV})$-oxide at the respective temperature (29 and $62 \mu \mathrm{m}$ at 1100 and $1200{ }^{\circ} \mathrm{C}$, respectively) is in excellent agreement with the experimental oxide scale thickness after $100 \mathrm{~h}$. Moreover, the fits of the oxide scale growth function result in exponents $n$ close to 2 and 3, namely $2.13\left(1100^{\circ} \mathrm{C}\right)$ and 2.94 
$\left(1200^{\circ} \mathrm{C}\right)$, revealing (almost) parabolic and cubic oxide scale growth, respectively (see Table 6-3) [216]. This suggests a change from parabolic to cubic oxidation kinetics with decreasing temperature. Conclusively, the oxide scale growth is diffusion-controlled, which is typical for high-temperature oxidation [262, 263]. The same observations apply to the eutectic-eutectoid alloy series A, B and C and the eutectoid reference alloy, which exhibit parabolic oxide scale growth kinetics at 1100 and $1200^{\circ} \mathrm{C}$ as well (see App. 38) [216]. The determined oxidation rate constants for all test temperatures and the corresponding $R_{a d j}^{2}$ values are provided for the eutectic reference alloy in Table 6-3 (see App. 38 for results on alloys A, C, D and the eutectoid alloy).

Table 6-3 Calculated oxidation rate constants $k_{n}$ of the eutectic alloy (based on Eq. 17) with variable exponents $n$ and the activation energy $Q_{k_{n=2}}$. For $800{ }^{\circ} \mathrm{C}$ a linear fitting method was applied resulting in the linear oxidation rate constant $k^{*} . R_{a d j}^{2}$ values are included. Table taken from Ref. [216].

\begin{tabular}{|c|c|c|c|c|c|c|}
\hline \multirow{2}{*}{$T /{ }^{\circ} \mathrm{C}$} & period of $t / \mathrm{h}$ & $n /-$ & $k_{n} / \mathrm{m}^{\mathrm{n}} \mathrm{s}^{-1}$ & $k^{*} / \mathrm{ms}^{-1}$ & $\begin{array}{c}Q_{k_{n=2}} / \\
\mathrm{kJ} / \mathrm{mol}\end{array}$ & $R_{\text {adj }}^{2} /-$ \\
\hline \multirow{2}{*}{800} & $1-1000$ & 4.45 & $1.16 \times 10^{-29}$ & - & & 0.82 \\
\cline { 2 - 6 } & $1-100$ & linear fitting & - & $8.25 \times 10^{-12}$ & & 0.97 \\
\cline { 2 - 6 } & $100-1000$ & 3.18 & $4.51 \times 10^{-23}$ & - & & 0.94 \\
\cline { 2 - 6 } & $100-1000$ & 2 (parabolic) & $4.41 \times 10^{-17}$ & - & & 0.61 \\
\hline \multirow{2}{*}{1100} & $1-100$ & 2.94 & $8.64 \times 10^{-20}$ & - & & 0.99 \\
\hline \multirow{2}{*}{1200} & $1-100$ & 2 (parabolic) & $2.38 \times 10^{-15}$ & - & \multirow{2}{*}{310} & 0.86 \\
\hline
\end{tabular}

In contrast, the oxide scale growth at $800{ }^{\circ} \mathrm{C}$ does not obey to a parabolic law, as an exponent of 4.45 is determined with a noteworthy inferior fit quality of $R_{a d j}^{2}=0.82$ (see Table 6-3) [216]. As such high exponents have not been reported for power-law oxidation kinetics so far, it is suggested that the oxidation kinetics are changing with time and, thus, separate oxidation periods are considered. During the initial stage of oxidation (up to $100 \mathrm{~h}$ ), the oxide scale growth is found to obey linear oxidation kinetics, as a linear fit function results in a high fit quality of $R_{a d j}^{2}=0.97$ [216]. This is in accordance with a reaction ratecontrolled oxidation mechanism, which is determined by surface reactions at the oxide scale/atmosphere or oxide scale/substrate interface [264].

This finding is especially supported by SEM analyses, confirming that no continuous oxide scale is formed up to $100 \mathrm{~h}$ of cyclic oxidation (see Fig. 6-23). The surface-near Moss regions 
preferentially oxidise in contrast to the slow oxidising $(\mathrm{Ti}, \mathrm{Mo})_{5} \mathrm{Si}_{3}$ regions, which leads to selective oxidation and a discontinuous oxide scale (see Fig. 6-23a and b). Hence, the required surface area of the respective interface is expected to be available for the oxidation reactions during oxidation testing up to $100 \mathrm{~h}$. Other oxidation mechanisms, which result in linear oxidation kinetics, like unhindered $\mathrm{O}$ access to the alloy substrate through porous and/or cracked oxide scales, are not assumed to be active, as the observed oxide scale formed at $800{ }^{\circ} \mathrm{C}$ is found to be crack-free without significant porosity. In contrast, for oxidation times longer than $100 \mathrm{~h}$, the formation of a continuous mixed Si-Ti-oxide scale is observed, which fully covers the alloy substrate (see Fig. 6-23c and d).
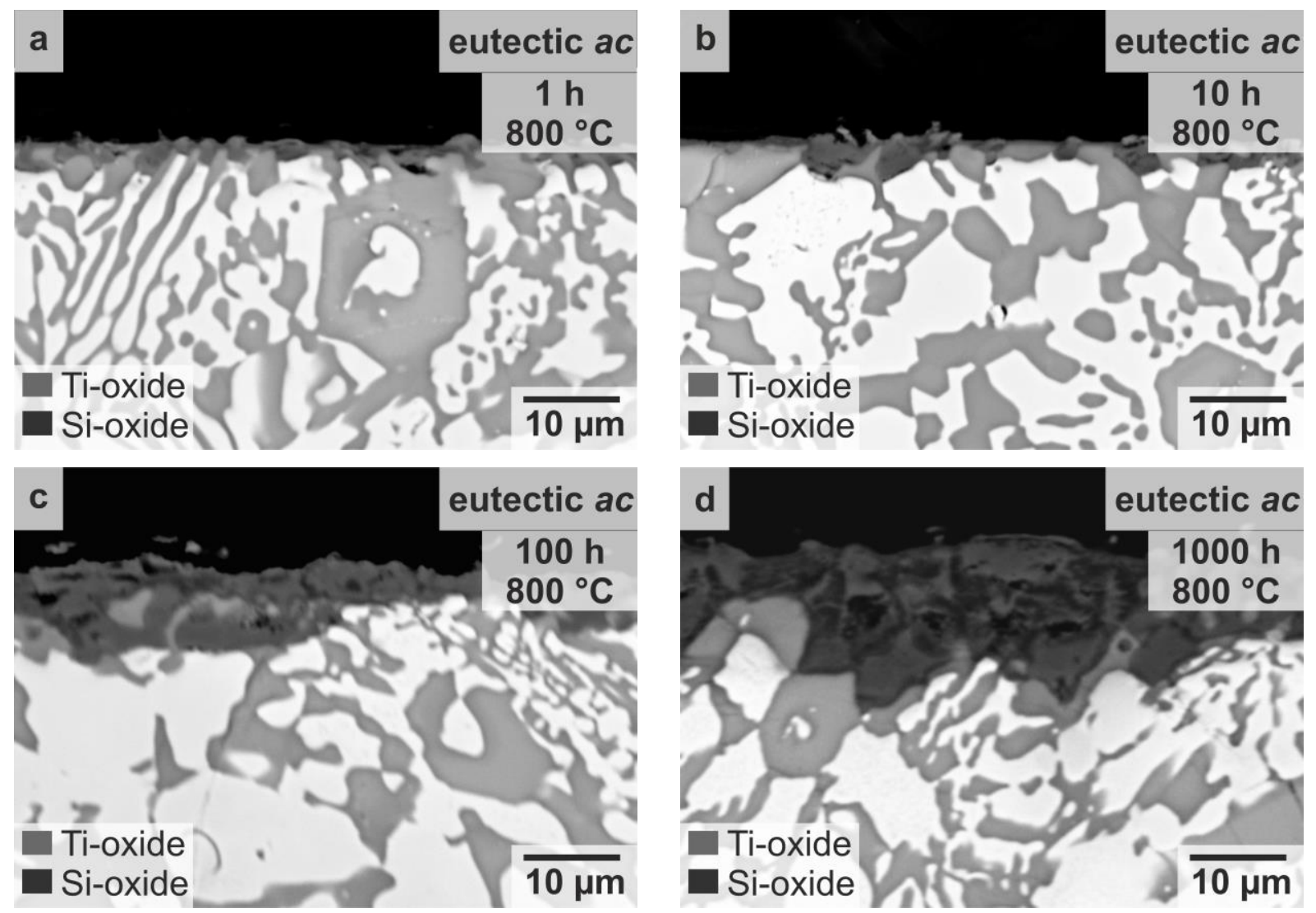

Fig. 6-23 Cross sectional BSE micrographs of the eutectic alloy after cyclic oxidation for 1 (a), 10 (b), 100 (c) and $1000 \mathrm{~h}$ (d) at $800^{\circ} \mathrm{C}$. According to Ref. [216].

This change in oxide scale morphology proposes a transition in oxidation mechanism, which is further supported by the fitting results of the long-term oxidation stage (100 to $1000 \mathrm{~h}$ ) by Eq. 17. An exponent of 3.18 is determined with a good fit quality of $R_{a d j}^{2}=0.94$ [216]. Thus, a change in oxidation kinetics from linear to cubic after $100 \mathrm{~h}$ of exposure to $800{ }^{\circ} \mathrm{C}$ is confirmed [216]. The cubic oxidation stage is likely to be determined by interface/boundary diffusion processes of $\mathrm{O}$ anions along grain or phase boundaries, as reported in literature for cubic behaviour [127-129]. This change in oxide scale growth kinetics from 
linear (with a significant low oxide scale growth rate constant of $8.25 \times 10^{-12} \mathrm{~ms}^{-1}$ ) to cubic seems to be responsible for the exceptional oxidation behaviour of the eutectic alloy at $800{ }^{\circ} \mathrm{C}$, demonstrating its pesting resistance.

Furthermore, the (almost) parabolic high-temperature oxide scale growth kinetics ascertained for the eutectic reference alloy, is also found for the eutectic-eutectoid alloy series and the eutectoid reference alloy (see App. 38). The respective parabolic oxidation rate constants $k_{n=2}$ were determined to be in the same order (for instance $1.5 \times 10^{-14}$ at $1200{ }^{\circ} \mathrm{C}$ ) with comparable activation energies in the range of 200 to $410 \mathrm{~kJ} / \mathrm{mol}$ [216] (see App. 38). Thus, no difference in oxidation kinetics is observed at higher temperatures between the pesting-resistant Ti-rich (> 43 or 40 at\% nominal Ti), and non-pesting-resistant Ti-lean alloy series, which could have been interpreted in order to develop a further understanding of the root causes for pesting resistance. In comparison, the parabolic oxidation rate constant of $\mathrm{Si}$ to $\mathrm{SiO}_{2}$ in $\mathrm{O}_{2}$ is reported to be in the range of $1 \times 10^{-17} \mathrm{~m}^{2} \mathrm{~s}^{-1}$ [265], which is several orders of magnitude lower than for the oxidation of the Mo-Si-Ti alloys. For the oxidation of (Ti,Mo) ${ }_{5} \mathrm{Si}_{3}$ in air at $1200{ }^{\circ} \mathrm{C}$, it is determined to be $4 \times 10^{-15} \mathrm{~m}^{2} \mathrm{~s}^{-1}$ [152], which is comparable to the Mo-Si-Ti alloys.

However, in order to further classify the observed oxidation behaviour of the Mo-Si-Ti alloys, the oxidation rate constants and activation energies are compared to the equivalent parameter for diffusion processes. As the oxidation rate constants are thermally activated [130] and proportional to the diffusion coefficient $D$ of the respective diffusing species through the corresponding oxide (see Eq. 18 in Sec. 2.3), these can be visualised in an Arrhenius plot combined with $D$ (see Fig. 6-24) [216]. This direct comparison is allowed, as the ratio of $D$ and $k_{n=2}$ is between 0 and 2 without any variance in magnitude.

Firstly, it is revealed that the activation energies of the parabolic oxidation rate constants are comparable to the activation energies for bulk diffusion of the oxidant $\mathrm{O}$ or reactants $\mathrm{Ti}$ and $\mathrm{Si}$ in the oxides $\mathrm{TiO}_{2}$ and $\mathrm{SiO}_{2}$ (comparable slopes in Fig. 6-24) [250, 266-270]. Additionally, the $\mathrm{Ti}$ ion diffusion (blue line) is considerably faster than the diffusion of $\mathrm{O}$ ions (red lines) in $\mathrm{TiO}_{2}$. This is in good agreement with the previously anticipated fast outwardgrowing character of $\mathrm{TiO}_{2}$ due to $\mathrm{Ti}$ ion outward diffusion, which has also been experimentally confirmed by Azim et al. in Ref. [47] for the oxidation of Mo-Si-B-Ti alloys. Further support provides the finding that the oxidation rate constants of the eutectic-eutectoid alloys are in the same order like the diffusion coefficient for bulk diffusion of $\mathrm{Ti}$ in $\mathrm{TiO}_{2}$ [216]. In contrast, the $\mathrm{Si}$ ion diffusion in $\mathrm{SiO}_{2}$ (yellow line) is slower than that of O ions 
(orange lines). This is also in good agreement with the growth characteristics of $\mathrm{SiO}_{2}$, which are reported to be dominated by $\mathrm{O}$ inward diffusion [265].

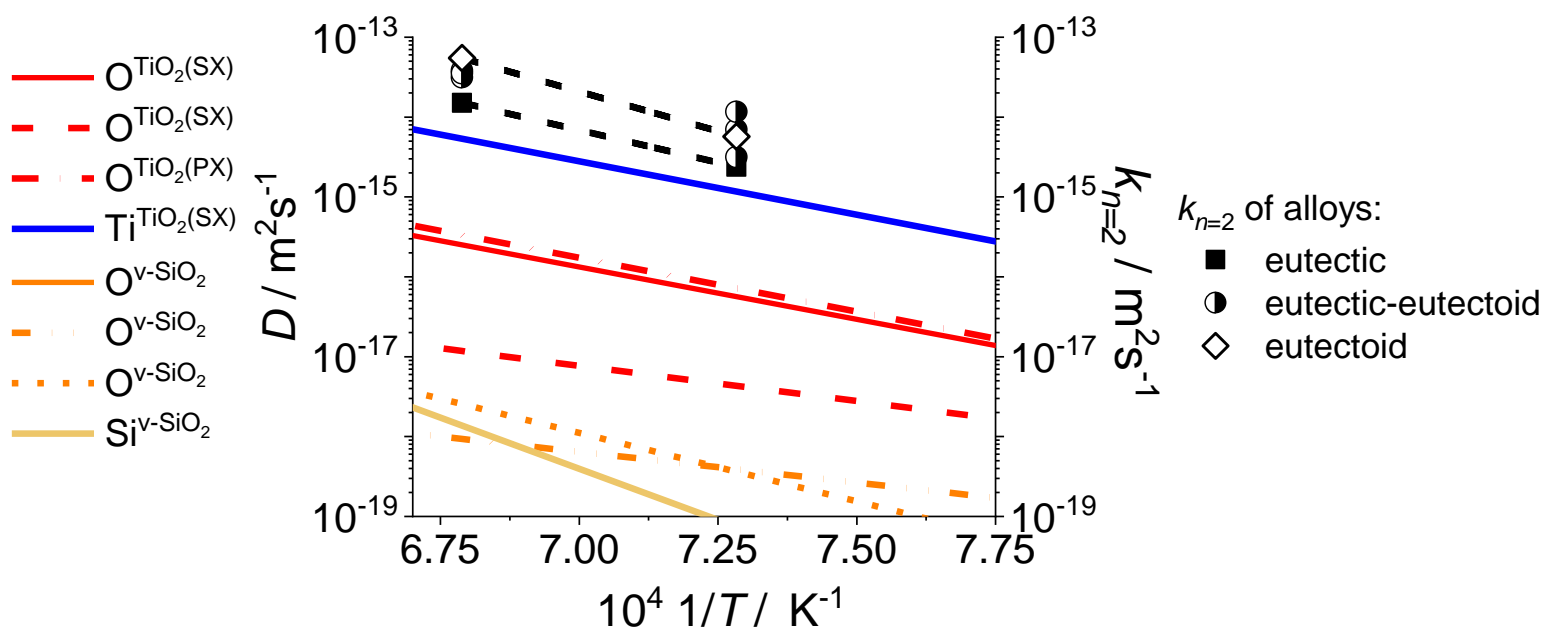

Fig. 6-24 Diffusion coefficient $D$ of $\mathrm{O}$ and Ti ions in single- (SX) and polycrystalline $\mathrm{TiO}_{2}$ (red and blue lines) and $\mathrm{O}$ and $\mathrm{Si}$ ions in vitreous (v) $\mathrm{SiO}_{2}$ (orange and yellow lines) as a function of the reciprocal temperature. Data taken from Refs. [267-272]. For comparison, the parabolic oxidation rate constants $k_{n=2}$ are included for the eutectic (filled squares) and eutectoid reference alloys (opened diamonds), as wells as for the intermediate eutectic-eutectoid alloys (half-opened circles). Note that only two data points are used for the determination of the activation energy of the parabolic oxidation rate constants for each alloy. According to Ref. [216].

In essence, the oxidation kinetics of the investigated Mo-Si-Ti alloys is determined by the combination of the kinetics of the microstructural constituents. Thus, the oxide scale growth kinetics of (Ti,Mo) ${ }_{5} \mathrm{Si}_{3}$ and Moss are briefly discussed (data on the kinetics of the constitutional elements are appended in App. 39): (Ti, Mo) ${ }_{5} \mathrm{Si}_{3}$ is reported to obey diffusioncontrolled parabolic oxide scale growth kinetics from 900 to $1300{ }^{\circ} \mathrm{C}$ with a parabolic oxidation rate constant being half an order of magnitude lower compared to the eutectic alloy [152]. The formation of an outer $\mathrm{TiO}_{2}$ scale on top of a duplex $\mathrm{SiO}_{2}-\mathrm{TiO}_{2}$ scale is observed and it is stated that the formation of volatile $\mathrm{MoO}_{3}$ is supressed [152]. In contrast, Ti-rich Moss undergoes linear weight loss due to the formation of porous, solid Ti-oxides and volatile $\mathrm{MoO}_{3}$ in the entire temperature range [215]. However, it is rather unlikely that the oxidation kinetics of the eutectic alloy at $800{ }^{\circ} \mathrm{C}$ is dominated by the linear weight loss kinetics of Moss, as its areal fraction is considerable with 0.4, but extremely low mass changes of 0.1 to $0.3 \mathrm{mg} / \mathrm{cm}^{2}$ are observed after $100 \mathrm{~h}$. Nevertheless, it is found that the 
linear oxidation kinetics at $800{ }^{\circ} \mathrm{C}$ turns to cubic for oxidation times longer than $100 \mathrm{~h}$, when a continuous oxide scale is formed and diffusion processes gain importance [216].

In conclusion, the study of the microstructural constitution and oxidation kinetics of the oxide scales formed on the eutectic alloy has revealed that the oxidation behaviour is determined by the interaction of Si- and Ti-oxides, which are formed upon simultaneous oxidation of Moss and (Ti,Mo) ${ }_{5} \mathrm{Si}_{3}$. While the oxidation at $800{ }^{\circ} \mathrm{C}$ obeys very slow linear to cubic oxidation kinetics, oxidation at elevated temperatures turns from almost cubic $\left(1100{ }^{\circ} \mathrm{C}\right)$ to parabolic $\left(1200^{\circ} \mathrm{C}\right)$, being diffusion-controlled [216]. The latter is attributed to significant diffusion processes enabling fast, continuous oxide scale formation. 


\section{Creep Behaviour}

This chapter includes published research by Obert et al. [224, 225] on the creep behaviour of selected Mo-Si-Ti alloys. Respective data, figures and argumentations are explicitly referenced or cited when being based on or extracted from them, respectively.

Chap. 6 has revealed that pesting-stability is achieved in a large variety of Mo-Si-Ti alloys, when these contain a high nominal Ti content (> 40 and 43 at\% in ( $\mathrm{Mo}, \mathrm{Ti})_{5} \mathrm{Si}_{3}$-containing or other eutectic-eutectoid alloys, respectively) and exhibit a fine-scaled microstructure. With regard to high-temperature applications, the creep behaviour is essential as well. Thus, in this chapter the creep resistance of the pesting-resistant Mo-Si-Ti alloys is presented and discussed in detail. For the sake of simplicity with respect to sample preparation all creep data were collected in compression mode.

\subsection{Assessment of the Creep Behaviour of the Eutectic-Eutectoid Alloys}

The pesting-resistant eutectic-eutectoid alloys were subjected to compressive creep testing at $1200^{\circ} \mathrm{C}$ with the aim to verify whether a successful combination of both, oxidation and creep resistance can be obtained. The resulting true creep rates are shown in Fig. 7-1 as a function of true strain. The evolution of the true creep rate with true strain is characterised by a significant drop during the primary stage leading to a creep rate minimum (highlighted by square markers in Fig. 7-1) at true strains in the range of 1.5 to $2.5 \%$ (alloy series A to C) or even 4 at\% (alloy D2). Subsequently, the creep rate increases. Thus, no macroscopic steady-state regime is reached in all alloy series. The same observations have been made for the eutectic and eutectoid reference alloys in Ref. [5]. The evaluation of the attained true strain at the creep rate minimum in dependence of the applied stress (see App. 40) reveals that these strains in the creep rate minimum are tendentially decreasing with increasing stress in specific stress ranges. However, for the alloy series A and alloy D1 an inconsistent slight decrease in true strain is observed at $50 \mathrm{MPa}$. This may point to a change in creep mechanism towards diffusional creep, as the duration of loading is considerably increased at this rather low stress level. 

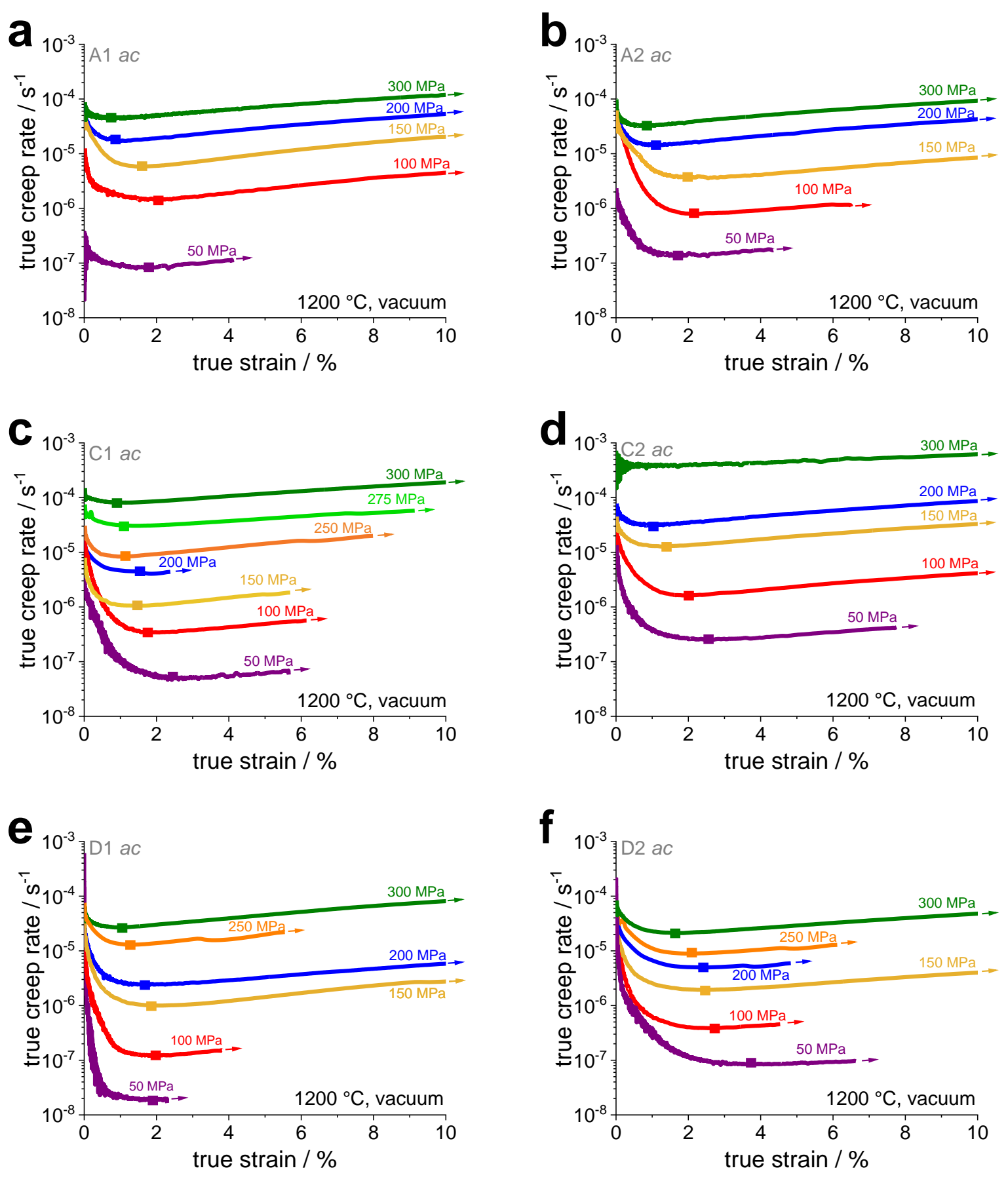

Fig. 7-1 True creep rates vs. true strain of the investigated alloy series A (a and b), $\mathrm{C}$ (c and d) and D (e and f) under compressive creep testing at $1200^{\circ} \mathrm{C}$. The minimum creep rates are highlighted by square markers. Data of alloy A1 according to Ref. [224] and of alloys C1, D1 and D2 according to Ref. [225].

The minimum creep rates are assessed in a double-logarithmic plot as a function of applied trues stress in Fig. 7-2. It is demonstrated that the eutectic-eutectoid alloys (diamond symbols) exhibit an intermediate creep resistance in comparison to the eutectic (green square symbols) and eutectoid (blue square symbols) reference alloys. For comparison, the 
range of the minimum creep rates obtained in the investigated alloys is framed by the minor creep performance of the monolithic phase $\mathrm{Ti}_{5} \mathrm{Si}_{3}$ [200] and the superior performing phase $\mathrm{Mo}_{5} \mathrm{Si}_{3}$ [198]. These considerably different creep resistances of the monolithic phases (black symbols) suggest that these might determine the creep resistance of the least creep-resistant $(\mathrm{Ti}, \mathrm{Mo})_{5} \mathrm{Si}_{3}$-containing eutectic alloy and of the most creep-resistant $(\mathrm{Mo}, \mathrm{Ti})_{5} \mathrm{Si}_{3}$-containing eutectoid alloy [5, 224].

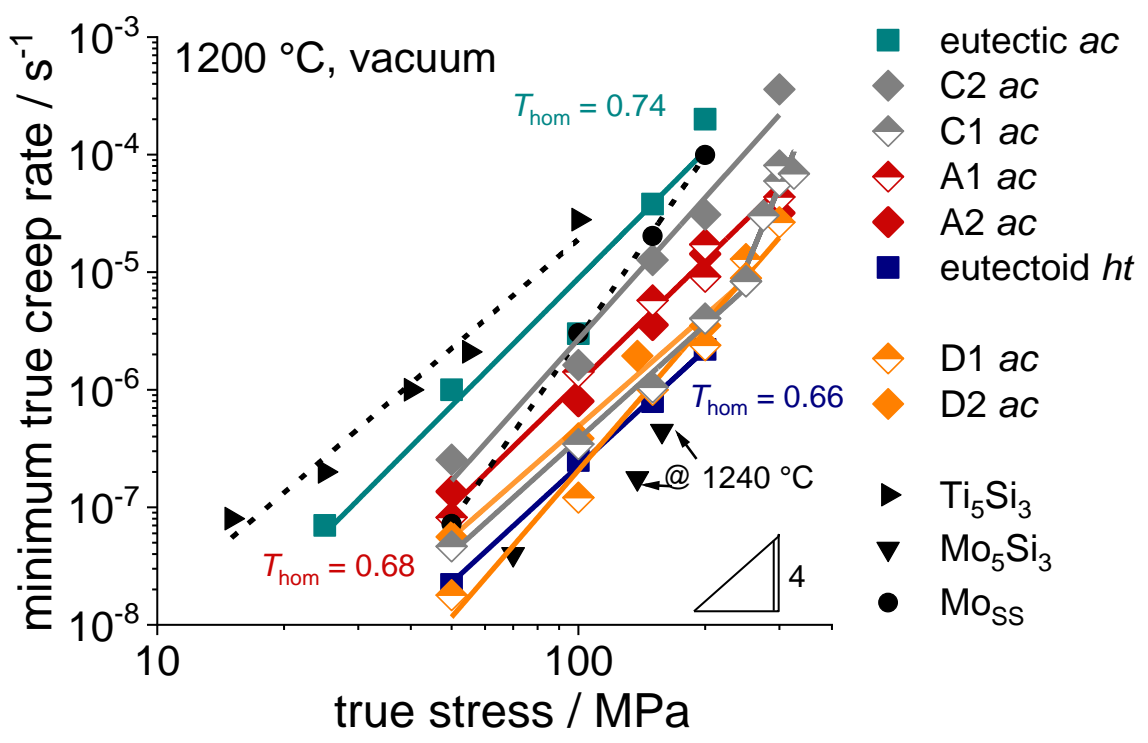

Fig. 7-2 Norton plot of the pesting-resistant alloy series A, C, D and alloy Mo-40Ti3Si as representative Moss in comparison to the eutectic and eutectoid reference alloys [5], as well as to literature data on the monolithic phases $\mathrm{Ti}_{5} \mathrm{Si}_{3}$ [200] and $\mathrm{Mo}_{5} \mathrm{Si}_{3}$ [198]. Data of alloy A1 ac taken from Ref. [224] and of alloys C1 $a c, \mathrm{D} 1 a c$ and D2 $a c$ from Ref. [225]. Plot according to Ref. [224].

However, in order to evaluate whether creep is controlled by the creep performance of the monolithic phases, the creep resistance of Moss needs to be considered as well. Therefore, additional creep tests were performed on several bcc Mo-Ti(-Si) single-phase alloys with Ti contents varying between 20 and 40 at\% (see Fig. 7-3a to c). Minimum and nearly steady state creep rates were determined for the Ti-lean (Mo-20Ti) and the high-Ti alloy variants (Mo-40Ti and Mo-40Ti-3Si), respectively, and are compared in the Norton plot shown in Fig. 7-3d. It is found that their creep resistance lies in between both reference alloys. In Fig. 7-2, the results for the high Ti-containing Moss (Mo-40Ti-3Si) are included (see black circular symbols), as it represents the chemical composition of the Moss within the investigated alloys reasonably well. Thus, the creep performance of Moss seems not to be decisive for the obtained creep resistance within the Mo-Si-Ti alloys. 

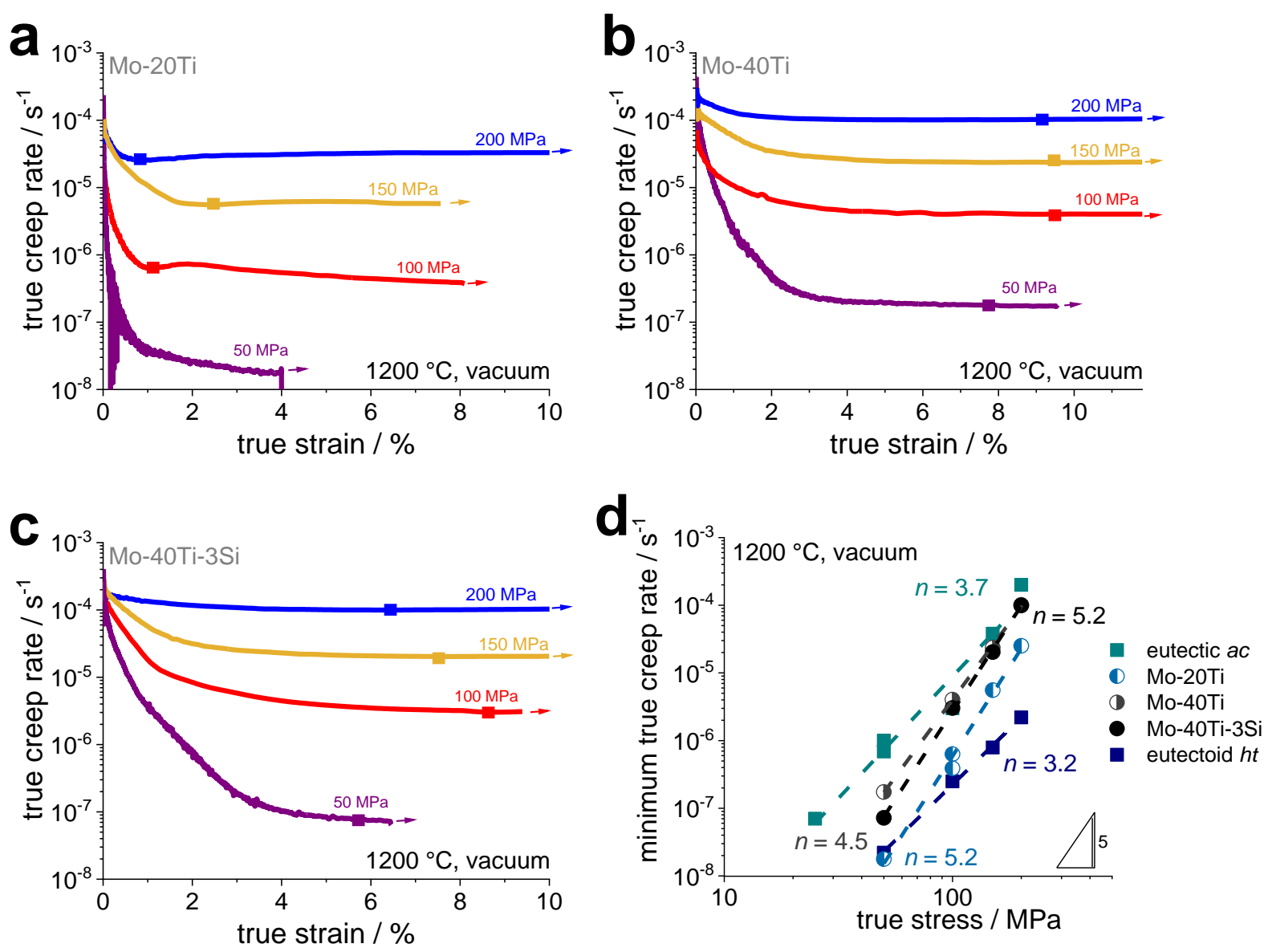

Fig. 7-3 True creep rate as a function of true strain during compressive creep testing at $1200^{\circ} \mathrm{C}$ of alloys Mo-20Ti (a), Mo-40Ti (b) and Mo-40Ti-3Si (c). The creep rate minima are highlighted by square markers. Corresponding Norton plot in comparison to the eutectic and eutectoid reference alloys [5] (d).

Further on, the stress exponents $n$ were determined based on the power law for creep (see Eq. 20 in Sec. 2.4) in order to investigate whether the creep behaviour of the intermediate Mo-Si-Ti alloys is controlled by the monolithic phases. The stress exponents were found to be in the range of 3 to 4 for most investigated alloys [224, 225] indicating dislocation climbcontrolled creep. This applies to the eutectic and eutectoid reference alloys as well, exhibiting stress exponents of 3.7 and 3.5, respectively [5]. Moreover, the same stress exponents were reported for three-phase Mo-Si-B-Ti alloys (Moss + (Ti,Mo) ${ }_{5} \mathrm{Si}_{3}+\mathrm{Mo}_{5} \mathrm{SiB}_{2}$ ) [4]. In this regard, alloy $\mathrm{C} 1$ is exceptional as it exhibits a sharp increase in the stress exponent from 3.2 to 8.6 at $250 \mathrm{MPa}$ [225]. This indicates a change in the dominating creep mechanism and possibly a transition towards power law (creep) break-down. [225] For comparison, the monolithic phases Moss and $\mathrm{Mo}_{5} \mathrm{Si}_{3}$ reveal increased stress exponents of 5.2 and 5.9 (here at $1240^{\circ} \mathrm{C}$ ) [145], respectively, whereas $\mathrm{Ti}_{5} \mathrm{Si}_{3}$ exhibits a stress exponent of 2.8 [200]. Conclusively, the creep behaviour of the investigated alloys is not solely determined by the 
individual creep performance of the monolithic phases, but presumably by their interaction and the microstructural morphology.

For further analysis, the apparent activation energy $Q_{c}$ was determined for the intermediate Mo-Si-Ti alloys by applying the Arrhenius correlation at $200 \mathrm{MPa}$ (see Eq. 20 in Sec. 2.4). All investigated alloys were found to possess apparent activation energies in the range of 400 to $530 \mathrm{~kJ} / \mathrm{mol}$ (see App. 41 for exact values), which is in the same order as the ones for the eutectic and eutectoid reference alloys [5]. For comparison, the activation energy for self-diffusion in Mo is reported to be in the range of 405 to $486 \mathrm{~kJ} / \mathrm{mol}$ [197, 273]. Thus, it is confirmed that the dominant creep mechanisms are similar for all investigated Mo-Si-Ti alloys. Due to the comparable apparent activation energies and similar active creep mechanisms, the minimum creep rates obtained in these alloys can be normalised by their respective solidus temperature as displayed in Fig. 7-4. Thereby, the usage of inverse homologous temperatures almost results in one single master straight (also observed for alloy A1 and both reference alloys in Ref. [224]). This proves that the observed differences in creep resistance of the investigated alloys are mainly determined by the different homologous temperature and, thus, by the solidus temperature of the alloys and not by the differing creep performance of $(\mathrm{Ti}, \mathrm{Mo})_{5} \mathrm{Si}_{3}$ or $(\mathrm{Mo}, \mathrm{Ti})_{5} \mathrm{Si}_{3}$. In conclusion, neither primary solidification of Moss (alloy A2) or (Mo,Ti) ${ }_{5} \mathrm{Si}_{3}$ (alloy $\mathrm{C} 1$ and alloy series D), nor a high volume fraction of eutectoid regions can be accounted for an improvement in creep resistance in terms of a significant deviation from the trend line [224, 225]. This is further proven by additional compression creep tests at 100 and $200 \mathrm{MPa}$ at deliberately adjusted temperatures, which represent the same homologous temperature $T_{h o m}$. Thus, alloy A1 and the eutectic reference alloy were tested at $T_{\text {hom }}=0.74$ and both reference alloys, the eutectic and eutectoid, at $T_{\text {hom }}=0.66$ (see App. 42). No difference in creep behaviour was observed (as also shown in Ref. [224] by a single cross check experiment for alloy A1 at $\left.T_{\text {hom }}=0.74\right)$.

However, this distinct solidus temperature-dependent behaviour of the Mo-Si-Ti alloys $[224,225]$ is not observed in the different Ti-rich Moss (see circular symbols in the normalised Arrhenius plot in Fig. 7-4), as these exhibit apparent activation energies varying between 438 to $630 \mathrm{~kJ} / \mathrm{mol}$ and do not show a single master straight when normalised by the solidus temperature. 


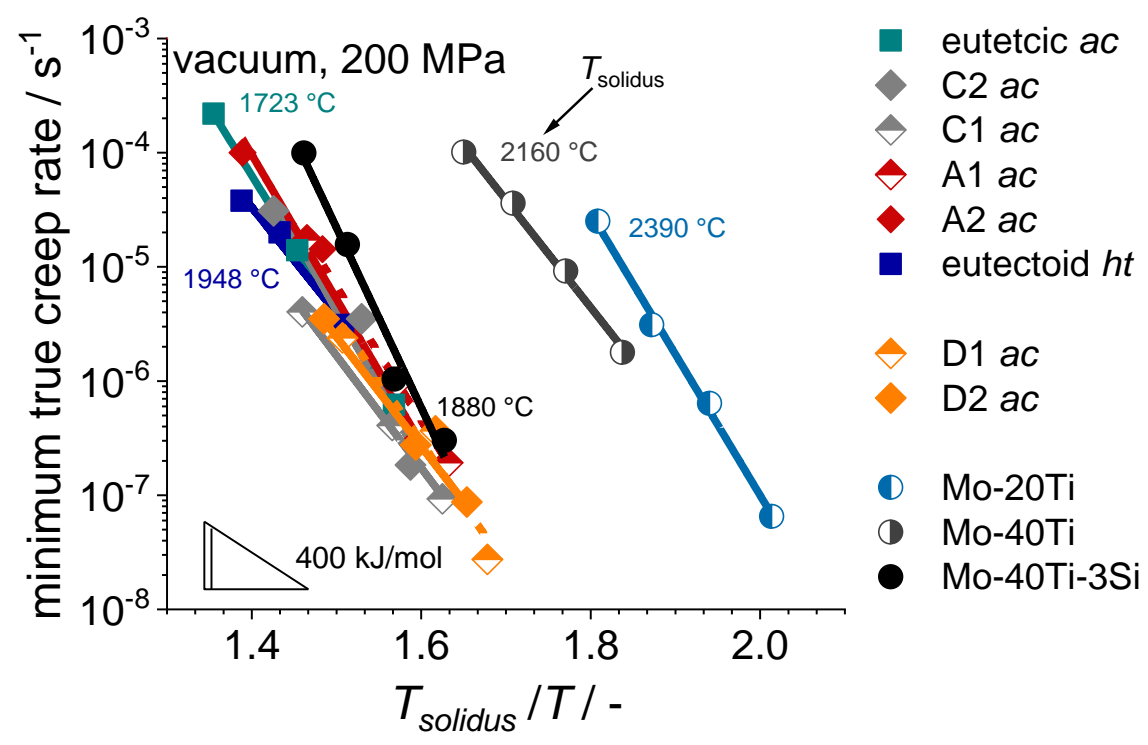

Fig. 7-4 Arrhenius plot normalised by the solidus temperature (data of alloy A1 ac according to Ref. [224]), which has been calculated by Pandat, for the investigated Mo-Si-Ti alloys including the eutectic and eutectoid reference alloy [5], as well as for several Mo-Ti-(Si) alloys. Selected solidus temperatures are provided next to the respective straights.

In order to evaluate the different contribution of the individual microstructural constituents to the overall creep deformation, microstructural analyses were undertaken after creep testing at $1200{ }^{\circ} \mathrm{C}$ and $200 \mathrm{MPa}$ (see Fig. 7-5). Note that no change in phase distribution was observed after creep for most alloys, which is in good agreement with the studies on the thermal stability of the microstructures in Sec. 5.4. The only exception is alloy D2, in which the eutectoid regions cannot be assigned anymore for strains larger than $5 \%$ indicating coagulation of phase regions, presumably of Moss. It is revealed that the eutectoid regions are less prone to creep deformation in the intermediate alloy series $\mathrm{A}$ and $\mathrm{C}$, as their lamellar morphology remains almost unaffected and no alignment with respect to the loading axis occurs up to $40 \%$ true strain (see Fig. 7-5a and b for alloy A1 and App. $43 \mathrm{a}$ to $\mathrm{d}$ for alloy series $\mathrm{C}$ ). In contrast, the eutectic regions are considerably degenerated with coagulated and deformed Moss regions, especially at high strains. Hence, the eutectic regions and particularly Moss are designated as main participants to plastic deformation under creep conditions. These observations are in accordance to studies on Mo-Si-B-Ti alloys, in which Moss was assumed to be the main participant to plastic deformation during creep [4].

Moreover, the analysis of the deformed microstructure of the high (Mo,Ti) $)_{5} \mathrm{Si}_{3}$-containing alloy series D reveals evidence of significant alignment of the $(\mathrm{Mo}, \mathrm{Ti})_{5} \mathrm{Si}_{3}$ regions to the 
loading axis after considerable plastic strain (> $5 \%$ ) (see Fig. 7-5c and d for alloy D2 and App. 43e and f for alloy D1). Additionally, degeneration and coagulation of Moss within the eutectic regions is observed as well [225]. Although the primarily solidified (Mo,Ti) ${ }_{5} \mathrm{Si}_{3}$ regions deform plastic, it is assumed that the eutectic regions are the main carrier of the creep deformation, especially at lower strain [225].
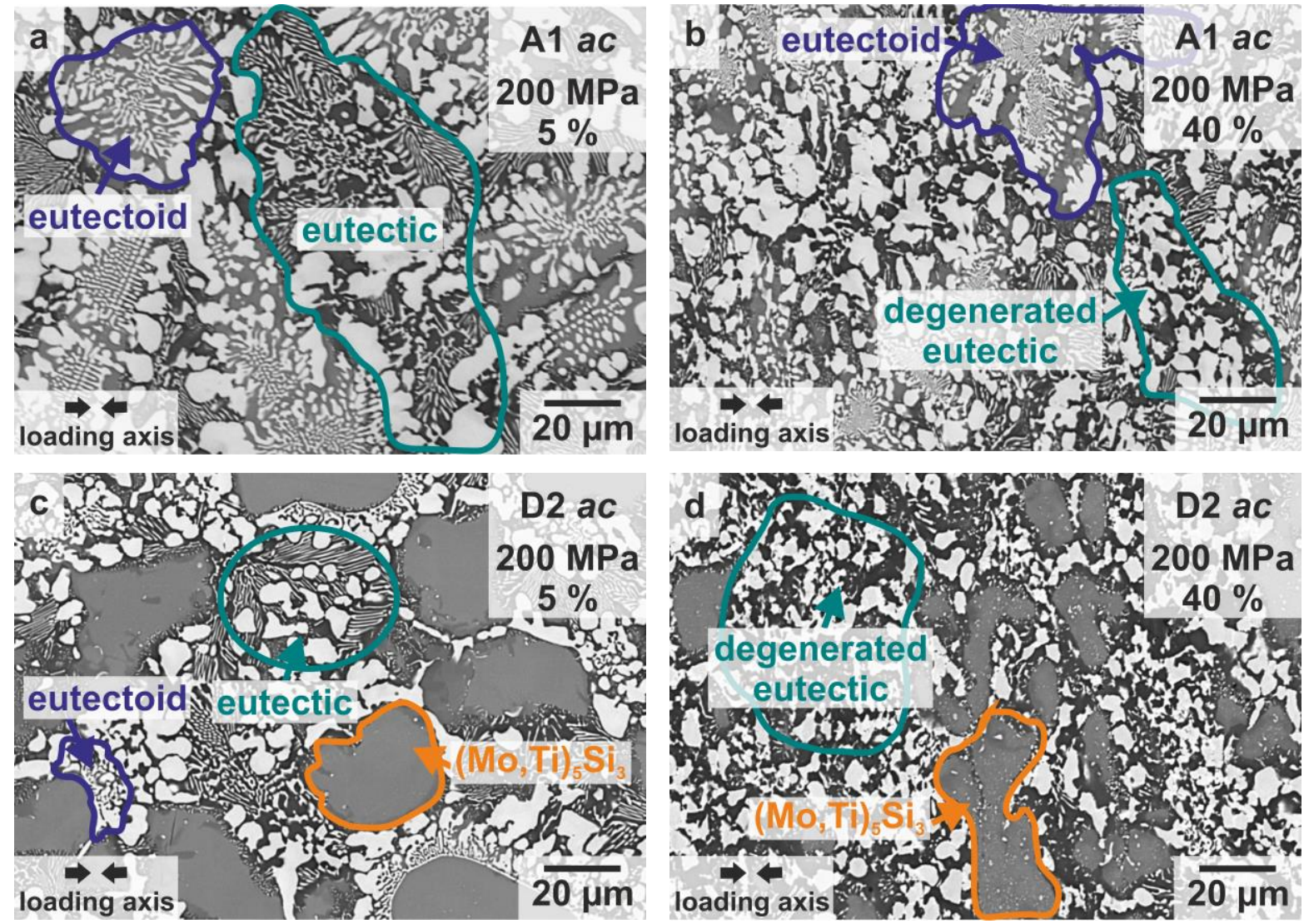

Fig. 7-5

BSE micrographs of the microstructures of the alloys A1 ac (a and b), D2 ac (c and d) after creep testing at $200 \mathrm{MPa}$ at $1200{ }^{\circ} \mathrm{C}$ with approximately 5 and $40 \%$ true strain.

In order to quantitatively assess the observed coagulation and alignment of Moss and primarily solidified (Mo,Ti) ${ }_{5} \mathrm{Si}_{3}$, the respective phase regions were approximated as ellipsoids in $a c$ condition and after creep deformation (analogously to Ref. [225]). The ellipsoid size and orientation towards the loading axis were evaluated (see schematic insets in Fig. 7-6). The number fraction $N$ of the phase regions with a size of 15 to $50 \mu \mathrm{m}^{2}$ and an orientation angle of $(90 \pm 17)^{\circ}$ to the loading axis is compared before and after creep testing (see Fig. 7-6). The coagulation of Moss is confirmed by the reduction in amount of small phase regions (15 to $50 \mu \mathrm{m}^{2}$ ) from more than $70 \%$ down to 60 to $50 \%$ in all investigated alloys with increasing strain up to $40 \%$ (square symbols in Fig. 7-6a) [225]. During creep testing, these particles align towards the loading axis to some extent in the eutectic reference alloy, 
alloys $\mathrm{C} 1$ and D2, as shown by the increasing percentage of particles oriented almost perpendicular to the loading axis (see circular symbols in Fig. 7-6a) [225]. In the other alloys, the alignment likely occurs as well, but cannot be reproduced by the ellipsoid approximation, which is not accurate for particle shapes differing significantly from ellipsoids.

The size of the $(\mathrm{Mo}, \mathrm{Ti})_{5} \mathrm{Si}_{3}$ does not change consistently during creep testing in the alloy series $\mathrm{C}$ and $\mathrm{D}$. The differences revealed by the ellipsoid analysis are caused by microstructural inhomogeneities due to AcM and not by creep deformation (square symbols in Fig. 7-6b). However, (Mo,Ti) ${ }_{5} \mathrm{Si}_{3}$ considerably aligns towards the loading axis at $40 \%$ strain.
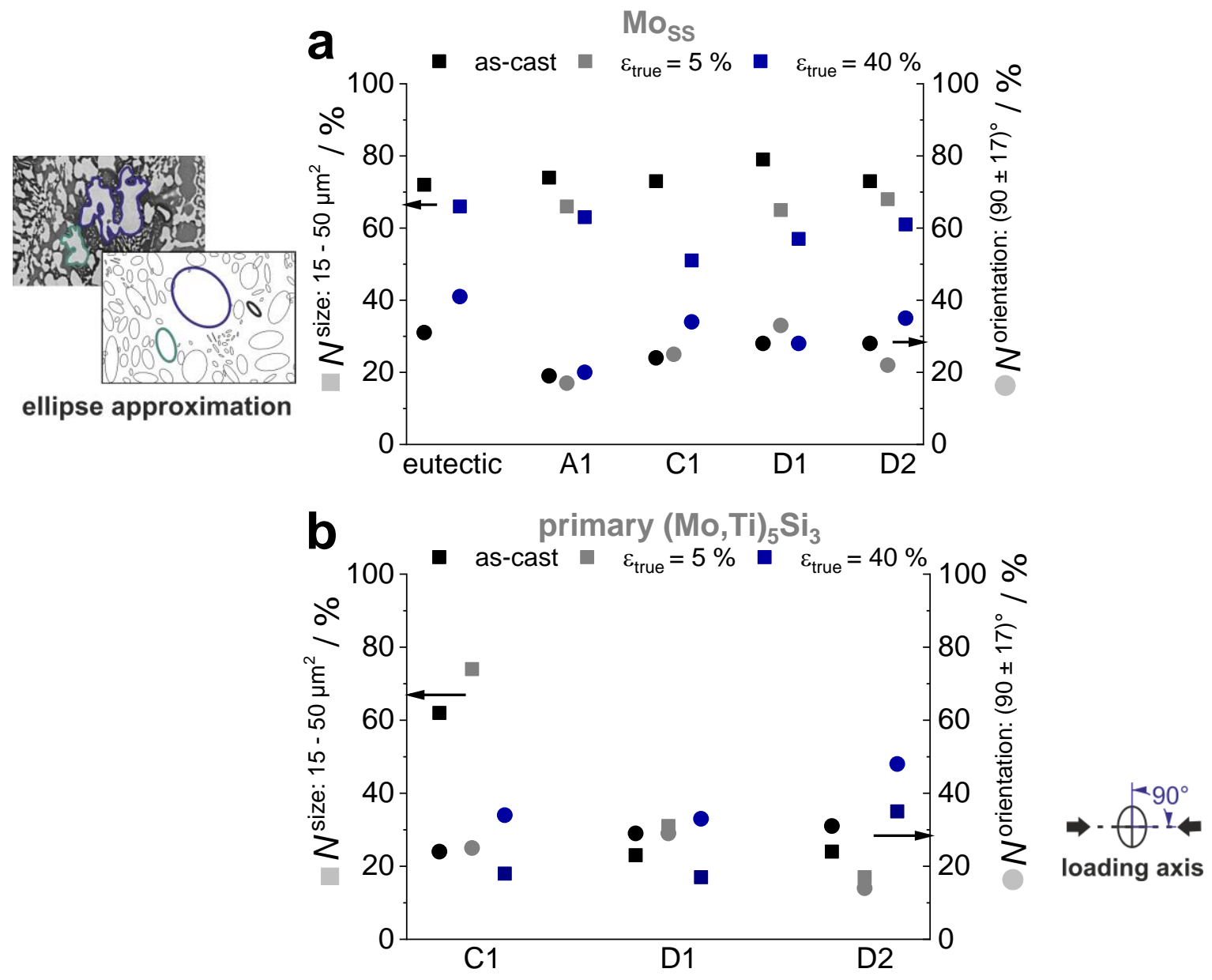

Fig. 7-6 Investigation of the phase regions Moss (a) and primarily solidified $(\mathrm{Mo}, \mathrm{Ti})_{5} \mathrm{Si}_{3}$ (b) approximated as ellipsoid-shaped particles in ac condition and after 5 and $40 \%$ true compressive creep strain in the eutectic alloy and alloys A1, C1, D1 and D2. The percentage $N$ of particles is compared for a particle size of 15 to $50 \mu \mathrm{m}^{2}$ (left axis, square symbols) and for an orientation of $(90 \pm 17)^{\circ}$ to the loading axis (right axis, circular symbols). Data on alloys C1, D1 and D2 according to Ref. [225]. 
In conclusion, the pesting-resistant alloy series A, C and D reveal an improved creep resistance compared to the eutectic alloy, which is controlled by their solidus temperature. The creep deformation is mainly carried by Moss, which significantly coagulates during creep testing.

\subsection{Impact of Artificial Coarsening on the Creep Performance}

With the aim of improving the creep resistance of representative Mo-Si-Ti alloys, artificially coarsened alloy variants $\left(h t^{*}\right)$ of the eutectic reference and alloy A1 were compression creep tested. The corresponding true creep rate vs. true strain dependencies of the $a c$ and $h t^{*}$ variants of both alloys reveal similar characteristics: (i) creep rate minima after the transient creep stage and (ii) comparable tendency of decreasing true strain, attained at the minimum creep rate, with increasing true stress (see App. 44). The results are summarised as Norton plot of the minimum creep rates in Fig. 7-7. It is revealed that the creep resistance of the eutectic alloy remains almost unaffected by the additional heat treatment, whereas a slight improvement is observed in alloy A1 after $h t^{*}$. This is further supported when applying other criteria than the minimum creep rates for developing the Norton plot (1\% true strain, $2 \%$ off-set from minimum creep rate and $5 \%$ true strain), as the same trends are observed (see Fig. 7-8 and App. 45 for comparison with the eutectic alloy).

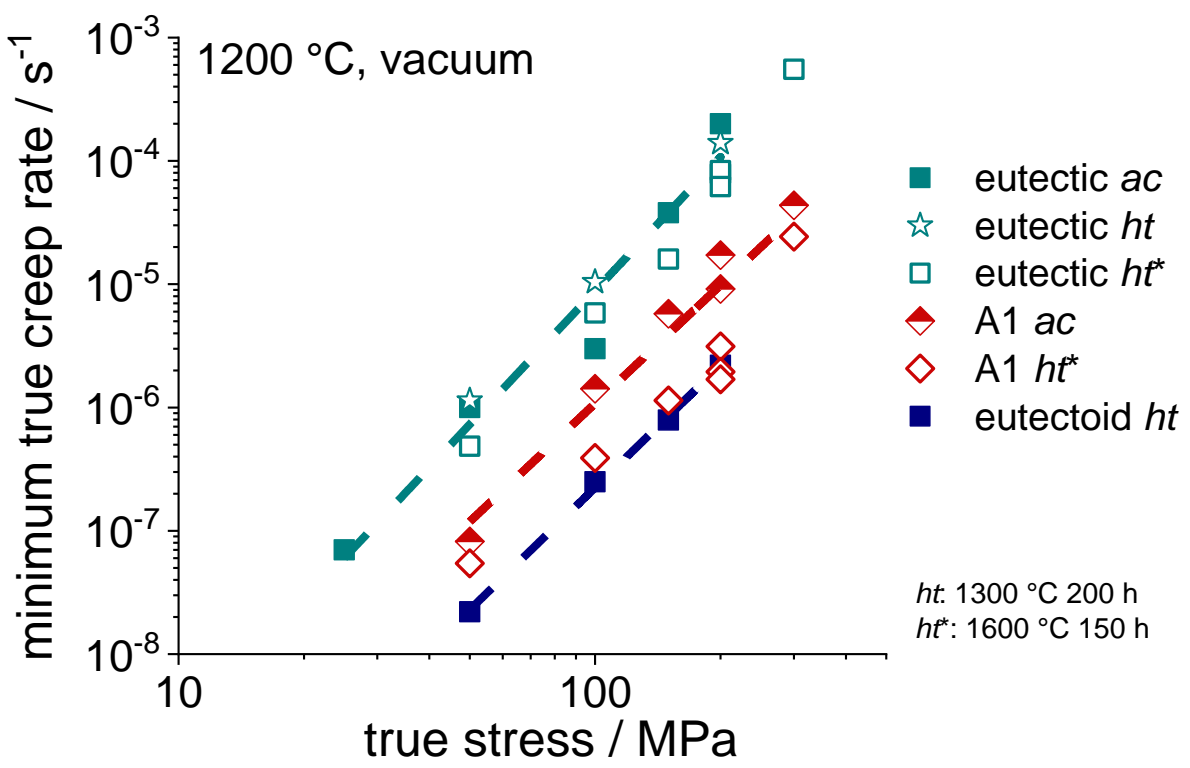

Fig. 7-7 Comparison of the minimum true creep rates attained in the eutectic reference alloy and alloy A1 in ac (half-/filled symbols) [5, 224], ht (star symbols) and $h t^{*}$ condition (opened symbols) in comparison to the eutectoid reference alloy [5]. 


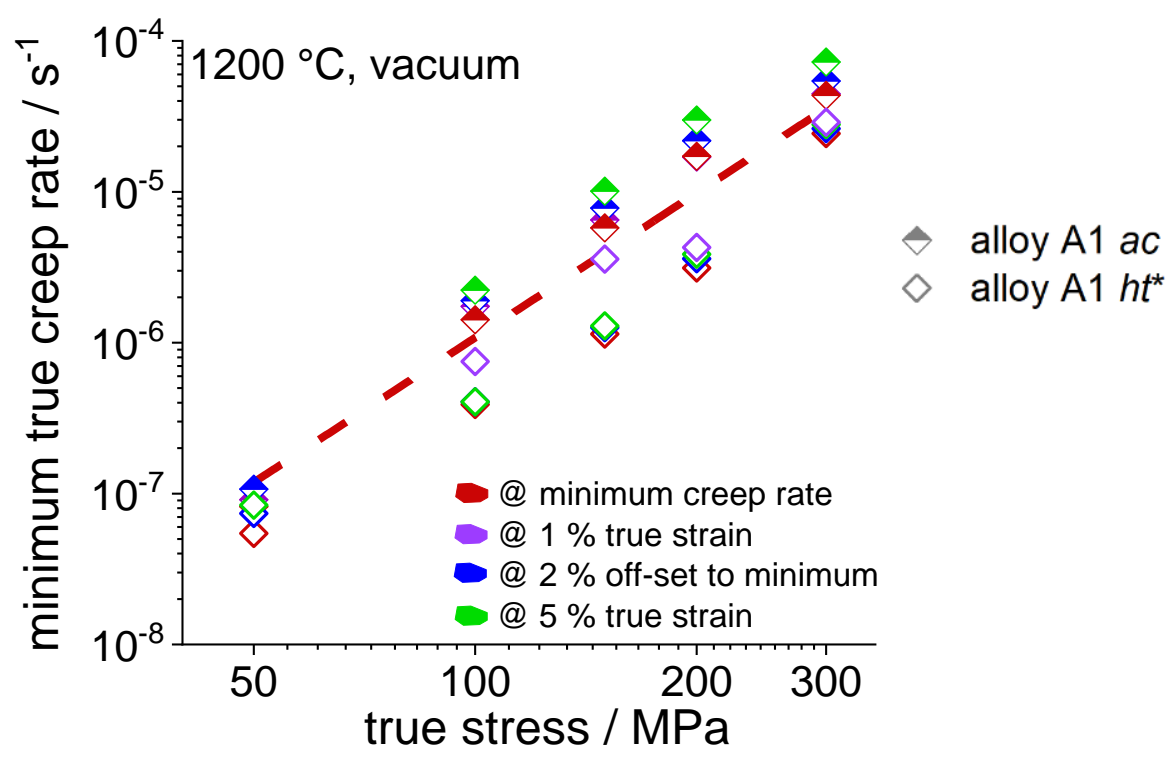

Fig. 7-8 Norton plot for alloy A1 for the creep rates at the minimum (red data points), after $1 \%$ true strain (purple data points), at $2 \%$ off-set to the minimum creep rate (blue data points) and after $5 \%$ true strain (green data points) for $a c$ and $h t^{*}$ condition. Data of alloy A1 $a c$ according to Ref. [224].

The unchanged creep performance of the eutectic alloy after $h t^{*}$ is unexpected, as considerable coarsening is achieved in the $h t^{*}$ variant. Coarser microstructures are typically known to be beneficial for creep resistance, as high-diffusivity pathways along phase boundaries are reduced. Thus, it is likely that the network structure of the present phases and their distribution are decisive for the creep resistance.

This assumption is supported by microstructural analyses of the crept microstructures (see Fig. 7-9). The assumed benefit of the coarser microstructure might be compensated by the prevalent 2D Moss network structure, which is characteristic for the $h t^{*}$ variant before (see Sec. 6.3, Fig. 6-13a) and after creep testing (see Fig. 7-9b). For comparison, rather interconnected $(\mathrm{Ti}, \mathrm{Mo})_{5} \mathrm{Si}_{3}$ networks are predominant before creep testing in $a c$ condition (not shown here). However, during creep testing, a 2D Moss networks structure is established as well (see Fig. 7-9a). Hence, since Moss is assumed to substantially contribute to the creep deformation, as has been previously discussed, the creep behaviour is likely to be dominated by the high volume fraction of Moss of around 50 vol\% and not by the morphology. 

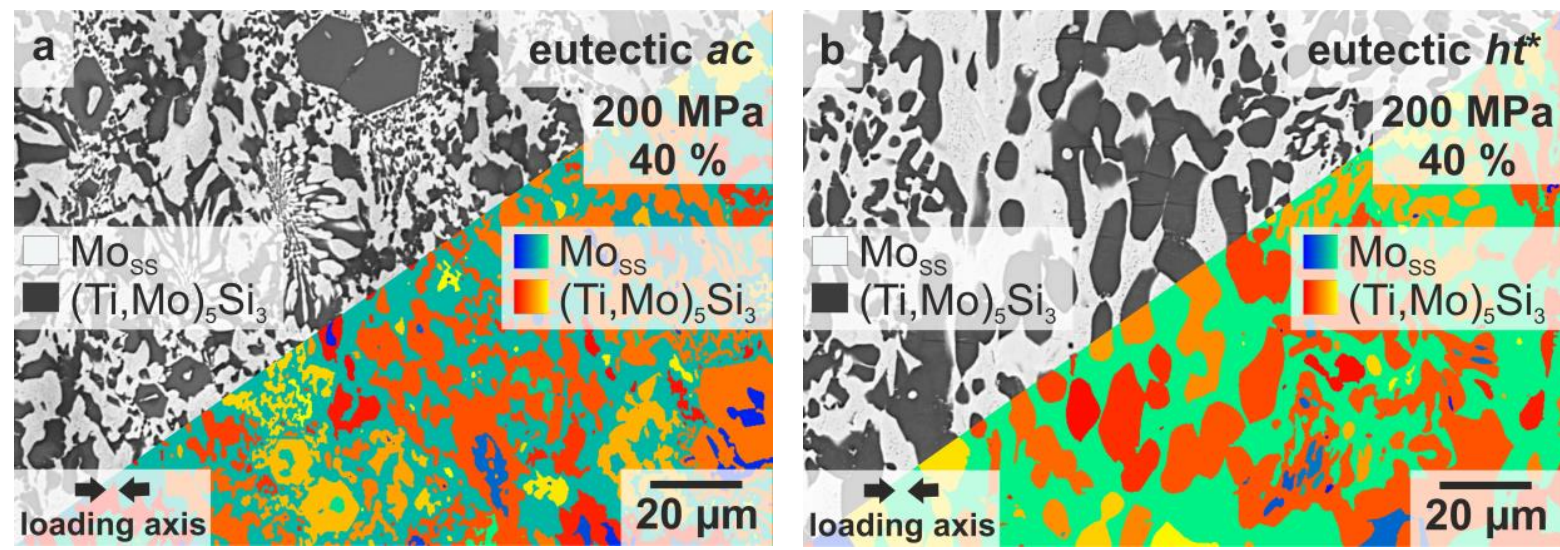

Fig. 7-9 BSE micrographs of the crept microstructures of the eutectic reference alloy in $a c$ and $h t^{*}$ condition after $40 \%$ strain. Colour-coded portions of the microstructures are included (Moss: blue to green, (Ti,Mo) ${ }_{5} \mathrm{Si}_{3}$ red to yellow).

Additionally, precipitates within Moss are observed after creep testing in both variants ( $a c$ and $\left.h t^{*}\right)$. These are likely to originate from the supersaturation of Moss in Si and Ti caused by fast cooling conditions and the decreasing element solubility with decreasing temperature $[36,80,82,274]$. This kind of precipitates were determined to be $\mathrm{Ti}_{5} \mathrm{Si}_{3}$ in Mo-Si-B-Ti alloys by Azim et al. in Ref. [48] and were accounted for the improved creep resistance of Ti-containing Mo-Si-based alloys by these authors [48]. However, creep tests on an additionally heat-treated variant of the eutectic alloy $\left(h t: 1300^{\circ} \mathrm{C}, 200 \mathrm{~h}\right)$, which already comprised precipitates within Moss prior to creep testing, revealed no improvement in creep resistance (see star symbols in Fig. 7-7). Moreover, these findings also apply to the creep results gained at 1100 and $1300{ }^{\circ} \mathrm{C}$, not revealing any difference between the $a c$ and $h t^{*}$ variant of the eutectic alloy (see Norton plot in App. 46).

In contrast, the creep performance of alloy A1 is improved by half an order of magnitude reduced minimum creep rates in $h t^{*}$ condition. This is most likely to be caused by the change in microstructural constituents from Moss + eutectic (Moss + (Ti, Mo) $\left.{ }_{5} \mathrm{Si}_{3}\right)+$ eutectoid (Moss $\left.+(\mathrm{Mo}, \mathrm{Ti})_{5} \mathrm{Si}_{3}\right)$ in ac condition to Moss $+(\mathrm{Ti}, \mathrm{Mo})_{5} \mathrm{Si}_{3}$ in $h t^{*}$ condition. Besides this change in present phases, the attained microstructure in $h t^{*}$ condition is considerably coarsened in comparison to the $a c$ variant. Additionally, a continuous, homogenous $2 \mathrm{D}$ silicide network is present in $a c$ (see Fig. 7-10a) and almost in $h t^{*}$ condition (see Fig. 7-10b). In the latter, large connected silicide regions are interwoven with local Moss networks. The ratio of Moss to (Ti,Mo) ${ }_{5} \mathrm{Si}_{3}$ is found to be approximately $1: 1 \mathrm{in}$ both, $a c$ and $h t^{*}$ condition, as it was observed for the eutectic reference alloy. Thus, it is likely that the creep behaviour is not solely dominated by the Moss volume fraction in the intermediate alloy A1, but also by the length scale of the microstructure. 

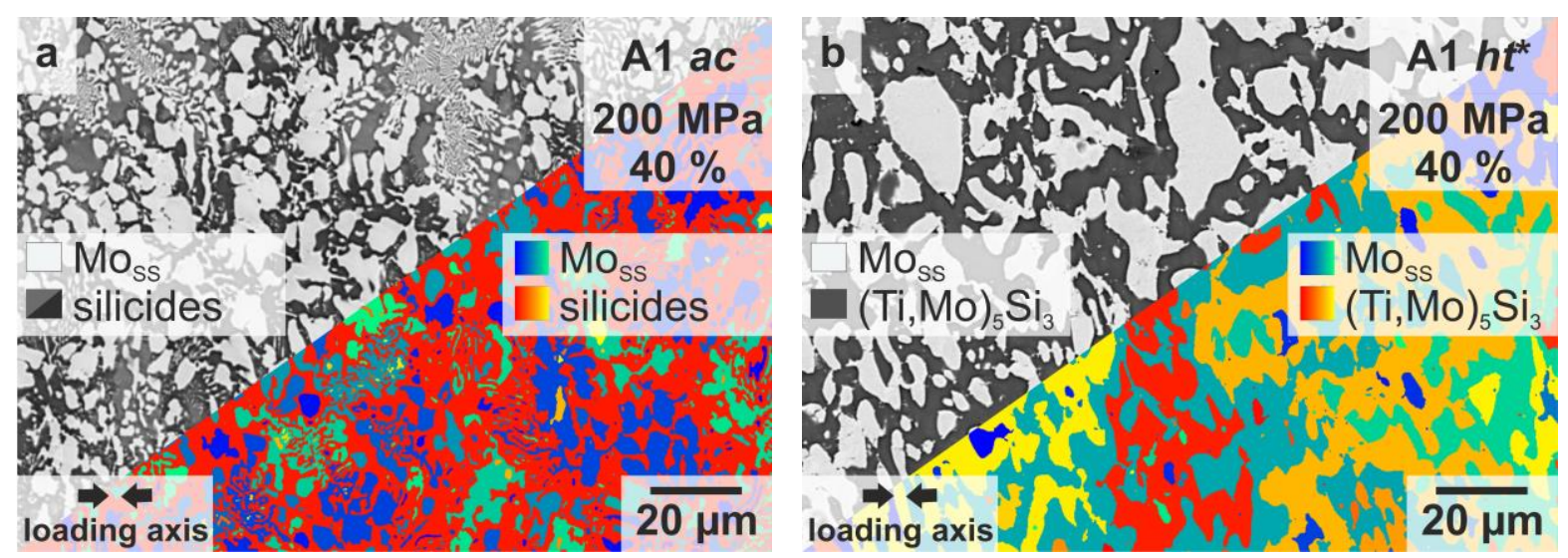

Fig. 7-10 BSE micrographs of the microstructures after creep testing at $1200{ }^{\circ} \mathrm{C}$ and $200 \mathrm{MPa}$ (40\% strain) of alloy A1 in $a c$ (a) and $h t^{*}$ condition (b). 


\section{Summary and Conclusion}

The successful development of light-weight pesting- and creep-resistant Mo-Si-Ti alloys for high-temperature applications has been presented. The pesting resistance of these alloys is attributed to the formation of a thin mixed Si-Ti-oxide scale at $800{ }^{\circ} \mathrm{C}$. Therefore, a minimum nominal Ti content of 43 at\% in the eutectic-eutectoid alloy series [215, 224] and 40 at\% in the (Mo,Ti) ${ }_{5} \mathrm{Si}_{3}$-containing alloys, respectively, is mandatory. Ti is considerably dissolved in the pesting-critical phase Moss, which was found to be less prone to pesting with an increasing Ti content, when tested as single-phase solid solution alloy [215]. Thus, a Ti content in Moss of at least 34 to 35 at\% in the alloy series is required to ensure pesting stability, as the evaporation of $\mathrm{MoO}_{3}$ is counterbalanced by the formation of solid, welladherent oxides. Moreover, it has been demonstrated that the impact of the microstructural length scale becomes significant for obtaining pesting resistance when the Ti content is close to the required threshold. At elevated temperatures of 1100 and $1200{ }^{\circ} \mathrm{C}$, a suitable oxidation resistance is provided by the formation of a two-layered oxide scale on all alloy series [224]. It is composed of a top $\mathrm{TiO}_{2}$ oxide scale and an underlying Si-Ti-oxide duplex scale. The latter is permeated by $2 \mathrm{D}$ connected Ti-oxide networks, which are likely to be $3 \mathrm{D}$ as well, strongly questioning that the Si-oxide represents the matrix forming oxide within the duplex scale. This is contradictory to studies on $(\mathrm{Ti}, \mathrm{Mo})_{5} \mathrm{Si}_{3},\left(\mathrm{Mo}, \mathrm{Ti}_{5} \mathrm{Si}_{3}\right.$ and $\mathrm{Mo}$ Si-B-Ti-Fe alloys reporting that $\mathrm{SiO}_{2}$ has to be the matrix phase within $\mathrm{SiO}_{2}-\mathrm{TiO}_{2}$ duplex oxide scales for achieving oxidation resistance [48, 70, 147, 151]. Additionally, the oxidation resistance capability of $\mathrm{TiO}_{2}$ is known to be unfavourable due to the high diffusion coefficient for $O$ [241] and the susceptibility to cracking [275]. Nevertheless, the oxide scales formed on the Mo-Si-Ti alloys are mostly crack-free [5, 215, 224]. APT measurements confirmed negligible solubility of $\mathrm{Si} / \mathrm{SiO}_{2}$ in $\mathrm{TiO}_{2}$ and vice versa [216], which is in good agreement with most recent studies on the $\mathrm{SiO}_{2}-\mathrm{TiO}_{2}$ system [276, 277]. However, it is most likely that the Ti-oxide is not detrimental for the oxidation resistance of the Mo$\mathrm{Si}$-Ti alloys due to the interactions with the present Si-oxide. This assumption is in accordance with observations made for Ti-Si alloys, which exhibit an improved oxidation resistance. It is achieved by $\mathrm{Si}$ additions resulting in a change in oxide scale morphology with a better adherence and decreased tendency to stratification [253].

The creep performance of the pesting-resistant Mo-Si-Ti alloys was found to be solidus temperature-dependent $[224,225]$. Thus, the Mo to Ti ratio needs to be maximised for fully exploiting their potential (on the expense of weight savings, tough). The adjustment 
of the microstructural length scale and network structure only resulted in a further improvement in creep resistance in intermediate eutectic-eutectoid alloys where a change in present phases to Moss $+(\mathrm{Ti}, \mathrm{Mo})_{5} \mathrm{Si}_{3}$ was triggered during the applied heat treatment. In contrast, no enhancement in creep resistance was attained for the artificially coarsened eutectic reference alloy.

Conclusively, the alloy design is firstly constrained by the nominal Ti threshold, which needs to be exceeded for achieving pesting-stability, and secondly by the solidus temperature, which needs to be maximised for achieving optimum resistance to loading under creep conditions. 


\section{Outlook}

The investigated Mo-Si-Ti alloys are promising for advanced high-temperature applications, as these represent the first light-weight $\left(\rho<7 \mathrm{~g} / \mathrm{cm}^{3}\right)$ refractory metal-based alloy system allowing operating temperatures beyond $1100{ }^{\circ} \mathrm{C}$ while maintaining sufficient oxidation and creep resistance throughout the entire temperature range. The alloy design approaches led to fine-scaled multiphase microstructures, comprising Moss and $\mathrm{M}_{5} \mathrm{Si}_{3}$ silicides. Thus, the brittle nature of the intermetallic phases is balanced as well as the proneness to pesting of Moss reduced. The latter is of utmost concern, as the establishment of an adequate oxidation resistance still remains challenging in refractory metal-based alloy systems. The high-melting refractory elements either suffer from pesting, like Mo and W [29, 31], or form non-protective oxides, like $\mathrm{Nb}$ and $\mathrm{Ta}$ [31, 278-280]. Thus, the formation of oxide scales like $\mathrm{Al}_{2} \mathrm{O}_{3}$ or $\mathrm{SiO}_{2}$, which are protective under certain conditions, needs to be facilitated by additional alloying elements [281]. In contrast, $\mathrm{Cr}_{2} \mathrm{O}_{3}$ does not provide protection beyond $1000{ }^{\circ} \mathrm{C}$ due to volatilisation. Thus, $\mathrm{Cr}_{2} \mathrm{O}_{3}$-forming alloy systems are not suitable for applications higher than $1000^{\circ} \mathrm{C}$ without oxidation protection coatings. In the case of the here investigated pesting-resistant Mo-Si-Ti alloys, the formation of sound oxide scales between 800 to $1200{ }^{\circ} \mathrm{C}$ is achieved by an appropriate ratio of the solid oxide forming elements $\mathrm{Ti}$ and $\mathrm{Si}$. However, the question arises whether these alloys can compete with either already commercially applied high-temperature alloys, like Ni-based superalloys, or with other potential high-temperature metal-based systems, which are focused on in current research projects. In this regard, commercially applied Ti-Al- and Fe-Albased alloys cannot serve as benchmark for the here targeted operating conditions, as these are already disqualified for applications at temperature above $800{ }^{\circ} \mathrm{C}$ because of a lack in oxidation or creep resistance [7, 8, 282, 283]. However, note that the comparison to the performance of state-of-the-art Ni-based superalloys at $1200{ }^{\circ} \mathrm{C}$ is rather not appropriate, too, as their application is restricted to $1150{ }^{\circ} \mathrm{C}$ because of approaching the $\gamma^{\prime}$ solvus temperature. Thus, alloy systems based on metals with a higher melting point than $\mathrm{Ni}$ $\left(T_{m}^{N i}=1455^{\circ} \mathrm{C}\right)$ are of particular interest. While Co-based $\left(T_{m}^{C o}=1495^{\circ} \mathrm{C}\right)$ and Pt-based alloys $\left(T_{m}^{P t}=1768^{\circ} \mathrm{C}\right)$ possess increased solidus temperatures, these are analogously precipitation-strengthened like $\gamma-\gamma^{\prime}$ Ni-based superalloys and, hence, $\gamma^{\prime}$ solvus temperatures still need to be considered ( $T_{\text {solvus }}^{\gamma \prime} \approx 1130$ to $\left.1150{ }^{\circ} \mathrm{C}[284,285]\right)$. Moreover, Co-based alloys, e.g. Co-Re-Cr alloys, only exhibit acceptable oxidation resistance up to $1000^{\circ} \mathrm{C}$, as at higher temperatures no continuous, protective $\mathrm{Cr}_{2} \mathrm{O}_{3}$ layers form [286, 287]. Contrary, Pt$\mathrm{Al}-\mathrm{X}(\mathrm{X}=\mathrm{Cr}, \mathrm{Ru}, \mathrm{Ni}, \ldots)$ alloys are characterised by the formation of passivating, thin 
$\mathrm{Al}_{2} \mathrm{O}_{3}$ oxide scales leading to an outstanding oxidation behaviour even up to $1300{ }^{\circ} \mathrm{C}[288$, 289]. However, the high cost for Pt and its high density $\left(21.45 \mathrm{~g} / \mathrm{cm}^{3}\right)$ are disadvantageous. In this regard Nb-Si- and Mo-Si-based systems $\left(T_{m}^{N b}=2477^{\circ} \mathrm{C}, T_{m}^{M o}=2623^{\circ} \mathrm{C}\right)$ remain as the only promising alternative high-temperature materials. Therefore, the critical requirements, like operating temperature range ${ }^{10}$ and density, as well as an overview of the oxidation behaviour at $1200{ }^{\circ} \mathrm{C}$ are given in Fig. 9-1 and Fig. 9-2.

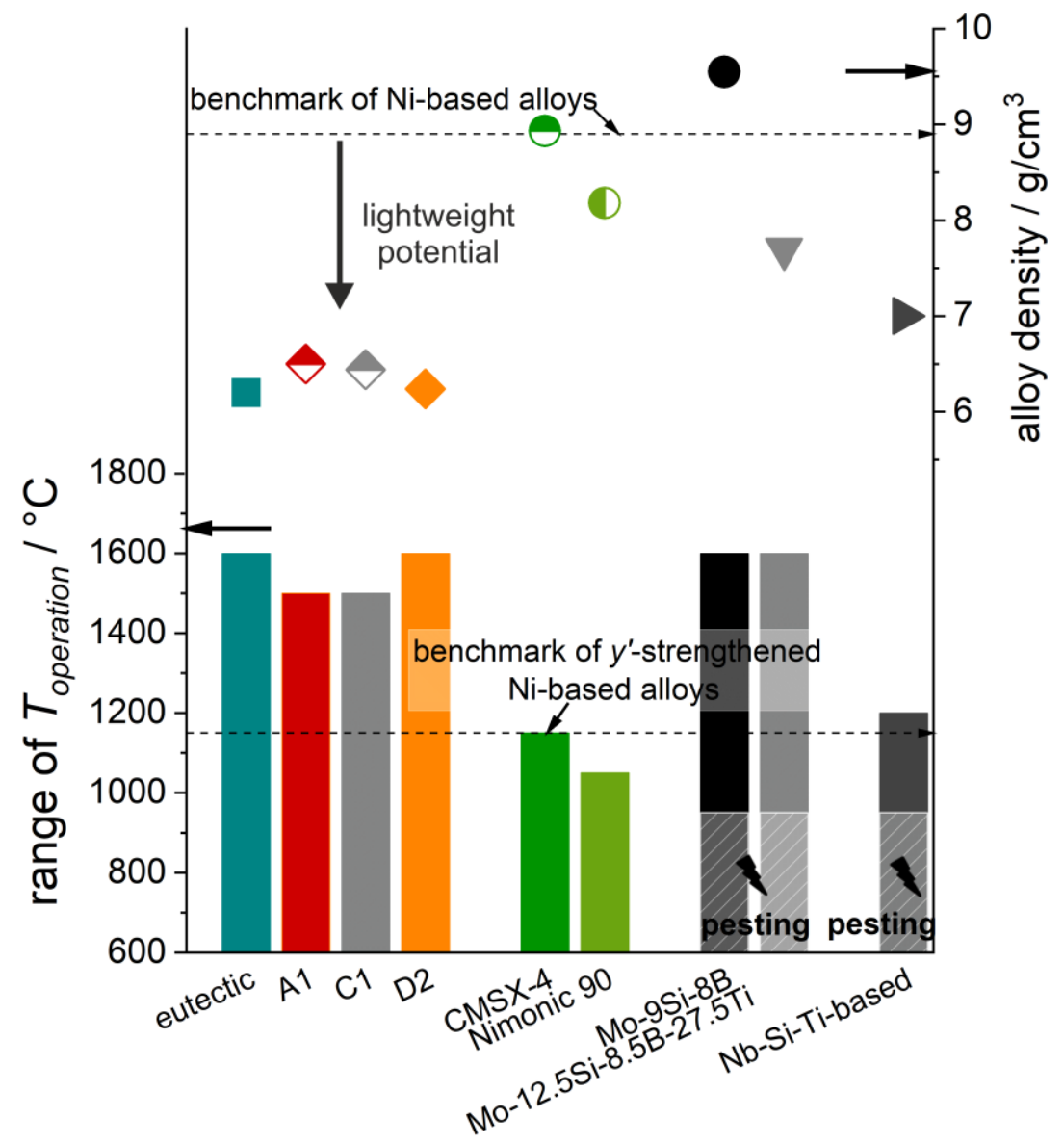

Fig. 9-1 Comparison of the density (upper diagram) and estimated temperature operation range (lower diagram) for selected Mo-Si-Ti alloys [5, 224, 225], and commercially applied Ni-based alloys [290-292] (highlighted by green colours) as well as Mo-Si- [4, 34] and Nb-Si-based alloys [293, 294] (highlighted by grey and black colours).

10 The temperature operation range is roughly estimated by not only considering solidus temperatures, but also temperatures where microstructural coarsening and/or phase transformations occur (e.g. at $1600{ }^{\circ} \mathrm{C}$ for alloys A1 and C1), as well as the lower critical temperature where pesting is observed. 

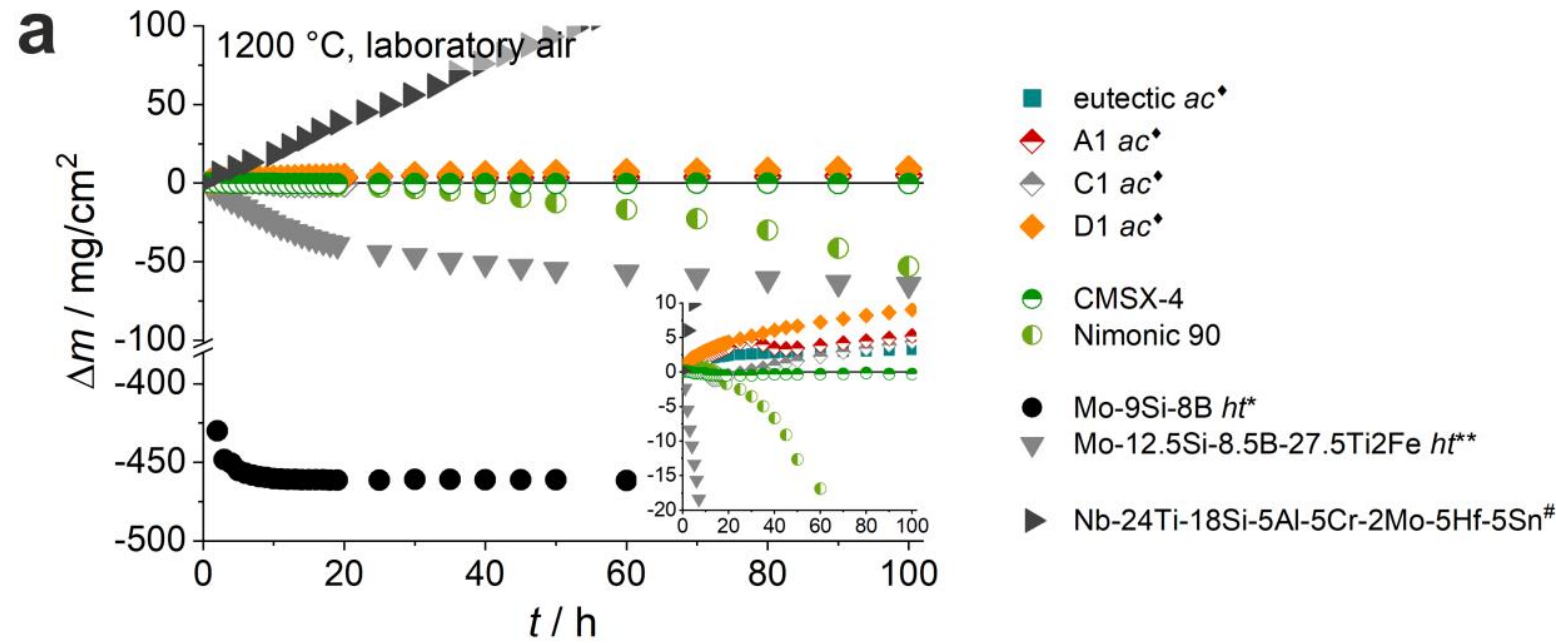

b

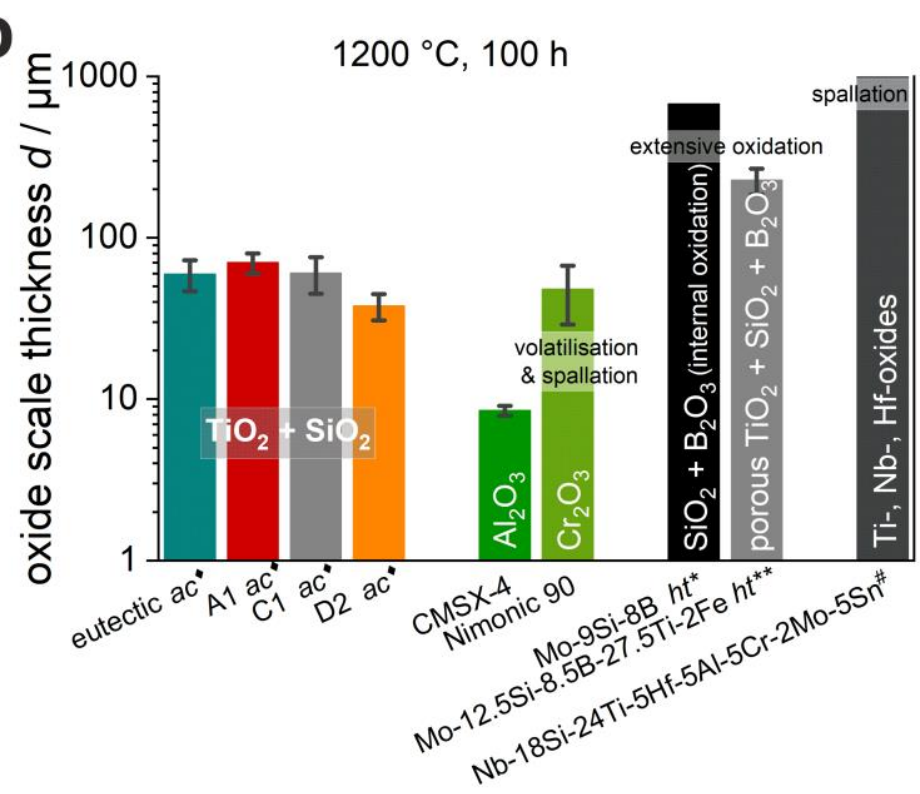

C CMSX-4

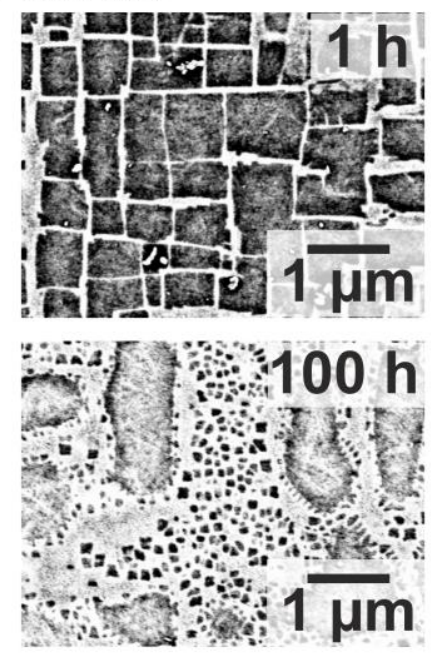

$h t^{*}: 1600^{\circ} \mathrm{C}, 150 \mathrm{~h} \quad h t^{* *}: 1600^{\circ} \mathrm{C}, 150 \mathrm{~h}+1400^{\circ} \mathrm{C}+100 \mathrm{~h} \quad$-data according to Obert et al. \# literature data

Fig. 9-2 Overview of the oxidation behaviour at $1200{ }^{\circ} \mathrm{C}$ in air: specific mass change (a) and oxide scale thickness after $100 \mathrm{~h}$ (b). Selected pesting-resistant Mo$\mathrm{Si}$-Ti alloys are compared to cast $\mathrm{Mo-Si}$ - and $\mathrm{Nb}$-Si-based alloys as well as commercially applied high-temperature Ni-based materials. The composition of the latter is included in App. 47 and the geometry of the oxidation samples is appended in App. 48. Changes in the morphology of the precipitates in CMSX-4 after exposure to $1200{ }^{\circ} \mathrm{C}$ for 1 and $100 \mathrm{~h}$ (c). Data according to Obert et al. [215, 224, 225] is marked by diamonds and data taken from other literature [295] by a hashtag.

It is revealed that Mo-Si-B-(Ti) and $\mathrm{Nb}-\mathrm{Si}-\mathrm{Ti}-\mathrm{X}$ alloys not only possess higher densities, but exhibit significantly higher specific mass changes during oxidation in comparison to 
the here presented pesting-resistant Mo-Si-Ti alloys. Thus, these are excluded for applications at $1200{ }^{\circ} \mathrm{C}$ and beyond. This applies to $\mathrm{Cr}_{2} \mathrm{O}_{3}$-forming Nimonic 90 as well, since volatilisation of $\mathrm{CrO}_{3}$ occurs at $1200{ }^{\circ} \mathrm{C}$. In contrast, the oxidation behaviour of the commercially applied CMSX-4 is superior to the Mo-Si-Ti alloys due to the formation a thin, passivating $\mathrm{Al}_{2} \mathrm{O}_{3}$ scale ensuring low mass changes. However, SEM analyses of the oxidised CMSX-4 samples confirm the microstructural instability at $1200{ }^{\circ} \mathrm{C}$ (see Fig. 9-2c).

Additionally, when considering the specific creep resistance (normalised by the density) at $1200{ }^{\circ} \mathrm{C}$ (see Fig. 9-3), it is clearly seen that Ni-based alloys, like CMSX-4, are exceeding their capability to withstand creep loading. Only the Mo-Si-B-(Ti) and Nb-Si-Ti-X alloys exhibit superior creep resistance to the investigated Mo-Si-Ti alloys. But these do not possess sufficient oxidation resistance at either below [41, 47, 155, 227], or above $1000{ }^{\circ} \mathrm{C}$ [295-299]. Hence, this screening demonstrates that the pesting-resistant Mo-Si-Ti alloys are competitive regarding their high-temperature oxidation behaviour and even superior regarding their specific creep performance at stresses higher than $100 \mathrm{MPa}$.

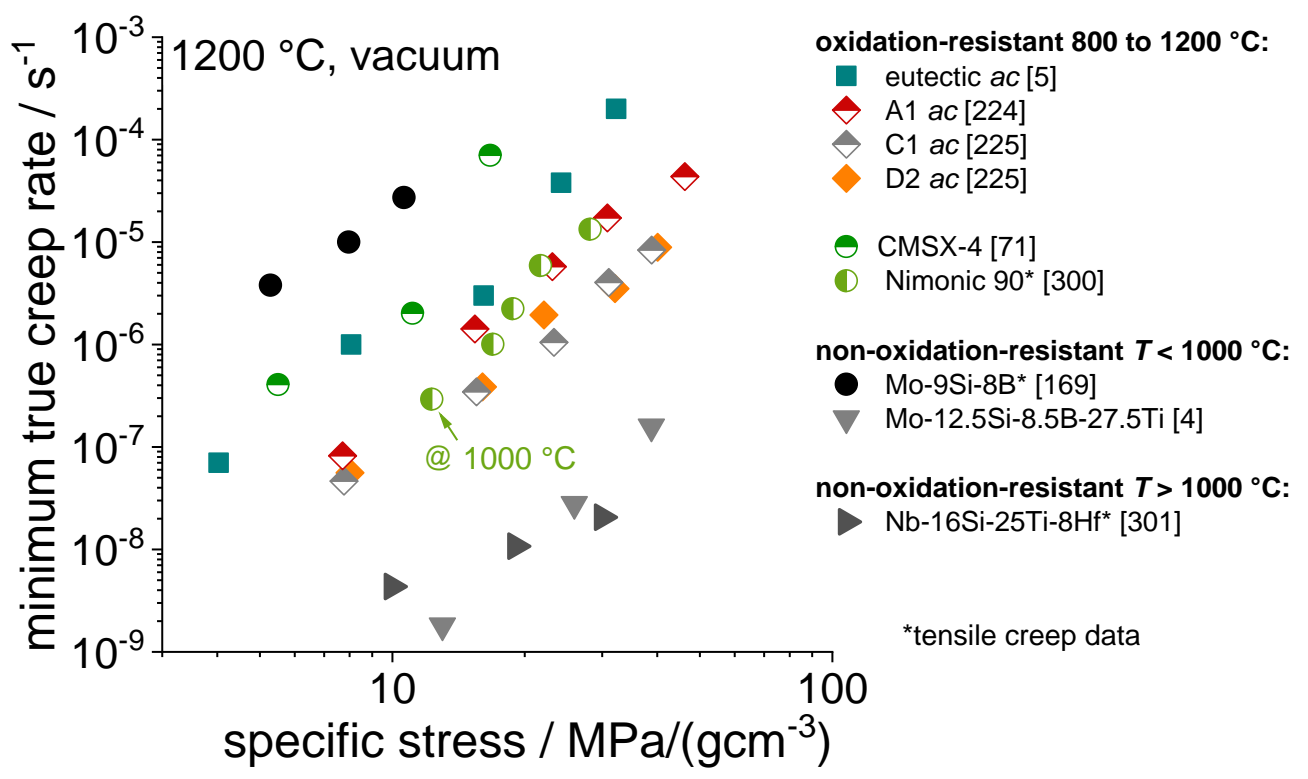

Fig. 9-3 Comparison of the creep performance of the novel Mo-Si-Ti alloys to other high-temperature alloy systems in a Norton plot normalised by the alloy density. Note the classification in oxidation- and non-oxidation-resistant alloys. Tensile data is marked by an asterisk. Data taken from Refs. [4, 5, 71, $169,224,225,300,301]$.

Moreover, the creep performance of the pesting-resistant Mo-Si-Ti alloys might be further improved by strengthening phases like TiC, whose beneficial potential has already been reported for Mo-Si-B-TiC alloys [302-304]. This may be tackled in future work. 


\section{References}

[1] A. Bauer, S. Neumeier, F. Pyczak, R. F. Singer, M. Göken, Creep properties of different $Y^{\prime}$-strengthened Co-base superalloys. Materials Science and Engineering: A, 2012, 550: 333-341. DOI: 10.1016/j.msea.2012.04.083.

[2] L. Klein, A. Bauer, S. Neumeier, M. Göken, S. Virtanen, High temperature oxidation of $\mathrm{Y}^{/} \mathrm{Y}^{\prime}$-strengthened Co-base superalloys. Corrosion Science, 2011, 53: 2027-2034. DOI: 10.1016/j.corsci.2011.02.033.

[3] L. Klein, M. S. Killian, S. Virtanen, The effect of nickel and silicon addition on some oxidation properties of novel Co-based high temperature alloys. Corrosion Science, 2013, 69: 43-49. DOI: 10.1016/j.corsci.2012.09.046.

[4] D. Schliephake, M. A. Azim, K. v. Klinski-Wetzel, B. Gorr, H.-J. Christ, H. Bei, E. P. George, M. Heilmaier, High-Temperature Creep and Oxidation Behavior of MoSi-B alloys with High Ti Contents. Metallurgical and Materials Transactions A, 2014, 45: 1102-1111. DOI: 10.1007/s11661-013-1944-z.

[5] D. Schliephake, A. Kauffmann, X. Cong, C. Gombola, M. A. Azim, B. Gorr, H.-J. Christ, M. Heilmaier, Constitution, oxidation and creep of eutectic and eutectoid Mo-Si-Ti alloys. Intermetallics, 2019, 104: 133-142. DOI: 10.1016/j.intermet.2018.10.028.

[6] C. H. Zenk, S. Neumeier, N. M. Engl, S. G. Fries, O. Dolotko, M. Weiser, S. Virtanen, M. Göken, Intermediate Co/Ni-base model superalloys - Thermophysical properties, creep and oxidation. Scripta Materialia, 2016, 112: 83-86. DOI: 0.1016/j.scriptamat.2015.09.018.

[7] H. Y. Chiu, C. M. Kuo, H. S. Wang, Creep Behavior of 409L and 436 Ferritic Stainless Steels Applied for Automotive Exhaust System. Applied Mechanics and Materials, 2013, 302: 252-257. DOI: 10.4028/www.scientific.net/AMM.302.252.

[8] Y.-T. Chiu, C.-K. Lin, J.-C. Wu, High-temperature tensile and creep properties of a ferritic stainless steel for interconnect in solid oxide fuel cell. Journal of Power Sources, 2011, 196: 2005-2012. DOI: 10.1016/j.jpowsour.2010.09.083.

[9] N. Birks, G. H. Meier, F. S. Pettit, Introduction to the High-Temperature Oxidation of Metals. 2006, 2, Cambridge University Press, Cambridge: p. xii, 17, 23, 41, 9599. ISBN: 978-1139-1639-03.

[10] M. P. Brady, J. G. Wright, B. Gleeson, Alloy design strategies for promoting protective oxide-scale formation. JOM, 2000, 52: 16-21. DOI: 10.1007/s11837-0000109-x.

[11] P. Kofstad, K. P. Lillerud, On high temperature oxidation of chromium: II. Properties of and the oxidation mechanism of chromium. Journal of The Electrochemical Society, 1980, 127: 2410-2419. DOI: 10.1149/1.2129481.

[12] R. L. Plaut, C. Herrera, D. M. Escriba, P. R. Rios, A. F. Padilha, A short review on wrought austenitic stainless steels at high temperatures: processing, microstructure, properties and performance. Materials Research, 2007, 10: 453460. DOI: $10.1590 / \mathrm{S} 1516-14392007000400021$ 
[13] G. R. Wallwork, A. Z. Hed, Some limiting factors in the use of alloys at high temperatures. Oxidation of Metals, 1971, 3: 171-184. DOI: 10.1007/BF00603485.

[14] C. S. Giggins, F. S. Pettit, Oxidation of Ni-Cr-Al alloys between $1000^{\circ}$ and $1200^{\circ} \mathrm{C}$. Journal of The Electrochemical Society, 1971, 118: 1782. DOI: 10.1149/1.2407837.

[15] F. H. Stott, G. C. Wood, M. G. Hobby, A comparison of the oxidation behavior of FeCr-Al, Ni-Cr-Al, and Co-Cr-Al alloys. Oxidation of Metals, 1971, 3: 103-113. DOI: 10.1007/BF00603481.

[16] S. Walston, A. Cetel, R. MacKay, K. Ohara, D. Duhl, R. Dreshfield, Joint development of a fourth generation single crystal superalloy, in NASA Center for Aerospace Information, $10^{\text {th }}$ International Symposium on Superalloys, Champion, Pennsylvania, 2004: 1-10. DOI: NASA/TM-2004-213062.

[17] T. M. Pollock, S. Tin, Nickel-based superalloys for advanced turbine engines: chemistry, microstructure and properties. Journal of Propulsion and Power, 2006, 22: 361-374. DOI: 10.2514/1.18239.

[18] W. Betz, H. Huff, W. Track, Zur Bewertung von Schutzschichten gegen Heißgaskorrosion an Gasturbinenschaufeln. Materialwissenschaft und Werkstofftechnik, 1976, 7: 161-166. DOI: 10.1002/mawe.19760070503.

[19] S. Carnot, Réflexions sur la puissance motrice du feu et sur les machines propres à développer cette puissance. Annales scientifiques de l'École Normale Supérieure, 1872, 1: 393-457. Available from: http://www.numdam.org/item?id= ASENS_1872_2_1__393_0 [cited 08/08/2020].

[20] J. H. Perepezko, The hotter the engine, the better. Science, 2009, 326: 1068-1069. DOI: $10.1126 /$ science.1179327.

[21] D. M. Dimiduk, J. H. Perepezko, Mo-Si-B alloys: developing a revolutionary turbine-engine material. MRS Bulletin, 2003, 28: 639-645. DOI: 10.1557/mrs2003.191.

[22] M. Göken, Chapter 3.2: Free Surface Structures and Properties, in Intermetallic Compounds - Principles and Practice, J. H. Westbrook, R. L. Fleischer, Editors, 2002, 3, John Wiley \& Sons Ltd, Chichester: p. 211-229. ISBN: 0-470-84585-6.

[23] R. C. Reed, Chapter 2: The physical metallurgy of nickel and its alloys, in The Superalloys - Fundamentals and Applications, 2006, Cambridge University Press, Cambridge: p. 33-103. ISBN: 978-0-521-07011-9.

[24] P. Caron, High y' solvus new generation nickel-based superalloys for single crystal turbine blade applications, T. M. Pollock, R. D. Kissinger, R. R. Bowman, K. A. Green, M. McLean, S. Olson, J. J. Schirra, Editors, in Superalloys 2000, TMS, Warrendale, Pennsylvania, 2000: 737-746. 10.7449/2000/Superalloys_2000_737_746.

[25] D. C. Cox, B. Roebuck, C. M. F. Rae, R. C. Reed, Recrystallisation of single crystal superalloy CMSX-4. Materials Science and Technology, 2003, 19: 440-446. DOI: 10.1179/026708303225010731. 
[26] K. P. L. Fullagar, R. W. Broomfield, M. Hulands, K. Harris, G. L. Erickson, S. L. Sikkenga, Aero engine test experience with CMSX-4® alloy single-crystal turbine blades. Journal of Engineering for Gas Turbines and Power, 1996, 118: 380-388. DOI: $10.1115 / 1.2816600$.

[27] A. Szczotok, R. Przeliorz, Phase transformations in CMSX-4 nickel-base superalloy, in IOP Conference Series: Materials Science and Engineering, Katowice, Poland, 2012, 35: 1-5. DOI: 10.1088/1757-899X/35/1/012005.

[28] Aerotime. Available from: https://www.aerotime.aero/aviation-blog/wpcontent/uploads/2016/04/ge9x.jpg [cited 20/08/2019].

[29] E. A. Gulbransen, Thermochemistry and the oxidation of refractory metals at high temperature. Corrosion, 1970, 26: 19-28. DOI: 10.5006/0010-9312-26.1.19.

[30] J. N. Ong, W. M. Fassell, Kinetics of oxidation of columbium and other refractory metals. Corrosion, 1962, 18: 382t-389t. DOI: 10.5006/0010-9312-18.10.382.

[31] O. Kubaschewski, B. E. Hopkins, Oxidation mechanisms of niobium, tantalum, molybdenum and tungsten. Journal of the Less Common Metals, 1960, 2: 172-180. DOI: 10.1016/0022-5088(60)90012-6.

[32] J. H. Perepezko, R. Sakidja, Oxidation-resistant coatings for ultra-hightemperature refractory Mo-based alloys. JOM, 2010, 62: 13-19. DOI: 10.1007/s11837-010-0148-x.

[33] J.-M. Kim, H. T.-H., J.-S. Park, H.-G. Kim, Oxidation resistance of Si-coated TZM alloy prepared through combined process of plasma spray and laser surface melting. Transactions of Nonferrous Metals Society of China, 2016, 26: 2603-2608. DOI: $10.1016 / \mathrm{S} 1003-6326(16) 64386-8$.

[34] P. Jéhanno, M. Heilmaier, H. Kestler, Characterization of an industrially processed Mo-based silicide alloy. Intermetallics, 2004, 12: 1005-1009. DOI: 10.1016/j.intermet.2004.03.006.

[35] E. J. Opila, Oxidation and volatilization of silica formers in water vapor. Journal of the American Ceramic Society, 2003, 86: 1238-1248. DOI: 10.1111/j.11512916.2003.tb03459.x.

[36] A. B. Gokhale, G. J. Abbaschian, The Mo-Si (molybdenum-silicon) system. Journal of Phase Equilibria, 1991, 12: 493-498. DOI: 10.1007/BF02645979.

[37] J. B. Berkowitz-Mattuck, R. R. Dils, High-Temperature Oxidation: II. Molybdenum Silicides. Journal of The Electrochemical Society, 1965, 112: 583-589. DOI: $10.1149 / 1.2423612$.

[38] C. G. McKamey, P. F. Tortorelli, J. H. DeVan, C. A. Carmichael, A study of pest oxidation in polycrystalline MoSiz. Journal of Materials Research, 1992, 7: 2747 2755. DOI: 10.1557/JMR.1992.2747.

[39] C. D. Wirkus, D. R. Wilder, High-temperature oxidation of molybdenum disilicide. Journal of the American Ceramic Society, 1966, 49: 173-177. DOI: 10.1111/j.11512916.1966.tb13227.x. 
[40] M. A. Azim, B. Gorr, H.-J. Christ, M. Heilmaier, U. Koch, M. Engelhard, Characterization of Oxidation Kinetics of Mo-Si-B-Based Materials. Oxidation of Metals, 2017, 87: 89-108. DOI: 10.1007/s11085-016-9659-3.

[41] M. K. Meyer, A. J. Thom, M. Akinc, Oxide scale formation and isothermal oxidation behavior of Mo-Si-B intermetallics at $600-1000^{\circ} \mathrm{C}$. Intermetallics, 1999, 7: 153 162. DOI: 10.1016/S0966-9795(98)00058-2.

[42] S. Paswan, R. Mitra, S. K. Roy, Oxidation behaviour of the Mo-Si-B and Mo-Si$\mathrm{B}-\mathrm{Al}$ alloys in the temperature range of $700-1300^{\circ} \mathrm{C}$. Intermetallics, 2007, 15 : 1217-1227. DOI: 10.1016/j.intermet.2007.02.012.

[43] G. Hasemann, I. Bogomol, D. Schliephake, P. I. Loboda, M. Krüger, Microstructure and creep properties of a near-eutectic directionally solidified multiphase $\mathrm{Mo}-\mathrm{Si}-$ B alloy. Intermetallics, 2014, 48: 28-33. DOI: 10.1016/j.intermet.2013.11.022.

[44] G. Hasemann, D. Kaplunenko, I. Bogomol, M. Krüger, Near-Eutectic Ternary MoSi-B Alloys: Microstructures and Creep Properties. JOM, 2016, 69: 2847-2853. DOI: 10.1007/s11837-016-2073-0.

[45] P. Jain, K. S. Kumar, Tensile creep of Mo-Si-B alloys. Acta Materialia, 2010, 58: 2124-2142. DOI: 10.1016/j.actamat.2009.11.054.

[46] J. H. Schneibel, P. F. Tortorelli, R. O. Ritchie, J. J. Kruzic, Optimization of Mo-SiB intermetallic alloys. Metallurgical and Materials Transactions A, 2005, 36: 525531. DOI: 10.1007/s11661-005-0166-4.

[47] M. A. Azim, S. Burk, B. Gorr, H.-J. Christ, D. Schliephake, M. Heilmaier, R. Bornemann, P. H. Bolívar, Effect of Ti (Macro-) Alloying on the High-Temperature Oxidation Behavior of Ternary Mo-Si-B Alloys at $820-1300{ }^{\circ} \mathrm{C}$. Oxidation of Metals, 2013, 80: 231-242. DOI: 10.1007/s11085-013-9375-1.

[48] M. A. Azim, D. Schliephake, C. Hochmuth, B. Gorr, H.-J. Christ, U. Glatzel, M. Heilmaier, Creep Resistance and Oxidation Behavior of Novel Mo-Si-B-Ti Alloys. JOM, 2015, 67: 2621-2628. DOI: 10.1007/s11837-015-1560-z.

[49] E. A. Beidler, I. E. Campbell, Highly refractory molybdenum alloys, 1954, US Patent 2665474A, USA.

[50] L. Brewer, A. W. Searcy, D. H. Templeton, C. H. Dauben, High-Melting Silicides. Journal of the American Ceramic Society, 1950, 33: 291-294. DOI: 10.1111/j.11512916.1950.tb14136.x.

[51] M. H. Weatherly, L. A. Conant, Refractory metal and silicon selfhealing high temperature alloy, 1960, US Patent 2939785A, USA.

[52] M. Akinc, M. K. Meyer, M. J. Kramer, A. J. Thom, J. J. Huebsch, B. Cook, Borondoped molybdenum silicides for structural applications. Materials Science and Engineering A, 1999, 261: 16-23. DOI: 10.1016/S0921-5093(98)01045-4.

[53] J. H. Schneibel, C. T. Liu, D. S. Easton, C. A. Carmichael, Microstructure and mechanical properties of $\mathrm{Mo}-\mathrm{Mo}_{3} \mathrm{Si}-\mathrm{Mo}_{5} \mathrm{SiB}_{2}$ silicides. Materials Science and Engineering: A, 1999, 261: 78-83. DOI: 10.1016/S0921-5093(98)01051-X. 
[54] S. Katrych, A. Grytsiv, A. Bondar, P. Rogl, T. Velkanova, M. Bohn, Structural materials: metal-silicon-boron: On the melting behavior of Mo-Si-B alloys. Journal of Alloys and Compounds, 2002, 347: 94-100. DOI: 10.1016/S09258388(02)00676-X.

[55] D. M. Berczik, Method for enhancing the oxidation resistance of a molybdenum alloy, and a method of making a molybdenum alloy, 1997, US Patent 005595616A, USA.

[56] D. M. Berczik, Oxidation resistant molybdenum alloy, 1997, US Patent 5693156A, USA.

[57] T. A. Parthasarathy, M. G. Mendiratta, D. M. Dimiduk, Oxidation mechanisms in Mo-reinforced $\mathrm{Mo}_{5} \mathrm{SiB}_{2}$ (T2)-Mo3Si alloys. Acta Materialia, 2002, 50: 1857-1868. DOI: 10.1016/S1359-6454(02)00039-3.

[58] H. Nowotny, E. Dimakopoulou, H. Kudielka, Untersuchungen in den Dreistoffsystemen: Molybdän-Silizium-Bor, Wolfram-Silizium-Bor und in dem System: $\mathrm{VSi}_{2}-\mathrm{TaSi}_{2}$. Monatshefte für Chemie und verwandte Teile anderer Wissenschaften, 1957, 88: 180-192. DOI: 10.1007/BF00901624.

[59] P. Mandal, A. J. Thom, M. J. Kramer, V. Behrani, M. Akinc, Oxidation behavior of Mo-Si-B alloys in wet air. Materials Science and Engineering: A, 2004, 371: 335 342. DOI: 10.1016/j.msea.2003.12.025.

[60] M. Kramer, A. Thom, O. Degirmen, V. Behrani, M. Akinc, Oxidation Behavior of Mo-Si-B Alloys in Wet Air. Technical Report, Ames Lab., IA (USA), 2002. DOI: 10.2172/797633.

[61] F. Chu, D. J. Thoma, K. J. McClellan, P. Peralta, Mo5Si3 single crystals: physical properties and mechanical behavior. Materials Science and Engineering: A, 1999, 261: 44-52. DOI: 10.1016/S0921-5093(98)01048-X.

[62] K. Ihara, K. Ito, K. Tanaka, M. Yamaguchi, Mechanical properties of Mo5 $\mathrm{SiB}_{2}$ single crystals. Materials Science and Engineering: A, 2002, 329-331: 222-227. DOI: 10.1016/S0921-5093(01)01575-1.

[63] I. Rosales, J. H. Schneibel, Stoichiometry and mechanical properties of Mos Si. Intermetallics, 2000, 8: 885-889. DOI: 10.1016/S0966-9795(00)00058-3.

[64] J. Schneibel, J. Kruzic, R. Ritchie, Mo-Si-B alloy development, in 17th Annual Conference on Fossil Energy Materials, 2003, Baltimore, Berkeley. Available from: https://www.osti.gov/servlets/purl/835685 [cited 30/07/2020].

[65] R. Sakidja, J. H. Perepezko, S. Kim, N. Sekido, Phase stability and structural defects in high-temperature Mo-Si-B alloys. Acta Materialia, 2008, 56: 5223-5244. DOI: 10.1016/j.actamat.2008.07.015.

[66] Y. Yang, H. Bei, S. Chen, E. P. George, J. Tiley, Y. A. Chang, Effects of Ti, Zr, and $\mathrm{Hf}$ on the phase stability of Moss $+\mathrm{Mos}_{3} \mathrm{Si}+\mathrm{Mo}_{5} \mathrm{SiB}_{2}$ alloys at $1600{ }^{\circ} \mathrm{C}$. Acta Materialia, 2010, 58: 541-548. DOI: 10.1016/j.actamat.2009.09.032.

[67] M. Meyer, M. Kramer, M. Akinc, Boron-doped molybdenum silicides. Advanced Materials, 1996, 8: 85-88. DOI: 10.1002/adma.19960080118. 
[68] K. Yoshimi, S. Nakatani, T. Suda, S. Hanada, H. Habazaki, Oxidation behavior of $\mathrm{Mo}_{5} \mathrm{SiB}_{2}$-based alloy at elevated temperatures. Intermetallics, 2002, 10: 407-414. DOI: 10.1016/S0966-9795(02)00013-4.

[69] M. F. Yan, J. B. MacChesney, S. R. Nagel, W. W. Rhodes, Sintering of optical waveguide glasses. Journal of Materials Science, 1980, 15: 1371-1378. DOI: 10.1007/BF00752116.

[70] S. Burk, B. Gorr, H.-J. Christ, D. Schliephake, M. Heilmaier, C. Hochmuth, U. Glatzel, High-temperature oxidation behaviour of a single-phase (Mo, $\left.\mathrm{Ti}_{5}\right)_{5 i} \mathrm{Si}_{3} \mathrm{Mo}-$ Si-Ti) alloy. Scripta Materialia, 2012, 66: 223-226. DOI: 10.1016/j.scriptamat.2011.10.042.

[71] M. Heilmaier, M. Krüger, H. Saage, Recent advances in the development of mechanically alloyed Mo silicide alloys, in Materials Science Forum, 2009, 633-634: 549-558. DOI: 10.4028/www.scientific.net/MSF.633-634.549.

[72] M. Krüger, S. Franz, H. Saage, M. Heilmaier, J. H. Schneibel, P. Jéhanno, M. Böning, H. Kestler, Mechanically alloyed Mo-Si-B alloys with a continuous a-Mo matrix and improved mechanical properties. Intermetallics, 2008, 16: 933-941. DOI: 10.1016/j.intermet.2008.04.015.

[73] J. J. Kruzic, J. H. Schneibel, R. O. Ritchie, Ambient- to Elevated-Temperature Fracture and Fatigue Properties of Mo-Si-B Alloys: Role of Microstructure. Metallurgical and Materials Transactions A, 2005, 36: 2393-2402. DOI: 10.1007/s11661-005-0112-5.

[74] J. H. Schneibel, M. J. Kramer, D. S. Easton, A Mo-Si-B intermetallic alloy with a continuous a-Mo matrix. Scripta Materialia, 2002, 46: 217-221. DOI: 10.1016/S1359-6462(01)01227-1.

[75] M. Krüger, D. Schliephake, P. Jain, K. S. Kumar, G. Schumacher, M. Heilmaier, Effects of Zr additions on the microstructure and the mechanical behavior of PM Mo-Si-B alloys. JOM, 2013, 65: 301-306. DOI: 10.1007/s11837-012-0475-1.

[76] H. Saage, M. Krüger, D. Sturm, M. Heilmaier, J. H. Schneibel, E. George, L. Heatherly, C. Somsen, G. Eggeler, Y. Yang, Ductilization of Mo-Si solid solutions manufactured by powder metallurgy. Acta Materialia, 2009, 57: 3895-3901. DOI: 10.1016/j.actamat.2009.04.040.

[77] D. Sturm, M. Heilmaier, J. H. Schneibel, P. Jéhanno, B. Skrotzki, H. Saage, The influence of silicon on the strength and fracture toughness of molybdenum. Materials Science and Engineering: A, 2007, 463: 107-114. DOI: 10.1016/j.msea.2006.07.153.

[78] M. K. Miller, A. J. Bryhan, Effect of Zr, B and C additions on the ductility of molybdenum. Materials Science and Engineering: A, 2002, 327: 80-83. DOI: 10.1016/S0921-5093(01)01880-9.

[79] M. K. Miller, E. A. Kenik, M. S. Mousa, K. F. Russell, A. J. Bryhan, Improvement in the ductility of molybdenum alloys due to grain boundary segregation. Scripta Materialia, 2002, 46: 299-303. DOI: 10.1016/S1359-6462(01)01242-8. 
[80] R. Kieffer, E. Cerwenka, Beitrag zum System Molybdän Silizium. Zeitschrift für Metallkunde, 1952, 43: 101-105. ISSN: 0044-3093.

[81] Y. Liu, G. Shao, P. Tsakiropoulos, Thermodynamic reassessment of the Mo-Si and Al-Mo-Si systems. Intermetallics, 2000, 8: 953-962. DOI: 10.1016/S09669795(00)00068-6.

[82] J. L. Murray, The Mo-Ti (Molybdenum-Titanium) System. Bulletin of Alloy Phase Diagrams, 1981, 2: 185-192. DOI: 10.1007/BF02881476.

[83] B. Predel, Mo-Ti (Molybdenum-Titanium), in Li-Mg-Nd-Zr. Zrandolt-Börnstein Group IV Physical Chemistry, O. Madelung, Editor, 1997, 5, Springer, Berlin, Heidelberg: p. 1-3. ISBN: 978-3-540-68538-8.

[84] A. W. Hull, X-ray crystal analysis of thirteen common metals. Physical Review, 1921, 17: 571-592. DOI: 10.1103/PhysRev.17.571.

[85] E. R. Jette, F. Foote, Precision determination of lattice constants. The Journal of Chemical Physics, 1935, 3: 605-616. DOI: 10.1063/1.1749562.

[86] A. N. Christensen, Preparation and characterization of $\mathrm{Mo}_{3} \mathrm{Si}$ and $\mathrm{Mo}_{5} \mathrm{Si}_{3}$. Acta Chemica Scandinavica, 1983, 37: 519-522. DOI: 10.3891/acta.chem.scand.37a0519 .

[87] B. Aronsson, The Crystal Structure of $\mathrm{Mo}_{5} 5 \mathrm{i}_{3}$ and $\mathrm{W}_{5} \mathrm{Si}_{3}$. Acta Chemica Scandinavica, 1955, 9: 1107-1110. DOI: 10.3891/acta.chem.scand.09-1107.

[88] S. V. N. Naidu, C. F. Mays, C. R. Houska, Integrated intensities and lattice parameters for $\mathrm{Mo}_{5} \mathrm{Si}_{3}$. Journal of the American Ceramic Society, 1982, 65: C-58C-59. DOI: 10.1111/j.1151-2916.1982.tb10419.x.

[89] H. Schachner, E. Cerwenka, H. Nowotny, Neue Silizide vom $\mathrm{M}_{5} \mathrm{Si}_{3}-\mathrm{Typ}$ mit D88Struktur. Monatshefte für Chemie und verwandte Teile anderer Wissenschaften, 1954, 85: 245-254. DOI: 10.1007/BF00900443.

[90] T. Kajitani, M. Hirabayashi, T. Kawase, K. Yamada, Site occupation and local vibration of hydrogen isotopes in hexagonal $\mathrm{Ti}_{5} \mathrm{Si}_{3} \mathrm{H}(\mathrm{D})_{1-x}$. Transactions of the Japan Institute of Metals, 1986, 27: 639-647. DOI: 10.2320/matertrans1960.27.639.

[91] H. Nowotny, H. Auer-Welsbach, J. Bruss, A. Kohl, Ein Beitrag zur Mn5Si3-Struktur (D 88-Typ). Monatshefte für Chemie und verwandte Teile anderer Wissenschaften, 1959, 90: 15-23. DOI: 10.1007/BF00901126.

[92] P. Pietrokowsky, P. Duwez, Crystal Structure of $\mathrm{Ti}_{5} \mathrm{Si}_{3}, \mathrm{Ti}_{5} \mathrm{Ge}_{3}, \mathrm{Ti}_{5} \mathrm{Sn}_{3} . \mathrm{JOM}, 1951$, 3: 772-773. DOI: 10.1007/BF03397370.

[93] A. Bondar, H.-L. Lukas, Molybdenum - Silicon - Titanium, in Light Metal Systems, Part 4, G. Effenberg, S. Ilyenko, Editors, 2006, 11A4, Springer-Verlag, Berlin, Heidelberg: p. 385-405.

[94] S.-H. Ha, K. Yoshimi, K. Maruyama, R. Tu, T. Goto, Compositional regions of single phases at $1800{ }^{\circ} \mathrm{C}$ in Mo-rich Mo-Si-B ternary system. Materials Science and Engineering: A, 2012, 552: 179-188. DOI: 10.1016/j.msea.2012.05.028. 
[95] H. J. Seifert, H. L. Lukas, G. Petzow, Thermodynamic optimization of the Ti-Si system. Zeitschrift fur Metallkunde, 1996, 87: 2-13. ISSN: 0044-3093.

[96] E. Ström, Mechanical properties of $\mathrm{Mo}_{5} \mathrm{Si}_{3}$ intermetallics as a function of composition. Materials Characterization, 2005, 55: 402-411. DOI: 10.1016/j.matchar.2005.09.001.

[97] J. J. Williams, Y. Y. Ye, M. J. Kramer, K. M. Ho, L. Hong, C. L. Fu, S. K. Malik, Theoretical calculations and experimental measurements of the structure of $\mathrm{Ti}_{5} \mathrm{Si}_{3}$ with interstitial additions. Intermetallics, 2000, 8: 937-943. DOI: 10.1016/S09669795(00)00064-9.

[98] D. H. Templeton, C. H. Dauben, The Crystal Structure of MosSi. Acta Crystallographica, 1950, 3: 261-262. DOI: 10.1107/S0365110X50000689.

[99] R. Rosenkranz, G. Frommeyer, W. Smarsly, Microstructures and properties of high melting point intermetallic $\mathrm{Ti}_{5} \mathrm{Si}_{3}$ and $\mathrm{Ti}_{5} \mathrm{Si}_{2}$ compounds, in Second International ASM Conference on High Temperature Aluminides and Intermetallics, San Diego, California, 1992: 288-294. DOI: 10.1016/B978-1-85166-822-9.50048-0.

[100] F. Chu, D. J. Thoma, K. McClellan, P. Peralta, Y. He, Synthesis and properties of $\mathrm{Mo}_{5} \mathrm{Si}_{3}$ single crystals. Intermetallics, 1999, 7: 611-620. DOI: 10.1016/S09669795(98)00059-4.

[101] F. C. Nix, D. MacNair, The thermal expansion of pure metals. II: molybdenum, palladium, silver, tantalum, tungsten, platinum, and lead. Physical Review, 1942, 61: 74-78. DOI: 10.1103/PhysRev.61.74.

[102] Y. S. Touloukian, R. K. Kirby, R. E. Taylor, T. Y. R. Lee, Thermophysical Properties of Matter - the TPRC Data Series, in Thermal Expansion - Nonmetallic Solids, 1977, 13, IFI/Plenum, New York: p. 1210-1212. Available from: https://apps.dtic.mil/sti/pdfs/ADA129116.pdf [cited 06/07/2020].

[103] H. L. Zhao, M. J. Kramer, M. Akinc, Thermal expansion behavior of intermetallic compounds in the Mo-Si-B system. Intermetallics, 2004, 12: 493-498. DOI: 10.1016/j.intermet.2004.01.005.

[104] J. H. Schneibel, C. J. Rawn, E. A. Payzant, C. L. Fu, Controlling the thermal expansion anisotropy of $\mathrm{Mo}_{5} \mathrm{Si}_{3}$ and $\mathrm{Ti}_{5} \mathrm{Si}_{3}$ silicides. Intermetallics, 2004, 12: 845850. DOI: 10.1016/j.intermet.2004.02.035.

[105] Y. Yang, Y. A. Chang, L. Tan, Y. Du, Experimental investigation and thermodynamic descriptions of the Mo-Si-Ti system. Materials Science and Engineering A, 2003, 361: 281-293. DOI: 10.1016/S0921-5093(03)00560-4.

[106] C. A. Nunes, R. Sakidja, Z. Dong, J. H. Perepezko, Liquidus projection for the Morich portion of the Mo-Si-B ternary system. Intermetallics, 2000, 8: 327-337. DOI: 10.1016/S0966-9795(99)00088-6.

[107] B. Bian, Y. Liu, Y. Du, Q. Min, H. Liu, S. Wen, P. Zhou, Measurement of the Interdiffusion Coefficients in Mo-Ti and Mo-Ti-Zr Beta Phase Alloys from 1273 to 1473 K. Journal of Phase Equilibria and Diffusion, 2019, 40: 206-218. DOI: 10.1007/s11669-019-00715-1. 
[108] R. Sakidja, H. Sieber, J. H. Perepezko, The formation of Mo precipitates in a supersaturated $\mathrm{Mo}_{5} \mathrm{SiB}_{2}$ intermetallic phase. Philosophical Magazine Letters, 1999, 79: 351-357. DOI: 10.1080/095008399177192.

[109] R. Bürgel, H. J. Maier, T. Niendorf, Kapitel 5: Hochtemperaturkorrosion, in Handbuch Hochtemperatur-Werkstofftechnik, 2011, 4, Vieweg+Teubner Verlag, Wiesbaden: p. 260-339. ISBN: 978-3-8348-9907-1.

[110] N. B. Pilling, R. E. Bedworth, The oxidation of metals at high temperature. Journal of the Institute of Metals, 1923, 29: 529-582. ISSN: 0020-2975.

[111] H. E. Evans, A. T. Donaldson, T. C. Gilmour, Mechanisms of Breakaway Oxidation and Application to a Chromia-Forming Steel. Oxidation of Metals, 1999, 52: 379402. DOI: $10.1023 / \mathrm{A}: 1018855914737$.

[112] A. S. Khanna, Introduction to High Temperature Oxidation and Corrosion. 2002, ASM International, Ohio: p. 72. ISBN: 0-87170-762-4.

[113] H. J. T. Ellingham, Reducibility of oxides and sulfides in metallurgical processes. Journal of the Society of Chemical Industry, 1944, 63: 125-133.

[114] M. P. Brady, J. L. Smialek, F. Terepka, Microstructure of alumina-forming oxidation resistant Al-Ti-Cr alloys. Scripta Metallurgica et Materialia, 1995, 32: 1659-1664. DOI: 10.1016/0956-716X(95)00251-P.

[115] V. P. Deodeshmukh, S. J. Matthews, D. L. Klarstrom, High-temperature oxidation performance of a new alumina-forming $\mathrm{Ni}-\mathrm{Fe}-\mathrm{Cr}-\mathrm{Al}$ alloy in flowing air. International Journal of Hydrogen Energy, 2011, 36: 4580-4587. DOI: 10.1016/j.ijhydene.2010.04.099.

[116] H. T. Mallikarjuna, N. L. Richards, W. F. Caley, Isothermal oxidation comparison of three Ni-based superalloys. Journal of Materials Engineering and Performance, 2017, 26: 2014-2023. DOI: 10.1007/s11665-017-2630-x.

[117] F. H. Stott, The Oxidation of Alumina-Forming Alloys, in Materials Science Forum, Switzerland, 1997, 251-254: 19-32. DOI: 10.4028/www.scientific.net/MSF.251254.19.

[118] D. W. McKee, S. C. Huang, The oxidation behavior of gamma-titanium aluminide alloys under thermal cycling conditions. Corrosion Science, 1992, 33: 1899-1914. DOI: 10.1016/0010-938X(92)90192-6.

[119] M. J. Balart, J. B. Patel, Z. Fan, Melt protection of Mg-Al based alloys. Metals, 2016, 6: 131-142. DOI: 10.3390/met6060131.

[120] G. C. Wood, High-temperature oxidation of alloys. Oxidation of Metals, 1970, 2: 1157. DOI: $10.1007 / \mathrm{BF} 00603581$.

[121] D. W. Aylmore, S. J. Gregg, W. B. Jepson, Oxidation of niobium in the temperature range $350-750^{\circ} \mathrm{C}$. Journal of The Electrochemical Society, 1960, 107: 495-501. DOI: $10.1149 / 1.2427731$.

[122] B. Cox, The oxidation and corrosion of zirconium and its alloys. Corrosion, 1960, 16: 124-128. DOI: 10.5006/0010-9312-16.4.124. 
[123] A. Gulbransen, K. F. Andrew, Breakaway Oxidation of Zirconium-Tin Alloys. Corrosion, 1958, 14: 50. DOI: 10.5006/0010-9312-14.1.50.

[124] I. Gurrappa, S. Weinbruch, D. Naumenko, W. J. Quadakkers, Factors governing breakaway oxidation of FeCrAl-based alloys. Materials and Corrosion, 2000, 51: 224-235. DOI: MACO224>3.0.CO;2-B.

[125] W. J. Quadakkers, K. Bongartz, The prediction of breakaway oxidation for alumina forming ODS alloys using oxidation diagrams. Materials and Corrosion, 1994, 45: 232-241. DOI: 10.1002/maco.19940450404.

[126] S. Mrowec, A. Stokłosa, Calculations of parabolic rate constants for metal oxidation. Oxidation of Metals, 1974, 8: 379-391. DOI: 10.1007/BF00603388.

[127] Z. Liu, W. Gao, Y. He, Modeling of oxidation kinetics of Y-doped Fe-Cr-Al alloys. Oxidation of Metals, 2000, 53: 341-350. DOI: 10.1023/A:1004545421739.

[128] D. Naumenko, B. Gleeson, E. Wessel, L. Singheiser, W. J. Quadakkers, Correlation between the microstructure, growth mechanism, and growth kinetics of alumina scales on a FeCrAlY alloy. Metallurgical and Materials Transactions A, 2007, 38: 2974-2983. DOI: 10.1007/s11661-007-9342-z.

[129] W. J. Quadakkers, Growth mechanisms of oxide scales on ODS alloys in the temperature range $1000-1100^{\circ} \mathrm{C}$. Materials and Corrosion, 1990, 41: 659-668. DOI: 10.1002/maco.19900411204.

[130] P. Kofstad, Oxidation of Metals: Determination of Activation Energies. Nature, 1957, 179: 1362-1363. DOI: 10.1038/1791362a0.

[131] C.-J. Han, C. R. Helms, Parallel oxidation mechanism for Si oxidation in dry $\mathrm{O}_{2}$. Journal of The Electrochemical Society, 1987, 134: 1297. DOI: 10.1149/1.2100661.

[132] N. Floquet, O. Bertrand, J. J. Heizmann, Structural and morphological studies of the growth of $\mathrm{MoO}_{3}$ scales during high-temperature oxidation of molybdenum. Oxidation of Metals, 1992, 37: 253-280. DOI: 10.1007/BF00665191.

[133] E. A. Gulbransen, K. F. Andrew, F. A. Brassart, Oxidation of Molybdenum $550^{\circ}$ to $1700^{\circ} \mathrm{C}$. Journal of The Electrochemical Society, 1963, 110: 952-959. DOI: $10.1149 / 1.2425918$.

[134] E. S. Jones, J. F. Mosher, R. Speiser, J. W. Spretnak, The Oxidation of Molybdenum. Corrosion, 1958, 14: 20-26. DOI: 10.5006/0010-9312-14.1.20.

[135] M. Simnad, A. Spilners, Kinetics and Mechanism of the Oxidation of Molybdenum. JOM, 1955, 7: 1011-1016. DOI: 10.1007/BF03377603.

[136] F. A. Rioult, S. D. Imhoff, R. Sakidja, J. H. Perepezko, Transient oxidation of MoSi-B alloys: effect of the microstructure size scale. Acta Materialia, 2009, 57: 46004613. DOI: 10.1016/j.actamat.2009.06.036.

[137] D. A. Berztiss, R. R. Cerchiara, E. A. Gulbransen, F. S. Pettit, G. H. Meier, Oxidation of $\mathrm{MoSi}_{2}$ and comparison with other silicide materials. Materials Science and Engineering: A, 1992, 155: 165-181. DOI: 10.1016/0921-5093(92)90324-T. 
[138] H. J. Grabke, G. H. Meier, Accelerated oxidation, internal oxidation, intergranular oxidation, and pesting of intermetallic compounds. Oxidation of Metals, 1995, 44: 147-176. DOI: 10.1007/BF01046726.

[139] J. H. Westbrook, D. L. Wood, "PEST" degradation in beryllides, silicides, aluminides, and related compounds. Journal of Nuclear Materials, 1964, 12: 208215. DOI: 10.1016/0022-3115(64)90142-4.

[140] E. Fitzer, Heizleiter für hohe Temperaturen, in Plansee Proc. $3^{\text {rd }}$ Seminar, Reutte/Tirol, 1959, 3: 175-202.

[141] J. Berkowitz-Mattuck, M. Rossetti, Basic factors controlling pest in high temperature systems. NASA Technical Reports, 1971, NASA-CR-125071: 1-27. Available from: https://ntrs.nasa.gov/api/citations/19720006901/ downloads/19720006901.pdf [cited 07/07/20].

[142] K. Yanagihara, T. Maruyama, K. Nagata, Effect of third elements on the pesting suppression of Mo-Si-X intermetallics (X= Al, Ta, Ti, Zr and Y). Intermetallics, 1996, 4: 133-S139. DOI: 10.1016/0966-9795(96)00019-2.

[143] P. J. Meschter, Low-temperature oxidation of molybdenum disilicide. Metallurgical Transactions A, 1992, 23: 1763-1772. DOI: 10.1007/BF02804369.

[144] S. Knittel, S. Mathieu, M. Vilasi, Oxidation behaviour of arc-melted and uniaxial hot pressed $\mathrm{MoSi}_{2}$ at $500{ }^{\circ} \mathrm{C}$. Intermetallics, 2010, 18: 2267-2274. DOI: 10.1016/j.intermet.2010.07.003.

[145] M. K. Meyer, M. Akinc, Oxidation Behavior of Boron-Modified $\mathrm{Mo}_{5} \mathrm{Si}_{3}$ at $800^{\circ}$ $1300^{\circ} \mathrm{C}$. Journal of the American Ceramic Society, 1996, 79: 938-944. DOI: 10.1111/j.1151-2916.1996.tb08528.x.

[146] I. Rosales, H. Martinez, D. Bahena, J. A. Ruiz, R. Guardian, J. Colin, Oxidation performance of $\mathrm{Mos}_{3} \mathrm{Si}$ with $\mathrm{Al}$ additions. Corrosion Science, 2009, 51: 534-538. DOI: 10.1016/j.corsci.2008.12.004.

[147] M. A. Azim, B. Gorr, H.-J. Christ, O. Lenchuk, K. Albe, D. Schliephake, M. Heilmaier, Effect of $\mathrm{Ti}$ content and nitrogen on the high-temperature oxidation behavior of $(\mathrm{Mo}, \mathrm{Ti})_{5} \mathrm{Si}_{3}$. Intermetallics, 2017, 90: 103-112. DOI: 10.1016/j.intermet.2017.05.023.

[148] Z. Tang, J. J. Williams, A. J. Thom, M. Akinc, High temperature oxidation behavior of $\mathrm{Ti}_{5} \mathrm{Si}_{3}$-based intermetallics. Intermetallics, 2008, 16: 1118-1124. DOI: 10.1016/j.intermet.2008.06.013.

[149] A. Rahmel, P. J. Spencer, Thermodynamic Aspects of TiAl and TiSi2 Oxidation: The Al-Ti-O and Si-Ti-O Phase Diagrams. Oxidation of Metals, 1991, 35: 53-68. DOI: 10.1007/BF00666500.

[150] S. Taniguchi, T. Minamida, T. Shibata, Oxidation Behaviour of $\mathrm{Ti}_{5} \mathrm{Si}_{3}$ at Temperatures between 1400 and 1700 K, in Materials Science Forum, 1997, 251254: 227-234. DOI: 10.4028/www.scientific.net/MSF.251-254.227.

[151] J. J. Williams, M. Akinc, Oxidation Resistance of $\mathrm{Ti}_{5} \mathrm{Si}_{3}$ and $\mathrm{Ti}_{5} \mathrm{Si}_{3} \mathrm{Z}_{\mathrm{x}}$ at $1000^{\circ} \mathrm{C}(\mathrm{Z}=$ C, N, or O). Oxidation of Metals, 2002, 58: 57-71. DOI: 10.1023/A:1016012507682. 
[152] S. Majumdar, P. K. Singh, A. K. Pandey, G. V. S. N. Rao, Kinetics of oxide scale growth on a $(\mathrm{Ti}, \mathrm{Mo})_{5} \mathrm{Si}_{3}$ based oxidation resistant $\mathrm{Mo}-\mathrm{Ti}-\mathrm{Si}$ alloy at $900-1300^{\circ} \mathrm{C}$. High Temperature Materials and Processes, 2019, 38: 533-540. DOI: 10.1515/htmp-2019-0056.

[153] S. Majumdar, B. Paul, P. K. Singh, J. Kishor, V. Kain, Effect of Si content on microstructure, mechanical and oxidation properties of hot pressed Mo-Ti-Si alloys. Intermetallics, 2018, 100: 126-135. DOI: 10.1016/j.intermet.2018.06.013.

[154] V. Supatarawanich, D. R. Johnson, C. C. T. Liu, Effects of microstructure on the oxidation behavior of multiphase Mo-Si-B alloys. Materials Science and Engineering A, 2003, 344: 328-339. DOI: 10.1016/S0921-5093(02)00446-X.

[155] S. Burk, B. Gorr, M. Krüger, M. Heilmaier, H.-J. Christ, Oxidation behavior of MoSi-B-(X) alloys: Macro-and microalloying (X= Cr, $\left.\mathrm{Zr}, \mathrm{La}_{2} \mathrm{O}_{3}\right)$. JOM, 2011, 63: 32-36. DOI: $10.1007 / \mathrm{s} 11837-011-0203-2$.

[156] N. P. Bansal, R. H. Doremus, Chapter 9: Viscosity, in Handbook of Glass Properties, 1986, Academic Press Inc., Orlando: p. 244. ISBN: 978-0-08-052376-7.

[157] S. Ochiai, Improvement of the oxidation-proof property and the scale structure of $\mathrm{Mos}_{3} \mathrm{Si}$ intermetallic alloy through the addition of chromium and aluminum elements. Intermetallics, 2006, 14: 1351-1357. DOI: 10.1016/j.intermet.2006.01.059.

[158] R. Sakidja, J. H. Perepezko, Alloying and microstructure stability in the hightemperature Mo-Si-B system. Journal of Nuclear Materials, 2007, 366: 407-416. DOI: 10.1016/j.jnucmat.2007.03.029.

[159] M. E. Kassner, M. T. Pérez-Prado, Chapter 1 and 2: Introduction and Five-PowerLaw Creep, in Fundamentals of Creep in Metals and Alloys, 2004, 1, Elsevier, Oxford: p. 1-76. ISBN: 0-08-043637-4.

[160] A. K. Mukherjee, J. E. Bird, J. E. Dorn, Experimental correlations for hightemperature creep, in Detroit Materials Engineering Congress of American Society for Metals, Detroit, 1968: 1-80. Available from: https://escholarship.org/uc/item/31p4z5v2 [cited 11/01/2021].

[161] N. F. Mott, The Mechanical Properties of Metals, in Proceedings of the Physical Society. Section B, 1951, 64: 729-742. DOI: 10.1088/0370-1301/64/9/301.

[162] N. F. Mott, Dislocations, plastic flow and creep. Proceedings of the Royal Society of London. Series A. Mathematical and Physical Sciences, 1953, 220: 1-14. DOI: 10.1098/rspa.1953.0167.

[163] N. F. Mott, F. R. N. Nabarro, Dislocation theory and transient creep, in Physical Society Bristol Conference Report, Bristol, 1948: 1-19. Available from: http://hdl.handle.net/10539/1195 [cited 17/10/2018].

[164] G. Gottstein, Kapitel 6: Mechanische Eigenschaften, in Physkalische Grundlagen der Materialkunde, G. Gottstein, Editor, 2007, 3, Springer, Berlin, Heidelberg: p. 197-302. ISBN: 978-3-540-71104-9. 
[165] O. D. Sherby, P. M. Burke, Mechanical behavior of crystalline solids at elevated temperature. Progress in Materials Science, 1967, 13: 325-390. DOI: 10.1016/00796425(68)90024-8.

[166] W. Blum, Role of Dislocation Annihilation during Steady-State Deformation. Physica Status Solidi (b), 1971, 45: 561-571. DOI: 10.1002/pssb.2220450219.

[167] H. Mughrabi, Revisiting "Steady-State" Monotonic and Cyclic Deformation: Emphasizing the Quasi-Stationary State of Deformation. Metallurgical and Materials Transactions A, 2020, 51: 1441-1456. DOI: 10.1007/s11661-019-05618-x.

[168] M. C. Chaturvedi, Y. Han, Effect of particle size on the creep rate of superalloy Inconel 718. Materials Science and Engineering, 1987, 89: L7-L10. DOI: 10.1016/0025-5416(87)90264-3.

[169] C. Hochmuth, D. Schliephake, R. Völkl, M. Heilmaier, U. Glatzel, Influence of zirconium content on microstructure and creep properties of Mo-9Si-8B alloys. Intermetallics, 2014, 48: 3-9. DOI: 10.1016/j.intermet.2013.08.017.

[170] W. J. Zhang, S. C. Deevi, Analysis of the minimum creep rates of TiAl alloys. Materials Science and Engineering: A, 2003, 362: 280-291. DOI: 10.1016/S09215093(03)00589-6.

[171] A. Bhaduri, Creep and Stress Rupture, in Mechanical Properties and Working of Metals and Alloys, R. Hull, C. Jagadish, Y. Kawazoe, R. M. Osgood, J. Parisi, U. W. Pohl, T.-Y. Seong, S.-I. Uchida, Z. M. Wang, Editors, 2018, 264, Springer Series in Materials Science, Singapore: p. 257-316. ISBN: 978-981-10-7209-3.

[172] W. D. Nix, J. C. Gibeling, D. A. Hughes, Time-dependent deformation of metals. Metallurgical Transactions A, 1985, 16: 2215-2226. DOI: 10.1007/BF02670420.

[173] O. D. Sherby, L. R. Orr, J. E. Dorn, Creep correlations of metals at elevated temperatures. JOM, 1954, 6: 71-80. DOI: 10.1007/BF03397983.

[174] O. D. Sherby, E. M. Taleff, Influence of grain size, solute atoms and second-phase particles on creep behavior of polycrystalline solids. Materials Science and Engineering: A, 2002, 322: 89-99. DOI: 10.1016/S0921-5093(01)01121-2.

[175] F. R. M. Nabarro, Grain size, stress, and creep in polycrystalline solids. Physics of the Solid State, 2000, 42: 1456-1459. DOI: 10.1134/1.1347484.

[176] G. K. Williamson, R. E. Smallman, III. Dislocation Densities in Some Annealed and Cold-Worked Metals from Measurements on the X-Ray Debye-Scherrer Spectrum. Philosophical Magazine, 1956, 1: 34-46. DOI: 10.1080/14786435608238074.

[177] G. B. Gibbs, The Thermodynamics of Thermally-Activated Dislocation Glide. Physica Status Solidi (b), 1965, 10: 507-512. DOI: 10.1002/pssb.2220100212.

[178] A. Orlová, J. Čadek, On the origin of the dislocation substructure during hightemperature creep. Philosophical Magazine, 1970, 21: 509-518. DOI: 10.1080/14786437008238435.

[179] B. Wilshire, C. J. Palmer, Grain size effects during creep of copper. Scripta Materialia, 2002, 46: 483-488. DOI: 10.1016/S1359-6462(01)01247-7. 
[180] M. F. Ashby, Boundary defects, and atomistic aspects of boundary sliding and diffusional creep. Surface Science, 1972, 31: 498-542. DOI: 10.1016/00396028(72)90273-7.

[181] F. R. N. Nabarro, Steady-state diffusional creep. Philosophical Magazine, 1967, 16: 231-237. DOI: $10.1080 / 14786436708229736$.

[182] C. Herring, Diffusional Viscosity of a Polycrystalline Solid. Journal of Applied Physics, 1950, 21: 437-445. DOI: 10.1063/1.1699681.

[183] F. R. N. Nabarro, Z. S. Basinski, D. B. Holt, The plasticity of pure single crystals. Advances in Physics, 1964, 13: 193-323. DOI: 10.1080/00018736400101031.

[184] R. S. Gordon, Mass transport in the diffusional creep of ionic solids. Journal of the American Ceramic Society, 1973, 56: 147-152. DOI: 10.1111/j.11512916.1973.tb15431.x.

[185] J. H. Hensler, G. V. Cullen, Grain shape change during creep in magnesium oxide. Journal of the American Ceramic Society, 1967, 50: 584-585. DOI: 10.1111/j.11512916.1967.tb15003.x.

[186] R. L. Coble, A model for boundary diffusion controlled creep in polycrystalline materials. Journal of Applied Physics, 1963, 34: 1679-1682. DOI: 10.1063/1.1702656.

[187] C. B. Carter, A. M. Donald, S. L. Sass, The study of grain boundary thickness using electron diffraction techniques. Philosophical Magazine A, 1980, 41: 467-475. DOI: $10.1080 / 01418618008239326$.

[188] R. E. Mistler, R. L. Coble, Grain-boundary diffusion and boundary widths in metals and ceramics. Journal of Applied Physics, 1974, 45: 1507-1509. DOI: 10.1063/1.1663451.

[189] D. Prokoshkina, V. A. Esin, G. Wilde, S. V. Divinski, Grain boundary width, energy and self-diffusion in nickel: effect of material purity. Acta Materialia, 2013, 61: 5188-5197. DOI: 10.1016/j.actamat.2013.05.010.

[190] M. F. Ashby, B. F. Dyson, Creep damage mechanics and micromechanisms, in $6^{\text {th }}$ International Conference on Fracture (ICF6), New Delhi, 1984: 3-30. DOI: 10.1016/B978-1-4832-8440-8.50017-X.

[191] T. Watanabe, Grain boundary sliding and stress concentration during creep. Metallurgical and Materials Transactions A, 1983, 14: 531-545. DOI: 10.1007/BF02643771.

[192] M. H. Yoo, H. Trinkaus, Crack and cavity nucleation at interfaces during creep. Metallurgical Transactions A, 1983, 14: 547-561. DOI: 10.1007/BF02643772.

[193] O. D. Sherby, P. M. Burke, Mechanical behavior of crystalline solids at elevated temperature. Progress in Materials Science, 1968, 13: 323-390. DOI: 10.1016/00796425(68)90024-8.

[194] H. J. Frost, M. F. Ashby, A second report on deformation mechansim maps. Engineering and Applied Physics, Harvard University Cambridge, Massachusetts, 1973: 1-108. ISSN: 0-08-029337-9. 
[195] G. S. Cho, G. B. Ahn, K. H. Choe, Creep microstructures and creep behaviors of pure molybdenum sheet at $0.7 \mathrm{~T}$. International Journal of Refractory Metals and Hard Materials, 2016, 60: 52-57. DOI: 10.1016/j.ijrmhm.2016.06.021.

[196] D. L. Anton, E. Hartford, D. M. Shah, P. Whitney, High temperature properties of refractory intermetallics, in MRS, Boston, Massachusetts, 1990, 213: 733-738. DOI: 10.1557/PROC-213-733.

[197] J. Askill, D. H. Tomlin, Self-diffusion in molybdenum. Philosophical Magazine, 1963, 8: 997-1001. DOI: 10.1080/14786436308214459.

[198] M. K. Meyer, M. J. Kramer, M. Akinc, Compressive creep behavior of Mo5Si3 with the addition of boron. Intermetallics, 1996, 4: 273-281. DOI: 10.1016/09669795(95)00048-8.

[199] R. Mitra, N. E. Prasad, Y. R. Mahajan, Mechanical behaviour of $\mathrm{Ti}_{5} \mathrm{Si}_{3}$ based alloys and composites. Transactions of the Indian Institute of Metals, 2008, 61: 427-433. DOI: $10.1007 / \mathrm{s} 12666-008-0075-5$.

[200] K. Sadananda, C. R. Feng, R. Mitra, S. C. Deevi, Creep and fatigue properties of high temperature silicides and their composites. Materials Science and Engineering A, 1999, 261: 223-238. DOI: 10.1016/S0921-5093(98)01070-3.

[201] T. Hayashi, K. Ito, K. Ihara, M. Fujikura, M. Yamaguchi, Creep of single crystalline and polycrystalline T2 phase in the Mo-Si-B system. Intermetallics, 2004, 12: 699704. DOI: 10.1016/j.intermet.2004.02.009.

[202] J. H. Schneibel, H. T. Lin, Creep properties of molybdenum silicide intermetallics containing boron. Materials at High Temperatures, 2002, 19: 25-28. DOI: 10.1179/mht.2002.19.1.004.

[203] J. H. Schneibel, High temperature strength of Mo-Mos Si-Mo5 $\mathrm{SiB}_{2}$ molybdenum silicides. Intermetallics, 2003, 11: 625-632. DOI: 10.1016/S0966-9795(03)00044-X.

[204] W. Cao, S.-L. Chen, F. Zhang, K. Wu, Y. Yang, Y. A. Chang, R. Schmid-Fetzer, W. A. Oates, PANDAT software with PanEngine, PanOptimizer and PanPrecipitation for multi-component phase diagram calculation and materials property simulation. Calphad, 2009, 33: 328-342. DOI: 10.1016/j.calphad.2008.08.004.

[205] S.-L. Chen, S. Daniel, F. Zhang, Y. A. Chang, X. Y. Yan, F.-Y. Xie, R. SchmidFetzer, W. A. Oates, The PANDAT software package and its applications. Calphad, 2002, 26: 175-188. DOI: 10.1016/S0364-5916(02)00034-2.

[206] S.-L. Chen, F. Zhang, F.-Y. Xie, S. Daniel, X.-Y. Yan, Y. A. Chang, R. SchmidFetzer, W. A. Oates, Calculating phase diagrams using PANDAT and PanEngine. JOM, 2003, 55: 48-51. DOI: 10.1007/s11837-003-0010-5.

[207] A. Kroupa, Modelling of phase diagrams and thermodynamic properties using Calphad method-Development of thermodynamic databases. Computational Materials Science, 2013, 66: 3-13. DOI: 10.1016/j.commatsci.2012.02.003.

[208] W. A. Oates, H. Wenzl, T. Mohri, On putting more physics into calphad solution models. Calphad, 1996, 20: 37-45. DOI: 10.1016/0364-5916(96)00011-9. 
[209] Y. Wang, S. Shang, L.-Q. Chen, Z.-K. Liu, Density functional theory-based database development and CALPHAD automation. JOM, 2013, 65: 1533-1539. DOI: $10.1007 / \mathrm{s} 11837-013-0751-8$.

[210] A. Jiju, Chapter 2: Fundamentals of Design of Experiments, in Design of Experiments for Engineers and Scientists, 2014, Elsevier, London and Waltham: p. 7-17. ISBN: 978-0-08-099417-8.

[211] D. A. Porter, K. E. Easterling, M. Y. Sherif, Chapter 4: Solidification, in Phase Transformations in Metals and Alloys, D. A. Porter, K. E: Easterling, M. Y. Sherif, Editors, 2009, 2, CRC Press, Boca Raton: p. 189-255. ISBN: 978-0-442-31638-9.

[212] E. Scheil, Bemerkungen zur Schichtkristallbildung. Zeitschrift für Metallkunde, 1942, 34: 70-72. ISSN: 0179-4841.

[213] Y.-Z. Zhao, Y.-H. Zhao, Q. Li, S.-L. Chen, J.-Y. Zhang, K.-C. Chou, Effects of step size and cut-off limit of residual liquid amount on solidification simulation of $\mathrm{Al}-$ $\mathrm{Mg}-\mathrm{Zn}$ system with Scheil model. Intermetallics, 2009, 17: 491-495. DOI: 10.1016/j.intermet.2008.12.006.

[214] K. J. Kurzydlowski, B. Ralph, Chapter 2: Basic concepts, definitions, techniques and relationships, in The quantitative description of the microstructure of materials, 1995, 3, CRC Press, Boca Raton: p. 81. ISBN: 0849389216.

[215] S. Obert, A. Kauffmann, S. Seils, S. Schellert, M. Weber, B. Gorr, H.-J. Christ, M. Heilmaier, On the chemical and microstructural requirements for the pestingresistance of Mo-Si-Ti alloys. JMR\&T, 2020, 9: 8556-8567. DOI: 10.1016/j.jmrt.2020.06.002.

[216] S. Obert, A. Kauffmann, S. Seils, T. Boll, S. Kauffmann-Weiß, H. Chen, R. Anton, M. Heilmaier, Microstructural and Chemical Constitution of the Oxide Scale formed on a Pesting-Resistant Mo-Si-Ti Alloy. Corrosion Science, 2021, 178: 109081.

[217] J. Angseryd, F. Liu, H.-O. Andrén, S. S. A. Gerstl, M. Thuvander, Quantitative APT analysis of $\mathrm{Ti}(\mathrm{C}, \mathrm{N})$. Ultramicroscopy, 2011, 111: 609-614. DOI: 10.1016/j.ultramic.2011.01.031.

[218] R. Kirchhofer, D. R. Diercks, B. P. Gorman, J. F. Ihlefeld, P. G. Kotula, C. T. Shelton, G. L. Brennecka, Quantifying Compositional Homogeneity in $\mathrm{Pb}(\mathrm{Zr}, \mathrm{Ti}) \mathrm{O}_{3}$ Using Atom Probe Tomography. Journal of the American Ceramic Society, 2014, 97: 2677-2697. DOI: 10.1111/jace.13135.

[219] F. Liu, K. Stiller, Atom probe tomography of thermally grown oxide scale on FeCrAl. Ultramicroscopy, 2013, 132: 279-284. DOI: 10.1016/j.ultramic.2013.02.004.

[220] F. Tang, B. Gault, S. P. Ringer, J. M. Cairney, Optimization of pulsed laser atom probe (PLAP) for the analysis of nanocomposite Ti-Si-N films. Ultramicroscopy, 2010, 110: 836-843. DOI: 10.1016/j.ultramic.2010.03.003.

[221] T. Boll, M. Thuvander, S. Koch, J. N. Wagner, N. Nedfors, U. Jansson, K. Stiller, An APT investigation of an amorphous Cr-B-C thin film. Ultramicroscopy, 2015, 159: 217-222. DOI: 10.1016/j.ultramic.2015.01.001. 
[222] J. B. Nelson, D. P. Riley, An experimental investigation of extrapolation methods in the derivation of accurate unit-cell dimensions of crystals. Proceedings of the Physical Society, 1945, 57: 160-177. DOI: 10.1088/0959-5309/57/3/302.

[223] D. S. Tsai, S. E. Hsu, M. P. Hung, A simple method for the determination of lattice parameters from powder X-ray diffraction data. Materials Transactions, JIM, 1989, 30: 474-479. DOI: 10.2320/matertrans1989.30.474.

[224] S. Obert, A. Kauffmann, M. Heilmaier, Characterisation of the oxidation and creep behaviour of novel Mo-Si-Ti alloys. Acta Materialia, 2020, 184: 132-142. DOI: 10.1016/j.actamat.2019.11.045.

[225] S. Obert, A. Kauffmann, R. Pretzler, D. Schliephake, F. Hinrichs, M. Heilmaier, The Creep Behaviour of Pesting-Resistant (Mo,Ti) ${ }_{5} \mathrm{Si}_{3}$-Containing EutecticEutectoid Mo-Si-Ti Alloys. Metals, 2021, 11: 169 (1-18). DOI: 10.3390/met11010169.

[226] S.-L. Chen, Y. Yang, S.-W. Chen, X.-G. Lu, Y. A. Chang, Solidification Simulation Using Scheil Model in Multicomponent Systems. Journal of Phase Equilibria and Diffusion, 2009, 30: 429-434. DOI: 10.1007/s11669-009-9568-0.

[227] S. Majumdar, B. Gorr, H.-J. Christ, D. Schliephake, M. Heilmaier, Oxidation mechanisms of lanthanum-alloyed Mo-Si-B. Corrosion Science, 2014, 88: 360-371. DOI: $10.1016 /$ j.corsci.2014.07.058.

[228] R. Janakiraman, G. H. Meier, F. S. Pettit, The effect of water vapor on the oxidation of alloys that develop alumina scales for protection. Metallurgical and Materials Transactions A, 1999, 30: 2905-2913. DOI: 10.1007/s11661-999-0128-3.

[229] M. Göbel, A. Rahmel, M. Schütze, The isothermal-oxidation behavior of several nickel-base single-crystal superalloys with and without coatings. Oxidation of Metals, 1993, 39: 231-261. DOI: 10.1007/BF00665614.

[230] A. Sato, H. Harada, A.-C. Yeh, K. Kawagishi, T. Kobayashi, Y. Koizumi, T. Yokokawa, J. X. Zhang, A $5^{\text {th }}$ generation SC superalloy with balanced high temperature properties and processability, in $11^{\text {th }}$ International Symposium of Superalloys, Champion, PA, 2008: 131-138. DOI: 10.7449/2008/superalloys_2008_131_138.

[231] P. Kofstad, P. B. Anderson, O. J. Krudtaa, Oxidation of titanium in the temperature range $800-1200^{\circ} \mathrm{C}$. Journal of the Less Common Metals, 1961, 3: 89-97. DOI: 10.1016/0022-5088(61)90001-7.

[232] G. Hetherington, The viscosity of vitreous silica. Physics and Chemistry of Glasses, 1964, 5: 130-136.

[233] J. J. Williams, M. J. Kramer, M. Akinc, Thermal expansion of Ti5 $\mathrm{Si}_{3}$ with Ge, B, C, N, or O additions. Journal of Materials Research, 2000, 15: 1780-1785. DOI: 10.1557/JMR.2000.0257.

[234] L. Zhang, J. Wu, Thermal expansion and elastic moduli of the silicide based intermetallic alloys $\mathrm{Ti}_{5} \mathrm{Si}_{3}(\mathrm{X})$ and $\mathrm{Nb}_{5} \mathrm{Si}_{3}$. Scripta Materialia, 1998, 38: 307-313. ISSN: 29037960. 
[235] Z. Tang, A. J. Thom, M. Akinc, Role of nitrogen on the oxidative stability of $\mathrm{Ti}_{5} \mathrm{Si}_{3}$ based alloys at elevated temperature. Intermetallics, 2006, 14: 537-543. DOI: 10.1016/j.intermet.2005.09.006.

[236] R. Beyers, Thermodynamic considerations in refractory metal-silicon-oxygen systems. Journal of Applied Physics, 1984, 56: 147-152. DOI: 10.1063/1.333738.

[237] J. J. English, Binary and Ternary Phase Diagrams of Columbium, Molybdenum, Tantalum, and Tungsten, 1961, DMIC Report, Ohio. p. 156-157.

[238] P. A. Farrar, L. P. Stone, H. Margolin, Titanium-Molybdenum-Oxygen System. Journal of Metals, 1956, 8: 595-600.

[239] T. Hatakeyama, S. Ida, N. Sekido, K. Yoshimi, Significant improvement of the oxidation resistance of MoSiBTiC-based multiphase alloys by $\mathrm{Ti}$ enrichment. Corrosion Science, 2020: 108937. DOI: 10.1016/j.corsci.2020.108937.

[240] J. Dai, J. Zhu, C. Chen, F. Weng, High temperature oxidation behavior and research status of modifications on improving high temperature oxidation resistance of titanium alloys and titanium aluminides: A review. Journal of Alloys and Compounds, 2016, 685: 784-798. DOI: 10.1016/j.jallcom.2016.06.212.

[241] J. Unnam, R. N. Shenoy, R. K. Clark, Oxidation of commercial purity titanium. Oxidation of Metals, 1986, 26: 231-252. DOI: 10.1007/BF00659186.

[242] D. Vojtěch, B. Bártová, T. Kubatík, High temperature oxidation of titanium-silicon alloys. Materials Science and Engineering: A, 2003, 361: 50-57. DOI: 10.1016/S0921-5093(03)00564-1.

[243] M. Yoshihara, Y.-W. Kim, Oxidation behavior of gamma alloys designed for high temperature applications. Intermetallics, 2005, 13: 952-958. DOI: 10.1016/j.intermet.2004.12.007.

[244] S. Andersson, B. Collén, U. Kuylenstierna, A. Magnéli, Phase analysis studies on the titanium-oxygen system. Acta Chemica Scandinavica, 1957, 11: 1641-1652.

[245] P. G. Wahlbeck, P. W. Gilles, Reinvestigation of the Phase Diagram for the System Titanium-Oxygen. Journal of the American Ceramic Society, 1966, 49: 180-183. DOI: $10.1111 / \mathrm{j} .1151-2916.1966 . t b 13229 . x$.

[246] P. Ehrlich, Phasenverhältnisse und magnetisches Verhalten im System Titan/Sauerstoff. Zeitschrift für Elektrochemie und angewandte physikalische Chemie, 1939, 45: 362-370. DOI: 10.1002/bbpc.19390450506.

[247] X. Cheng, S. G. Roscoe, Corrosion behavior of titanium in the presence of calcium phosphate and serum proteins. Biomaterials, 2005, 26: 7350-7356. DOI: 10.1016/j.biomaterials.2005.05.047.

[248] J. Pouilleau, D. Devilliers, F. Garrido, S. Durand-Vidal, E. Mahé, Structure and composition of passive titanium oxide films. Materials Science and Engineering: B, 1997, 47: 235-243. DOI: 10.1016/S0921-5107(97)00043-3.

[249] R. R. Merritt, B. G. Hyde, L. A. Bursill, D. K. Philp, The thermodynamics of the titanium + oxygen system: An isothermal gravimetric study of the composition range $\mathrm{Ti}_{3} \mathrm{O}_{5}$ to $\mathrm{TiO}_{2}$ at $1304 \mathrm{~K}$. Philosophical Transactions of the Royal Society of 
London. Series A, Mathematical and Physical Sciences, 1973, 274: 627-661. DOI: 10.1098/rsta.1973.0078.

[250] D. A. Venkatu, L. E. Poteat, Diffusion of titanium of single crystal rutile. Materials Science and Engineering, 1970, 5: 258-262. DOI: 10.1016/0025-5416(70)90014-5.

[251] J. I. Goldstein, S. K. Choi, F. J. J. V. Loo, G. F. Bastin, R. Metselaar, Solid-state Reactions and Phase Relations in the Ti-Si-O System at $1373 \mathrm{~K}$. Journal of the American Ceramic Society, 1995, 78: 313-322. DOI: 10.1111/j.11512916.1995.tb08802.x.

[252] J. Stringer, Some observations on the kinetics of oxidation of titanium at high temperatures. Journal of the Less Common Metals, 1964, 6: 207-213. DOI: 10.1016/0022-5088(64)90100-6.

[253] A. M. Chaze, C. Coddet, Influence of silicon on the oxidation of titanium between 550 and $700^{\circ} \mathrm{C}$. Oxidation of Metals, 1987, 27: 1-20. DOI: 10.1007/BF00656726.

[254] M. Yoshihara, K. Miura, Effects of $\mathrm{Nb}$ addition on oxidation behavior of TiAl. Intermetallics, 1995, 3: 357-363. DOI: 10.1016/0966-9795(95)94254-C.

[255] M. Metikos-Huković, A. Kwokal, J. Piljac, The influence of niobium and vanadium on passivity of titanium-based implants in physiological solution. Biomaterials, 2003, 24: 3765-3775. DOI: 10.1016/S0142-9612(03)00252-7.

[256] R. K. Kirby, Thermal expansion of rutile from 100 to 700 K. Journal of Research of the National Bureau of Standards. Section A, Physics and Chemistry, 1967, 71: 363-369. DOI: 10.6028/jres.071A.041.

[257] G. Frommeyer, R. Rosenkranz, Structures and properties of the refractory silicides $\mathrm{Ti}_{5} \mathrm{Si}_{3}$ and $\mathrm{TiSi}_{2}$ and Ti-Ai-(Al) eutectic alloys, in NATO Advanced Research Workshop on Metallic Materials with High Structural Efficiency, Kiev, 2003. Available from: https://apps.dtic.mil/dtic/tr/fulltext/u2/a426363.pdf [cited 12/01/2021].

[258] P. Hidnert, Thermal expansion of titanium. Journal of Research of the National Bureau of Standards, 1943, 30: 101-105. Available from: https://nvlpubs.nist.gov/nistpubs/jres/30/jresv30n2p101_A1b.pdf [cited 17/07/19].

[259] J. W. Edwards, R. Speiser, H. L. Johnston, High Temperature Structure and Thermal Expansion of Some Metals as Determined by X-Ray Diffraction Data. I. Platinum, Tantalum, Niobium, and Molybdenum. Journal of Applied Physics, 1951, 22: 424-428. DOI: 10.1063/1.1699977.

[260] I. Blech, U. Cohen, Effects of humidity on stress in thin silicon dioxide films. Journal of Applied Physics, 1982, 53: 4202-4207. DOI: 10.1063/1.331244.

[261] G. B. Gibbs, Vacancy generation and the kinetics of oxidation. Philosophical Magazine, 1968, 18: 1175-1180. DOI: 10.1080/14786436808227748

[262] A. T. Fromhold, Parabolic oxidation of metals. Physics Letters A, 1969, 29: 157 158. DOI: 10.1016/0375-9601(69)90088-7. 
[263] R. A. Rapp, The high temperature oxidation of metals forming cation-diffusing scales. Metallurgical Transactions B, 1984, 15: 195-212. DOI: 10.1007/BF02667322.

[264] E. W. Haycock, Transitions from Parabolic to Linear Kinetics in Scaling of Metals. Journal of The Electrochemical Society, 1959, 106: 771-775. DOI: $10.1149 / 1.2427495$.

[265] B. E. Deal, A. S. Grove, General Relationship for the Thermal Oxidation of Silicon. Journal of Applied Physics, 1965, 36: 3770-3778. DOI: 10.1063/1.1713945.

[266] P. F. Dennis, R. Freer, Oxygen self-diffusion in rutile under hydrothermal conditions. Journal of Materials Science, 1993, 28: 4804-4810. DOI: 10.1007/BF00414275.

[267] J. C. Mikkelsen, Self-diffusivity of network oxygen in vitreous $\mathrm{SiO}_{2}$. Applied Physics Letters, 1984, 45: 1187-1189. DOI: 10.1063/1.95086.

[268] D. K. Moore, D. J. Cherniak, E. B. Watson, Oxygen diffusion in rutile from 750 to $1000{ }^{\circ} \mathrm{C}$ and 0.1 to $1000 \mathrm{MPa}$. American Mineralogist, 1998, 83: 700-711. DOI: 10.2138/am-1998-7-803.

[269] J. Rodríguez-Viejo, F. Sibieude, M. T. Clavaguera-Mora, C. Monty, ${ }^{18} \mathrm{O}$ diffusion through amorphous $\mathrm{SiO}_{2}$ and cristobalite. Applied Physics Letters, 1993, 63: 19061908. DOI: $10.1063 / 1.110644$.

[270] T. Takahashi, S. Fukatsu, K. M. Itoh, M. Uematsu, A. Fujiwara, H. Kageshima, Y. Takahashi, K. Shiraishi, Self-diffusion of $\mathrm{Si}$ in thermally grown $\mathrm{SiO}_{2}$ under equilibrium conditions. Journal of Applied Physics, 2003, 93: 3674-3676. DOI: 10.1063/1.1554487.

[271] M. Dechamps, P. Lehr, Sur l'oxydation du titane a en atmosphère d'oxygène: Rôle de la couche oxydée et mécanisme d'oxydation. Journal of the Less Common Metals, 1977, 56: 193-207. DOI: 10.1016/0022-5088(77)90041-8.

[272] E. W. Sucov, Diffusion of Oxygen in Vitreous Silica. Journal of the American Ceramic Society, 1963, 46: 14-20. DOI: 10.1111/j.1151-2916.1963.tb13763.x.

[273] K. Maier, H. Mehrer, G. Rein, Self-Diffusion in Molybdenum. Zeitschrift für Metallkunde, 1979, 70: 271-276. ISSN: 00443093.

[274] J. H. Perepezko, R. Sakidja, S. Kim, Z. Dong, J. S. Park, Multiphase microstructures and stability in high temperature Mo-Si-B alloys, K. J. Hemker, D. M. Dimiduk, Editors, in $3^{\text {rd }}$ International Symposium on Structural Intermetallics, TMS, Warrendale, 2001: 505-514.

[275] J. E. L. Gomes, A. M. Huntz, Comparison of the kinetics and morphologic properties of titanium, Ti-1.5 Ni and Ti-2.5 Cu during oxidation in pure oxygen between 600 and $820^{\circ} \mathrm{C}$. Oxidation of Metals, 1980, 14: 471-498. DOI: 10.1007/BF00603475.

[276] S. A. Kirillova, V. I. Almjashev, V. V. Gusarov, Phase relationships in the $\mathrm{SiO}_{2-}$ $\mathrm{TiO}_{2}$ system. Russian Journal of Inorganic Chemistry, 2011, 56: 1464-1471. DOI: $10.1134 / \mathrm{S} 0036023611090117$. 
[277] Y. Ren, Y. Fei, J. Yang, W. Bai, $\mathrm{SiO}_{2}$ solubility in rutile at high temperature and high pressure. Journal of Earth Science, 2009, 20: 274-283. DOI: 10.1007/s12583009-0025-0.

[278] P. Kofstad, The oxidation behavior of tantalum at $700-1000^{\circ} \mathrm{C}$. Journal of The Electrochemical Society, 1963, 110: 491-501. DOI: 10.1149/1.2425799.

[279] P. Kofstad, S. Espevik, Low-Pressure Oxidation of Niobium at $1200^{\circ}-1700^{\circ} \mathrm{C}$. Journal of The Electrochemical Society, 1965, 112: 153-160. DOI: $10.1149 / 1.2423485$.

[280] R. A. Perkins, G. H. Meier, The oxidation behavior and protection of niobium. JOM, 1990, 42: 17-21. DOI: 10.1007/BF03221046.

[281] B. A. Pint, J. R. Distefano, I. G. Wright, Oxidation resistance: one barrier to moving beyond Ni-base superalloys. Materials Science and Engineering: A, 2006, 415: 255263. DOI: 0.1016/j.msea.2005.09.091.

[282] B. P. Bewlay, S. Nag, A. Suzuki, M. J. Weimer, TiAl alloys in commercial aircraft engines. Materials at High Temperatures, 2016, 33: 549-559. DOI: 10.1080/09603409.2016.1183068.

[283] E. Schwaighofer, B. Rashkova, H. Clemens, A. Stark, S. Mayer, Effect of carbon addition on solidification behavior, phase evolution and creep properties of an intermetallic B-stabilized Y-TiAl based alloy. Intermetallics, 2014, 46: 173-184. DOI: 10.1016/j.intermet.2013.11.011.

[284] Y. Chen, C. Wang, J. Ruan, S. Yang, T. Omori, R. Kainuma, K. Ishida, J. Han, Y. $\mathrm{Lu}, \mathrm{X}$. Liu, Development of low-density $\mathrm{Y}^{\prime} \mathrm{Y}^{\prime} \mathrm{Co}-\mathrm{Al}$-Ta-based superalloys with high solvus temperature. Acta Materialia, 2020, 188: 652-664. DOI: 10.1016/j.actamat.2020.02.049.

[285] P. Pandey, S. Mukhopadhyay, C. Srivastava, S. K. Makineni, K. Chattopadhyay, Development of new $\mathrm{Y}^{\prime}$-strengthened Co-based superalloys with low mass density, high solvus temperature and high temperature strength. Materials Science and Engineering: A, 2020, 790: 139578. DOI: 10.1016/j.msea.2020.139578.

[286] B. Gorr, V. Trindade, S. Burk, H.-J. Christ, M. Klauke, D. Mukherji, J. Rösler, Oxidation behaviour of model cobalt-rhenium alloys during short-term exposure to laboratory air at elevated temperature. Oxidation of Metals, 2009, 71: 157-172. DOI: $10.1007 / \mathrm{s} 11085-008-9133-\mathrm{y}$.

[287] B. Gorr, L. Wang, S. Burk, M. Azim, S. Majumdar, H.-J. Christ, D. Mukherji, J. Rösler, D. Schliephake, M. Heilmaier, High-temperature oxidation behavior of Mo$\mathrm{Si}-\mathrm{B}-$ based and $\mathrm{Co}-\mathrm{Re}-\mathrm{Cr}$-based alloys. Intermetallics, 2014, 48: 34-43. DOI: 10.1016/j.intermet.2013.10.008.

[288] J. K. Odusote, L. A. Cornish, L. H. Chown, Oxidation kinetics and mechanisms of growth of alumina scale on precipitation-hardened $\mathrm{Pt}-\mathrm{Al}-\mathrm{Cr}-\mathrm{Ru}$ alloys. Corrosion Science, 2012, 63: 119-128. DOI: 10.1016/j.corsci.2012.05.018.

[289] J. K. Odusote, L. A. Cornish, L. H. Chown, R. M. Erasmus, Isothermal Oxidation Behaviour of a Two-Phase $\mathrm{Y}^{\prime} \mathrm{Y}^{\prime}$ Precipitation-Hardened Quaternary Pt-Based Alloys 
in Air at $1,350{ }^{\circ} \mathrm{C}$. Oxidation of Metals, 2012, 78: 123-143. DOI: $10.1007 / \mathrm{s} 11085$ 012-9295-5.

[290] Nimonic 75 data sheet, Special Metals. Available from: https://www.specialmetals.com/assets/smc/documents/alloys/nimonic/nimonicalloy-75.pdf [cited 15/01/2021].

[291] Haynes International, Haynes 230 datasheet. Available from: http://haynesintl.com/docs/default-source/pdfs/new-alloy-brochures/hightemperature-alloys/brochures/230-brochure.pdf [cited 15/01/2021].

[292] J. B. Wahl, K. Harris, Improved $3^{\text {rd }}$ Generation Single Crystal Superalloy CMSX-4 Plus (SLS) - a study of evolutionary alloy development, 2018. Available from: https://cannonmuskegon.com/wp-content/uploads/2018/08/Improved-3rdGeneration-Single-Crystal-Superalloy-CMSX-4\%C2\%AE-Plus-SLS.pdf [cited 16/01/2021].

[293] J. S. Wang, Y. W. Kang, C. R. Li, Phase diagram and phase equilibrium studies on ultra high temperature alloys of Nb-Si-Ti, Y. Han, Y. Wu, G. Li, F. Pan, R. Fan, X. Liu, Editors, in Chinese Materials Conference on Special and High Performance Structural Materials, CMC, Guiyang, 2016, 849: 618-625. DOI: 10.4028/www.scientific.net/MSF.849.618.

[294] J. Yang, G. Zhuo, K. Jiang, X. Zhu, L. Su, The Oxidation Resistance of Nb-Si-Based Alloys at Intermediate and High Temperatures. Materials, 2020, 13: 1229 (1-11). DOI: $10.3390 / \mathrm{ma1} 3051229$.

[295] J. Geng, P. Tsakiropoulos, G. Shao, A thermo-gravimetric and microstructural study of the oxidation of $\mathrm{Nbss} / \mathrm{Nb}_{5} \mathrm{Si}_{3}$-based in situ composites with $\mathrm{Sn}$ addition. Intermetallics, 2007, 15: 270-281. DOI: 10.1016/j.intermet.2006.06.003.

[296] K. S. Chan, Cyclic oxidation response of multiphase niobium-based alloys. Metallurgical and Materials Transactions A, 2004, 35: 589-597. DOI: 10.1007/s11661-004-0370-7.pdf.

[297] W. Jun, G. Xiping, G. Jinming, Effects of B on the microstructure and oxidation resistance of $\mathrm{Nb}$-Ti-Si-based ultrahigh-temperature alloy. Chinese Journal of Aeronautics, 2009, 22: 544-550. DOI: 10.1016/S1000-9361(08)60139-9.

[298] Y. Murayama, S. Hanada, High temperature strength, fracture toughness and oxidation resistance of $\mathrm{Nb}-\mathrm{Si}-\mathrm{Al}-\mathrm{Ti}$ multiphase alloys. Science and Technology of Advanced Materials, 2002, 3: 145-156. DOI: 10.1016/S1468-6996(02)00005-0.

[299] L. Su, L. Jia, K. Jiang, H. Zhang, The oxidation behavior of high $\mathrm{Cr}$ and $\mathrm{Al}$ containing $\mathrm{Nb}$-Si-Ti-Hf-Al-Cr alloys at 1200 and $1250^{\circ} \mathrm{C}$. International Journal of Refractory Metals and Hard Materials, 2017, 69: 131-137. DOI: 10.1016/j.ijrmhm.2017.08.006.

[300] W. J. Evans, F. F. Harrison, Friction stress $\sigma_{0}$ and relationship between initial and secondary creep rates in precipitation-hardened nickel-base alloy. Metal Science, 1979, 13: 641-649. ISSN: 0306-3453.

[301] M. R. Jackson, B. P. Bewlay, J.-C. Zhao, Niobium-silicide based composites resistant to low temperature pesting, 2002, US Patent 6419765B1, USA. 
[302] S. Y. Kamata, D. Kanekon, Y. Lu, N. Sekido, K. Maruyama, G. Eggeler, K. Yoshimi, Ultrahigh-temperature tensile creep of TiC-reinforced Mo-Si-B-based alloy. Scientific Reports, 2018, 8: 1-14. DOI: 10.1038/s41598-018-28379-w.

[303] S. Uemura, S. Y. Kamata, K. Yoshimi, S. Tsurekawa, Microstructural evolution during high-temperature tensile creep at $1,500^{\circ} \mathrm{C}$ of a MoSiBTiC alloy. High Temperature Materials and Processes, 2020, 39: 136-145. DOI: 10.1515/htmp2020-0039.

[304] K. Yoshimi, J. Nakamura, D. Kanekon, S. Yamamoto, K. Maruyama, H. Katsui, T. Goto, High-temperature compressive properties of TiC-added Mo-Si-B alloys. JOM, 2014, 66: 1930-1938. DOI: 10.1007/s11837-014-1097-6.

[305] Spacemat Product Data Ti6Al4V. Available from: https://www.spacematdb.com/spacemat/datasearch.php?name=Ti\%206Al $\% 204 \mathrm{~V}$ [cited 08/01/2020]. 


\section{Appendix}

$\begin{array}{cc}\mathrm{L} \rightleftharpoons \operatorname{Moss}+\mathrm{Mo}_{2} \mathrm{~B} \text { (binary eutectic) } & \text { Eq. (A.1) } \\ \mathrm{L} \rightleftharpoons \operatorname{Moss}+\mathrm{Mos}_{5} \mathrm{SiB}_{2} \text { (binary eutectic) } & \text { Eq. (A.2) } \\ \mathrm{L}+\operatorname{Moss} \rightleftharpoons \mathrm{Mos}_{\mathrm{s}} \mathrm{Si} \text { (peritectic) } & \text { Eq. (A.3) } \\ \mathrm{L} \rightleftharpoons \operatorname{Moss}+\operatorname{Mos} \mathrm{Si}+\mathrm{Mos}_{5} \mathrm{SiB}_{2} \text { (ternary eutectic) } & \text { Eq. (A.4) }\end{array}$

App. 1 Phase reactions of special interest within the ternary Mo-Si-B system [106]. 


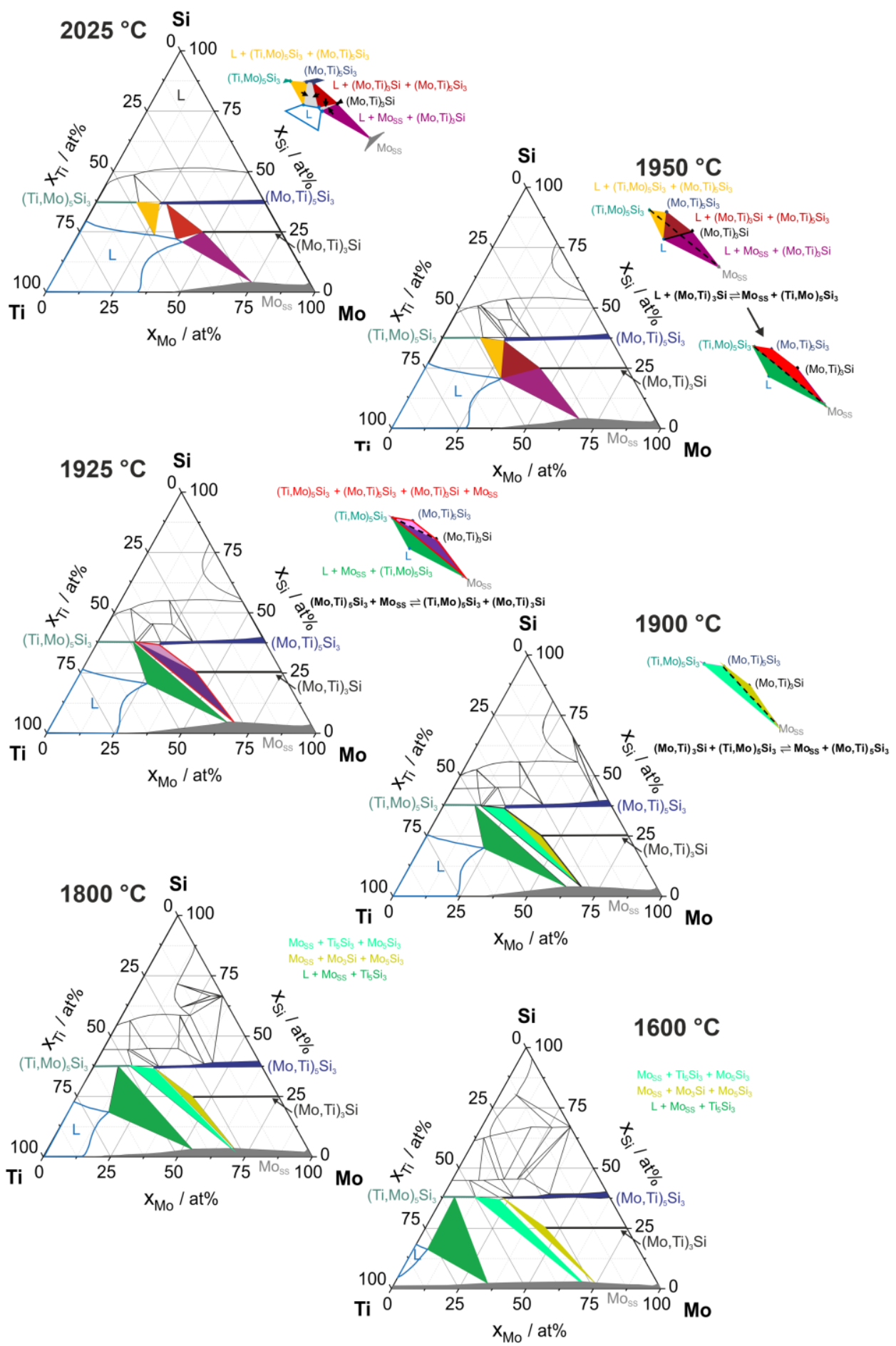

App. 2 Isothermal sections of the ternary Mo-Si-Ti system with highlighted phase equilibria (coloured regions) and reactions (listed to the right next to the insets) at relevant temperatures calculated with Pandat. The insets to the right display the phase regions, which participate at the reaction. The solid and dashed black lines connect those phases, which are reactants or reaction products, respectively. The small black arrows in the isothermal section at $2025^{\circ} \mathrm{C}$ symbolise the expansion direction of the phase regions if the temperature would be decreased. 


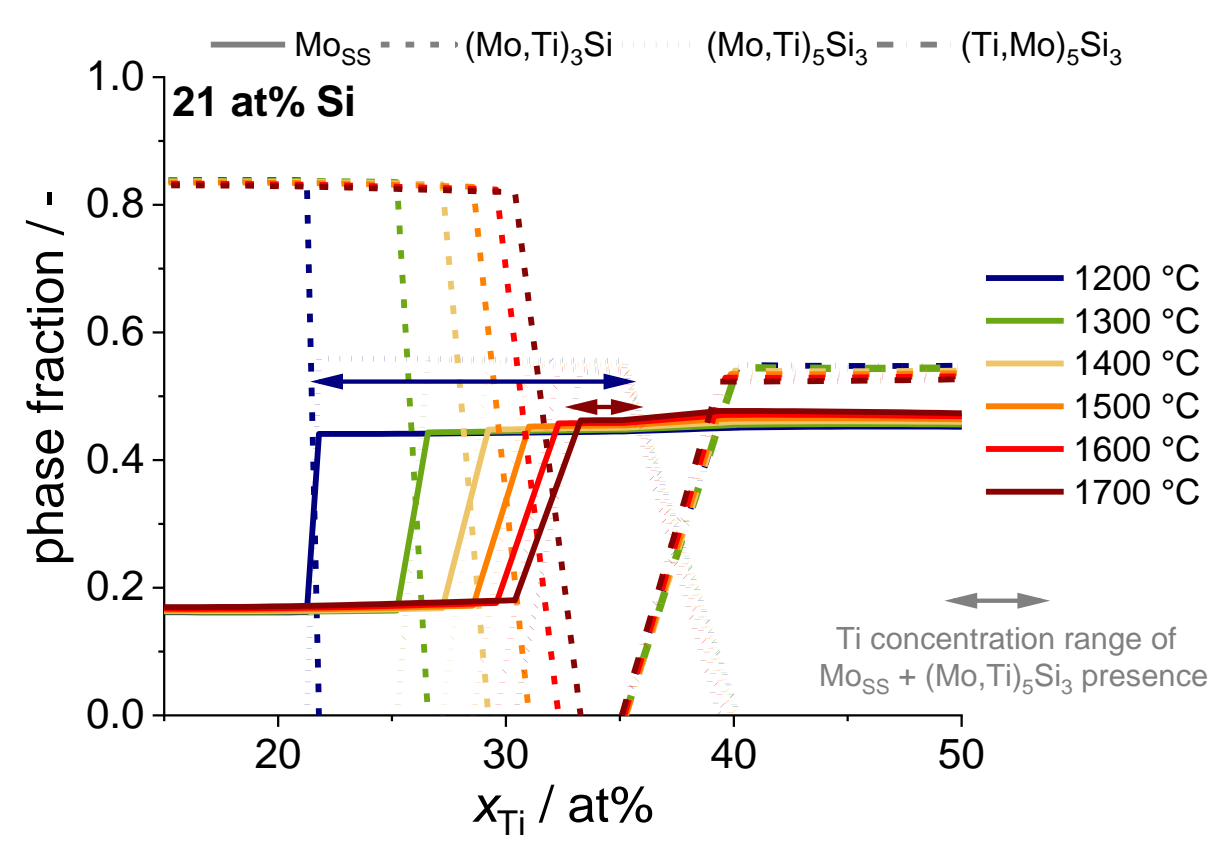

App. 3 Calculated phase fractions in thermodynamic equilibrium for a fixed Si concentration of 21 at\% and temperatures varying from 1200 to $1700{ }^{\circ} \mathrm{C}$ (differently colour-coded). The vertical arrows highlight the Ti concentration range, where Moss (solid line) and $\left(\mathrm{Mo}, \mathrm{Ti}_{5} \mathrm{Si}_{3}\right.$ (dotted line) are present and thus, where the eutectoid decomposition of (Mo,Ti) $)_{3} \mathrm{Si}$ (dashed line) has occurred.
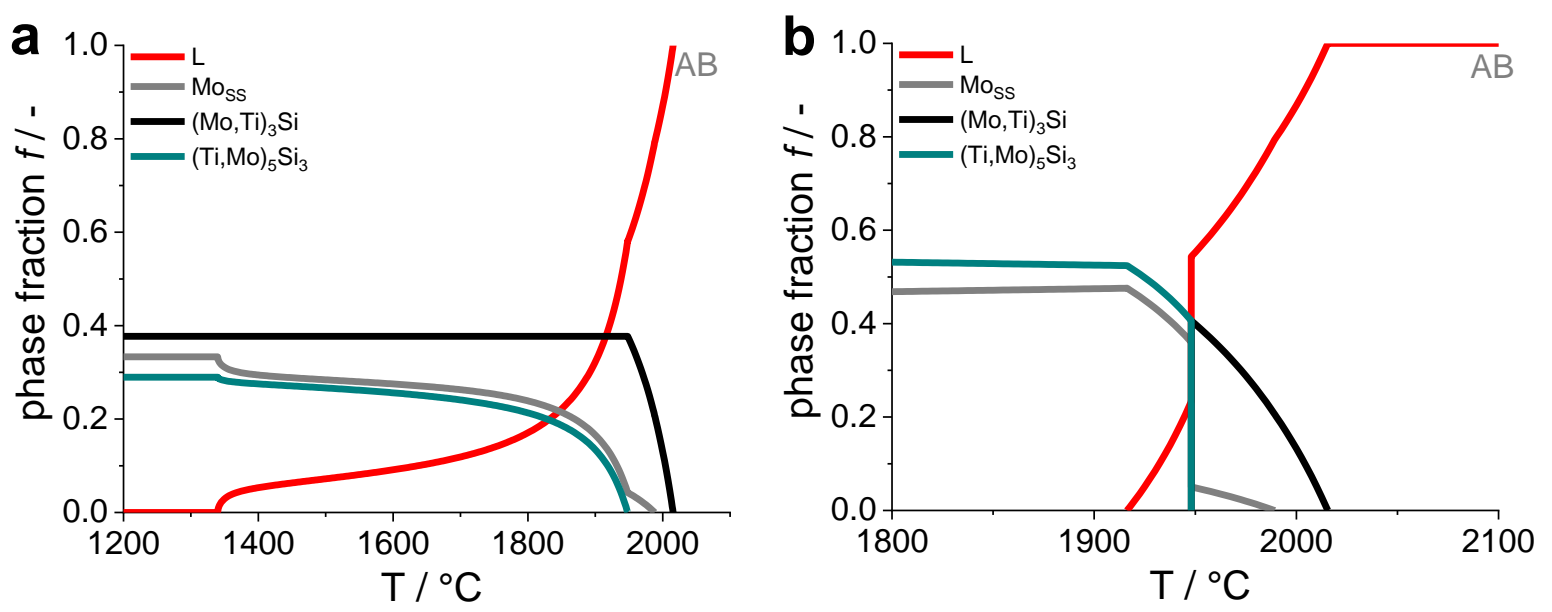

App. 4

Thermodynamic calculations for alloy $\mathrm{AB}$ in Scheil (a) and equilibrium (b) conditions. 

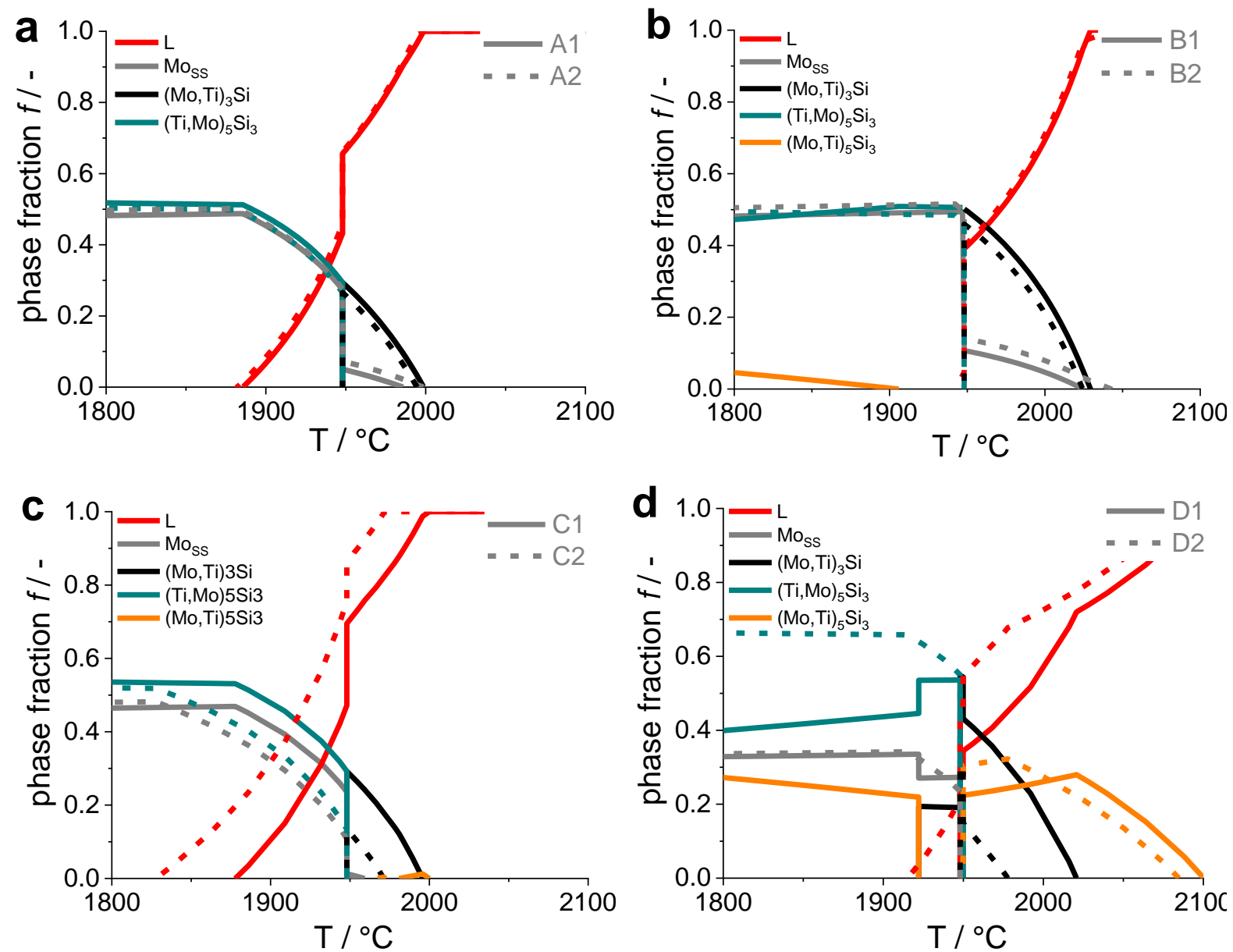

App. 5 Solidification simulations in equilibrium for the alloys series A (a), B (b), C (c) and D (d). The alloy variants 1 and 2 are symbolised by solid and dotted lines, respectively. 


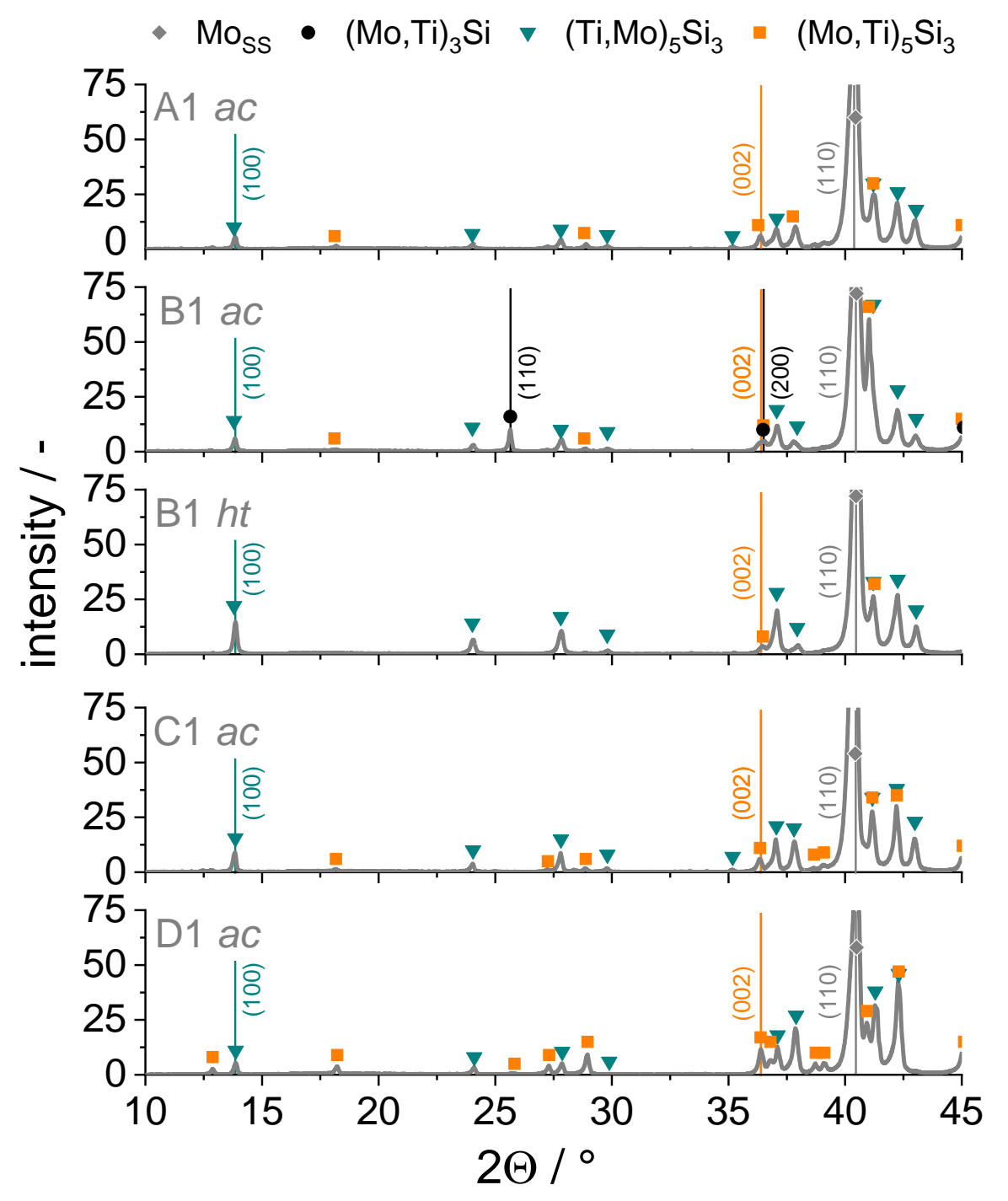

App. 6 XRD pattern of alloys A1, B1 in the $a c$ and $h t$ condition, respectively, and alloys $\mathrm{C} 1$ and $\mathrm{D} 1$ in the $a c$ condition, including the assignment of the identified phases. Data on alloys A1 and B1 according to Ref. [224] and of alloys C1 and D1 according to Ref. [225]. 


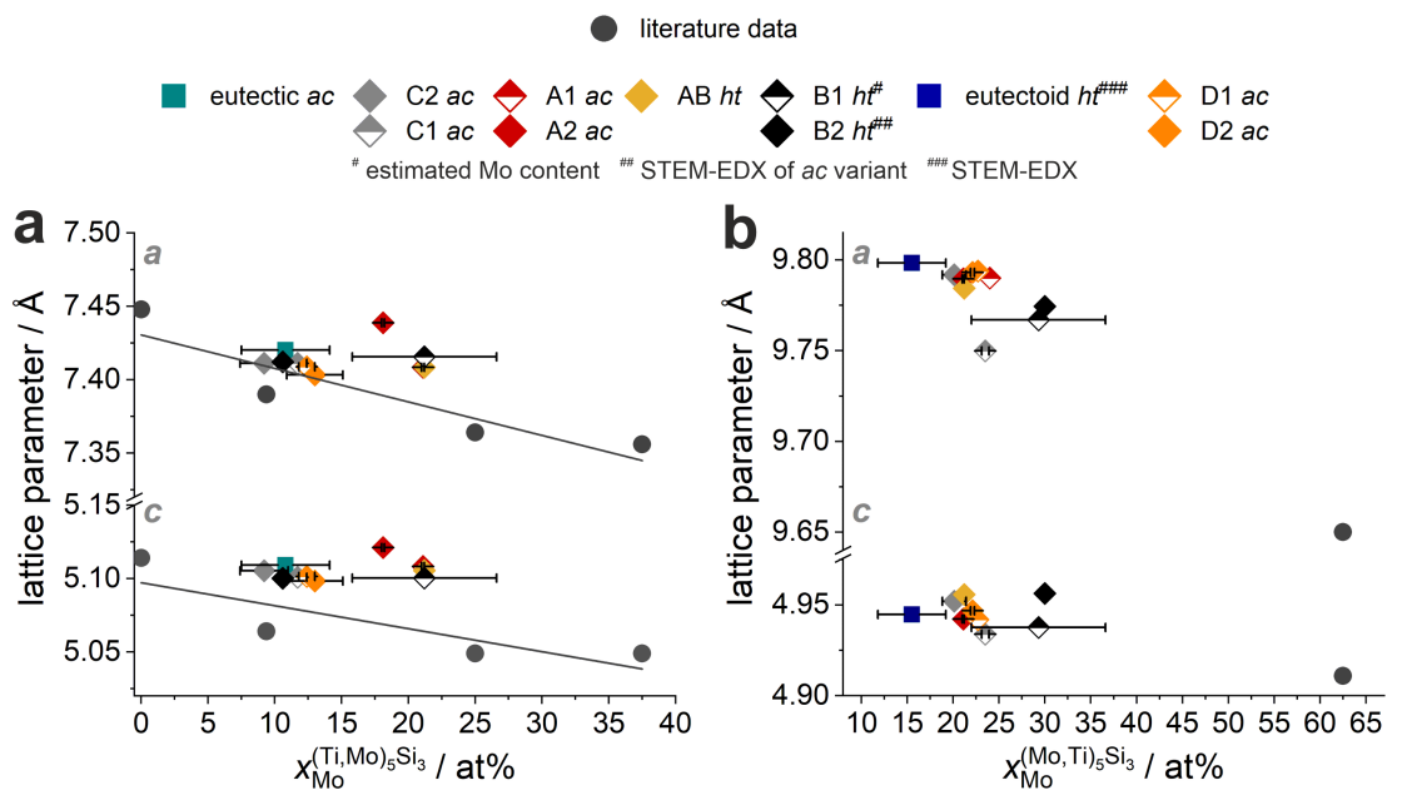

App. 7 Lattice parameter $a$ and $c$ of hexagonal (Ti,Mo) ${ }_{5} \mathrm{Si}_{3}$ (a) and tetragonal $(\mathrm{Mo}, \mathrm{Ti})_{5} \mathrm{Si}_{3}(\mathrm{~b})$ in the investigated alloy series $\mathrm{A}$ to $\mathrm{D}$ and the eutectic and eutectoid reference alloys in dependence of the Mo content in the respective $\mathrm{M}_{5} \mathrm{Si}_{3}$ silicide. Literature data (depicted as dark grey circles), taken from Refs. [86, 89, 91], are included for comparison.

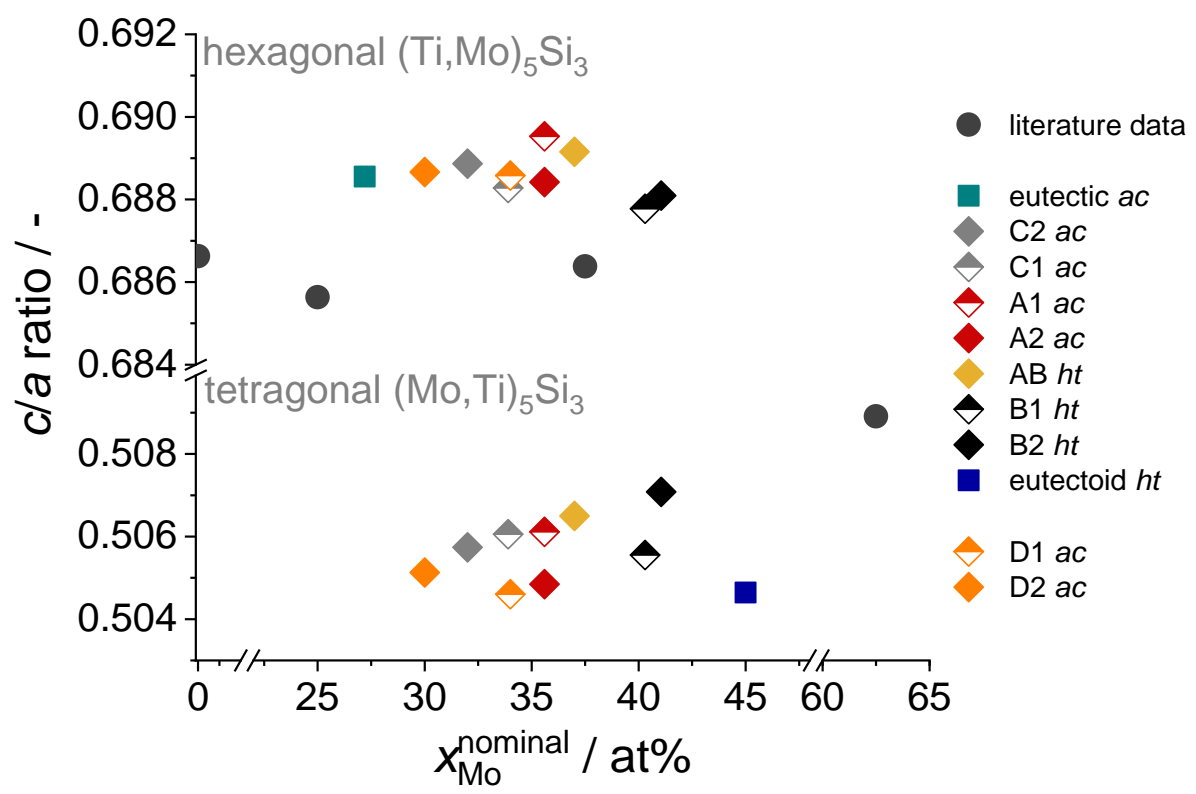

App. $8 \quad c / a$ ratio of hexagonal $\mathrm{Mn}_{5} \mathrm{Si}_{3}$-type $\mathrm{D} 88$ (Ti,Mo) ${ }_{5} \mathrm{Si}_{3}$ and tetragonal $\mathrm{W}_{5} \mathrm{Si}_{3}-$ type $\left(\mathrm{Mo}, \mathrm{Ti}_{5}{ }_{5} \mathrm{Si}_{3}\right.$ in dependence of the nominal Mo concentration of the investigated alloys. Literature data (dark grey circles), taken from Refs. [86, 89, 91], are included for comparison. 
App. 9 Chemical composition of the phases present in the eutectic and eutectoid reference alloys in $a c$ and $h t$ state, respectively, and alloy $\mathrm{B} 1$ in the $a c$ state determined by STEM-EDX (average values of minimum five line scans are listed). According to Ref. [215].

\begin{tabular}{|c|c|c|c|c|}
\hline \# alloy & phase & Mo / at\% & $\mathrm{Si} / \mathrm{at} \%$ & $\mathrm{Ti} / \mathrm{at} \%$ \\
\hline \multirow{2}{*}{ eutectic $a c$} & Moss & $58.7 \pm 5.3$ & $2.4 \pm 0.3$ & $38.9 \pm 5.5$ \\
\hline & $(\mathrm{Ti}, \mathrm{Mo})_{5} \mathrm{Si}_{3}$ & $13.3 \pm 3.8$ & $23.2 \pm 3.0$ & $63.5 \pm 4.0$ \\
\hline \multirow{4}{*}{$\mathrm{B} 1 a c$} & Moss (eutectic) & $69.3 \pm 4.1$ & $2.7 \pm 0.1$ & $28.0 \pm 4.0$ \\
\hline & $\mathrm{M}_{5} \mathrm{Si}_{3}$ (eutectic) & $21.2 \pm 5.4$ & $24.6 \pm 4.3$ & $54.2 \pm 1.5$ \\
\hline & Moss (eutectoid) & $69.8 \pm 4.3$ & $4.8 \pm 2.1$ & $25.5 \pm 2.3$ \\
\hline & $\mathrm{M}_{5} \mathrm{Si}_{3}$ (eutectoid) & $29.3 \pm 7.3$ & $22.8 \pm 2.9$ & $47.9 \pm 4.9$ \\
\hline \multirow{4}{*}{ eutectoid $h t$} & Moss & $74.1 \pm 0.5$ & $2.6 \pm 0.3$ & $20.6 \pm 0.3$ \\
\hline & $\begin{array}{c}\text { cuboidal precipitates in } \\
\text { Moss }\end{array}$ & $16.3 \pm 1.4$ & $30.3 \pm 0.9$ & $49.5 \pm 1.1$ \\
\hline & $\begin{array}{c}\text { spherical precipitates in } \\
\text { Moss }\end{array}$ & $59.7 \pm 1.6$ & $10.3 \pm 0.9$ & $26.7 \pm 1.2$ \\
\hline & $(\mathrm{Mo}, \mathrm{Ti})_{5} \mathrm{Si}_{3}$ & $15.5 \pm 3.7$ & $29.5 \pm 1.7$ & $42.6 \pm 2.2$ \\
\hline
\end{tabular}

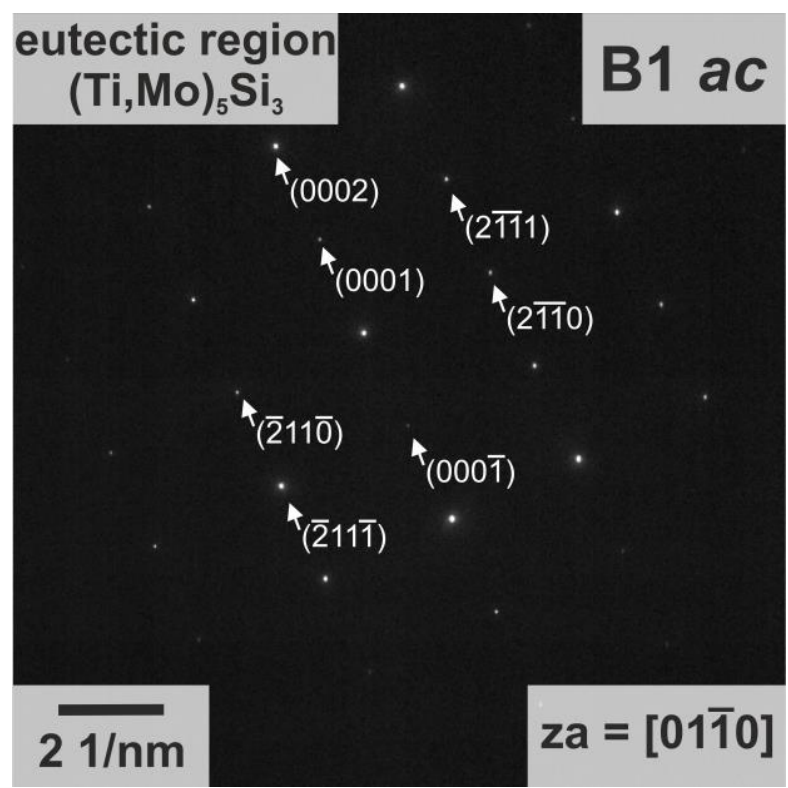

App. 10 TEM-selected area diffraction $(\mathrm{SAD})$ pattern of $(\mathrm{Ti}, \mathrm{Mo})_{5} \mathrm{Si}_{3}$ in the eutectic region of alloy $\mathrm{B} 1$ in the $a c$ state [215]. 


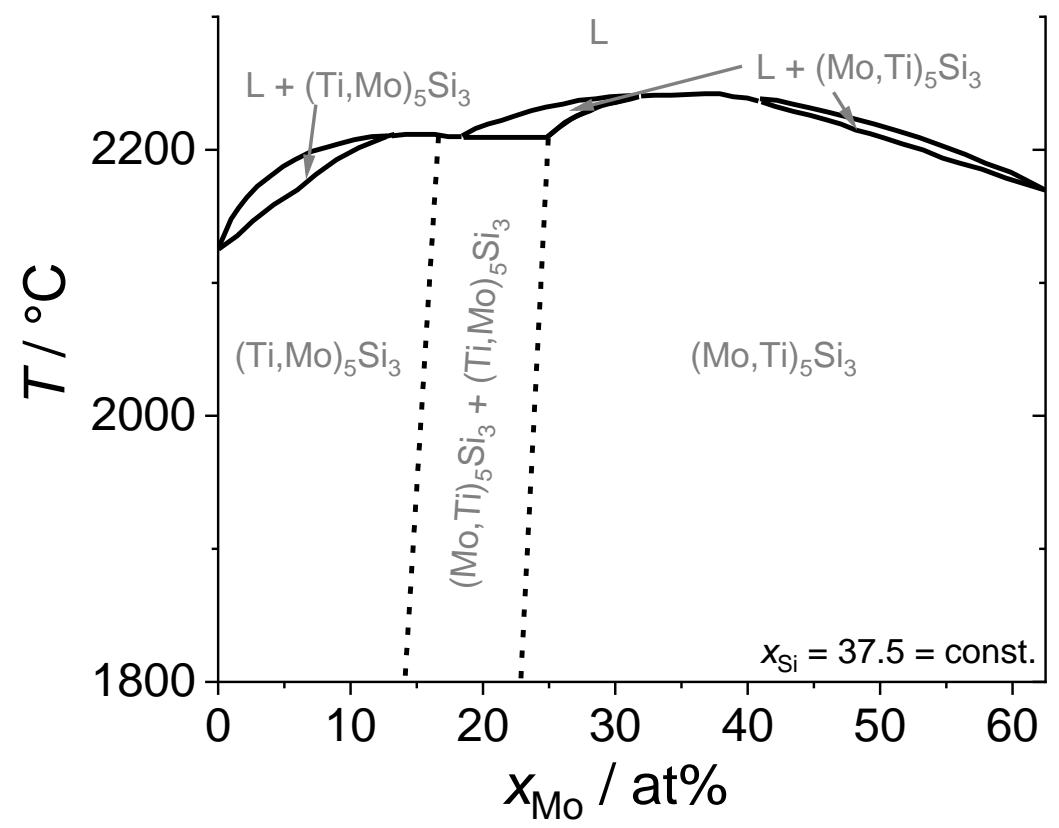

App. 11 Pseudo-binary section of $\mathrm{Ti}_{5} \mathrm{Si}_{3}-\mathrm{Mo}_{5} \mathrm{Si}_{3}$, (two-phase region has to be taken as tentative, highlighted by dashed lines). According to thermodynamic calculations with Pandat and matched with data from Ref. [93].
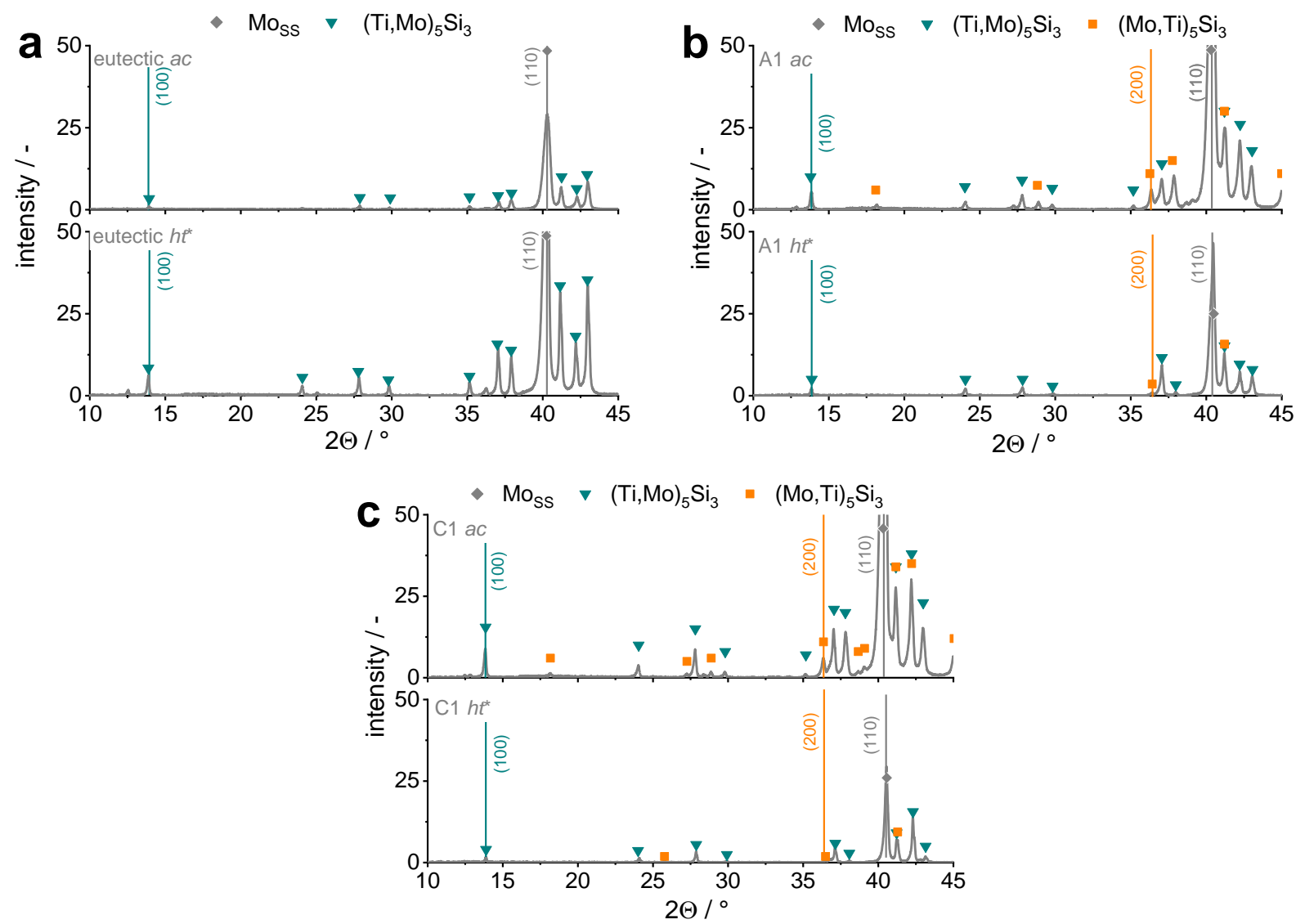

App. 12 XRD pattern of the eutectic reference alloy (a) and alloys A1 (b) and C1 (b) in $a c$ and $h t^{*}\left(1600{ }^{\circ} \mathrm{C}, 150 \mathrm{~h}\right)$ condition. 

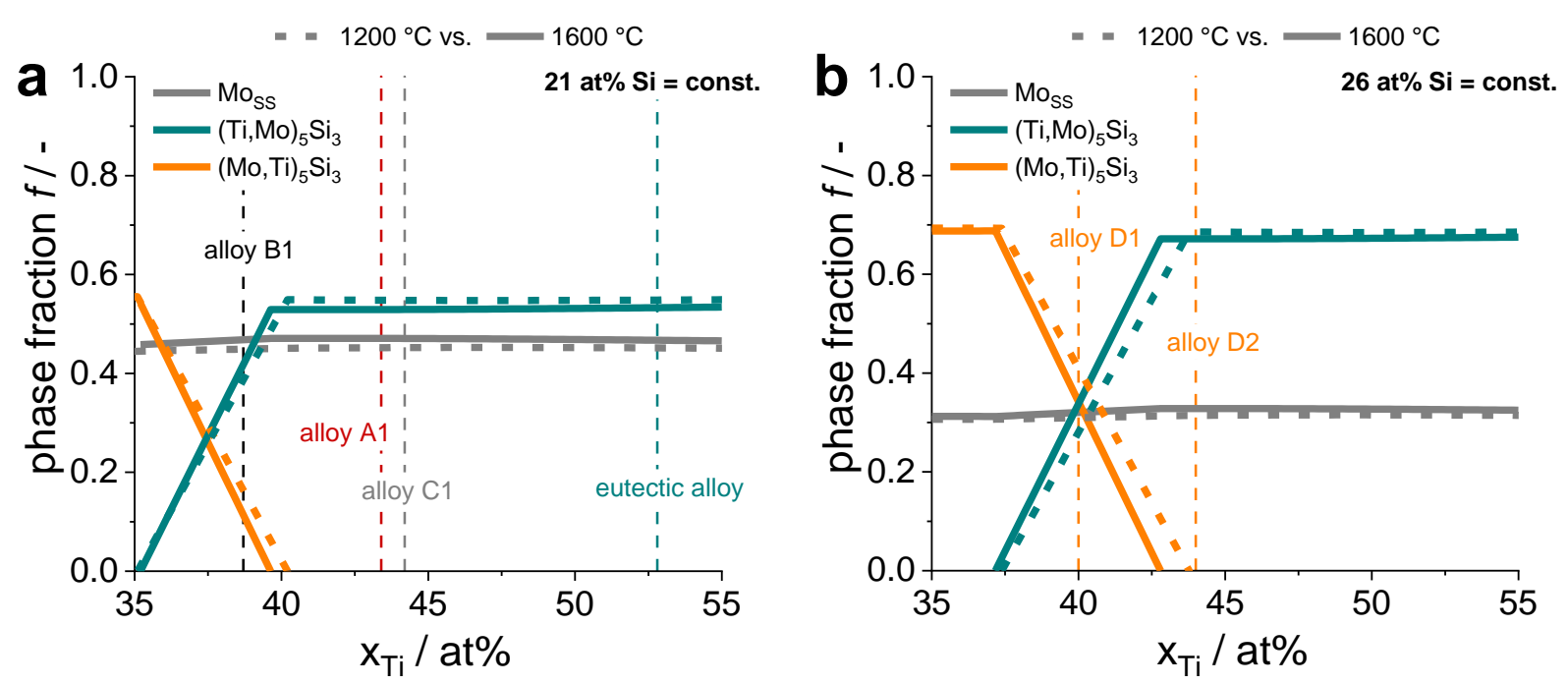

App. 13 Thermodynamic predicted phase fraction $f$ for equilibrium conditions at 1200 and $1600^{\circ} \mathrm{C}$ as a function of the nominal content Ti $x_{T i}^{\text {nominal }}$ (dashed and solid lines, respectively) for Si set constant at 21 (a) and 26 at\% (b). The location of selected alloys (eutectic, A1, B1, C1, D1 and D2) is included.
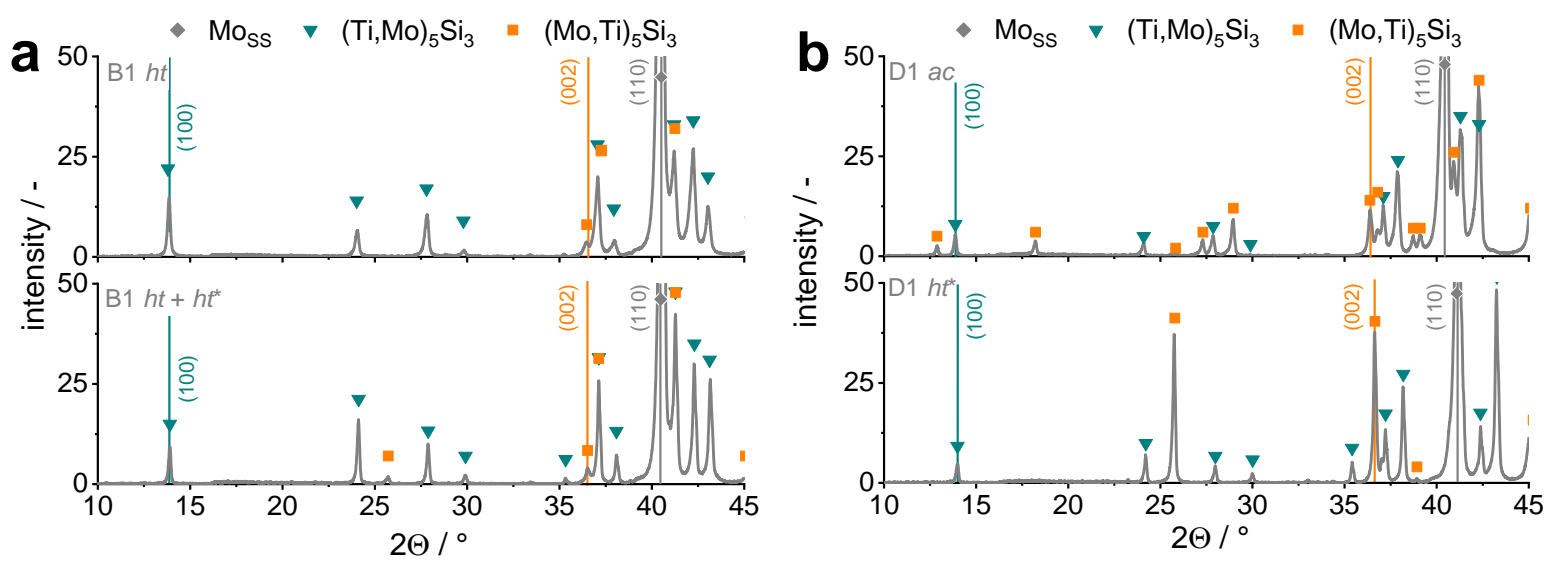

App. 14 XRD pattern of alloy B1 in $h t$ and $h t+h t^{*}$ condition (a) and of alloy D1 in $a c$ and $h t^{*}$ condition (b). $h t: 1300^{\circ} \mathrm{C}, 200 \mathrm{~h} ; h t^{*}: 1600{ }^{\circ} \mathrm{C}, 150 \mathrm{~h}$. Data on alloy D1 $a c$ according to Ref. [225]. 

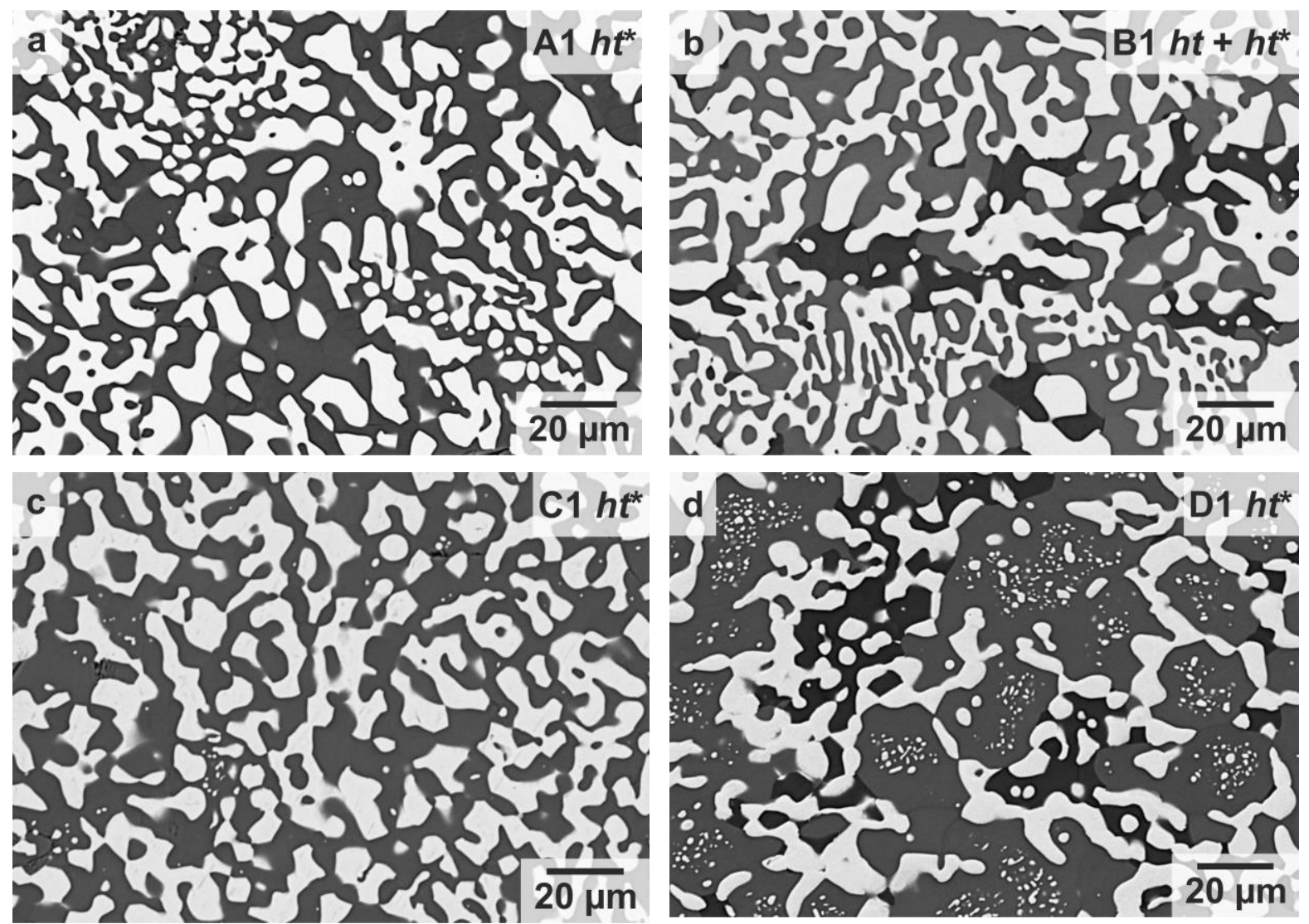

App. 15

BSE micrographs of the alloys A1 (a), B1 (b), C1 (c) and D1 (d) after heat treatment $h t^{*}$ at $1600{ }^{\circ} \mathrm{C}$ for $150 \mathrm{~h}$. 

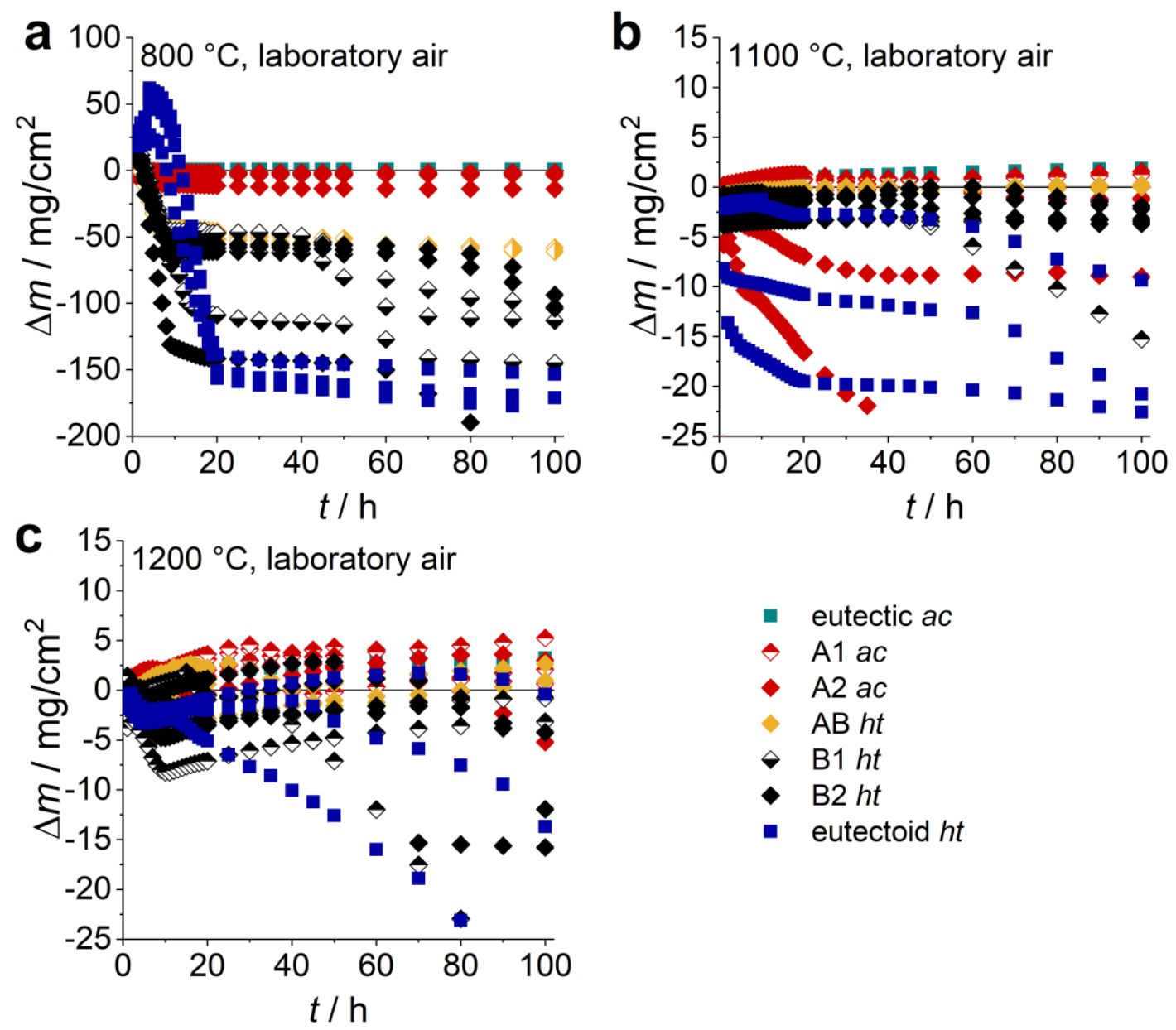

- eutectic ac

$\rightarrow \mathrm{A} 1 \mathrm{ac}$

- A2 ac

- $\mathrm{AB} h t$

$\diamond \mathrm{B} 1 h t$

$\checkmark \mathrm{B} 2 h t$

- eutectoid $h t$

App. 16 Specific weight change as function of the test duration of cyclic oxidation in laboratory air at $800^{\circ} \mathrm{C}(\mathrm{a}), 1100$ (b) and $1200^{\circ} \mathrm{C}$ (c) for at least three samples for each alloy of the alloy series A and B and the eutectic and eutectoid reference alloys. Data on the reference alloys, alloys A1 and B1 according to Ref. [224], data on alloy $\mathrm{AB}$ at $800^{\circ} \mathrm{C}$ according to Ref. [215]. 

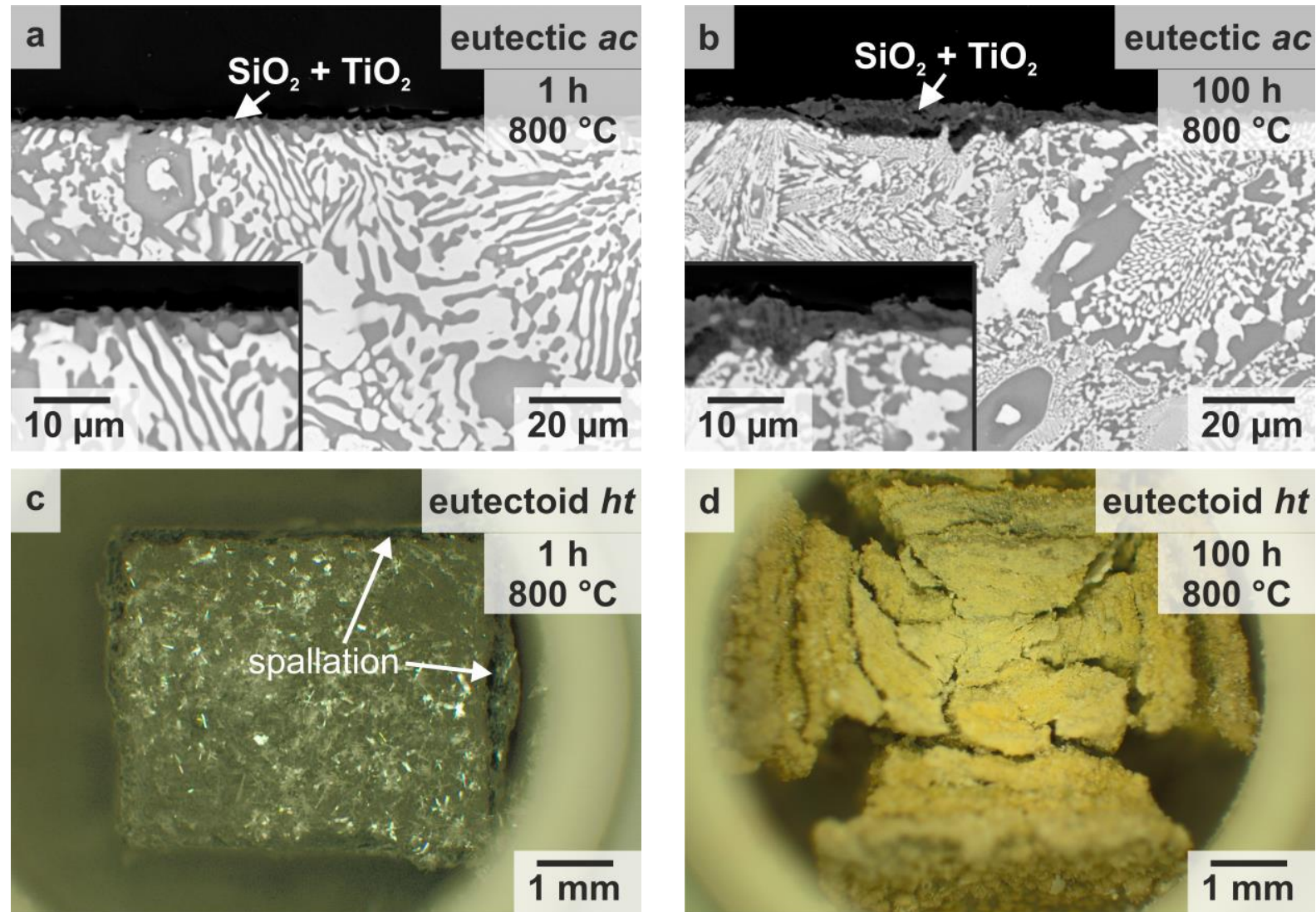

App. 17 Oxidised samples after 1 and $100 \mathrm{~h}$ at $800 \mathrm{~h}$ of the eutectic (representative BSE micrograph, a and b) and eutectoid reference alloy (macroscopic sample overview, c and d). (d) according to Ref. [224]. 

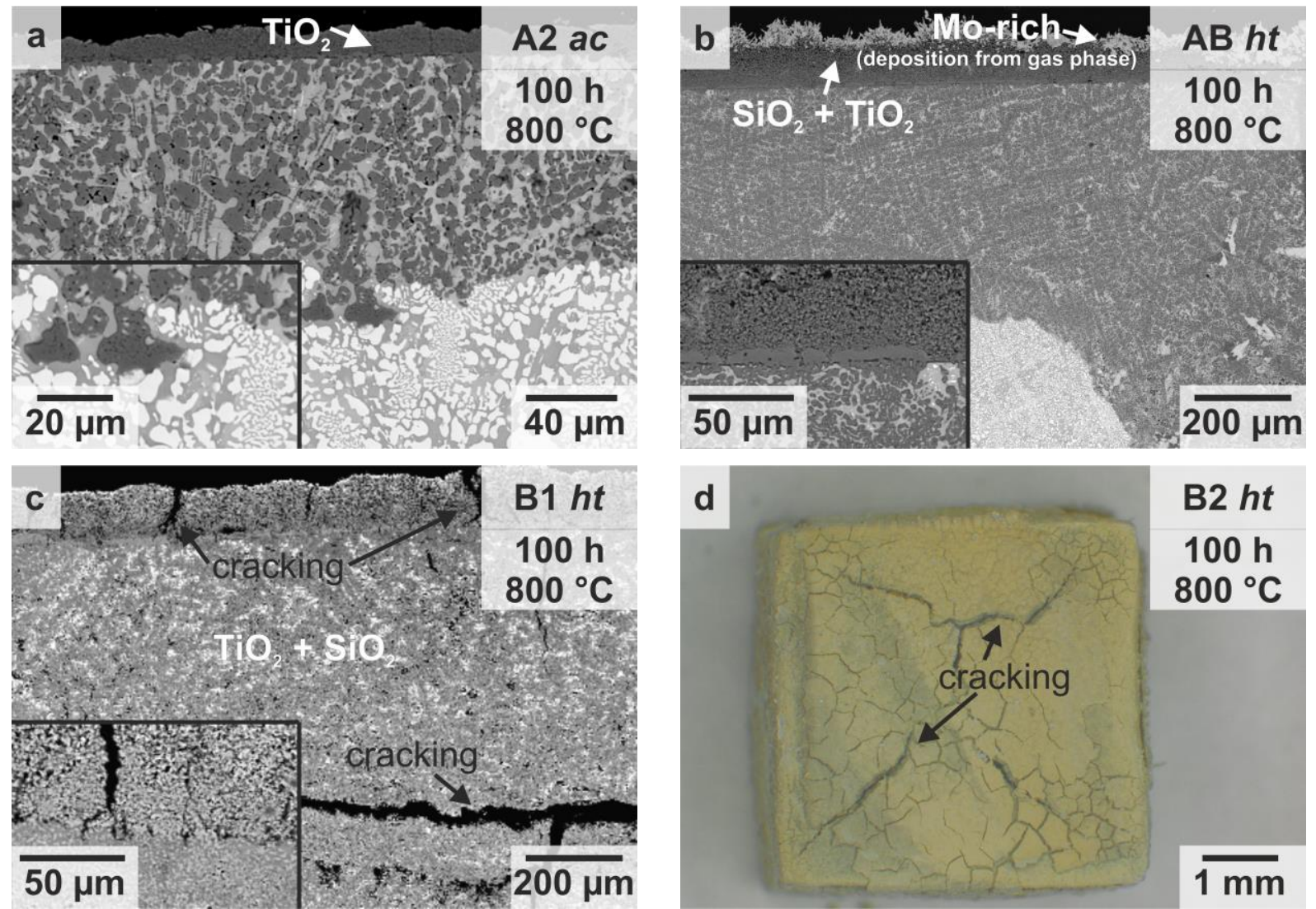

App. 18 BSE micrographs of the cyclically oxidised cross sections of alloys A2 ac (a), $\mathrm{AB} h t(\mathrm{~b})$ and $\mathrm{B} 1 h t(\mathrm{c})$; and macroscopic image of alloy $\mathrm{B} 2 h t(\mathrm{~d})$ after $100 \mathrm{~h}$ at $800^{\circ} \mathrm{C}$ in laboratory air. (d) according to Ref. [224].
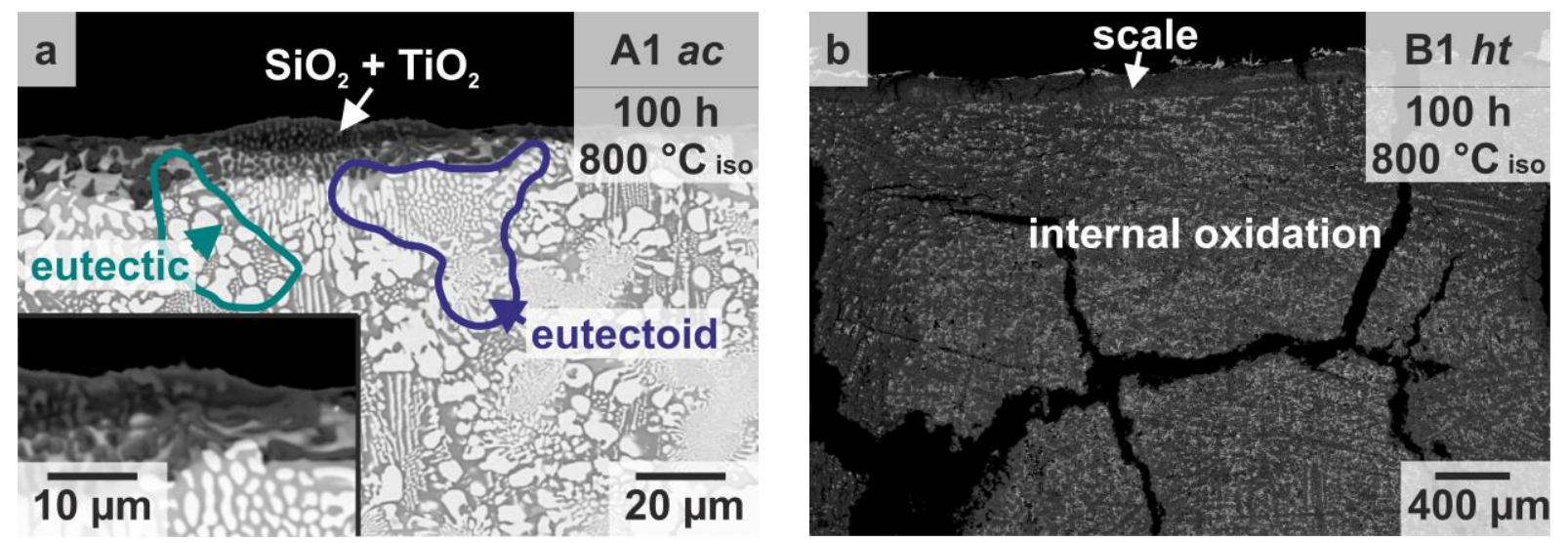

App. 19 Cross sectional BSE micrographs of samples oxidised isothermally at $800{ }^{\circ} \mathrm{C}$ for $100 \mathrm{~h}$ of alloys $\mathrm{A} 1 \mathrm{ac}$ (a) and $\mathrm{B} 1 \mathrm{ht}(\mathrm{b})$. 

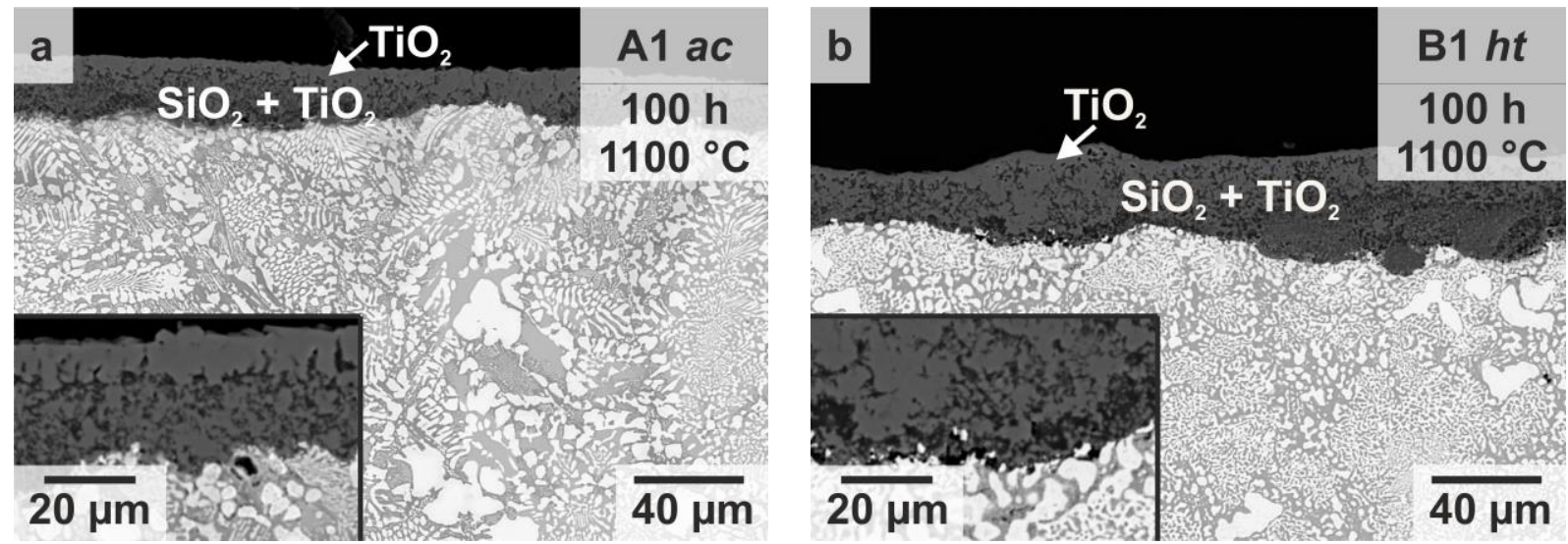

App. 20 Cross sectional BSE micrographs of alloys A1 ac (a) and B1 ht (b) after $100 \mathrm{~h}$ of cyclic oxidation in air at $1100{ }^{\circ} \mathrm{C}$.

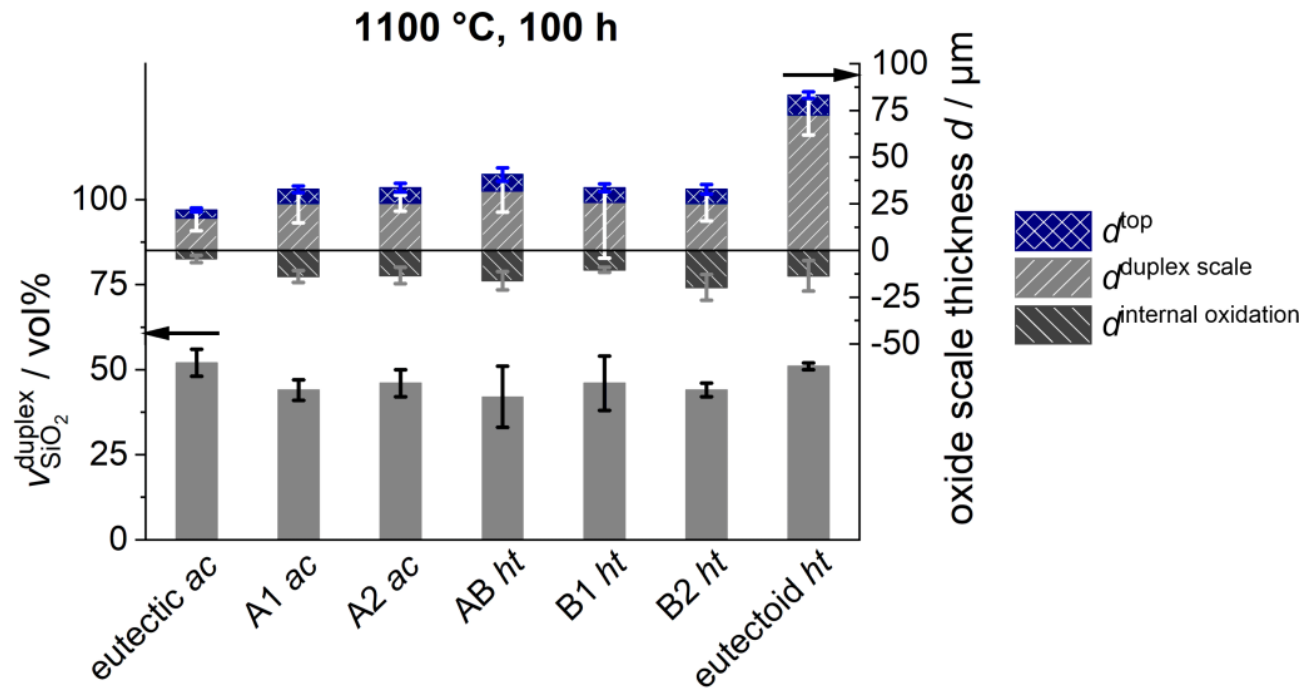

App. 21 Evaluation of the oxide scale thickness (upper bar chart) and the volume fraction of $\mathrm{SiO}_{2}$ within the $\mathrm{SiO}_{2}-\mathrm{TiO}_{2}$ duplex scale (lower bar chart) at $1100{ }^{\circ} \mathrm{C}, 100 \mathrm{~h}$ for both reference alloys, alloy series $\mathrm{A}$ and $\mathrm{B}$, as well as alloy AB. 

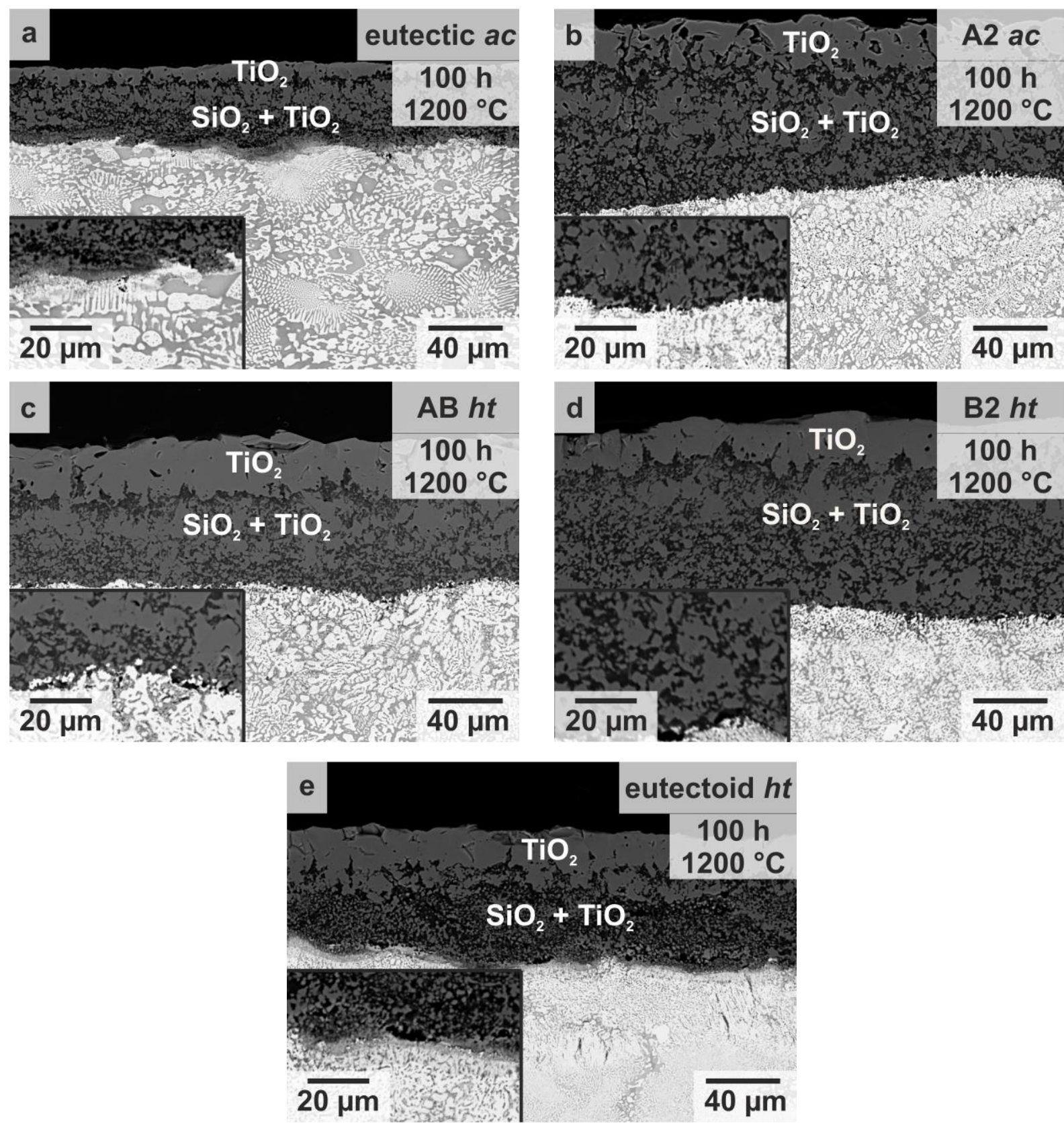

App. 22 BSE micrographs of the cross sections of the cyclically oxidised samples at $1200{ }^{\circ} \mathrm{C}$ after $100 \mathrm{~h}$ of the investigated eutectic alloy (a), alloy A2 ac (b), alloy $\mathrm{AB} h t(\mathrm{~d})$, alloy B2 $h t(\mathrm{~d})$ and the eutectoid reference alloy (e). 
$m_{O}^{\text {scale }}=m_{O}^{\text {duplex }}+m_{O}^{\text {top }}+m_{O}^{\text {internal }}=m_{{\text {in } \text { TiO }_{2}}^{\text {duplex }}}+m_{{\mathrm{O} \text { in } \mathrm{SiO}_{2}}^{\text {duplex }}}+m_{\mathrm{O}_{\text {in } \mathrm{TiO}_{2}}}^{\text {top }}+m_{O}^{\text {internal }}$

neglection of the internal oxidation: $m_{O}^{\text {internal }}=0$

$$
\begin{aligned}
& m_{\mathrm{O}_{\text {in } \mathrm{TiO}_{2}}}=2 n_{\mathrm{TiO}_{2}} M_{O} \\
& m_{{\mathrm{O} \text { in } \mathrm{SiO}_{2}}}=2 n_{\mathrm{SiO}_{2}} M_{O}
\end{aligned}
$$

leading to:

$$
m_{O}^{\text {scale }}=2 n_{\mathrm{TiO}_{2}}^{\text {duplex }} M_{O}+2 n_{\mathrm{SiO}_{2}}^{\text {duplex }} M_{\mathrm{O}}+2 n_{\mathrm{TiO}_{2}}^{\text {top }} M_{O}
$$

applying:

$$
\begin{gathered}
n=m / M \text { and } m=\rho V \\
m_{O}^{\text {scale }}=2 M_{O}\left(\frac{\rho_{\mathrm{TiO}_{2}} V_{\mathrm{TiO}_{2}}^{\text {duplex }}}{M_{\mathrm{TiO}_{2}}}+\frac{\rho_{\mathrm{SiO}_{2}} V_{\mathrm{SiO}_{2}}^{\text {duplex }}}{M_{\mathrm{SiO}_{2}}}+\frac{\rho_{\mathrm{TiO}_{2}} V^{\text {top }}}{M_{\mathrm{TiO}_{2}}}\right)
\end{gathered}
$$

with:

$$
\begin{gathered}
V_{\mathrm{TiO}_{2}}^{\text {duplex }}=v_{\mathrm{TiO}_{2}}^{\text {duplex }} V^{\text {duplex }} \text { and } V_{\mathrm{SiO}_{2}}^{\text {duplex }}=v_{\mathrm{SiO}_{2}}^{\text {duplex }} V^{\text {duplex }} \\
m_{O}^{\text {scale }}=2 \mathrm{M}_{\mathrm{O}}\left[V^{\text {duplex }}\left(\frac{\rho_{\mathrm{TiO}_{2}} v_{\mathrm{TiO}_{2}}^{\text {duplex }}}{M_{\mathrm{TiO}_{2}}}+\frac{\rho_{\mathrm{SiO}_{2}} v_{\mathrm{SiO}_{2}}^{\text {duplex }}}{M_{\mathrm{SiO}_{2}}}\right)+V^{\text {top }} \frac{\rho_{\mathrm{TiO}_{2}}}{M_{\mathrm{TiO}_{2}}}\right]
\end{gathered}
$$

applying:

$$
m_{M o}^{\text {vapour }}=\Delta m-m_{O}^{\text {scale }} \text { and } n=m / M
$$

amount of metallic species consumed during the oxidation process:

$$
\begin{gathered}
n_{\mathrm{Mo}}^{\text {vapour }}=\frac{m_{\mathrm{Mo}}^{\text {vapour }}}{M_{\mathrm{Mo}}} \\
n_{\mathrm{Si}}^{\text {scale }}=n_{\mathrm{Si}}^{\text {duplex }}=n_{\mathrm{SiO}_{2}}^{\text {duplex }}=\frac{m_{\mathrm{SiO}_{2}}^{\text {duplex }}}{M_{\mathrm{SiO}_{2}}}=\frac{\rho_{\mathrm{SiO}_{2} V_{\mathrm{SiO}_{2}}^{\text {duplex }}}}{M_{\mathrm{SiO}_{2}}}=\frac{\rho_{\mathrm{SiO}_{2}}}{M_{\mathrm{SiO}_{2}}} v_{\mathrm{SiO}_{2}}^{\text {duplex }} V^{\text {duplex }} \\
n_{\mathrm{Ti}}^{\mathrm{Scale}}=n_{\mathrm{Ti}}^{\text {duplex }}+n_{\mathrm{Ti}}^{\text {top }}=n_{\mathrm{TiO}_{2}}^{\text {duplex }}+n_{\mathrm{TiO}_{2}}^{\text {top }}=\frac{m_{\mathrm{TiO}_{2}}^{\text {duplex }}+m_{\mathrm{TiO}_{2}}^{\text {top }}}{M_{\mathrm{TiO}_{2}}} \\
=\frac{\rho_{\mathrm{TiO}_{2}}}{M_{\mathrm{TiO}_{2}}}\left(v_{\mathrm{TiO}_{2}}^{\text {duplex }} V^{\text {duplex }}+V^{\text {top }}\right)
\end{gathered}
$$

App. 23 Calculation of the amount $n$ of metallic species Ti, Si and Mo consumed during oxidation to a solid oxide scale or to vapour [224]. 


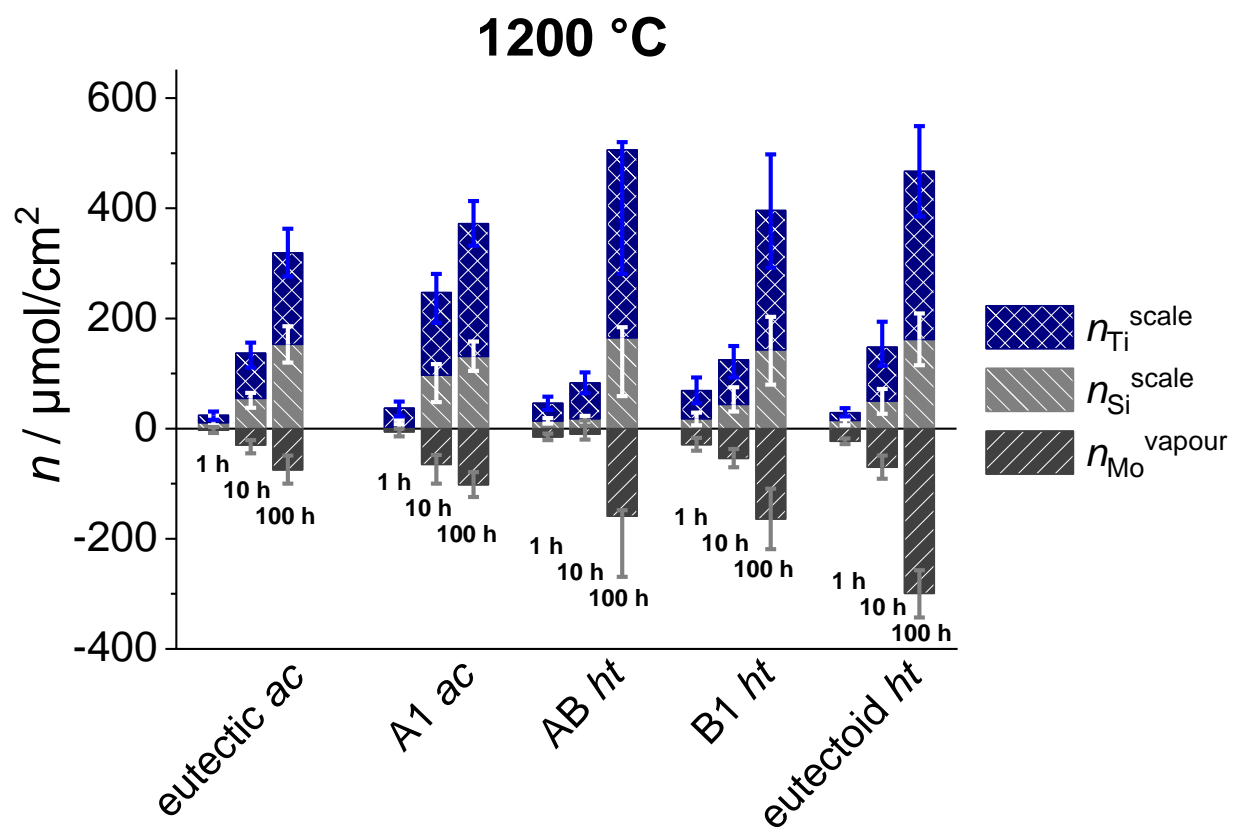

App. 24 Calculated amounts of oxidised species Ti, Si and Mo at $1200{ }^{\circ} \mathrm{C}$ after 1,10 and $100 \mathrm{~h}$ of cyclic oxidation in representative alloys of the investigated alloy series, including both reference alloys.

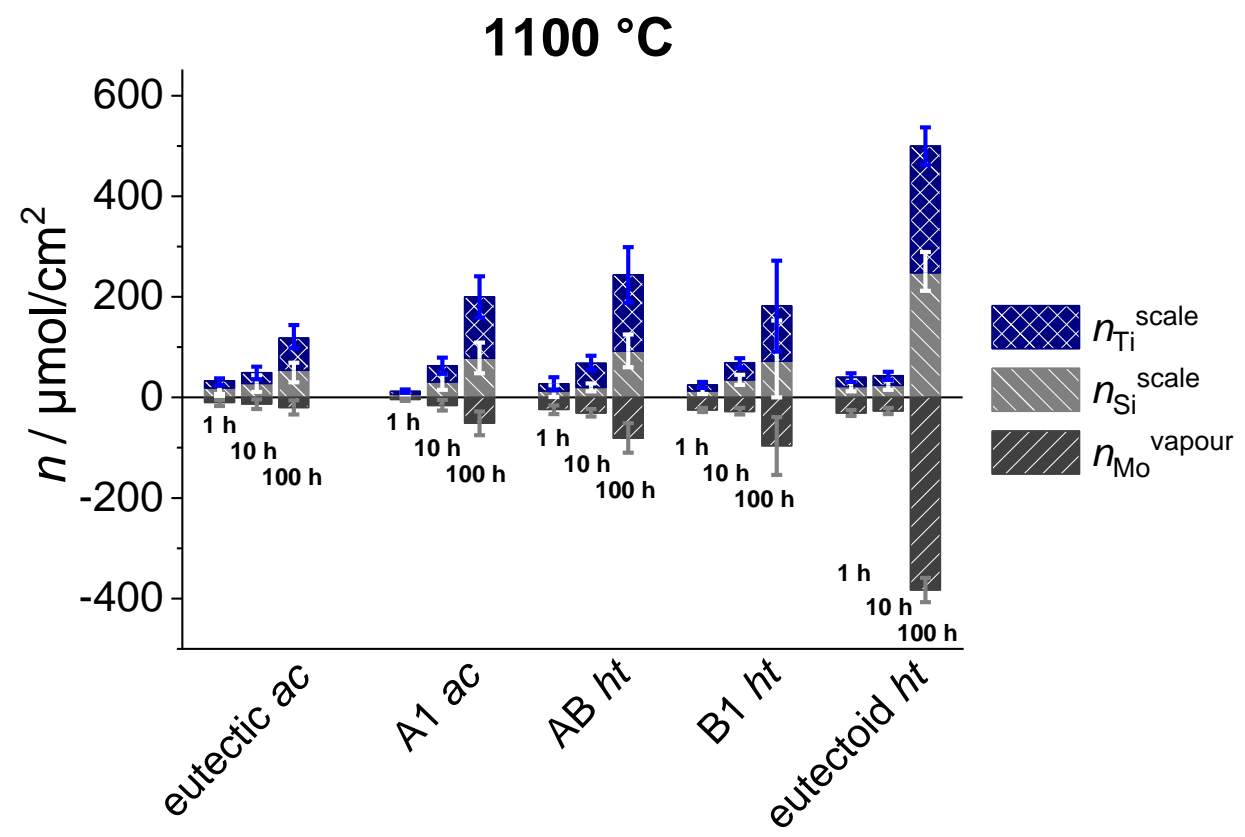

App. 25 Calculated amounts of oxidised species Ti, Si and Mo at $1100{ }^{\circ} \mathrm{C}$ after 1,10 and $100 \mathrm{~h}$ of cyclic oxidation in representative alloys of the investigated alloy series, including both reference alloys. 

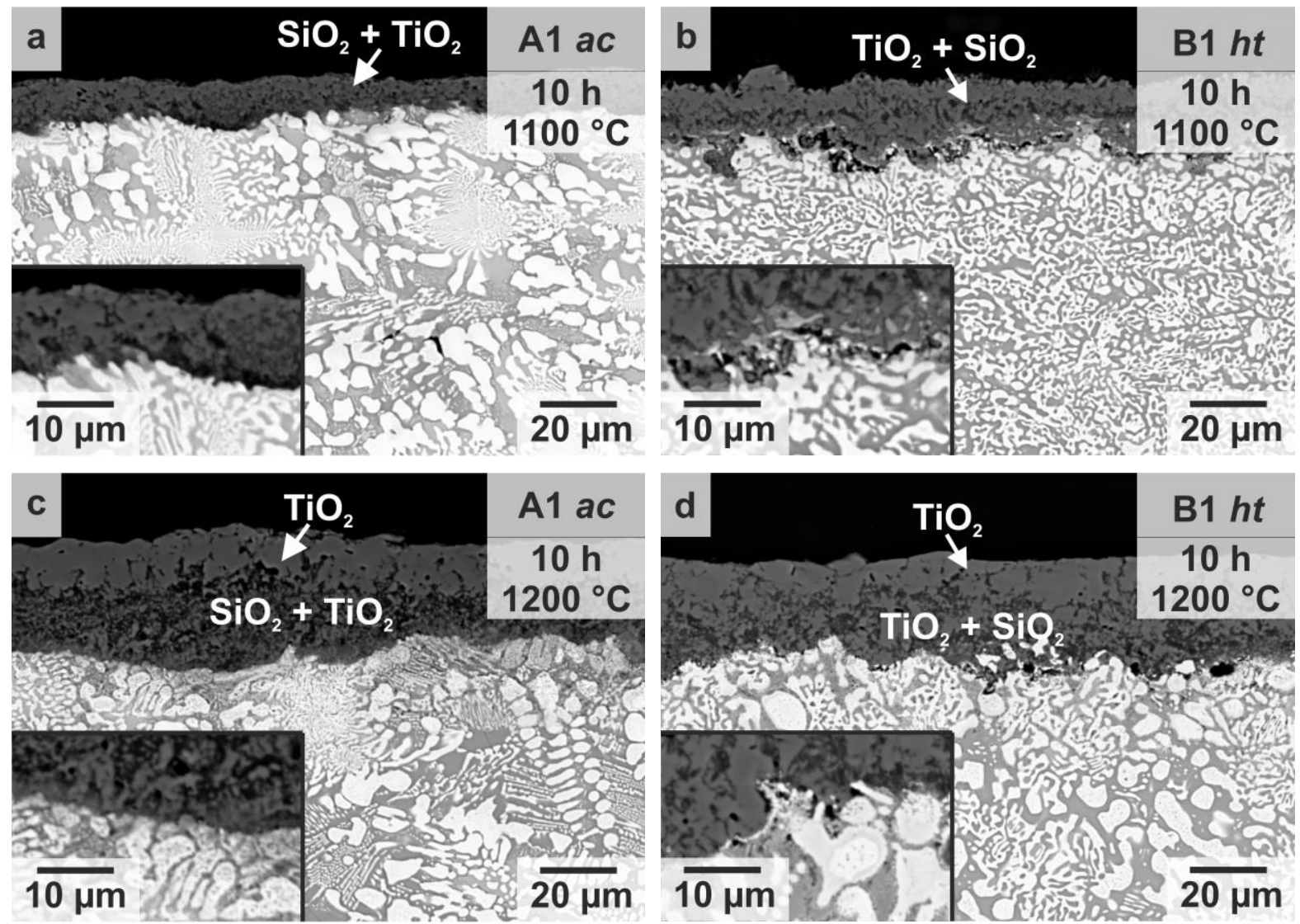

App. 26 BSE micrographs of oxidised samples of alloys A1 ac and B1 ht after $10 \mathrm{~h}$ at 1100 (a and b) and $1200{ }^{\circ} \mathrm{C}(\mathrm{c}$ and $\mathrm{d})$, respectively.
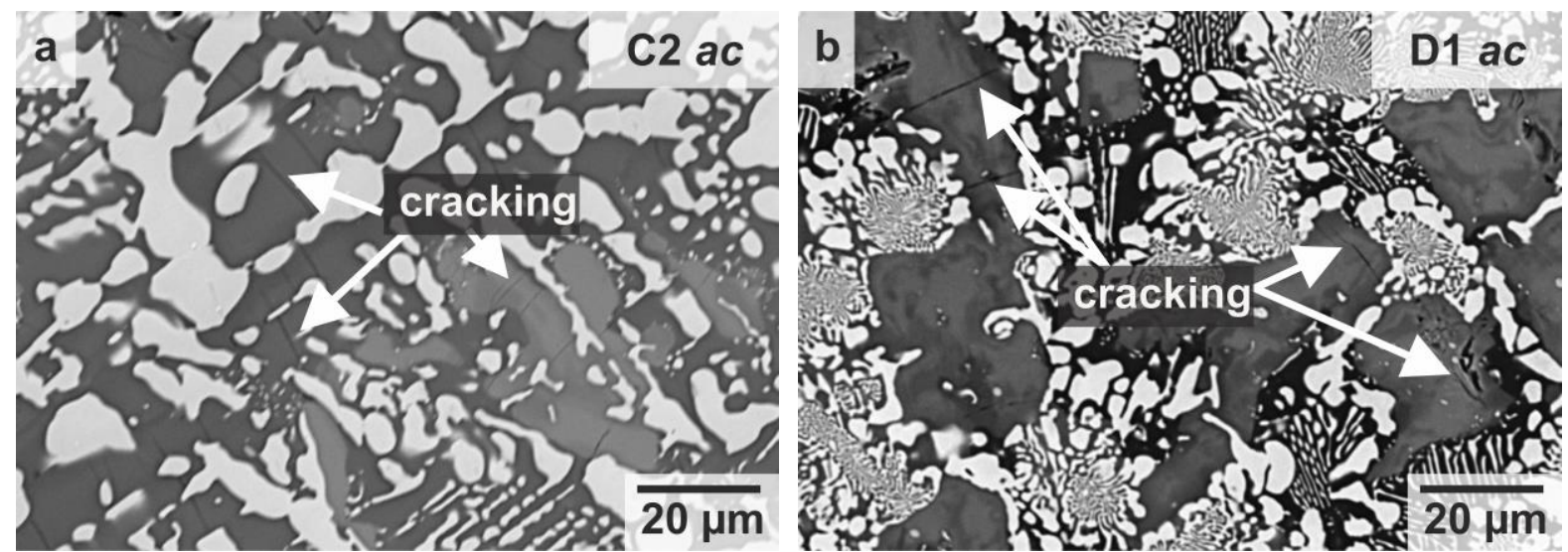

App. 27 BSE micrographs of the microstructures of alloys C2 $a c$ (a) and D1 $a c$ (b) with cracks in the silicides highlighted by white arrows. 

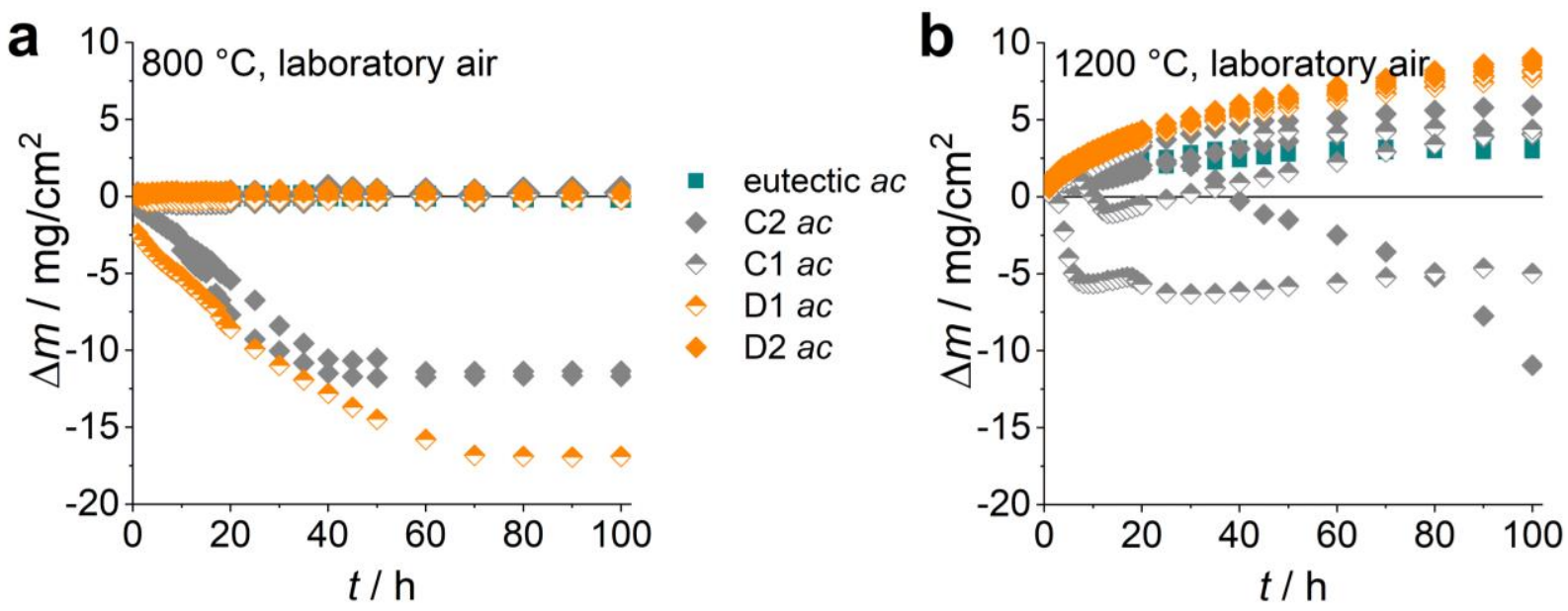

App. 28 Specific mass change during cyclic oxidation at 800 (a) and $1200{ }^{\circ} \mathrm{C}$ (b) in laboratory air for the alloy series $\mathrm{C}$ and $\mathrm{D}$ in comparison to the eutectic reference alloy (three samples per each alloy are displayed). Selected data points of alloys C1, D1 and D2 according to Ref. [225] and of the eutectic reference alloy according to Ref. [224].
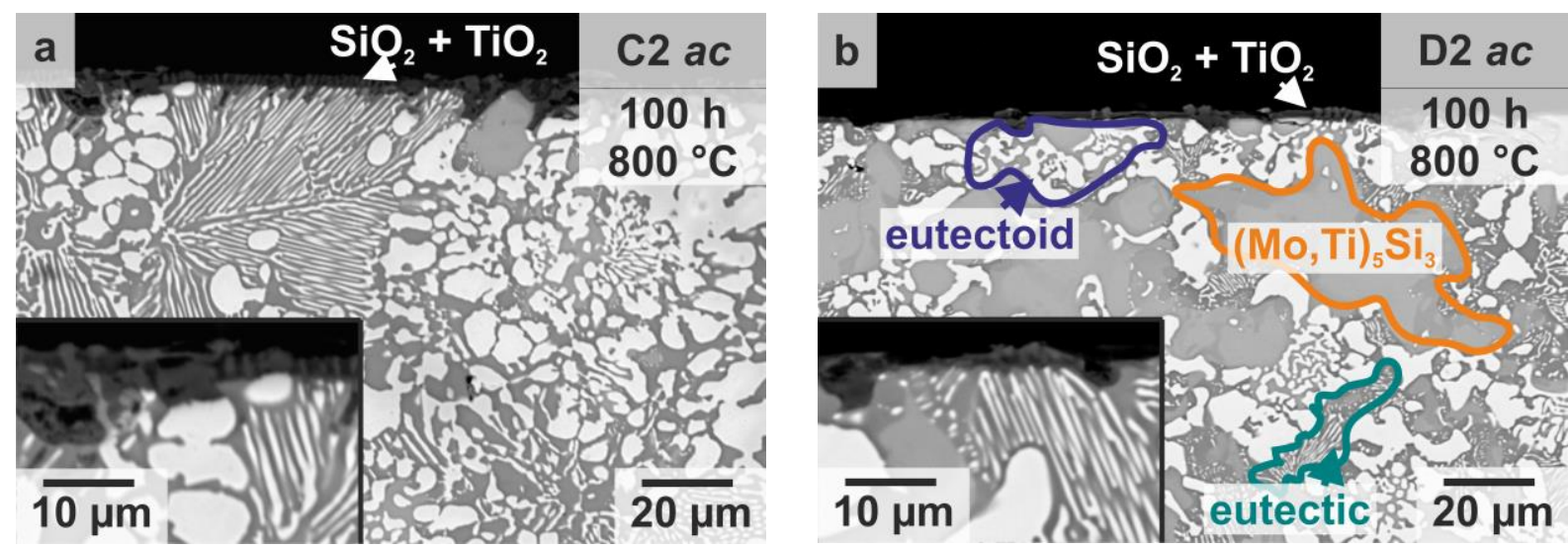

App. 29 BSE micrographs of the cross sections of cyclically oxidised samples at $800{ }^{\circ} \mathrm{C}$ for $100 \mathrm{~h}$ of alloys $\mathrm{C} 2 a c(\mathrm{a})$ and $\mathrm{D} 2 a c(\mathrm{~b})$. 

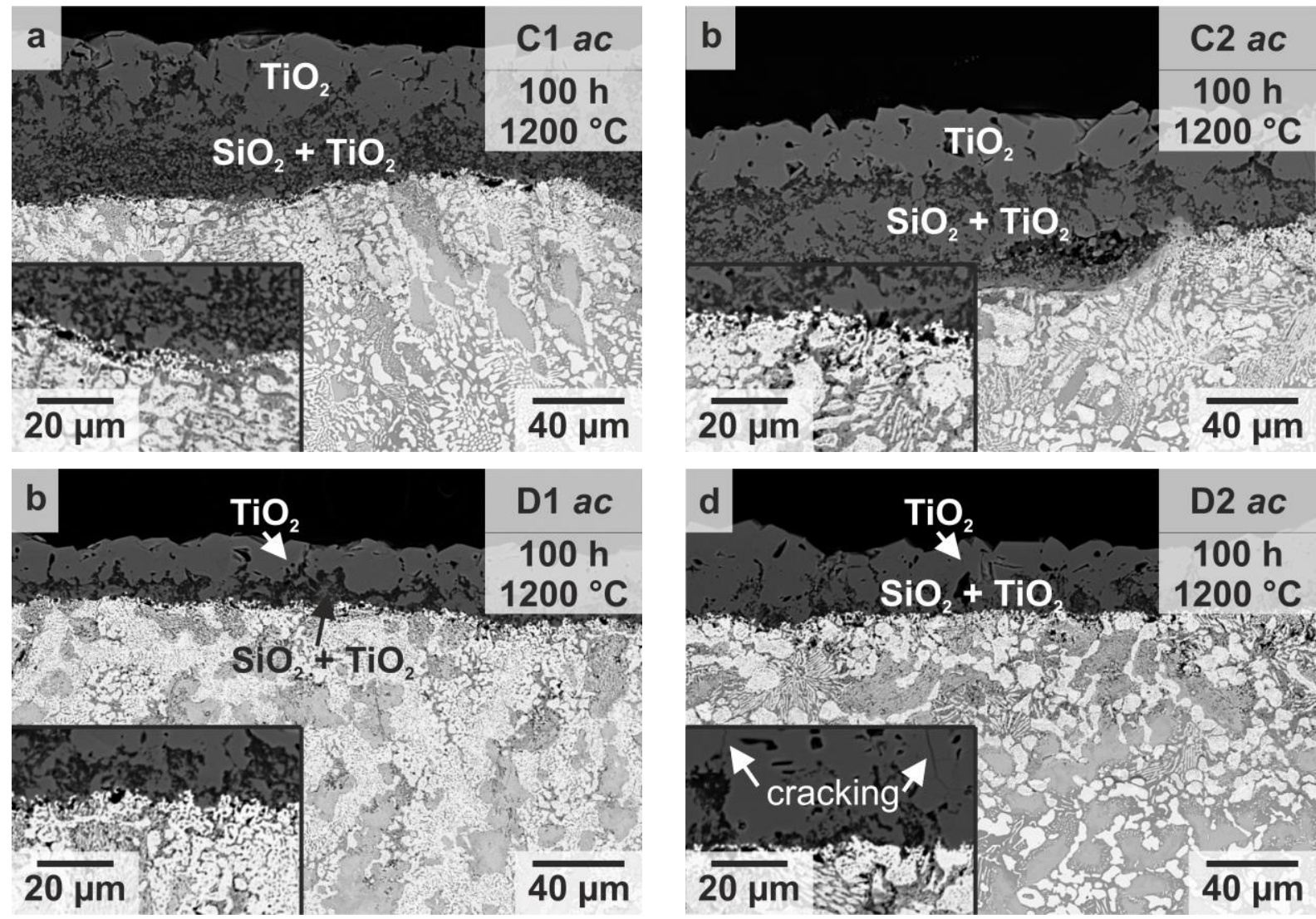

App. 30 Cross sectional BSE micrographs of the oxidised samples of alloys C1 (a), C2 (b), D1 (c) and D2 (d) after $100 \mathrm{~h}$ of cyclic oxidation at $1200{ }^{\circ} \mathrm{C}$ in air.
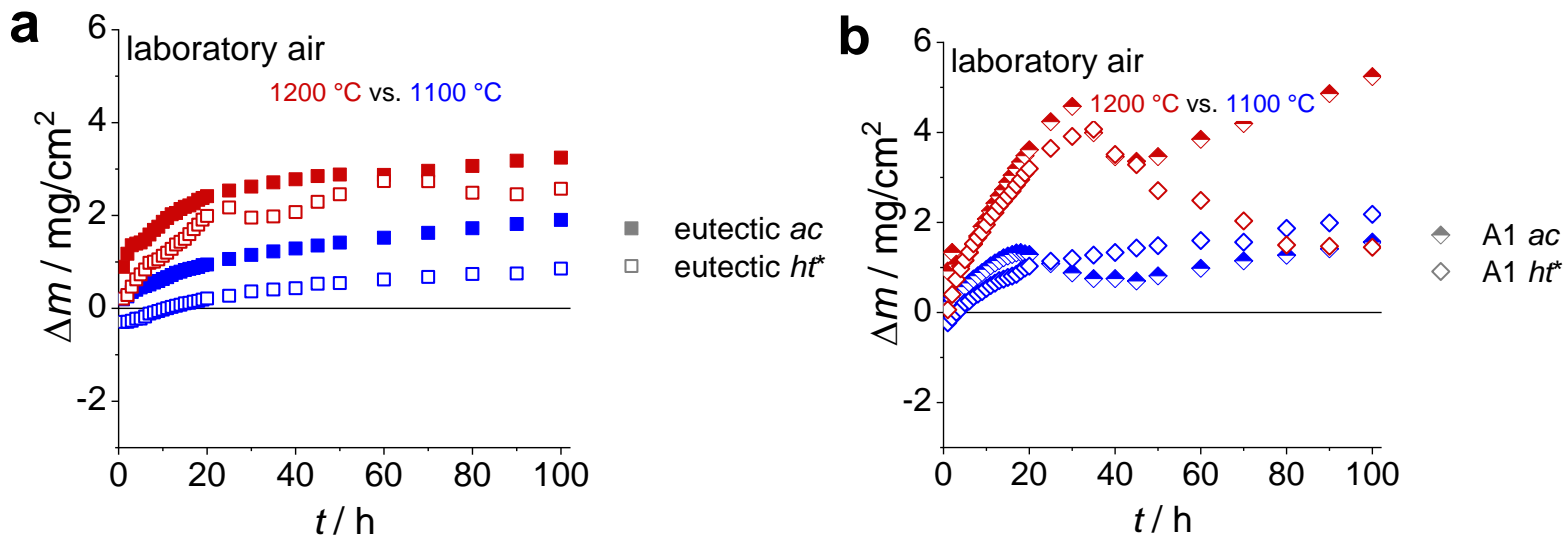

App. 31 Specific weight change as a function of test duration during cyclic oxidation of the eutectic alloy (a) and alloy A1 (b) in ac (half-/filled symbols) and $h t^{*}$ condition (opened symbols), respectively, at 1100 (blue symbols) and $1200{ }^{\circ} \mathrm{C}$ (red symbols) in air. Only one of three representative sample is shown for each condition. Data for the eutectic alloy $a c$ and $h t^{*}$ at $1200{ }^{\circ} \mathrm{C}$ are taken from Ref. [215] and of alloy A1 $a c$ at $1200{ }^{\circ} \mathrm{C}$ according to Ref. [224]. 


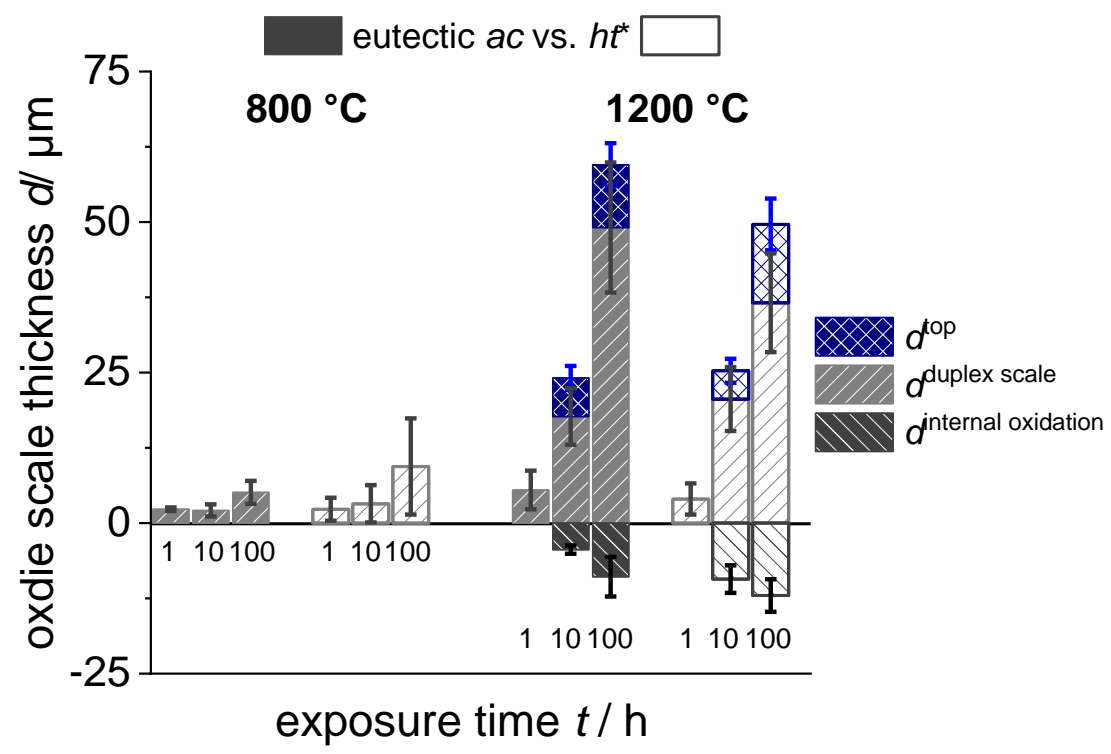

App. 32 Evolution of the oxide scale thickness of the eutectic alloy in ac (filled bars) and $h t^{*}$ condition (opened bars) during cyclic oxidation at 800 and $1200{ }^{\circ} \mathrm{C}$. Data according to Ref. [215].

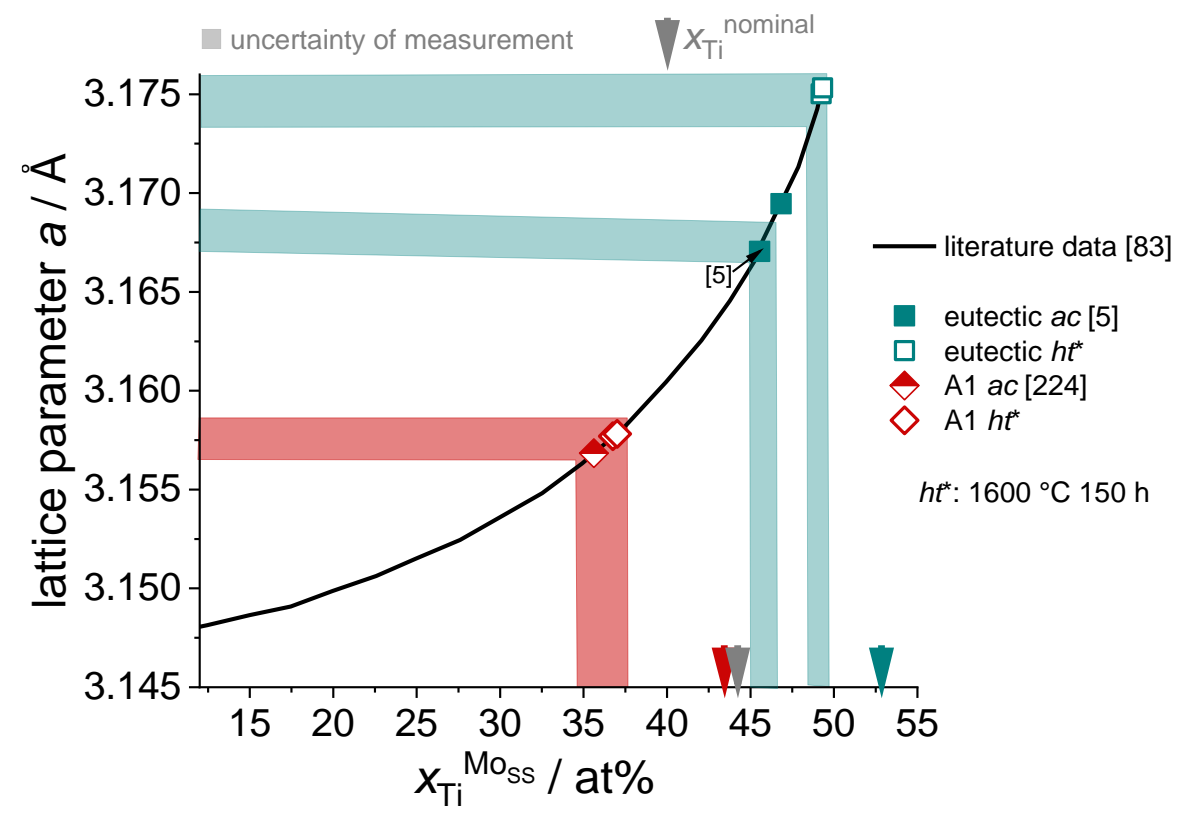

App. 33 Lattice parameter of Moss in $a c$ [224] and $h t^{*}$ variants of the eutectic reference alloy and alloy A1 determined by XRD and compared to the Ti content of Moss based on literature data [83]. 


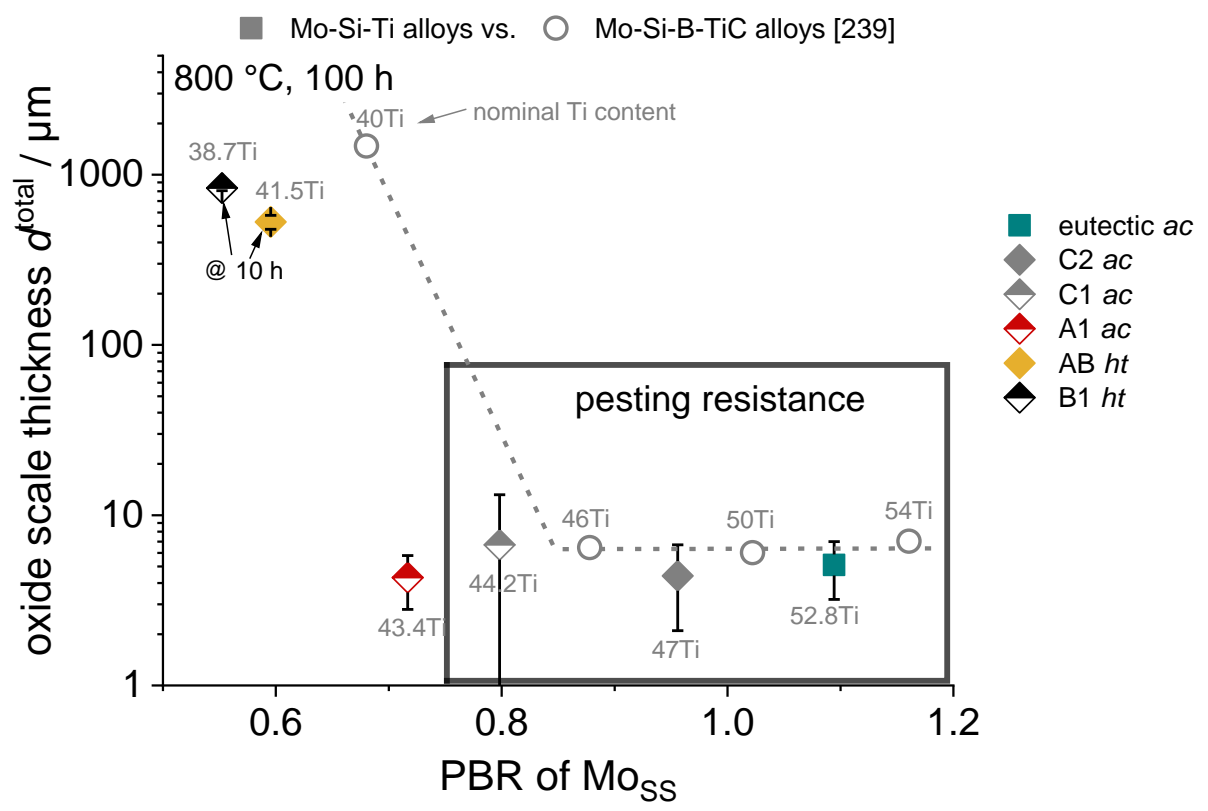

App. 34 Modified PBR ratio of Moss (according to Ref. [239]) being present in the investigated Mo-Si-Ti alloy series A, AB and B (closed and half-opened coloured symbols), including the eutectic reference alloy, in comparison to Tirich Mo-Si-B-TiC alloys (opened circles) [239]. Data on the eutectic alloy and alloy A1 according to Ref. [224] and of alloy C1 to Ref. [215].
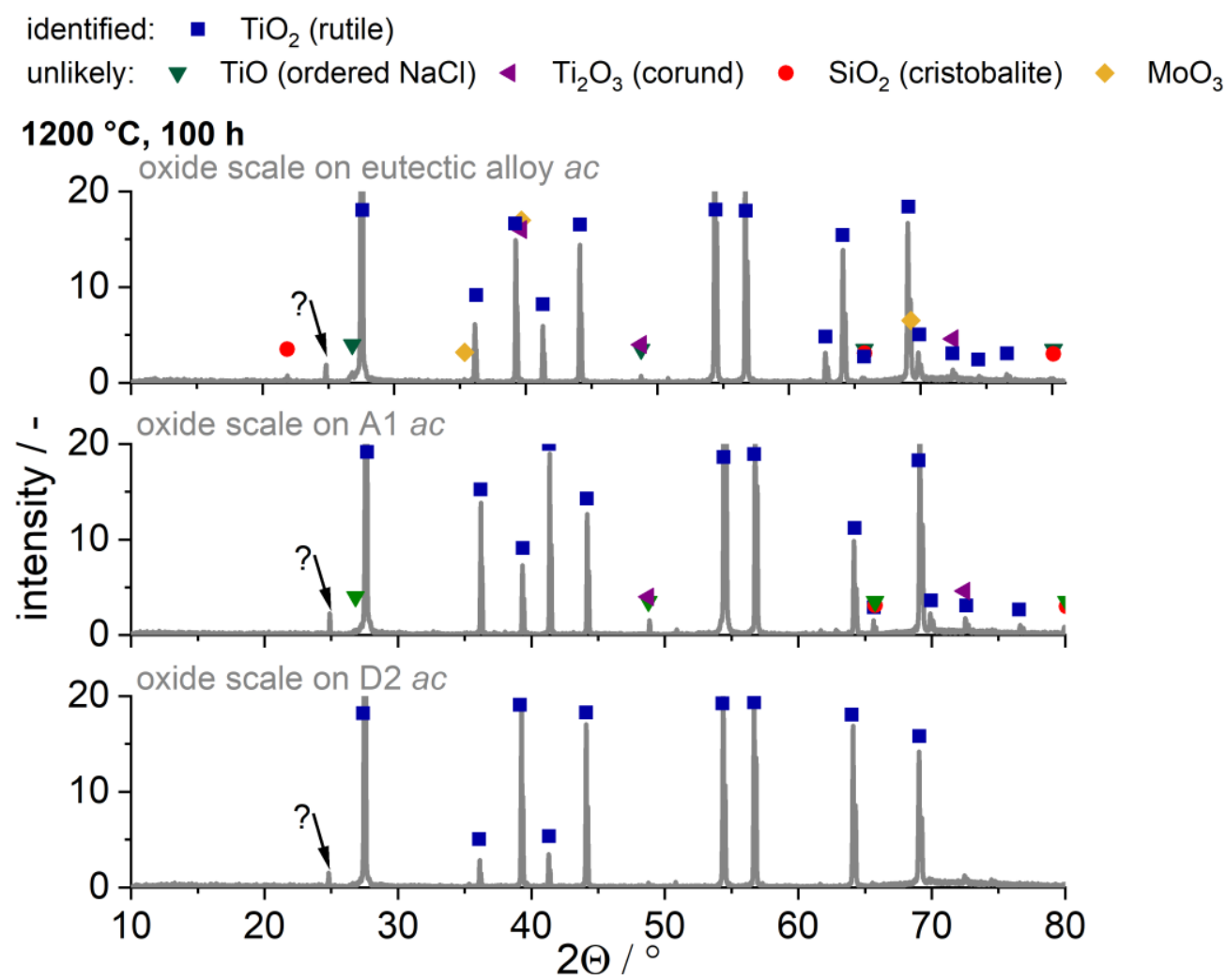

App. 35 XRD pattern of the oxidised sample surfaces after $100 \mathrm{~h}$ at $1200^{\circ} \mathrm{C}$ of the eutectic alloy and alloys A1 and D1. 
App. 36 Considered crystal structures of oxides, which did not match the GIXRD pattern. According to Ref. [216].

\begin{tabular}{|c|c|c|}
\hline oxide & crystal structure & space group \\
\hline \multirow{2}{*}{ Mo-oxide } & $\mathrm{VO}_{2}$-type $\mathrm{MoO}_{2}$ & P $121 / \mathrm{c} 1$ \\
\hline & rutile $\mathrm{MoO}_{2}$ & $\mathrm{P} 42 / \mathrm{m} \mathrm{n} \mathrm{m}$ \\
\hline Si-oxide & rutile $\mathrm{SiO}_{2}$ & $\mathrm{P} 4_{2} / \mathrm{m} \mathrm{n} \mathrm{m}$ \\
\hline \multirow{6}{*}{ Ti-oxide } & NaCl-type $\mathrm{TiO}$ & $\mathrm{F} \mathrm{m} \overline{3} \mathrm{~m}$ \\
\hline & anatase $\mathrm{TiO}_{2}$ & $\mathrm{I} 4_{1} / \mathrm{a} \mathrm{m} \mathrm{d} \mathrm{Z}$ \\
\hline & brookite $\mathrm{TiO}_{2}$ & $\mathrm{Pbc} \mathrm{a}$ \\
\hline & corundum $\mathrm{Ti}_{2} \mathrm{O}_{3}$ & $\mathrm{R} \overline{3} \mathrm{c}$ \\
\hline & monoclinic $\mathrm{Ti}_{3} \mathrm{O}_{5}$ & C $12 / \mathrm{m} 1$ \\
\hline & pseudobrookite $\mathrm{Ti}_{3} \mathrm{O}_{5}$ & $\mathrm{C} \mathrm{m} \mathrm{C} \mathrm{m}$ \\
\hline
\end{tabular}

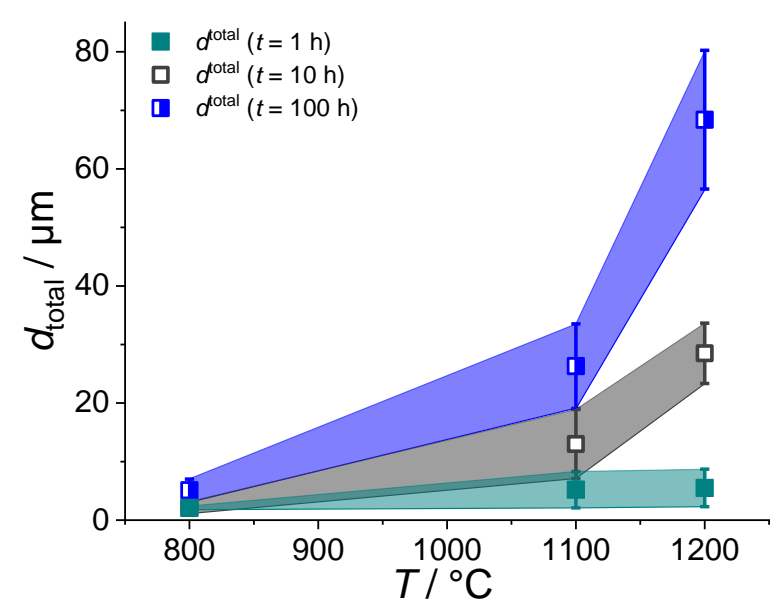

App. 37 Evolution of the oxide scale thickness in total as a function of temperature formed on the eutectic reference alloy. According to Ref. [216]. 
App. 38 Summary of the exponents $n$ (being *fixed to 2 (grey shaded rows), as well as adjusted variably (white rows)), oxidation rate constants $k_{n}, R_{a d j}^{2}$ values and activation energy $Q_{k_{n=2}}$ of the parabolic oxidation rate constants $k_{n=2}$ of the oxide scale growth kinetics of the investigated pesting-resistant alloy series in comparison to the eutectoid reference alloy at 1100 and $1200{ }^{\circ} \mathrm{C}$ (according to Eq. 17).

\begin{tabular}{|c|c|c|c|c|c|c|c|}
\hline \multirow{2}{*}{ \# alloy } & \multicolumn{3}{|c|}{$1100^{\circ} \mathrm{C}$} & \multicolumn{3}{|c|}{$1200^{\circ} \mathrm{C}$} & \multirow{2}{*}{$\begin{array}{l}\boldsymbol{Q}_{\boldsymbol{k}_{\boldsymbol{n}=2}} / \\
\mathrm{kJ} / \mathrm{mol}\end{array}$} \\
\hline & $n /-$ & $k_{n} / \mathrm{m}^{\mathrm{n}^{-}} \mathrm{s}^{-1}$ & $R_{a d j}^{2} l-$ & $n /-$ & $k_{n} / \mathrm{m}^{\mathrm{n}^{-1}}$ & $R_{a d j}^{2} /$ - & \\
\hline \multirow{2}{*}{ eutectic $a c$} & $2.00^{*}$ & $2.38 \times 10^{-15}$ & 0.86 & $2.00 *$ & $1.51 \times 10^{-14}$ & 0.96 & \multirow{2}{*}{310} \\
\hline & 2.94 & $8.64 \times 10^{-20}$ & 0.99 & 2.13 & $3.56 \times 10^{-15}$ & 0.96 & \\
\hline \multirow{2}{*}{$\mathrm{A} 1 a c$} & $2.00 *$ & $6.95 \times 10^{-15}$ & 0.99 & $2.00 *$ & $3.13 \times 10^{-14}$ & 0.92 & \multirow{2}{*}{253} \\
\hline & 2.13 & $1.75 \times 10^{-15}$ & 0.99 & 1.92 & $7.24 \times 10^{-14}$ & 0.92 & \\
\hline \multirow{2}{*}{$\mathrm{A} 2 a c$} & $2.00 *$ & $6.49 \times 10^{-15}$ & 0.77 & $2.00 *$ & $6.00 \times 10^{-14}$ & 0.95 & \multirow{2}{*}{374} \\
\hline & 2.31 & $2.73 \times 10^{-16}$ & 0.78 & 2.64 & $1.21 \times 10^{-19}$ & 1.00 & \\
\hline \multirow{2}{*}{$\mathrm{C} 1 a c$} & $2.00^{*}$ & $4.34 \times 10^{-15}$ & 0.86 & $2.00 *$ & $3.13 \times 10^{-14}$ & 0.96 & \multirow{2}{*}{332} \\
\hline & 1.00 & $6.60 \times 10^{-7}$ & 1.00 & 2.00 & $3.12 \times 10^{-14}$ & 0.96 & \\
\hline \multirow{2}{*}{$\mathrm{C} 2 a c$} & $2.00 *$ & $3.14 \times 10^{-15}$ & 0.95 & $2.00 *$ & $3.53 \times 10^{-14}$ & 0.97 & \multirow{2}{*}{407} \\
\hline & 1.67 & $1.22 \times 10^{-13}$ & 0.97 & 1.96 & $4.84 \times 10^{-14}$ & 1.00 & \\
\hline \multirow{2}{*}{ D1 $a c$} & $2.00 *$ & $2.61 \times 10^{-15}$ & 0.85 & $2^{*}$ & $2.16 \times 10^{-14}$ & 0.97 & \multirow{2}{*}{355} \\
\hline & 1.52 & $5.92 \times 10^{-13}$ & 0.96 & 2.17 & $3.12 \times 10^{-15}$ & 0.98 & \\
\hline \multirow{2}{*}{$\mathrm{D} 2 a c$} & $2.00 *$ & $3.68 \times 10^{-15}$ & 0.94 & $2.00 *$ & $3.88 \times 10^{-14}$ & 0.99 & \multirow{2}{*}{396} \\
\hline & 1.63 & $1.93 \times 10^{-13}$ & 0.99 & 1.84 & $1.80 \times 10^{-13}$ & 1.00 & \\
\hline \multirow{2}{*}{ eutectoid $h t$} & $2.00 *$ & $5.71 \times 10^{-15}$ & 0.50 & $2.00 *$ & $5.47 \times 10^{-14}$ & 0.99 & \multirow{2}{*}{380} \\
\hline & 0.91 & $6.41 \times 10^{-10}$ & 0.92 & 2.08 & $2.33 \times 10^{-14}$ & 1.00 & \\
\hline
\end{tabular}


App. 39 Literature data on oxidation kinetics (weight change kinetics marked by asterisk).

\begin{tabular}{|c|c|c|c|c|c|c|}
\hline & $T /{ }^{\circ} \mathrm{C}$ & $\begin{array}{c}\text { oxidation } \\
\text { behaviour }\end{array}$ & $k^{*} / \mathrm{ms}^{-1}$ & $k_{n=2} / \mathrm{m}^{n} \mathrm{~S}^{-1}$ & $\begin{array}{c}Q_{k_{n=2}} / \\
\mathrm{kJmol}^{-1}\end{array}$ & Ref. \\
\hline \multirow{2}{*}{$\mathrm{Si}$ in $\mathrm{O}_{2}$} & 800 & linear + parabolic & $8.3 \times 10^{-13}$ & $3.6 \times 10^{-19}$ & $120-154$ & {$[265]$} \\
\cline { 2 - 8 } & 1200 & linear + parabolic & $2.7 \times 10^{-10}$ & $1.2 \times 10^{-17}$ & - & \\
\hline \multirow{2}{*}{ Ti in $\mathrm{O}_{2}$} & $\begin{array}{c}400 \text { to } \\
600\end{array}$ & cubic & - & - & - & {$[39]$} \\
& $\begin{array}{c}700 \text { to } \\
900\end{array}$ & parabolic + linear* & - & - & 221 & {$[39,47]$} \\
\cline { 2 - 8 } & $>900$ & linear* & - & - & - & {$[39,48]$} \\
\hline \multirow{2}{*}{ Mo in $\mathrm{O}_{2}$} & $<650$ & parabolic & - & - & 375 & {$[49,50,51]$} \\
\hline & $>800$ & linear* & - & - & 82 & \\
\hline
\end{tabular}

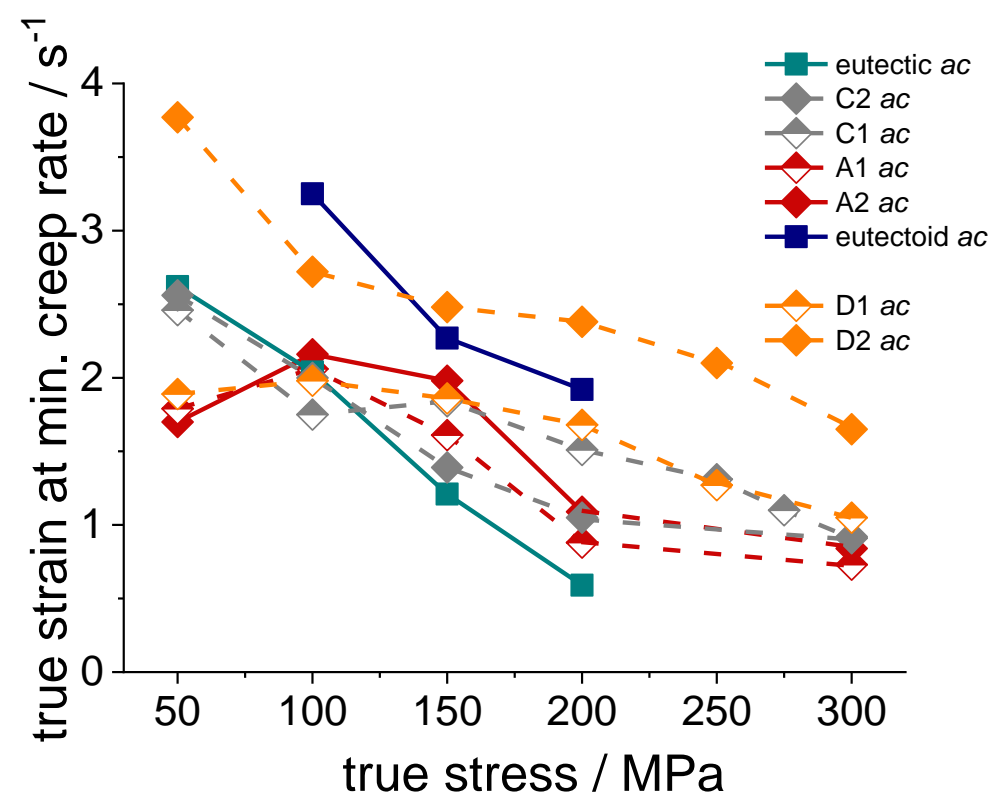

App. 40 True strain attained at the creep rate minima as a function of the applied true stress for the intermediate alloy series and both reference alloys. Data of both reference alloys taken from Ref. [5] and data of alloy A1 ac according to Ref. [224] and of alloys C1, D1 and D2 according to Ref. [225]. 
App. 41 Apparent activation energy for creep $Q_{c}$ of the investigated pesting-resistant Mo-Si-Ti alloys in $a c$ condition.

\begin{tabular}{|c|c|c|c|c|c|c|}
\hline \# alloy & A1 & A2 & C1 & C2 & D1 & D2 \\
\hline$Q_{c} / \mathrm{kJ} / \mathrm{mol}$ & $484[224]$ & $528[224]$ & $405[225]$ & 531 & $463[225]$ & $403[225]$ \\
\hline
\end{tabular}

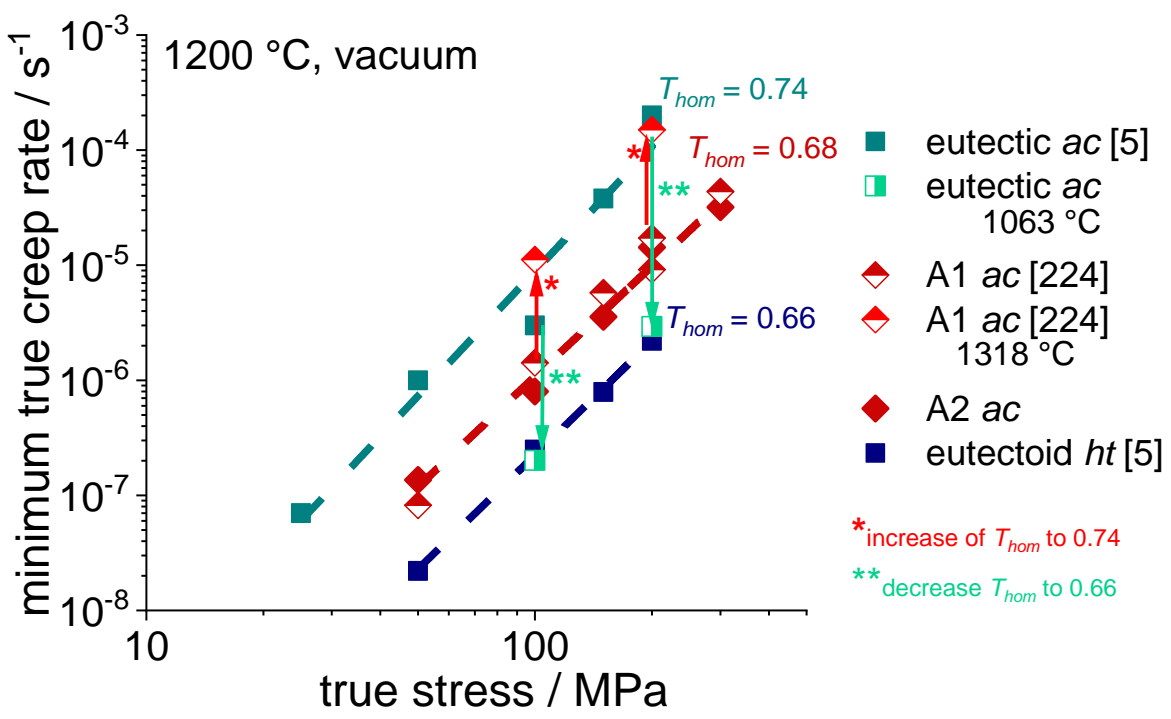

App. 42 Norton plot at $1200{ }^{\circ} \mathrm{C}$ including selected compression creep tests at $1063{ }^{\circ} \mathrm{C}$ of the eutectic alloy at the homologous temperature of 0.66 (half-opened, light green symbols) and $1318^{\circ} \mathrm{C}$ of alloy $\mathrm{A} 1$ at the homologous temperature of 0.74 (half-opened, bright red diamonds). Selected data of $\mathrm{A} 1 \mathrm{ac}$ at $1318^{\circ} \mathrm{C}$ taken from Ref. [224]. 

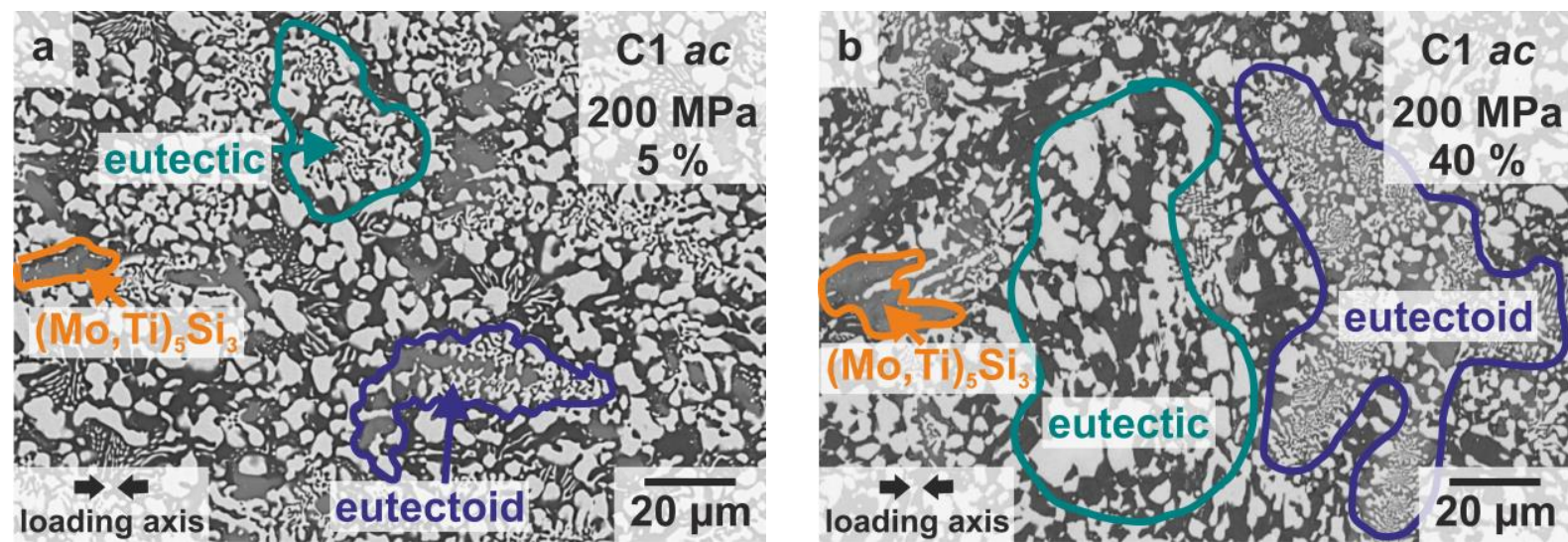

c Give a d ac

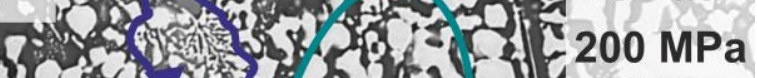
1C. eutectoid loading axis $\Rightarrow \mathrm{s}$.
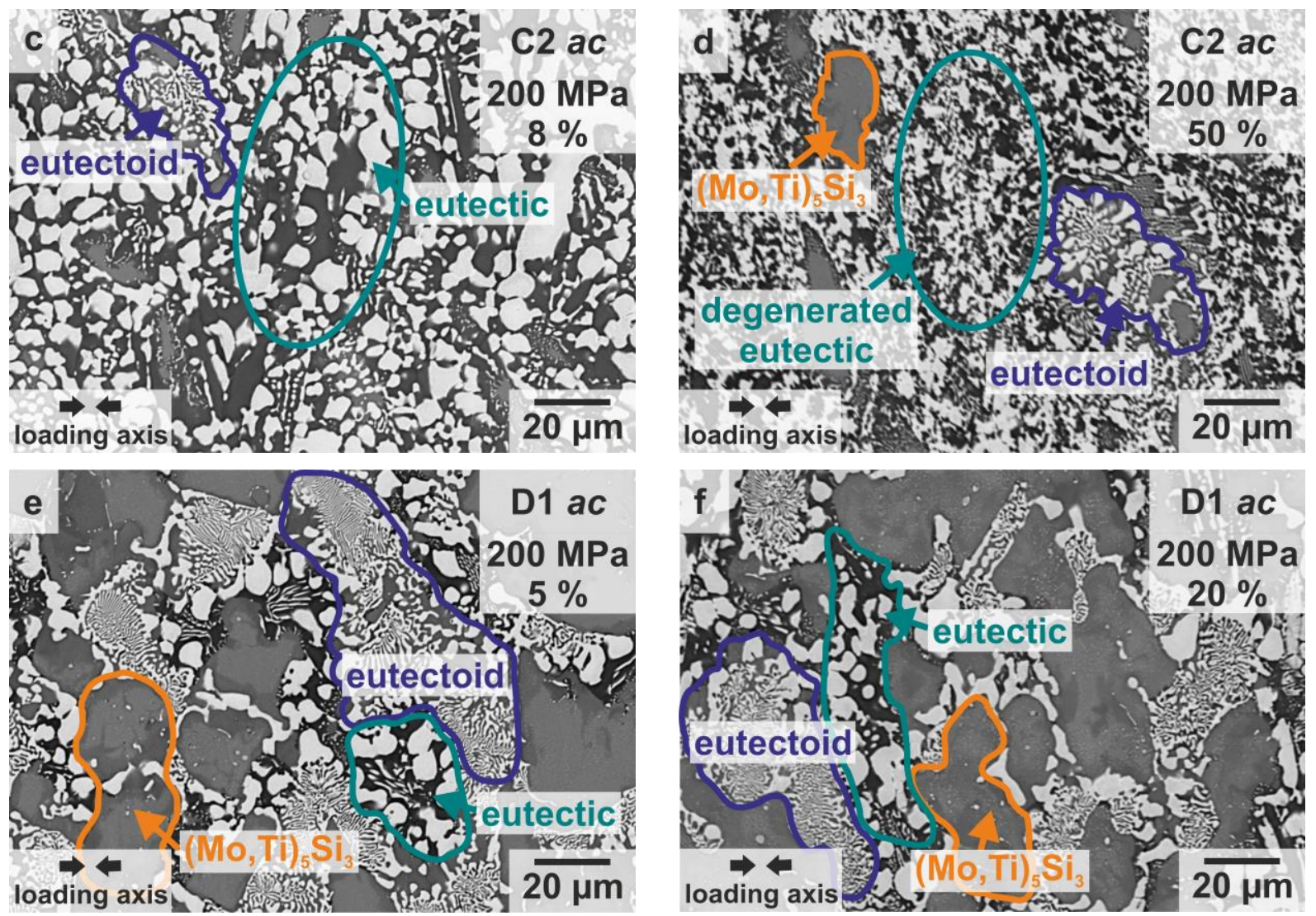

App. 43 BSE micrographs of the deformed microstructures of alloys C1 (a and b), C2 (c and d) and D1 (e and f) after different strains at $1200^{\circ} \mathrm{C}$ and $200 \mathrm{MPa}$. 

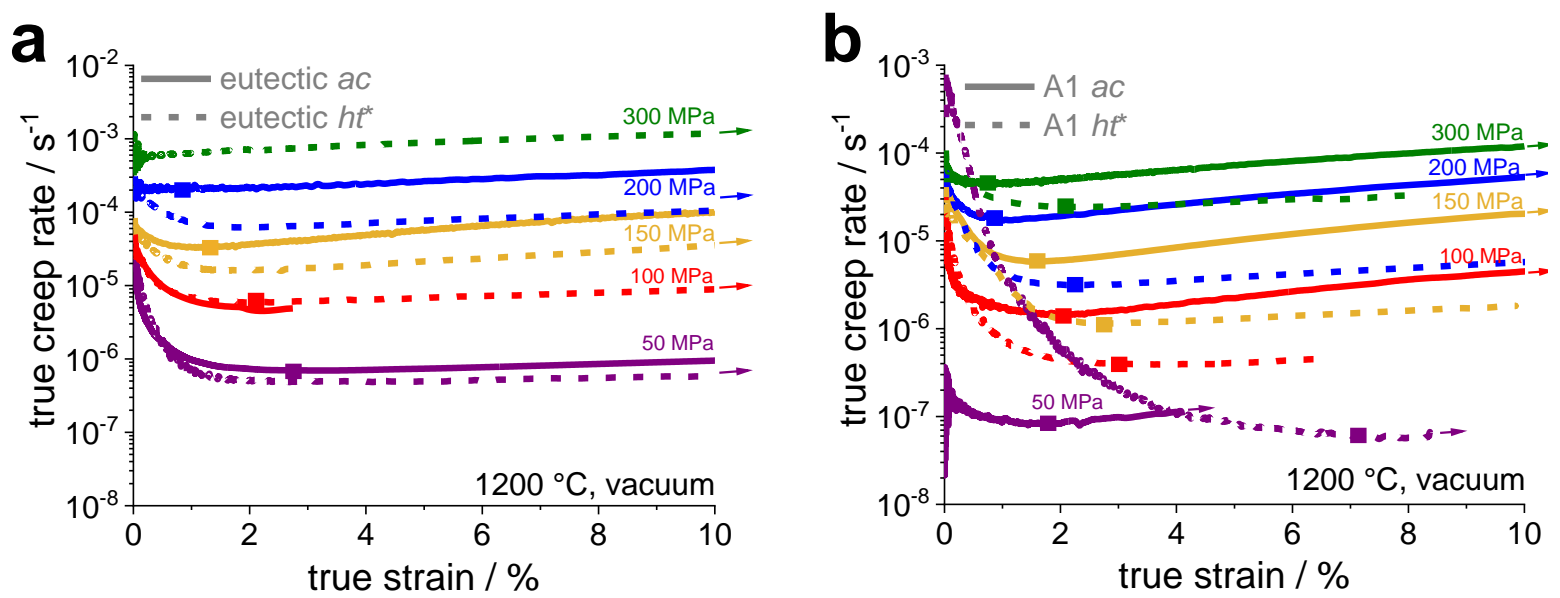

App. 44 Evolution of the true creep rate in dependence of the true strain during compression creep testing of the eutectic (a) and A1 (b) $a c$ and $h t^{*}\left(1600{ }^{\circ} \mathrm{C}\right.$, $150 \mathrm{~h}$ ) alloy variants at $1200^{\circ} \mathrm{C}$. Data on the eutectic reference alloy in $a c$ condition taken from Ref. [5] and of alloy A1 ac according to Ref. [224].

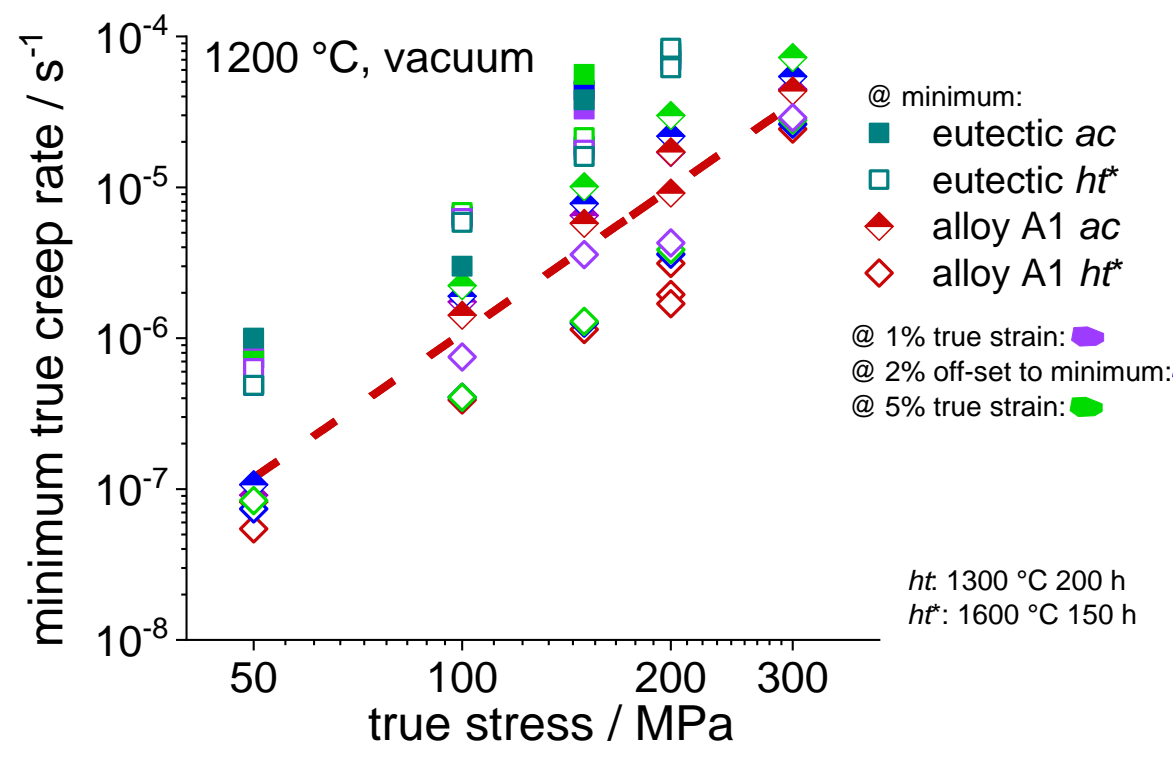

App. 45 Norton plot for the eutectic reference alloy and alloy A1 for the creep rates at the minimum (turquoise and red data points, respectively), after $1 \%$ true strain (purple data points), at $2 \%$ off-set to the minimum creep rate (blue data points) and after $5 \%$ true strain (green data points) for $a c$ and $h t^{*}$ condition. Data of alloy A1 $a c$ according to Ref. [224] and of the eutectic alloy $a c$ taken from Ref. [5]. 


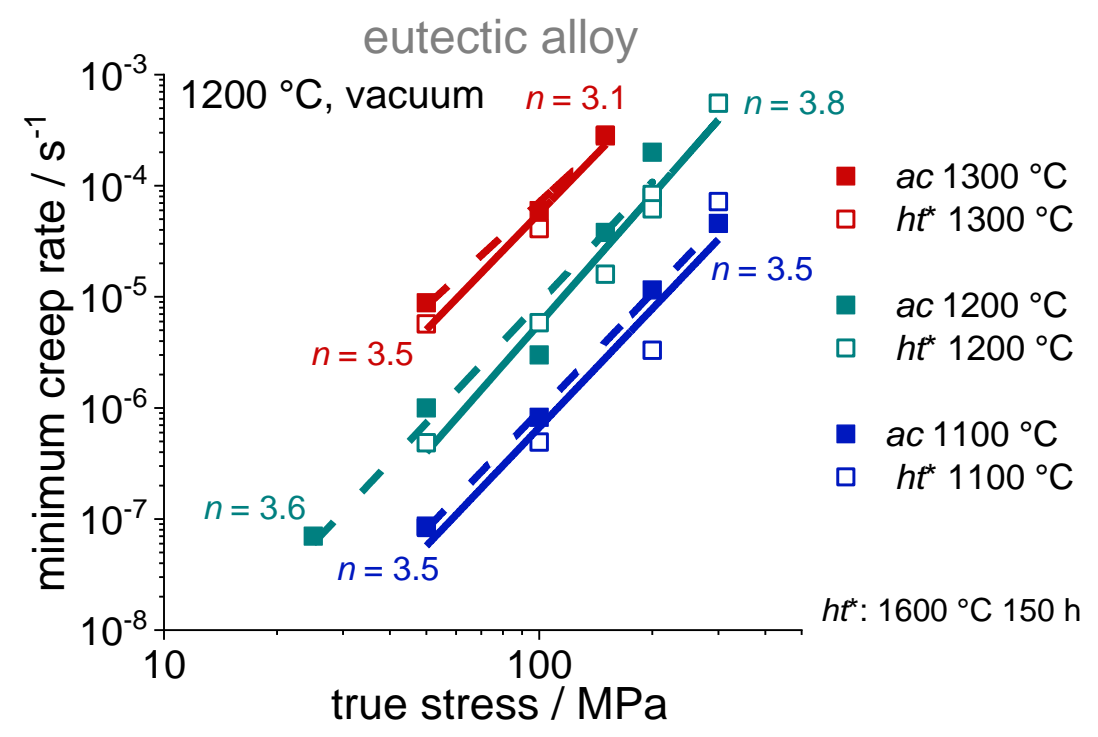

App. 46 Norton plot of the eutectic alloy in $a c$ (filled symbols) and $h t^{*}$ condition (opened symbols) at 1100 (blue), 1200 (green) and $1300{ }^{\circ} \mathrm{C}$ (red). Data of the eutectic reference alloy in $a c$ condition at $1200{ }^{\circ} \mathrm{C}$ taken from Ref. [5].

\begin{tabular}{|c|c|c|c|c|c|c|c|c|c|}
\hline EDX / at\% & $\mathrm{Al}$ & $\mathrm{Cr}$ & $\mathrm{Re}$ & $\mathrm{Ta}$ & $\mathrm{Mo}$ & \multicolumn{2}{|c|}{$\mathrm{Co}$} & $\mathrm{Ni}$ \\
\hline CMSX-4 & $6.0 \pm 0.2$ & $5.3 \pm 0.1$ & $2.4 \pm 0.2$ & $6.2 \pm 1.8$ & $2.0 \pm 0.2$ & $11.3 \pm 0.3$ & $66.7 \pm 1.1$ \\
\hline \begin{tabular}{|c|c|c|c|c|c|c|c|}
\hline EDX / at\% \\
Nimonic
\end{tabular} & $\mathrm{C}$ & $\mathrm{Al}$ & $\mathrm{Si}$ & $\mathrm{Ti}$ & $\mathrm{Cr}$ & $\mathrm{Mn}$ & $\mathrm{Fe}$ & $\mathrm{Co}$ & $\mathrm{Ni}$ \\
\hline 90
\end{tabular}

App. 47 EDX analysis of commercially applied CMSX-4 (upper table) and Nimonic 90 (lower table).

\begin{tabular}{|c|c|c|}
\hline \# alloy & geometry of oxidation samples & Refs. \\
\hline Mo-Si-Ti alloys & cuboids of $(5 \times 5 \times 4) \mathrm{mm}^{3}$ & {$[224,225]$} \\
\hline CMSX-4 & cuboids of around $(4 \times 4 \times 3) \mathrm{mm}^{3}$ & \\
\hline Nimonic 90 & discs of diameter $10 \mathrm{~mm}$, height $\approx 4 \mathrm{~mm}$ & this thesis \\
\hline Mo-9Si-8B & cuboids of $(5 \times 3 \times 3) \mathrm{mm}^{3}$ & \\
\hline Mo-12.5Si-8.5B-27.5Ti-2Fe & cuboids of $(5 \times 3 \times 3) \mathrm{mm}^{3}$ & {$[295]$} \\
\hline
\end{tabular}

App. 48 Geometry of oxidation samples tested at $1200^{\circ} \mathrm{C}$ in air. 


\section{List of Figures}

Fig. 1-1 Specific core power as a function of the turbine inlet temperature of commercial turbine engines (grey dots) compared to the ideal performance (black line); according to Ref. [20]. Top right inset: cutaway view image of a gas turbine [28]. 2

Fig. 2-1 Liquidus projection of the ternary Mo-Si-B system. Data taken from Ref. [54], schematic isotherms in $100 \mathrm{~K}$ steps calculated with Pandat.

Fig. 2-2 Isothermal section of the ternary Mo-Si-B system at $1600{ }^{\circ} \mathrm{C}$. Phase equilibria of special interest are highlighted: Moss $+\mathrm{Mo}_{3} \mathrm{Si}+\mathrm{Mo}_{5} \mathrm{SiB}_{2}$ (blue triangle), $\mathrm{Mo}_{5} \mathrm{Si}_{3}$

$+\mathrm{Mo}_{3} \mathrm{Si}+\mathrm{Mo}_{5} \mathrm{SiB}_{2}$ (green triangle). Data taken from Ref. [58].

Fig. 2-3 Schematic overview of the main alloying concepts of Mo-Si-based alloys. ....... 6

Fig. 2-4 BSE micrographs of alloy Mo-9Si-8B, PM-manufactured as-sintered, very finescaled (a) and AcM as-cast (b); alloy Mo-12.5Si-8.5B-27.5Ti-2Fe, AcM heat-treated (c) and alloy Mo-20Si-52.8Ti, AcM as-cast (d). Coloured proportions of the microstructures are included (Moss: blue to green, silicide phases: red to orange), connected pixel clusters are the same colour.

Fig. 2-5 Liquidus projection of the ternary Mo-Si-Ti system with the relevant metal-rich section being labelled, including the binary systems. Zoomed-in views are provided in insets (a) and (b). Combination of thermodynamic calculations with Pandat and literature data [36, 80-83].

Fig. 2-6 Isothermal section of the ternary Mo-Si-Ti system at $1600{ }^{\circ} \mathrm{C}$ calculated with Pandat. Three-phase fields of special interest are highlighted; red: Moss + $(\mathrm{Ti}, \mathrm{Mo})_{5} \mathrm{Si}_{3}+(\mathrm{Mo}, \mathrm{Ti})_{5} \mathrm{Si}_{3}$, orange: Moss $+(\mathrm{Mo}, \mathrm{Ti})_{5} \mathrm{Si}_{3}+(\mathrm{Mo}, \mathrm{Ti})_{3} \mathrm{Si}$. The $(\mathrm{Mo}, \mathrm{Ti})_{3} \mathrm{Si}$ phase region is highlighted by the blue line and the eutectic reaction $\mathrm{e}_{4}$ by the green circle in the Ti-rich corner.

Fig. 2-7 Schematic transport mechanisms of oxidation reactions. According to p. 41 in Ref. [9]. 15

Fig. 2-8 Schematic Ellingham-Richardson plot. According to p. 23 in Ref. [9] and Ref. [119].

Fig. 2-9 Idealised specific weight change kinetics. According to p. 253 in Ref. [109]...17

Fig. 2-10 Schematic overview on the oxidation mechanisms of typical Mo-Si-B and Mo-

Si-B-Ti alloys compared to the novel eutectic Mo-Si-Ti alloy below and above $1000{ }^{\circ} \mathrm{C}$. According to observations made in Refs. [4, 5, 40, 47, 48]. .23 
Fig. 2-11 Schematic evolution of the creep strain $\varepsilon$ as a function of time $t$ under constant tensile stress $\sigma i$ (a) and the corresponding evolution of the creep rate $\varepsilon$ with time (b). According to p. 282 in Ref. [164]. .26

Fig. 2-12 Deformation mechanism maps: schematic (a) [180] and for pure Mo (b) [194]. 30

Fig. 2-13 Results of compressive and tensile (marked by *) creep tests as double logarithmic plot of minimum true creep rate vs. applied true stress of typical MoSi-B (black circles) and Mo-Si-B-Ti alloys (grey triangles) in comparison to novel Mo-Si-Ti alloys (coloured squares) and CMSX-4 (orange diamonds). .32

Fig. 4-1 Solidification simulation of alloy A1 (Mo-21Si-43.4Ti) for equilibrium (a) and Scheil conditions (b).

Fig. 4-2 Calculated metal-rich portion of the ternary Mo-Si-Ti liquidus projection (according to Ref. [224]), including schematic detailed views of the composition profile of the liquid (coloured lines) during solidification in Scheil condition. The investigated alloys are highlighted by coloured symbols.

Fig. 4-3 Scheil solidification simulations for alloy series A (a), B (b), C (c) and D (d). The alloy variants 1 are symbolised by solid lines, whereas the variants 2 by dotted lines. The phase fraction assigned as primarily solidified (Moss in alloy series A and $\mathrm{B},(\mathrm{Mo}, \mathrm{Ti})_{5} \mathrm{Si}_{3}$ in alloy series $\left.\mathrm{D}\right)$ is highlighted by the yellow circle and arrow......47

Fig. 5-1 BSE micrographs of the eutectic (a) and eutectoid (b) alloys, alloy series A (c and d) and $\mathrm{B}$ (e to h) in the $a c$ and/or $h t$ condition ( $\left.1300^{\circ} \mathrm{C}, 200 \mathrm{~h}\right)$. Micrographs $\mathrm{c}$ and f according to Ref. [224].

Fig. 5-2 BSE micrographs of alloy $\mathrm{AB}$ in the $a c$ (a) and $h t$ (b) condition. 51

Fig. 5-3 Experimentally determined (filled bars) and thermodynamic (hatched bars) volume fractions $v$ of the microstructural constituents in the investigated alloys of series A and B and alloy AB in $a c$ and $h t$ condition. Data of alloys A1 $a c$ and B1 $h t$ are taken from Ref. [224]..... .52

Fig. 5-4 BSE micrographs of the (Mo,Ti) ${ }_{5} \mathrm{Si}_{3}$-containing alloy series $\mathrm{C}$ (a and b) and $\mathrm{D}(\mathrm{c}$ and $d$ ) in the $a c$ condition. $c$ and d according to Ref. [225]. .54

Fig. 5-5 Experimentally determined volume fractions (filled bars) of the microstructural constituents in the alloy series $\mathrm{C}$ and $\mathrm{D}$ in $a c$ condition in comparison to the thermodynamically predicted values for Scheil condition. Data of alloys C1, D1 and D2 according to Ref. [225]. .55

Fig. 5-6 Experimentally determined lattice parameters of Moss in the alloys A to D including the eutectic and eutectoid reference alloys compared to literature data of binary bcc Mo-Ti solid solutions (black line) taken from Ref. [83]. The estimated 
uncertainty of measurement is $0.001 \AA$ as indicated by the semi-transparent regions. The nominal Ti content of the alloys is given by the coloured arrows along the abscissa. According to Ref. [224]

Fig. 5-7 HAADF images and corresponding STEM-EDX maps of the constitutional elements Mo (red), Si (green) and Ti (orange) of the eutectic reference alloy in $a c$ condition (a), alloy B1 in ac condition (b) and the eutectoid reference alloy in $h t$ condition (precipitates in Moss circled in white) (c), including a more detailed analysis of the precipitates in Moss (d). According to Ref. [215]. .58

Fig. 5-8 Comparison of the phase-specific chemical composition of Moss (a), (Ti,Mo) ${ }_{5} \mathrm{Si}_{3}$ and $(\mathrm{Mo}, \mathrm{Ti})_{5} \mathrm{Si}_{3}$ (b) in the eutectic reference alloy, alloys $\mathrm{A} 1, \mathrm{~B} 1$ and the eutectoid reference alloy determined by standard-related EDX (diamond symbols), STEMEDX (half-opened squares, data according to Ref. [215]) and thermodynamic calculations for equilibrium (opened triangles).

Fig. 5-9 Interface boundary fraction $P$ of the investigated alloys in the $a c$ state and after specific heat treatments including the eutectic and eutectoid reference alloys (data for $a c$ and selected $h t$ variants according to Refs. [215, 224, 225] and of the eutectic reference alloy in $a c$ and $h t^{*}$ condition according to Ref. [215]) and other typical MoSi-based alloy systems (data taken from Refs. [4, 136]).

Fig. 6-1 Specific weight change $\Delta m$ as a function of oxidation time $t$ during cyclic oxidation of the alloy series A and B in comparison to the eutectic and eutectoid reference alloys at $800{ }^{\circ} \mathrm{C}$ (a), 1100 (b) and $1200{ }^{\circ} \mathrm{C}$ (c). Data on the reference alloys, alloys $\mathrm{A} 1$ and $\mathrm{B} 1$ according to Ref. [224], data on alloy $\mathrm{AB}$ at $800^{\circ} \mathrm{C}$ according to Ref. [215]. Data of CMSX-4 are included for comparison at 800 [231] and $1100{ }^{\circ} \mathrm{C}$ [228, 230].

Fig. 6-2 Representative BSE micrographs of the investigated alloys after cyclic oxidation at $800^{\circ} \mathrm{C}$ in laboratory air for 1 and $100 \mathrm{~h}$, respectively: alloy A1 ac (a and b), alloy AB $h t$ (c) and alloy B1 $h t$ (d). (a, b, d) according to Ref. [224].

Fig. 6-3 Cross sectional BSE micrographs of alloy A1 ac after 1 (a) and $100 \mathrm{~h}$ (b) and of alloy $\mathrm{B} 1 \mathrm{ht}$ after 1 (c) and $100 \mathrm{~h}(\mathrm{~d})$ of cyclic oxidation at $1200{ }^{\circ} \mathrm{C}$ in laboratory air. (b, d) according to Ref. [224]. 70

Fig. 6-4 Thickness of the sub-oxide scales (upper bar chart) compared to the volume fraction of $\mathrm{SiO}_{2}$ in the $\mathrm{SiO}_{2}-\mathrm{TiO}_{2}$ duplex scale (lower bar chart) after $100 \mathrm{~h}$ at $1200{ }^{\circ} \mathrm{C}$. Data of alloys A1, B1 and reference alloys according to Ref. [224] .71

Fig. 6-5 Colour-coded images of the oxide scales formed on the eutectic alloy in ac condition (a), alloy A1 ac (b, according to Ref. [224]), alloy B1 $h t$ (c) and the eutectoid reference alloy in $h t$ condition (d) after $100 \mathrm{~h}$ at $1200{ }^{\circ} \mathrm{C}$. $\mathrm{SiO}_{2}$ is highlighted by 
warm colours (red to yellow) while $\mathrm{TiO}_{2}$ is highlighted by cold colours (blue to green). The connected pixels are coloured in the same colour. Exemplary penetrating $\mathrm{TiO}_{2}$ pathways are symbolised by black, arrowed lines. .72

Fig. 6-6 Calculated quantity of the oxidised species Ti and Si, forming solid oxides, and of oxidised Mo, evaporating as volatile $\mathrm{MoO}_{3}$, after $100 \mathrm{~h}$ at $1200{ }^{\circ} \mathrm{C}$ (upper bar chart) and the ratio of the respective species (lower bar chart). According to Ref. [224] .74

Fig. 6-7 BSE micrographs of isothermally pre-oxidised samples $\left(1100^{\circ} \mathrm{C}, 10 \mathrm{~h}\right.$ ) and subsequent cyclic oxidation at $800^{\circ} \mathrm{C}$ for $100 \mathrm{~h}$ of alloys A1 ac (a), according to Ref. [224], and B1 $h t(\mathrm{~b})$. 76

Fig. 6-8 Specific weight change of alloys A1 $a c$ and $\mathrm{B} 1 \mathrm{ht}$ at $800^{\circ} \mathrm{C}$ after isothermal preoxidation at 1100 (diamond symbols) and $1200{ }^{\circ} \mathrm{C}$ (triangular symbols) for $10 \mathrm{~h}$. Note that two samples per each testing condition are shown. .77

Fig. 6-9 BSE micrographs of isothermally pre-oxidised samples of alloys A1 ac (a) and B1 $h t(b)$ and subsequent cyclic oxidation at $800{ }^{\circ} \mathrm{C}$ for $100 \mathrm{~h}$. 78

Fig. 6-10 Specific mass change $\Delta m$ as a function of test duration $t$ of the alloy series $\mathrm{C}$ and D during cyclic oxidation at 800 (a) and $1200{ }^{\circ} \mathrm{C}$ (b) in laboratory air, including the eutectic reference alloy for comparison. Data of alloys C and D taken from Refs. $[215,225]$ and of the eutectic alloy from Ref. [224]. (Only one representative oxidation sample is shown, results of three tested ones are provided in App. 28.)79

Fig. 6-11 BSE micrographs of the cross sections of cyclically oxidised samples of alloys $\mathrm{C} 1$ (a) and D1 (b) after $100 \mathrm{~h}$ at $800{ }^{\circ} \mathrm{C}$ (the ones for alloys $\mathrm{C} 2$ and D2 are appended in App. 29). 80

Fig. 6-12 Comparison of the sub-oxide scale thicknesses (upper bar chart) and the volume fraction of $\mathrm{SiO}_{2}$ within the $\mathrm{SiO}_{2}-\mathrm{TiO}_{2}$ duplex scale (lower bar chart) of the alloy series $\mathrm{C}$ and D including the eutectic reference alloy after $100 \mathrm{~h}$ of cyclic oxidation at $1200^{\circ} \mathrm{C}$. Data of the eutectic alloy taken from Ref. [224] and data on alloys $\mathrm{C} 1$ and D according to Ref. [225].

Fig. 6-13 BSE micrographs of the eutectic alloy (a) and alloy A1 (b) after heat treatment $\left(h t^{*}\right)$ at $1600{ }^{\circ} \mathrm{C}$ for $150 \mathrm{~h}$. Corresponding coloured portions of the microstructures are included (Moss is highlighted by cold colours from blue to green, while ( $\mathrm{Ti}, \mathrm{Mo})_{5} \mathrm{Si}_{3}$ is highlighted by warm colours from red to yellow)........82

Fig. 6-14 Specific weight change during cyclic oxidation at $800^{\circ} \mathrm{C}$ of the eutectic alloy and alloy $\mathrm{A} 1$ in $a c$ and $h t^{*}\left(1600^{\circ} \mathrm{C}, 150 \mathrm{~h}\right)$ condition, respectively. Data of the eutectic alloy in $a c$ condition taken from Ref. [224] and in $h t^{*}$ condition from Ref. [215]. 83 
Fig. 6-15 Cross sectional BSE micrographs of oxidation samples of the eutectic alloy $h t^{*}$ during cyclic (a) and isothermal (iso) (b) oxidation at $800^{\circ} \mathrm{C}$ for $100 \mathrm{~h}$ and of alloy $\mathrm{A} 1 h t^{*}$ after cyclic oxidation at $800{ }^{\circ} \mathrm{C}$ for $1 \mathrm{~h}(\mathrm{c})$. (a, b) according to Ref. [215]. 84

Fig. 6-16 Nominal Ti content (opened diamonds) vs. the Ti content in Moss being either determined globally via XRD (coloured symbols analogous to Fig. 4-2), or locally via STEM-EDX (half-opened squares) for the investigated alloys in correlation with the volume fraction of the microstructural constituents/phases. According to Ref. [215], except results on alloy $\mathrm{C} 1$ and alloy series D, which are according to Ref. [225]. .86

Fig. 6-17 Specific weight change of bcc Mo-Ti(-Si) alloys during cyclic oxidation at $800{ }^{\circ} \mathrm{C}$ in laboratory air (one representative sample is shown among three tested in total for each alloy). According to Ref. [215].

Fig. 6-18 BSE micrographs of alloy Mo-20Ti (a) and Mo-40Ti-3Si (b) after $1 \mathrm{~h}$ of oxidation at $800^{\circ} \mathrm{C}$ in laboratory air. According to Ref. [215]. .88

Fig. 6-19 GIXRD pattern at an incident angle $\omega=1.2^{\circ}$ of the oxidised samples of the $a c$ eutectic alloy after $100 \mathrm{~h}$ at 800 (a) and $1200^{\circ} \mathrm{C}(\mathrm{b})$. Intensities are plotted in log scale. According to Ref. [216].

Fig. 6-20 Characteristic parts of the mass spectra of a Ti-oxide region of the oxide scale formed at $800{ }^{\circ} \mathrm{C}$ after $100 \mathrm{~h}(\mathrm{a})$, of the top oxide scale formed at $1200{ }^{\circ} \mathrm{C}$ after $100 \mathrm{~h}$ (b) and of a Ti-oxide (c) and Si-oxide region (d) of the underlying duplex scale of the eutectic alloy. According to Ref. [216].

Fig. 6-21 Isothermal sections of the ternary Ti-Si-O system at $1200{ }^{\circ} \mathrm{C}$ (a) and the ternary Mo-Si-O system at 700 to $1000{ }^{\circ} \mathrm{C}$ (b). According to Refs. [237, 252].

Fig. 6-22 Evolution of the (sub-)oxide scale thicknesses $d$ ( $d_{\text {total }}, d_{\text {top }}$ of the top Tioxide, $d_{\text {duplex }}$ of the underlying duplex scale, $d_{\text {int }}$ of the internal oxidation zone) at $1200{ }^{\circ} \mathrm{C}$ as a function of exposure time $t$ (a), including fit functions according to Eq. 17 with $n$ being adjusted variably (dotted lines). For comparison, $d_{\text {total }}$ is plotted in logarithmic manner as a function of $t$ for 800,1100 and $1200{ }^{\circ} \mathrm{C}$ and fitted accordingly (b). All data are from the eutectic reference alloy according to Ref. [216]. 96

Fig. 6-23 Cross sectional BSE micrographs of the eutectic alloy after cyclic oxidation for 1 (a), 10 (b), 100 (c) and $1000 \mathrm{~h}(\mathrm{~d})$ at $800^{\circ} \mathrm{C}$. According to Ref. [216]. 98

Fig. 6-24 Diffusion coefficient $D$ of $\mathrm{O}$ and Ti ions in single- (SX) and polycrystalline $\mathrm{TiO}_{2}$ (red and blue lines) and $\mathrm{O}$ and $\mathrm{Si}$ ions in vitreous (v) $\mathrm{SiO}_{2}$ (orange and yellow lines) as a function of the reciprocal temperature. Data taken from Refs. [268-273]. For comparison, the parabolic oxidation rate constants $k_{n=2}$ are included for the 
eutectic (filled squares) and eutectoid reference alloys (opened diamonds), as wells as for the intermediate eutectic-eutectoid alloys (half-opened circles). Note that only two data points are used for the determination of the activation energy of the parabolic oxidation rate constants for each alloy. According to Ref. [216]. 100

Fig. 7-1 True creep rates vs. true strain of the investigated alloy series A (a and b), C (c and d) and D (e and f) under compressive creep testing at $1200{ }^{\circ} \mathrm{C}$. The minimum creep rates are highlighted by square markers. Data of alloy A1 according to Ref. [224] and of alloys C1, D1 and D2 according to Ref. [225].

Fig. 7-2 Norton plot of the pesting-resistant alloy series A, C, D and alloy Mo-40Ti-3Si as representative Moss in comparison to the eutectic and eutectoid reference alloys [5], as well as to literature data on the monolithic phases $\mathrm{Ti}_{5} \mathrm{Si}_{3}$ [200] and $\mathrm{Mo}_{5} \mathrm{Si}_{3}$ [198] (a). Data of alloy A1 ac taken from Ref. [224]. Plot according to Ref. [224]. 104

Fig. 7-3 True creep rate as a function of true strain during compressive creep testing at $1200{ }^{\circ} \mathrm{C}$ of alloys Mo-20Ti (a), Mo-40Ti (b) and Mo-40Ti-3Si (c). The creep rate minima are highlighted by square markers. Corresponding Norton plot in comparison to the eutectic and eutectoid reference alloys [5] (d). 105

Fig. 7-4 Arrhenius plot normalised by the solidus temperature (data of alloy A1 ac according to Ref. [224]), which has been calculated by Pandat, for the investigated Mo-Si-Ti alloys including the eutectic and eutectoid reference alloy [5], as well as for several Mo-Ti-(Si) alloys. Selected solidus temperatures are provided next to the respective straights. 107

Fig. 7-5 BSE micrographs of the microstructures of the alloys A1 ac (a and b), D2 ac (c and d) after creep testing at $200 \mathrm{MPa}$ at $1200{ }^{\circ} \mathrm{C}$ with approximately 5 and $40 \%$ true strain. 108

Fig. 7-6 Investigation of the phase regions Moss (a) and primarily solidified (Mo,Ti) ${ }_{5} \mathrm{Si}_{3}$ (b) approximated as ellipsoid-shaped particles in ac condition and after 5 and $40 \%$ true compressive creep strain in the eutectic alloy and alloys A1, C1, D1 and D2. The percentage $N$ of particles is compared for a particle size of 15 to $50 \mu \mathrm{m}^{2}$ (left axis, square symbols) and for an orientation of $(90 \pm 17)^{\circ}$ to the loading axis (right axis, circular symbols). Data on alloys C1, D1 and D2 according to Ref. [225]. ..109

Fig. 7-7 Comparison of the minimum true creep rates attained in the eutectic reference alloy and alloy A1 in ac (half-/filled symbols) [5, 224], $h t$ (star symbols) and $h t^{*}$ condition (opened symbols) in comparison to the eutectoid reference alloy [5]...110

Fig. 7-8 Norton plot for alloy A1 for the creep rates at the minimum (red data points), after $1 \%$ true strain (purple data points), at $2 \%$ off-set to the minimum creep rate 
(blue data points) and after $5 \%$ true strain (green data points) for $a c$ and $h t^{*}$ condition. Data of alloy A1 ac according to Ref. [224].

Fig. 7-9 BSE micrographs of the crept microstructures of the eutectic reference alloy in $a c$ and $h t^{*}$ condition after $40 \%$ strain. Colour-coded portions of the microstructures are included (Moss: blue to green, (Ti,Mo) ${ }_{5} \mathrm{Si}_{3}$ red to yellow).

Fig. 7-10 BSE micrographs of the microstructures after creep testing at $1200{ }^{\circ} \mathrm{C}$ and $200 \mathrm{MPa}$ (40\% strain) of alloy A1 in $a c$ (a) and $h t^{*}$ condition (b)

Fig. 9-1 Comparison of the density (upper diagram) and estimated temperature operation range (lower diagram) for selected Mo-Si-Ti alloys [5, 224, 225], and commercially applied Ni-based alloys [290-292] (highlighted by green colours) as well as Mo-Si- [4, 34] and Nb-Si-based alloys [293, 294] (highlighted by grey and black colours).

Fig. 9-2 Overview of the oxidation behaviour at $1200{ }^{\circ} \mathrm{C}$ in air: specific mass change (a) and oxide scale thickness after $100 \mathrm{~h}$ (b). Selected pesting-resistant Mo-Si-Ti alloys are compared to cast Mo-Si- and Nb-Si-based alloys as well as commercially applied high-temperature Ni-based materials. The composition of the latter is included in App. 47 and the geometry of the oxidation samples is appended in App. 48. Changes in the morphology of the precipitates in CMSX-4 after exposure to $1200{ }^{\circ} \mathrm{C}$ for 1 and $100 \mathrm{~h}$ (c). Data according to Obert et al. [215, 224, 225] is marked by diamonds and data taken from other literature [295] by a hashtag.

Fig. 9-3 Comparison of the creep performance of the novel Mo-Si-Ti alloys to other hightemperature alloy systems in a Norton plot normalised by the alloy density. Note the classification in oxidation- and non-oxidation-resistant alloys. Tensile data is marked by an asterisk. Data taken from Refs. [4, 5, 71, 169, 224, 225, 300, 301]. .. 


\section{List of Tables}

Table 2-1 Overview on the physical properties of the relevant phases in the ternary MoSi-Ti system. .11

Table 2-2 Overview on the oxidation behaviour of the relevant phases in Mo-Si-based alloy systems. .22

Table 2-3 Overview on the creep behaviour of the monolithic phases in Mo-Si-based alloys. *data for tensile test conditions. ${ }^{* *}$ calculation based on literature data. Secondary creep rates $\dot{\varepsilon}_{I I}$ are distinguished from the minimum creep rates $\dot{\varepsilon}_{\text {min }}$ by bold, blue letters. ..31

Table 4-1 Comparison of the alloys selected for investigation. 45

Table 6-1 Chemical composition of the different oxide regions determined by APT after peak deconvolution [216]. .93

Table 6-2 CTE data of $\mathrm{Ti}, \mathrm{Mo}, \mathrm{Ti}_{5} \mathrm{Si}_{3}, \mathrm{TiO}_{2}, \mathrm{SiO}_{2}$ and the eutectic reference alloy, as well as Ti-Si-based alloys. .95

Table 6-3 Calculated oxidation rate constants $k_{n}$ of the eutectic alloy (based on Eq. 17) with variable exponents $n$ and the activation energy $Q_{k_{n=2}}$. For $800{ }^{\circ} \mathrm{C}$ a linear fitting method was applied resulting in the linear oxidation rate constant $k^{*} . R_{a d j}^{2}$ values are included. Table taken from Ref. [216]. . .97 


\section{Work-Related Publications}

- Ref. [224]: S. Obert, A. Kauffmann, M. Heilmaier: Characterisation of the oxidation and creep resistance of novel Mo-Si-Ti alloys, Acta Materialia 184 (2020), 132-142.

- Ref. [215]: S. Obert, A. Kauffmann, S. Seils, S. Schellert, M. Weber B. Gorr, H.-J. Christ, M. Heilmaier: On the chemical and microstructural requirements for the pesting-resistance of Mo-Si-Ti alloys, JMR\&T 9 (2020), 8556-8567.

- Ref. [216]: S. Obert, A. Kauffmann, S. Seils, T. Boll, S. Kauffmann-Weiss, H. Chen. M. Heilmaier: Microstructural and chemical constitution of the oxide scale formed on a pesting-resistant Mo-Si-Ti alloy, Corrosion Science 178 (2021), 109081 (1-11).

- Ref. [225]: S. Obert, A. Kauffmann, R. Pretzler, D. Schliephake, F. Hinrichs, M. Heilmaier: The Creep Behaviour of Pesting-Resistant (Mo,Ti) ${ }_{5}$ Si $i_{3}$-Containing Eutectic-Eutectoid Mo-Si-Ti Alloys, Metals 11 (2021), 169 (1-18).

- M. Weber, B. Gorr, H.-J. Christ, S. Obert, A. Kauffmann, M. Heilmaier: Effect of water vapor on the oxidation behavior of the eutectic high-temperature alloy Mo-20Si-52.8Ti, AEM 22 (2020), 2000217 (1-7).

- R. Anton, N. Laska, U. Schulz, S. Obert, M. Heilmaier: Magnetron sputtered silicon coatings as oxidation protection for Mo-based alloys, AEM 22 (2020), 2000218 (1-8).

- T. Hatakeyama, A. Kauffmann, S. Obert, C. Gombola, Martin Heilmaier, K. Yoshimi: $O x$ idation Resistance, Creep Strength and Room-Temperature Fracture Toughness of Mo28Ti-14Si-6C-6B Alloy, Materialia 16 (2021), 101108 (1-11).

- O. Kauss, S. Obert, I. Bogomol, T. Wablat, N. Siemensmeyer, K. Naumenko, M. Krüger: Temperature Resistance of Mo ${ }_{3}$ Si: Phase Stability, Microhardness, and Creep Properties, Metals 11 (2021), 564 (1-17). 


\section{Eigenständigkeitserklärung}

Hiermit erkläre ich eidesstattlich gemäß $§ 13$ Absatz 2 Satz 2 Ziffer 3 der Promotionsordnung des Karlsruher Instituts für Technologie (KIT) für die KIT-Fakultät für Maschinenbau, dass es sich bei dieser eingereichten Dissertation zum Thema

\section{Characterisation of the Oxidation and Creep Behaviour of Novel Mo-Si-Ti Alloys}

um meine eigenständig erbrachte Leistung handelt. Ich habe nur die angegebenen Quellen und Hilfsmittel benutzt und mich keiner unzulässigen Hilfe Dritter bedient. Insbesondere habe ich wörtlich oder sinngemäß aus anderen Werken übernommene Inhalte als solche kenntlich gemacht. Die Arbeit oder Teile davon habe ich bislang nicht an einer Hochschule des In- oder Auslands als Bestandteil einer Prüfungs- oder Qualifikationsleistung vorgelegt.

Die Richtigkeit der vorstehenden Erklärungen bestätige ich.

Die Bedeutung der eidesstattlichen Versicherung und die strafrechtlichen Folgen einer unrichtigen oder unvollständigen eidesstattlichen Versicherung sind mir bekannt.

Ich versichere an Eides statt, dass ich nach bestem Wissen die reine Wahrheit erklärt und nichts verschwiegen habe. 


\section{Acknowledgement}

First of all, I would like to express my special gratitude to Prof. Dr.-Ing. Martin Heilmaier for providing the opportunity for this research work, his exceptional support and his scientific, advisory opinion. Moreover, I would like to thank Prof. Dr.-Ing. habil. Manja Krüger for being my second examiner.

I would also like to extent my profound gratitude to Dr.-Ing. Alexander Kauffmann, who has supported me throughout my entire $\mathrm{PhD}$ time and has given me valuable, deep scientific assistance and guidance within the field of research and has also considerably contributed to the development of my soft skills.

I would like to pass on my sincere thanks to the (former) colleagues of the team Physical Metallurgy of the Institute of Applied Materials (IAM) of Karlsruhe Institute of Technology (KIT). Especially to Dr.-Ing. Anke Schmitt, Dr.-Ing. Hans Chen, Camelia Schulz, Stephan Laube, Dr.-Ing. Sascha Seils, Dr.-Ing. Daniel Schliephake, Aditya T. Srinivasan, Georg Winkens and Frauke Hinrichs for their technical, scientific and mental support.

A special note of gratitude is extended to my collaboration partners Matthias Weber, Prof. Dr.-Ing. habil. Bronislava Gorr and Prof. Dr.-Ing. Hans-Jürgen Christ from the Department of Mechanical Engineering of the University of Siegen, as well as to Ronja Anton, Dr. Nadine Laska and Prof. Dr.-Ing. Uwe Schulz from the Institute of Materials Research of the German Aerospace Center (DLR) for the excellent cooperation and scientific discussions. I am also grateful for the support of Dr.-Ing. Sandra Kauffmann-Weiß (KIT), Dr. rer. nat. Torben Boll (KIT), Dr.-Ing. Peter Mettnich (DLR) and Steven Schellert (University of Siegen). Additionally, I would like to acknowledge the help of the colleagues of the administration, the technicians in the workshop and especially the technicians and laboratory assistants of IAM. Moreover, the experimental assistance by the following students Erika E. Bárcena Pérez, David Probst, Lara Alavi, Fabio Vetro’ and Mike Görtz; and especially by Leon Winheim and Rupert Pretzler is highly acknowledged.

Finally, I would like to acknowledge the financial support by Deutsche Forschungsgemeinschaft (DFG) (framework HE 1872/33-1).

Last but not least, I would like to thank my family and friends, especially Werner, for their support and encouragement. 